\title{
EVALUATION OF THE STRUCTURE OF LEVEE TRANSITIONS ON WAVE RUNUP AND OVERTOPPING BY PHYSICAL MODELING
}

\author{
A Thesis \\ by \\ DRAKE BENJAMIN OAKS
}

\begin{abstract}
Submitted to the Office of Graduate Studies of Texas A\&M University in partial fulfillment of the requirements for the degree of MASTER OF SCIENCE
\end{abstract}

May 2010

Major Subject: Ocean Engineering 


\title{
EVALUATION OF THE STRUCTURE OF LEVEE TRANSITIONS ON WAVE RUNUP AND OVERTOPPING BY PHYSICAL MODELING
}

\author{
A Thesis
}

by

\section{DRAKE BENJAMIN OAKS}

\author{
Submitted to the Office of Graduate Studies of \\ Texas A\&M University \\ in partial fulfillment of the requirements for the degree of \\ MASTER OF SCIENCE
}

Approved by:

Chair of Committee, Patrick J. Lynett

Committee Members, Billy L. Edge Achim Stössel

Head of Department, John Niedzwecki

May 2010

Major Subject: Ocean Engineering 


\begin{abstract}
Evaluation of the Structure of Levee Transitions on Wave Runup and Overtopping by

Physical Modeling. (May 2010)

Drake Benjamin Oaks, B.S., Texas A\&M University

Chair of Advisory Committee: Dr. Patrick J. Lynett
\end{abstract}

Coastal regions are continually plagued by high water levels induced by river flooding or hurricane induced storm surges. As with any protective structure, it is essential to understand potential problematic regions which could result in a devastating loss for the regions nations value most. Coastal protective systems are primarily comprised of floodwalls and levees, each of which has practiced methodologies utilized for estimating their performance under design conditions. Methodologies concerning spatial variability are limited however, and transitions where earthen levees merge with floodwalls are considered vulnerable areas to erosion and possible breaching. Physical modeling of a specified levee transition is undergone in a three-dimensional wave basin to evaluate this hypothesis, and the detailed results of this assessment are presented within this thesis.

From the physical model testing, analysis of the data reveals that the overtopping rates of the levee transition tend to be larger than traditional overtopping techniques have predicted. The runup values and floodwall wave heights tend to show potential problematic areas and mimic the variation of overtopping along the levee transition. 
Under the design conditions tested, extreme overtopping conditions and associated water level values propose that in order for the structure to sustain the hydraulic conditions, it must be well protected. It is shown that the variation of the still water level plays the largest role in the magnitude of the measured values, and increasing the peak wave period and wave heights also yields greater overtopping and water levels at the structure. Overall these extreme overtopping rates and water levels experienced at the structure irrefutably expose a greater risk of erosion and breaching of the protective structure than initially predicted. This study highlights the need to understand specific spatial variability along coastal protective systems, and provides a better understanding of the mechanisms affecting overtopping for the specific structure tested. 


\section{ACKNOWLEDGEMENTS}

First and foremost, I would like to thank those who have always put me first and foremost, my family. Their incessant and unconditional encouragement, support, and love throughout any endeavor have always been my most influential motivator. I am extremely fortunate and blessed to have such wonderful family and friends who have provided me with an endless amount of support and confidence.

I would like to thank Dr. Billy Edge for giving me the opportunity to take on such a demanding project, allowing me to gain a broad perception of both theoretical and physical concepts. His work ethic and continual confidence in me provided me with an experience that reached beyond the realm of academia. I would like to thank Dr. Patrick Lynett for taking over as my primary advisor after Dr. Edge's retirement and for providing me with endless ideas and guidance throughout both my undergraduate and graduate career. I will always admire the depth of his knowledge while maintaining the ability to explain the basics. I would also like to thank Dr. Robert Randall for his continual guidance, counsel, and encouragement throughout my career at Texas A\&M University; he fueled the spark of my initial interest in Ocean Engineering and has always had an open door. I am also thankful for Dr. Achim Stössel for his time and contributions in reviewing this research.

This research would not be possible without the help of the lab assistants at the Haynes Coastal Engineering Laboratory, especially Johnnie Reed and Po Yeh-Hung. John Reed is the voice of common sense among the students and faculty in any Ocean Engineering laboratory at Texas A\&M University. Lastly, I would like to thank all of my 
friends and colleagues as well as the faculty and staff at Texas A\&M University for their continual understanding and support throughout my undergraduate and graduate studies. 


\section{NOMENCLATURE}

\begin{tabular}{|c|c|}
\hline ADCIRC & Advanced Circulation Model \\
\hline ADV & Acoustic Doppler Velocimetry \\
\hline $\mathrm{CH}$ & Floodwall or Runup Gauge Channel \\
\hline $\mathrm{CHL}$ & Coastal Hydraulics Laboratory \\
\hline $\mathrm{cm}$ & Centimeter \\
\hline ERDC & Engineering Research and Development Center \\
\hline $\mathrm{ft}$ & Foot \\
\hline$g$ & Gravitational Acceleration \\
\hline GDP & Gross Domestic Product \\
\hline$h$ & Water Depth, Depth of Levee Toe \\
\hline $\mathrm{H}$ & Horizontal Dimension, Used for Defining Levee Slope \\
\hline$H_{2} \%$ & $2 \%$ Crest Elevation \\
\hline$H^{\prime}{ }_{2 \%}$ & Dimensionless $2 \%$ Crest Elevation, Simple Scaling \\
\hline$H_{2 \%}^{t}$ & Dimensionless $2 \%$ Crest Elevation, Tuned Scaling \\
\hline$H_{m o}$ & Zeroth-moment Wave Height \\
\hline$H_{i}$ & Incident Characteristic Wave Height \\
\hline$H_{s}$ & Significant Wave Height \\
\hline$H_{s}^{\prime}$ & Dimensionless Floodwall Significant Wave Height, Simple Scaling \\
\hline$H_{s}^{t}$ & Dimensionless Floodwall Significant Wave Height, Tuned Scaling \\
\hline in & Inch \\
\hline
\end{tabular}




\begin{tabular}{|c|c|}
\hline IPET & Interagency Performance Evaluation Taskforce \\
\hline$k$ & Wave Number \\
\hline 1 & Liter \\
\hline $1 / \mathrm{s} / \mathrm{m}$ & Liters per Second per Meter \\
\hline$L_{o p}$ & Offshore (Deepwater) Wavelength \\
\hline$L_{i}$ & Incident Characteristic Wave Length \\
\hline $\mathrm{m}$ & Meter \\
\hline MACE & MatLab® Toolbox for Coastal Engineers \\
\hline $\mathrm{mm}$ & Millimeter \\
\hline MRGO & Mississippi River Gulf Outlet \\
\hline MSP & Mean Shoreline Position \\
\hline MSP' & Dimensionless Mean Shoreline Position, Simple Scaling \\
\hline$M S P^{t}$ & Dimensionless Mean Shoreline Position, Tuned Scaling \\
\hline MWL & Mean Water Level \\
\hline$M W L$ & Dimensionless Mean Water Level, Simple Scaling \\
\hline$M W L^{t}$ & Dimensionless Mean Water Level, Tuned Scaling \\
\hline No. & Number \\
\hline NOAA & National Oceanic and Atmospheric Association \\
\hline OT & Overtopping \\
\hline$q, \mathrm{Q}$ & Overtopping Rate \\
\hline$q^{\prime}$ & Dimensionless Overtopping Rate, Simple Scaling \\
\hline$q^{t}$ & Dimensionless Overtopping Rate, Tuned Scaling \\
\hline
\end{tabular}


q50, q90 Overtopping Rate Exceeded by 50\% and 10\% of Waves

$\mathrm{R}^{2} \quad$ Coefficient of Determination

$R_{c} \quad$ Freeboard

$R_{u 2 \%}, R_{2} \% \quad 2 \%$ Runup Level

$R^{\prime}{ }_{2 \%} \quad$ Dimensionless 2\% Runup, Simple Scaling

$R_{2 \%}^{t} \quad$ Dimensionless 2\% Runup, Tuned Scaling

STWAVE Steady State Spectral Wave Model

SWL Still Water Level

sec, $s \quad$ Second

$t \quad$ Denotes Tuned Parameter

$T_{p} \quad$ Peak Wave Period

TAW Technical Advisory Committee on Flood Defence

TR Wireless Wave Gauge Transmitter

USACE United States Army Corps of Engineers

V Vertical Dimension, Used for Defining Levee Slope

WAM Wave Prediction Model

$x \quad$ Distance from Midpoint of Levee Transition, Positive Towards Leveesection

$\alpha \quad$ Angle of Levee Slope

$\gamma_{b} \quad$ Reduction Factor for Berm

$\gamma_{f} \quad$ Reduction Factor for Slope Roughness

$\gamma_{h} \quad$ Reduction Factor for Shallow Foreshore 
$\gamma_{v}$

$\gamma_{\beta}$

$\zeta$

$\eta$

$\xi_{\text {op }}$
Reduction Factor for Vertical Wall

Reduction Factor for Oblique Wave Angle Attack

Exponent Utilized in Tuned Scaling

Free Surface, Surface of Water

Iribarren Number; Similarity Parameter 
TABLE OF CONTENTS

Page

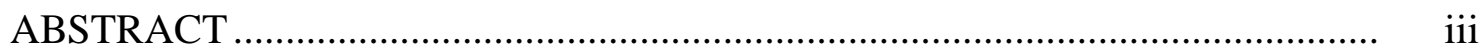

ACKNOWLEDGEMENTS ................................................................. $\quad \mathrm{v}$

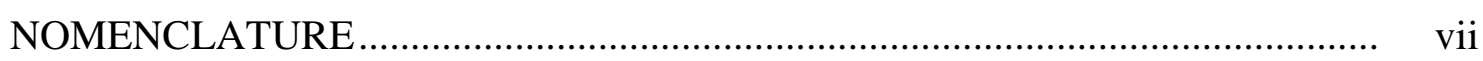

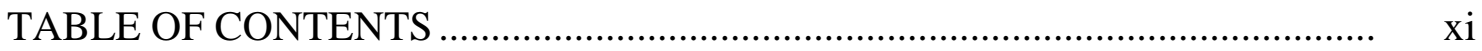

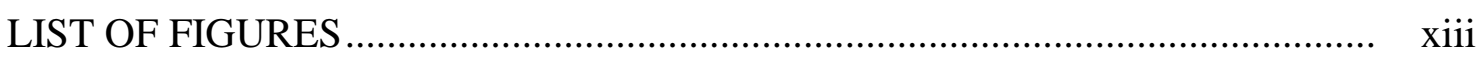

LIST OF TABLES …..........................................................................

1. INTRODUCTION: MOTIVATION OF RESEARCH AND OVERVIEW OF

LEVEES AND FLOODWALLS ...................................................... 1

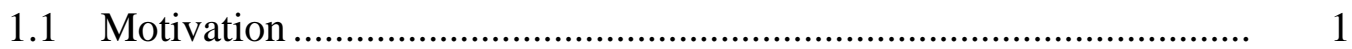

1.2 Overtopping and Runup on Levees and Floodwalls ......................... 2

1.3 Thesis Content ................................................................................... 4

2. BACKGROUND AND LITERATURE REVIEW ........................................ 6

2.1 Introduction ............................................................................... 6

2.2 Necessity of Protective Structures..................................................... 8

2.3 Hurricane Protection System.............................................................. 10

2.4 Damages to Levees and Floodwalls .................................................. 15

2.5 Overtopping and Runup Calculations ............................................ 18

2.6 Previous and Current Experiments and Studies ............................... 21

2.7 Summary of Literature Review ..................................................... 26

3. SCOPE OF PROJECT ......................................................................... 28

3.1 Introduction .................................................................... 28

3.2 Levee Transition................................................................... 28

3.3 Dimensions of Modeled Structure..................................................... 29

3.4 Hydraulic Conditions ....................................................................... 31

3.5 Haynes Coastal Engineering Laboratory........................................ 32 
4. EXPERIMENTAL SETUP AND CALIBRATION …................................... 35

$4.1 \quad$ Introduction ....................................................................... 35

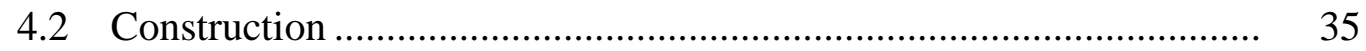

4.3 Instrumentation..................................................................... 46

4.4 Wave Generator Calibration........................................................... 58

4.5 Physical Model Testing ............................................................ 60

4.6 Physical Modeling Problems and Solutions.................................... 64

5. DATA ANALYSIS ........................................................................... 65

5.1 Introduction .......................................................................... 65

5.2 Runup along Levee Section......................................................... 65

5.3 Wave Heights along Floodwall Section ........................................ 67

5.4 Overtopping Rates along Levee Transition..................................... 69

5.5 Three - Gauge Array ............................................................ 72

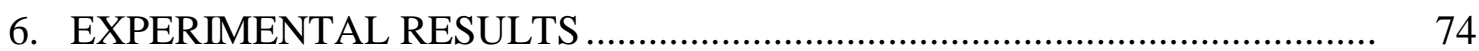

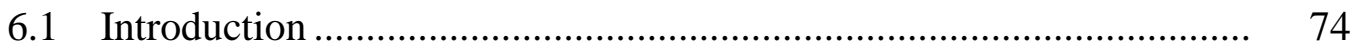

6.2 Levee Runup and Floodwall Wave Height .................................... 75

6.3 Overtopping Rates along Levee Transition...................................... 81

6.4 Dimensionless Levee Runup and Floodwall Wave Height................ 87

6.5 Dimensionless Overtopping Rates ............................................... 96

7. SUMMARY AND CONCLUSIONS..................................................... 100

REFERENCES ................................................................................... 103

APPENDIX A: LEVEE AND FLOODWALL CONFIGURATIONS

AND FAILURES .......................................................... 107

APPENDIX B: PHYSICAL MODEL PICTURES ...................................... 110

APPENDIX C: $\quad$ RESULTING EXPERIMENTAL PLOTS .............................. 115

APPENDIX D: $\quad$ RESULTING DIMENSIONLESS PLOTS ............................ 120

VITA 


\section{LIST OF FIGURES}

FIGURE $\quad$ Page

$1 \quad$ Wave Runup Definition ................................................................. 3

2 Possible Overtopping Scenarios for Earthen Levee ............................. 4

3 United States Population Density Variations and Trends

Between Coastal and Noncoastal Regions from 1980 to 2008 ................. 9

$4 \quad$ Location of City of New Orleans, Louisiana ...................................... 11

$5 \quad$ Hurricane Protection System (2005) ................................................. 12

$6 \quad$ HPS after Hurricane Katrina ...................................................... 14

$7 \quad$ Stages of Erosion for Earthen Levee................................................. 17

$8 \quad$ Hurricane Katrina Induced Floodwall Failure Modes in HPS .................. 18

$9 \quad$ Example of Overtopping Simulator in Action and Erosion Effects .......... 24

10 Example Levee Transition ............................................................... 29

11 Levee Section Prototype Cross-sectional Dimensions .......................... 30

12 Floodwall Section Prototype Cross-sectional Dimensions ...................... 31

13 Haynes Coastal Engineering Laboratory............................................ 33

14 Rock Beach at Haynes Laboratory …................................................ 34

15 New Orleans Levee Transition................................................................ 35

16 Plan View Levee Transition Model in Laboratory................................ 37

17 Levee Transition Model Cross-sectional Dimensions............................. 38

18 Initial Construction of Levee Transition Model....................................... 39 
FIGURE $\quad$ Page

19 Placement of Concrete in Levee Transition Model................................. 40

20 Completed Levee Section of Levee Transition Model........................... 41

21 Placement of Concrete in Floodwall Section of Levee

Transition Model .................................................................... 42

22 Finished Transition of Levee Transition Model................................... 43

23 Painted Levee Transition Model .............................................................. 44

24 Grid Line Dimensions ................................................................ 45

25 Levee Section Grid Lines ............................................................. 45

26 Post-Construction Levee Transition Model ........................................ 46

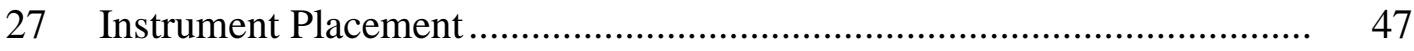

28 Floodwall Gauge Placement........................................................... 48

29 Floodwall Gauge and Overtopping Container Placement....................... 49

30 Runup Gauge Dimensions ............................................................. 50

31 Runup Gauge Actual Placement .................................................... 51

32 Overtopping Container Placement ......................................................... 53

33 Wireless Wave Gauge Locations ................................................... 55

34 Three-gauge Array Placement ........................................................... 55

35 Front View of Levee Transition Model............................................... 56

36 Floodwall Side Isometric View of Levee Transition Model................... 57

37 Levee Side Isometric View of Levee Transition Model ......................... 58

38 Floodwall Side of Levee Transition Model during Test No. 07 ............... 61 
FIGURE $\quad$ Page

39 Levee Side of Levee Transition Model during Test No. 07 .................... 62

40 Floodwall Side of Levee Transition Model during Test No. 03 .............. 63

41 Levee Side of Levee Transition Model during Test No. 03 .................... 63

42 Example of Runup Gauge Time Series, Test No. 06, CH 1................... 66

43 Example of Floodwall Gauge Time Series, Test No. 06, CH 6 ............... 68

44 Wave Overtopping Calculation Tool for Levee Section

(Wave Overtopping 2007)............................................................. 71

45 Wave Overtopping Calculation Tool for Floodwall Section

(Wave Overtopping 2007)............................................................ 72

46 Floodwall Wave Heights and Levee Runup, Test No. 01 ...................... 76

47 Floodwall Wave Heights and Levee Runup, Test No. 03 ...................... 78

48 Floodwall Wave Heights and Levee Runup, Test No. 05 ....................... 79

49 Floodwall Wave Heights and Levee Runup, Test No. 07 ....................... 80

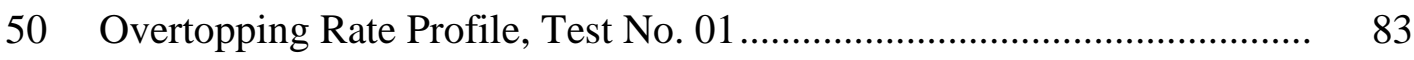

51 Overtopping Rate Profile, Test No. 03 …................................................ 84

52 Overtopping Rate Profile, Test No. 05 ............................................ 85

53 Overtopping Rate Profile, Test No. 07 f.......................................... 85

54 Experienced Undertow in Test No. 01 .............................................. 86

55 Dimensionless Floodwall MWL, Simple Scaling …............................ 90

56 Dimensionless Levee MSP, Simple Scaling …................................... 90

57 Dimensionless Floodwall MWL, Tuned Scaling ................................. 94 
FIGURE $\quad$ Page

58 Dimensionless Levee MSP, Tuned Scaling ........................................ 95

59 Dimensionless Overtopping Rates, Simple Scaling ............................ 97

60 Dimensionless Floodwall Overtopping Rates, Tuned Scaling ................. 99

61 Dimensionless Levee Overtopping Rates, Tuned Scaling ...................... 99 


\section{LIST OF TABLES}

TABLE Page

1 Requested Hydraulic Conditions ................................................... 32

2 Requested Hydraulic Conditions in Model Units ............................... 59

3 Achieved Hydraulic Conditions, Prototype Units .............................. 60 


\section{INTRODUCTION: MOTIVATION OF RESEARCH AND OVERVIEW OF}

\section{LEVEES AND FLOODWALLS}

\subsection{Motivation}

Throughout many coasts and low lying areas globally, periodical floods and storm surges cause significant and catastrophic damage. These damages cause considerable losses of life and economic sufferings. For regions plagued by these incidents of drastic rises of water level, a common first and ultimate line of defense is levees and floodwalls (Hughes and Nadal, 2008). Levees and floodwalls offer sufficient protection against high rises in water level and can protect large areas from inundation; however, the levee and floodwall system is only as durable as its most tenuous area. Once a particular area is breached, the previously protected region immediately becomes vulnerable. One particular area of interest that is heavily dependent on a complex system of levees and floodwalls is that of New Orleans, Louisiana, at the mouth of the Mississippi River. Here, flooding could be the result of either flooding of the Mississippi River or the effects of storm surges induced by hurricanes making landfall at or near this location. Moreover, the levees and floodwalls in this locale are not only exposed to storm surges during hurricanes, but they are also bombarded with waves and wave induced currents to further erode and destroy the levees and floodwalls (Sills et. al, 2008; IPET, 2007). Within this complex system of floodwalls and earthen levees, it is important to understand potential problem areas which could possibly fail during times of flooding. A specific location, highlighted by this proposed research, occurs where an

This thesis follows the style of the journal of Coastal Engineering. 
earthen levee transitions into a floodwall with an incorporated levee.

The basic objectives of this research are as follows:

- Conduct laboratory investigation of levee transition in three-dimensional shallow water wave basin

- Analyze the resulting data and identify potential problem areas within structure

- Provide comparison of experimental overtopping measurements with typical empirical design formulae

- Develop relationships between hydraulic conditions and experienced overtopping for the specific structure tested

\subsection{Overtopping and Runup on Levees and Floodwalls}

It is essential to understand the mechanisms of overtopping and runup as well as the general configuration of the coastal protective structure emphasized in this research to fully grasp the objectives of this research. Levees are, for the purposes of this research, simply compacted mounds of earthen material used to prevent floodwater and waves from inundating coastal or low-lying regions. Floodwalls are essentially vertical walls which extend from an earthen foundation that too protect low-lying areas from the forces of the ocean or high water levels. Of course, both of these structures exist in current coastal protection systems; therefore, there are many locations in which the structures must transition from a levee section to a floodwall section. Ultimately, the most influential force which jeopardizes the structural integrity of levees and floodwalls is erosion. The two most common mechanisms that provoke erosion are runup and 
overtopping.

The term runup is defined as the vertical rise in water elevation due to waves on the flood-side of a dike or levee with respect to a defined horizontal datum, which is usually the Still Water Level (SWL). The SWL is defined as the water level elevation in the absence of waves. Figure 1 illustrates these definitions; the runup value depicted here is the $2 \%$ runup, or the runup value that is exceeded by only $2 \%$ of incident waves. In Figure 1 , the $2 \%$ runup value is measured in reference to the SWL. The flood-side slope of the levee is $\alpha$, and $h$ is the water depth (Stockdon et al., 2006; van der Meer and Janssen, 1995).

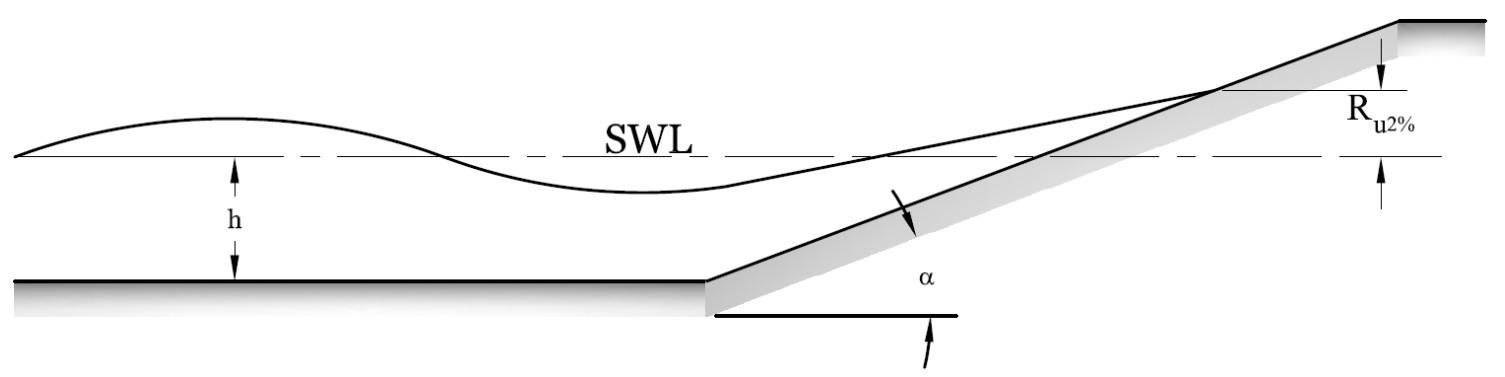

Figure 1. Wave Runup Definition (after van der Meer and Janssen 1995).

Overtopping rate is defined as the flux of water per unit width transmitting over a coastal protective structure, caused by a runup value or high water level which exceeds the levee crest. Figure 2 provides a graphic to further define overtopping. According to Hughes (2008) and Hughes and Nadal (2008), overtopping can be the result of three different scenarios. Overtopping can be induced by wind-generated waves only (Figure 2a), a storm surge in which the floodwater level exceeds the levee crest height (Figure 
2b), or a combination of the two, which arguably results in the greatest structural devastation (Figure 2c). The principal distinction between the wave-only overtopping and surge overtopping is the intermittence, and unsteadiness of the overtopping (Hughes and Nadal, 2008).

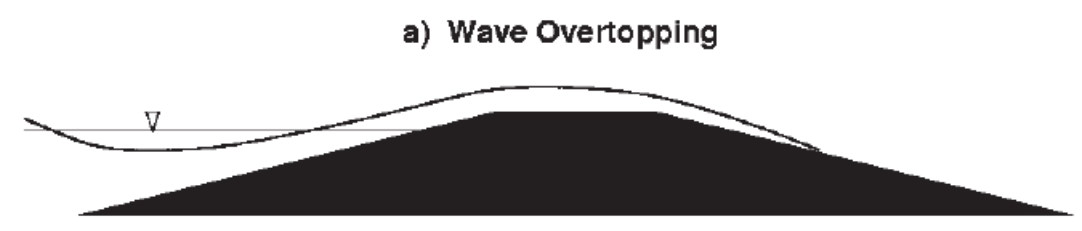

b) Surge Overtopping

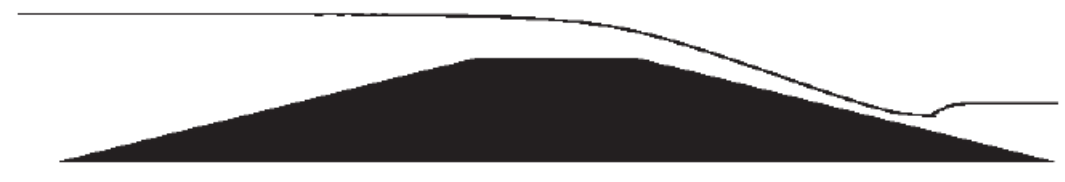

c) Wave and Surge Overtopping

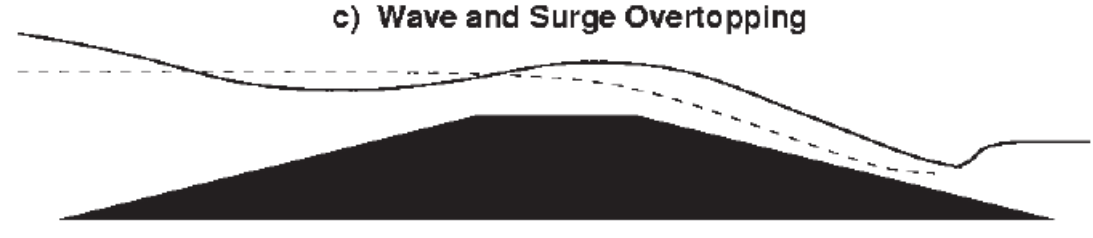

Figure 2. Possible Overtopping Scenarios for Earthen Levee (Hughes, 2008).

\subsection{Thesis Content}

The presented research is divided into seven sections. Section 1 provides a debut of the research, including the motivation of the research as well as an introductory explanation of the mechanisms and methodologies further explored in this research. Section 2 is comprised of a detailed literature review split into seven sections. Disregarding the introduction and summary, Section 2 primarily emphasizes the 
necessity of protective coastal structures, highlights an existing protection system, displays potential damages to levees and floodwalls, provides empirical overtopping and runup design equations, and lists previous and current studies and experiments. Section 3 introduces the scope of the project and elaborates on the specific structure being evaluated, how the structure is modeled, the testing parameters, as well as the facility which contains the three-dimensional shallow water wave basin employed to conduct this research.

Section 4 provides an overall description of the experimental setup within the laboratory. It details the construction of the model as well as the instrumentation utilized during testing and their appropriated functions. Section 4 also provides a basic description of instrument calibration, as well as methods used to calibrate the wave generator, and lastly, the section concludes with an overview of the actual physical model testing and the associated problems and solutions experienced during testing. From the physical modeling, Section 6 discusses the experimental results including: runup along the levee section, wave heights along the floodwall section, overtopping rates along the entire levee transition, as well as a dimensionless analysis of the results. To close, Section 7 iterates the conclusions drawn and provides a summary of the research presented within this thesis. 


\section{BACKGROUND AND LITERATURE REVIEW}

\subsection{Introduction}

Globally and historically, coastal protective structures have provided protection for coastal communities, preserving nations' economic growth, and international commerce (Hughes and Nadal, 2008). The attempt to determine solutions to incessant erosion problems, the onslaught of nearshore processes, and the management of coastal flooding has been an interest in coastal regions for centuries. These "coastal zone problems" have been recorded as far back as 1000-2000 B.C. in the Mediterranean Sea (Sorensen, 2006). Historically, coastal engineering has been the primary focus to preserve commerce and military interests; however, going to the beach and coast is now a "family affair" as well (NOAA, 2004; Sorensen, 2006). Providing protection for the widespread economic benefits of coastal development is necessary for local, state, and federal growth. Further discussion of the necessity of coastal protective structures is iterated in Section 2.2.

There are numerous examples of protective coastal structures and systems that are designed to protect coastal populations and infrastructures. In interest of this thesis, one particular coastal protection system is explored in detail. The Hurricane Protection System (HPS) is a vast system of floodwalls, levees, river locks and closures, as well as transitions among these well known coastal defenses (Link, 2009; Sills et. al, 2008). Recently, the HPS was struck by a massive storm surge resulting in significant flooding exceeding the current (2005) design standards. Consequently, the region originally protected by the HPS experienced significant losses (Link, 2009). Since the catastrophe, 
numerous studies have been conducted to further explore the unforeseen design failures to hopefully mitigate and avoid future economic, property, and population losses (Dean et al., 2009; Ebersole et al., 2009; Hughes, 2008; Link, 2009; Sills et al., 2008). Details of the HPS and the catastrophe are iterated in Section 2.3.

Assessment of design failures in levee and floodwall systems is critical in understanding these unaccounted vulnerabilities. There are numerous methods of failures and combinations of failures that levee and floodwall systems encounter during inundation by storm surges, bombardment of wave forces, and erosion forces due to overtopping and runup. Understanding and classifying these failure modes eventually provide a better prediction of existing structures' probable performance during major flooding (Ebersole et al., 2009; Hughes, 2008; Hughes and Nadal, 2008; Link, 2009; Schüttrumpf and van Gent, 2003; Sills et al., 2008). Section 2.4 further discusses various failure modes of levees and floodwalls as observed after significant storms, or high water level events.

In addition to design failure assessment, one needs a means of understanding the processes involved as a levee or floodwall is overtopped. Basic empirical equations and numerical definitions of overtopping and runup are discussed in Section 2.5. These empirical equations and methods are utilized worldwide to best approximate overtopping values for design (Hughes and Nadal, 2008; Pullen et al., 2007; TAW, 2002; van der Meer and Janssen, 1995).

To serve as validation of the prescribed equations, many experiments, evaluations, and studies have been conducted to review the effects of wave overtopping 
and wave runup on nearshore protective structures. Section 2.6 serves as a brief synopsis of past and current studies involving wave overtopping and wave runup on levee systems. These studies provide a foundation for the research illustrated in this thesis and enlighten the reader on how this thesis furthers and contributes to the studies that attempt to explain the complex mechanisms of wave overtopping and wave runup on levees and floodwalls. Lastly, Section 2.7 will serve to reiterate the literature reviewed.

\subsection{Necessity of Coastal Protective Structures}

Regions exposed to coastal environments are sometimes those which we value most; however, these are the regions that experience the greatest threat to the forces induced by the oceans, coastal storms, and flooding (Pullen et al., 2007). As of 2003, it is estimated that over $53 \%$ of the United States population is coastal-residing, and only $17 \%$, excluding Alaska, of the United States is within coastal counties. In other words, approximately 153 million people inhabit only 673 coastal counties in the United States. Not only is the coastal population presently abundant, it is speculated that these current statistics and coastal populations are continually increasing. Since 1980, 33 million people have moved to the coast (Crossett et al., 2005). Figure 3 provides a graphical representation of the variation among coastal and noncoastal population densities in the United States for the previous 28 years.

Not only are communities, cities, and citizens major components of our coastal regions, but marine commerce is also economically important. Over $95 \%$ of the United States trade by volume, which is approximately $37 \%$ of trade by value, is imported and exported through marine commerce. "Waterborne cargo alone contributes more than 
$\$ 742$ billion to the U.S. GDP and creates employment for more than 13 million citizens" (NOAA, 2004). These values are important when assessing the obligation of protecting our coastal infrastructures, communities, and commerce.

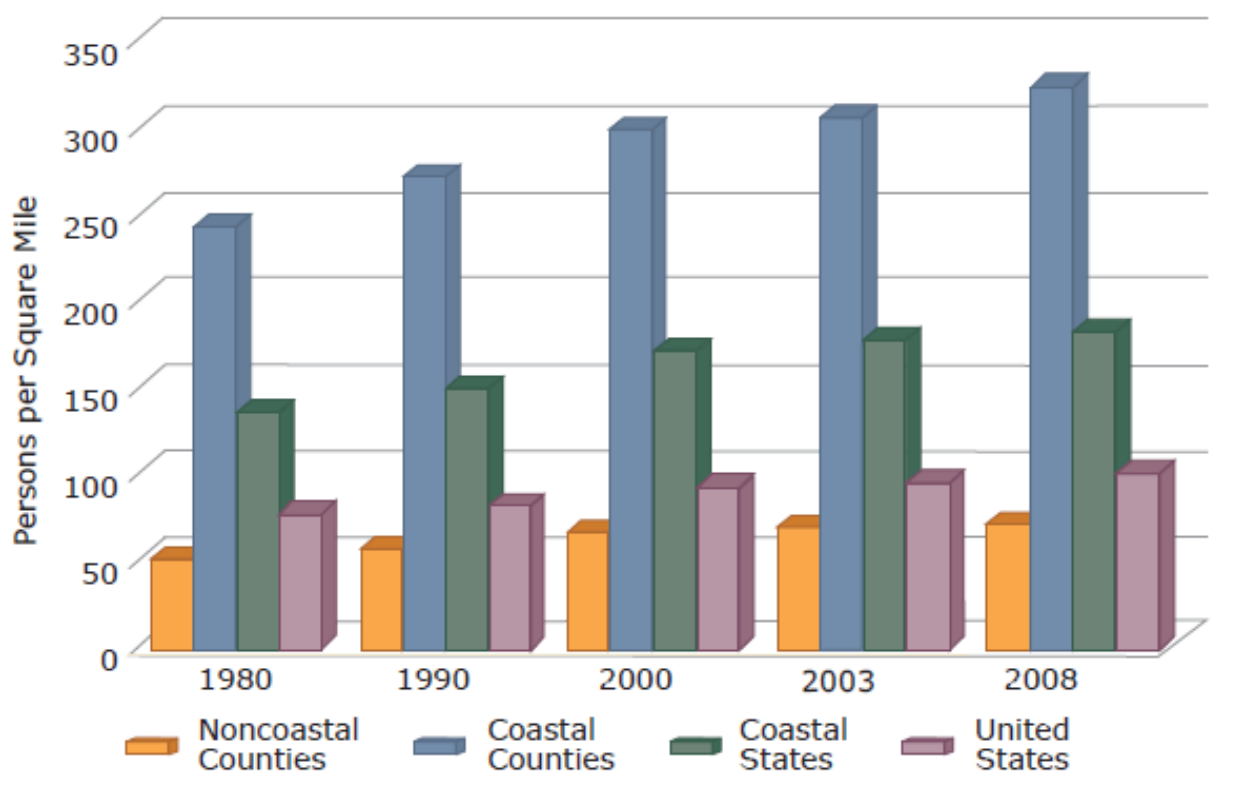

Figure 3. United States Population Density Variations and Trends Between Coastal and Noncoastal Regions from 1980 to 2008 (Crossett et al., 2005).

As mentioned in Section 2.1, going to the beach or visiting coastal communities has become a "family affair" (NOAA, 2004). As of year 2000, 54\% of all seasonal homes reside in coastal counties, which are approximately 2.1 million seasonal homes. It is important to note that the people inhabiting these seasonal homes are not accounted for in the coastal county's population numbers; therefore, "several coastal counties that are low in population emerge as being popular seasonal destinations" (Crossett et al., 
2005). In 2003, a 7\% increase in visits to the beach occurred, which equals nearly 110 million trips made by United States families. Of the 110 million trips, $35 \%$ of the visitations lasted at least a week in duration (NOAA, 2004). With these statistics, it is evident that recreational construction and development, such as hotels, condominiums, recreational areas, etcetera, are a vital component in the coastal economy. In fact, in some locations, commercial development is the primary contributor to the overall development and the coastal economy (Crossett et al., 2005). According to NOAA (2004), “Travel and tourism is the Nation's largest employer and second largest contributor to the GDP, generating over $\$ 700$ billion annually...with coastal states earning $85 \%$ of all U.S. tourism revenues."

The affinity for the coast is apparent, as expressed by the statistics. In regard to the information presented, it is obviously necessary to ensure protection of coastal communities for preservation of local, state, and national economies. In order for nations to continue marine commerce, meet energy demands through oil shipments, import and export necessary goods, and protect the overwhelming coastal populations, governments must first protect these coastal developments (NOAA, 2004).

\subsection{Hurricane Protection System}

To further understand the focus of the paper, and provide a paradigm of an existing coastal protection system, this section will highlight the Hurricane Protection System utilized in the City of New Orleans, Louisiana. The City of New Orleans is surrounded by the Mississippi River on one side and salt marshes and wetlands on the other side, which are below sea level. The site was founded in 1718, and it is historically 
claimed that "the royal engineer of King Louis XIV, Sieur Blond de la Tour, advised against settling on this area" (Sills et al., 2008). Regardless, the French began populating the region, and this area along the Mississippi River bend became known as the "Crescent City" (Sills et al., 2008). The location of the city relative to the state of Louisiana is illustrated in Figure 4.

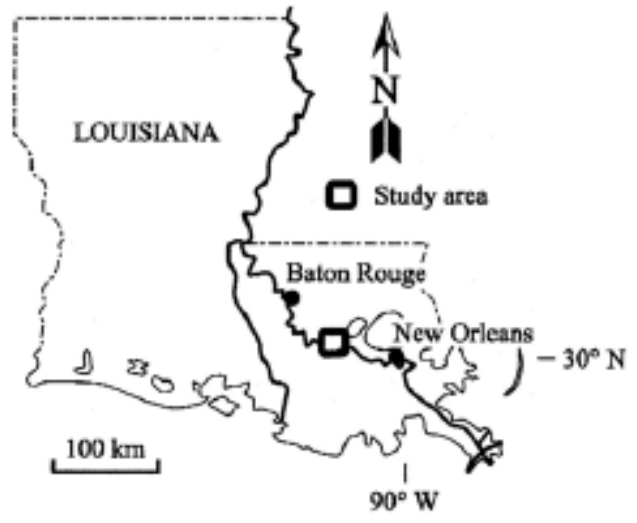

Figure 4. Location of City of New Orleans, Louisiana (IPET, 2007).

Inevitably, the region was continually plagued by the onslaught of coastal flooding and inundation; therefore, the French settlers decided to create their own system of levees to alleviate the coastal flooding. These efforts continued for centuries. In 1879 the earliest Federal efforts commenced. The efforts increased until the United States Army Corps of Engineers (USACE) submitted a "flood protection plan" known as the "barrier plan" in 1964 (Link, 2009; Sills, et al., 2008). The "barrier plan" now (2005) consists of levees, floodwalls, and gates at the entrance to Lake Pontchartrain. This protection system, now known (2005) as the HPS shown in Figure 5, was "compromised 
by numerous legal and fiscal battles," and ultimately, some of the protective structures were lower than the "authorized design elevations and remained incomplete" (Link, 2009).

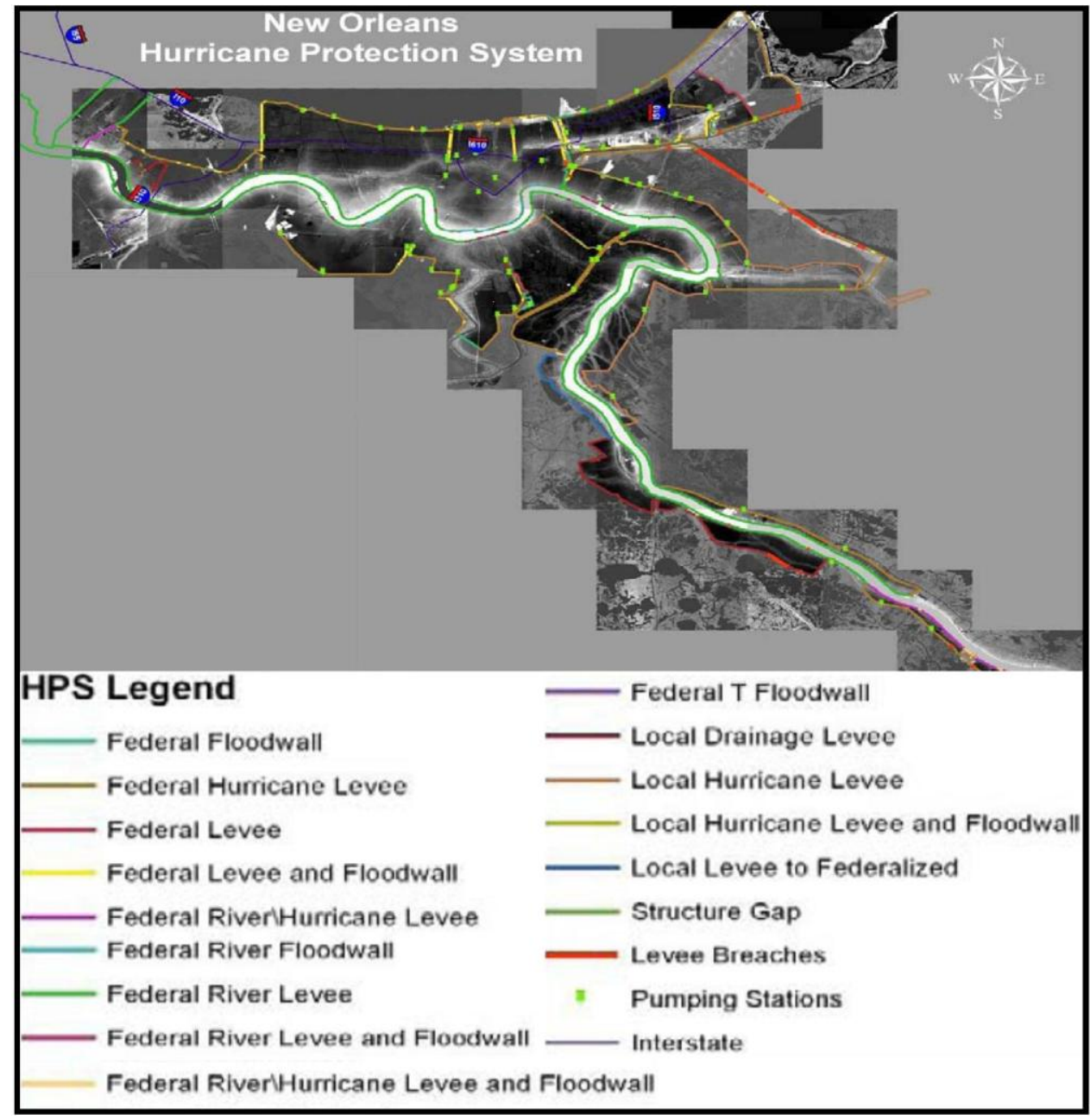

Figure 5. Hurricane Protection System (2005) (modified from IPET, 2007).

As of 2005, the New Orleans HPS was comprised of 350 miles of protective structures, 56 miles of which are floodwalls (Link, 2009; IPET, 2007). Not only were the 
design levels of the protection system compromised, the construction process was enduring; the final design of the HPS was not scheduled for completion until the year 2015. This serves as a significant risk for the "Crescent City" by basically hoping a major flooding event would not take advantage of this deficiency (Sills et al., 2008).

On August 29, 2005, the most influential global disaster at the time, since 1970, occurred (Link, 2009). Hurricane Katrina made landfall on August 29, 2005, as a Category 3 hurricane on the Saffir-Simpson scale. It brought with it a massive storm surge, the highest measured surge recorded on a NOAA buoy, causing significant flooding that easily overtopped and breached the HPS system. The waves induced by Hurricane Katrina reached up to $16.8 \mathrm{~m}$ offshore, which equaled the highest recorded wave heights recorded on a NOAA buoy (Link, 2009; Sills et al., 2008). Four decades had passed since the last major storm, Hurricane Betsy, had flooded and overwhelmed the City of New Orleans. Since that time, of course, complacency had set in the minds of the residing citizens (Sills et al., 2008). This factor alone had caused problems in the evacuation efforts and resulted in a considerable loss of life, which reached a toll in excess of 1600. Hurricane Katrina caused 200 miles of damages to the floodwalls and levees, which is over $60 \%$ of the total HPS. Figure 6 depicts the damages of the HPS. The red indicates areas of significant damage to the protective system. These significant damages quickly resulted in a total of 50 structural breaches. The major contributor to the floodwaters was the collapse of four floodwalls that were exposed to loads which exceeded their design limits (Link, 2009). The total losses to the city, including indirect losses, reached an estimated $\$ 200$ billion. These data exemplify the necessity of coastal 
structures and risk of living in a coastal community, especially those equal or below sea level (Link, 2009).

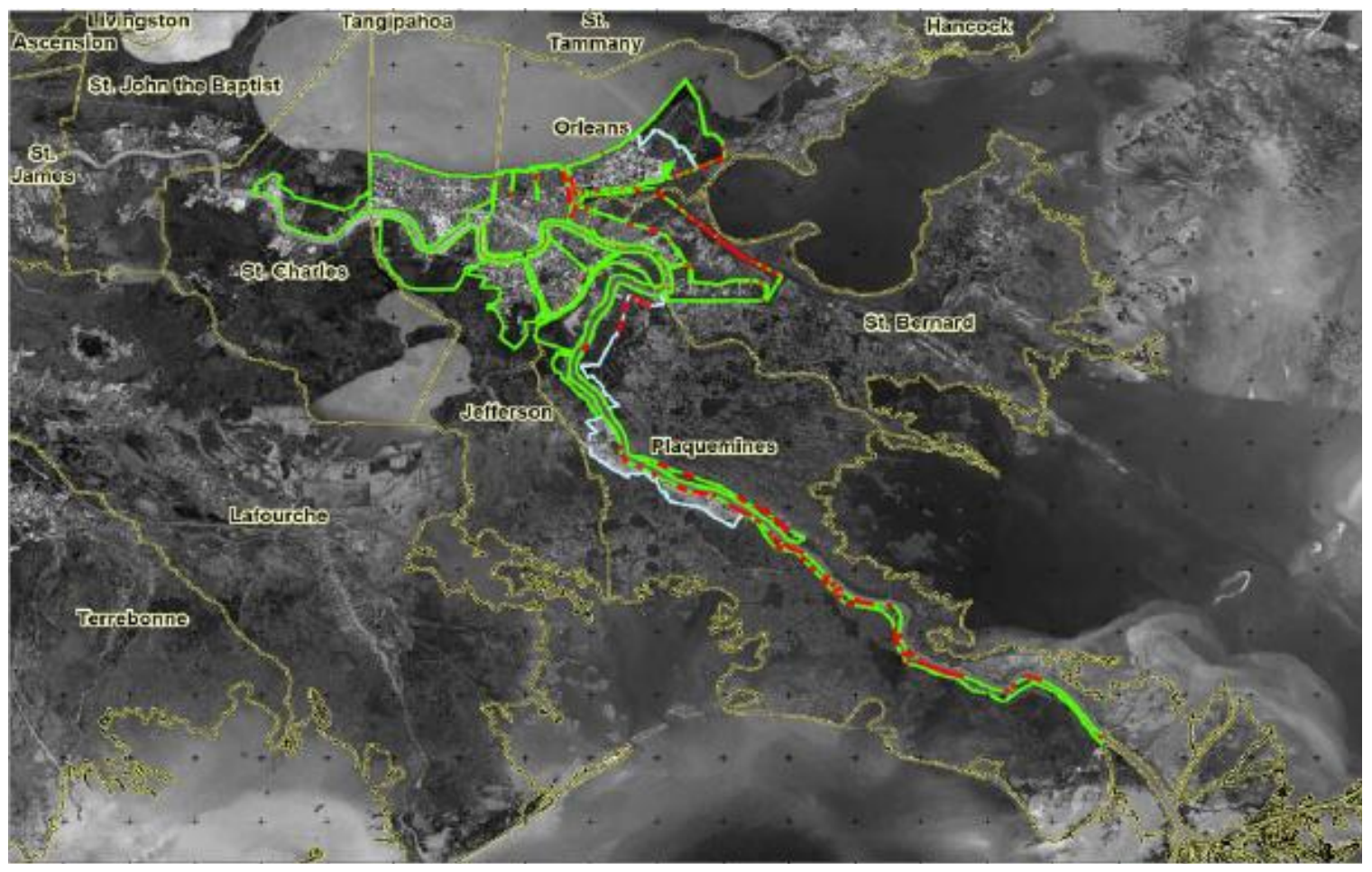

Figure 6. HPS after Hurricane Katrina (Link, 2009).

Almost immediately after the storm, ASCE formed a reconnaissance visit to the devastated area. Due to the unforeseen forces of the storm surges and waves, the inspection team was unprepared to witness the extensive damage. The region was barren; "Entire residential city blocks were reduced to rubble or nothing more than foundation slabs" (Nicholson, 2007). Nicholson (2007) also reported, "In areas where the houses had largely withstood the forces of the flooding, the mounds of ruined personal effects had an equally sobering effect." Not only did the ruins provide an 
overwhelming economical impact, the effects of the remnants were also personally and psychologically influential. Further details of the damages to the floodwalls and levees are provided in the next section.

\subsection{Damages to Levees and Floodwalls}

After significant flooding events and ultimate failures in various levee and floodwall systems, such as those provoked by Hurricane Katrina, thorough assessment is undergone to explain these failure modes. Directly after Hurricane Katrina, assessment teams were dispersed to evaluate the structural integrity and the response of the levee system. The primary investigative team formed was declared the Interagency Performance Evaluation Taskforce, IPET (Link, 2009; Sills et al., 2008). It was the sole duty of the team to "determine the facts and put those facts to work in the repair and rebuilding of hurricane protection in New Orleans" (Link, 2009). Through these recent studies and investigations, numerous levee and floodwall failures have been condensed and classified based upon specific causes and results of examined failures.

For levees, the most frequent cause of failure is induced by overtopping. Hughes (2008), Nicholson (2007), and van Gent (2002) have provided explanations and evidence of this occurrence. It is proven, and expected, that as a levee or floodwall is exposed to the forces of storm surge and waves, the velocities experienced due to overtopping cause significant erosion. There are three possible scenarios for earthen levee overtopping, as described by Hughes (2008) and portrayed in Figure 2. Of course, if failure of the revetment, or flood-side protection, occurs, breaching is highly probable. Another failure mode is known as piping. Piping is basically defined as "internal erosion" caused by 
water being forced through or under the levee embankment. Not only does erosion occur on the flood-side and by piping, but it is considered by some that the more vulnerable part of the levee is the land-side, which is also referred to as the protected-side or backside (Dean et al., 2009; Hughes, 2008, IPET, 2007; van Gent, 2002).

Regardless of the means of overtopping, once it has begun, erosion is generally imminent. In the case of the HPS failures, no breaching occurred without overtopping (IPET, 2007). The magnitude of the erosion is mostly dependent on the velocities of the overtopping water and the composition of the levee surface. These aspects determine the shearing forces involved as the water flows over the levee, and, based upon estimates of overtopping rates, are the principles which govern the design of levee systems. Earthen levees are sometimes protected by concrete blocks, foreshore berms for wave dissipation, or sufficient grass or vegetation cover to reduce erosion or shearing forces directly on the levee slope or crest (Dean et al., 2009). Figure 7 provides an illustration to explain a possible evolution of an overtopped earthen levee due to erosion. Examples of other levee failures can be viewed in Appendix A. Overtopping failure mechanisms are highlighted in this section due to the focus on overtopping analysis in the overall scope of work described in Section 3.

Similar to levees, floodwalls are just as vulnerable to overtopping. Once overtopping begins on a floodwall, significant erosion initiates directly behind the floodwall. This is particularly the case for I-wall floodwalls. An example of an I-wall floodwall is presented in Figure 8. I-wall floodwalls tend to not have scour protection on the backside of the floodwall, unlike a T-wall floodwall, named for its inverted T-shape. 
For the case of the HPS failures, the I-wall floodwalls fared much better due to the limited scouring on the backside (IPET, 2007). Appendix A provides an illustration of the difference between I-walls and T-wall floodwalls.

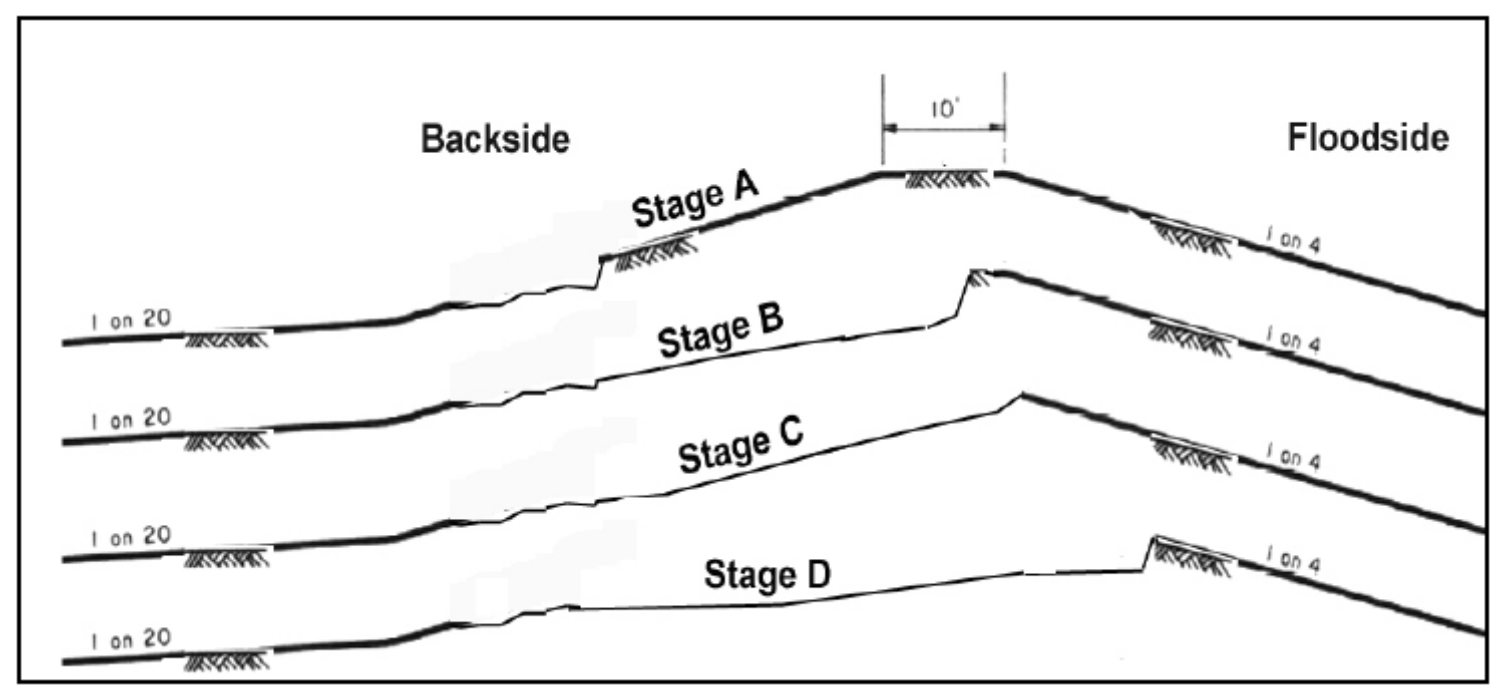

Figure 7. Stages of Erosion for Earthen Levee (IPET, 2007).

Another inconvenience with the use of floodwalls is the susceptibility to deflection. This failure mode is outlined in Figure 8. The hydrostatic pressures, currents, and dynamic pressures of the storm surge and waves result in deflection of the floodwall. Ultimately, the foundations of the floodwalls cannot withstand these forces, and the vertical wall begins to tilt. This of course results in significant erosion and overtopping, which eventually leads to breaching of the protective structure (Link, 2009; IPET, 2007; Sills et al., 2008). 


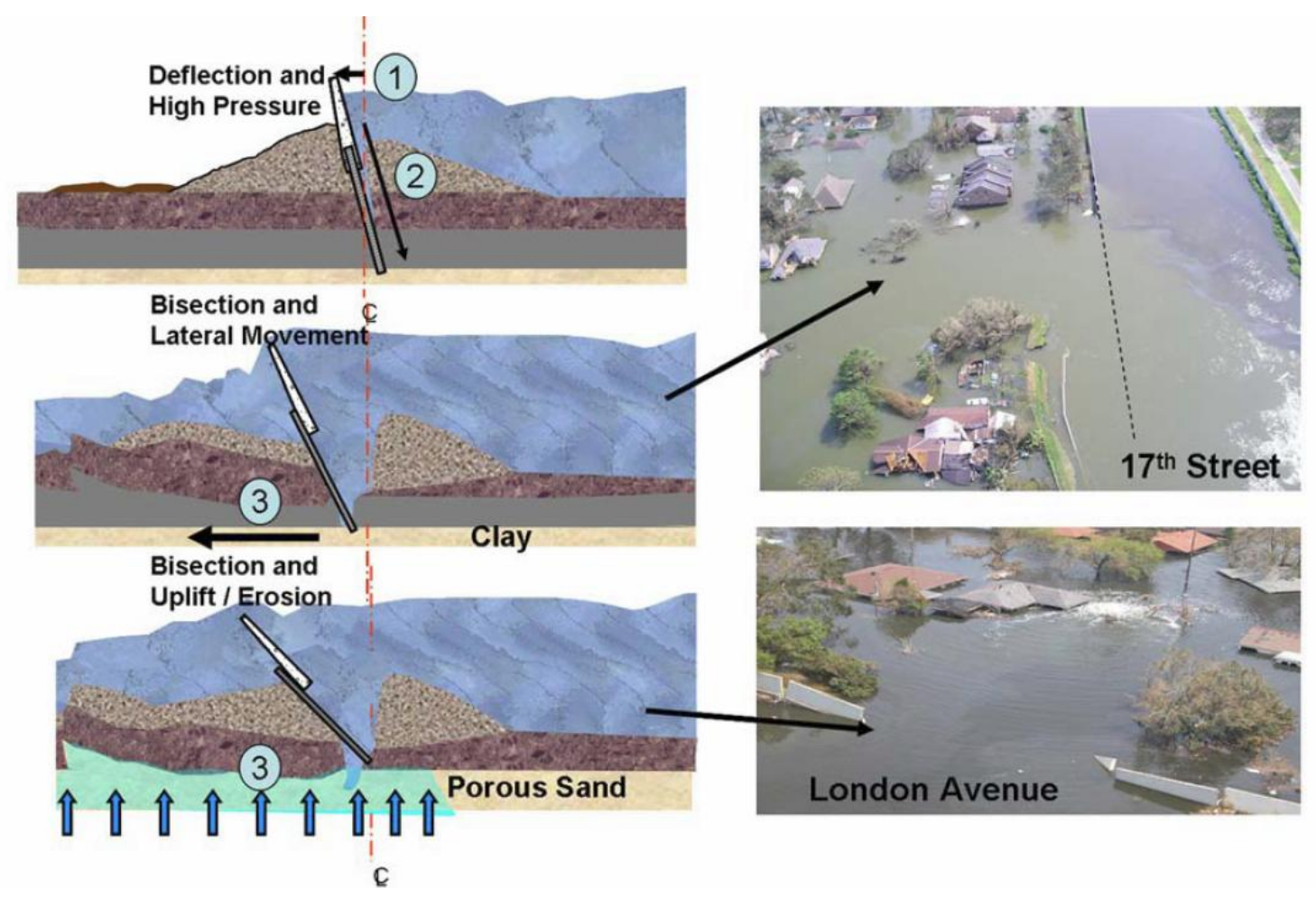

Figure 8. Hurricane Katrina Induced Floodwall Failure Modes in HPS (Link, 2009).

\subsection{Overtopping and Runup Calculations}

Accounting for the wave runup, and essentially the wave overtopping, on a coastal protective structure is essential for determining final design characteristics of the coastal structure (Pullen et al., 2007; TAW, 2002). The focus of this thesis and the experiments discussed in Section 4 are in reference to wave-only overtopping and runup; therefore, the equations and formulae presented in this section provide a basis of the empirical overtopping and runup equations developed for wave-only overtopping and runup.

Common factors proven to affect wave overtopping and runup can be divided basically into two categories: levee geometry and hydraulic conditions. Factors such as 
seaward slope, berms, revetment, vegetation cover, crest width, crest height, and crest slope can all be classified under levee geometry. Characteristics such as incident wave heights, wave periods, wave direction, and water depth are all aspects of experienced hydraulic conditions (Schüttrumpf and van Gent, 2003). To condense a common calculation of comparing the offshore signficant wave height to the structure's slope, van der Meer and Janssen (1995) and Stockdon et al. (2006) introduce and define the Iribarren number, or surf similarity parameter, as:

$$
\xi_{o p}=\frac{\tan \alpha}{\sqrt{H_{s} / L_{o p}}}
$$

where $\alpha$ is the flood-side slope of the structure, $H_{s}$ is the offshore significant wave height (defined as average of the highest one-third wave), and $L_{o p}$ is the offshore wave length dependent upon the peak wave period, which is further expressed and linked by the linear dispersion relation as:

$$
L_{o p}=\frac{g T_{p}^{2}}{2 \pi}
$$

where $g$ is gravitational acceleration, and $T_{p}$ is the peak wave period. With these definitions in place, the general formula for runup on a dike or levee is expressed as follows:

$$
\frac{R_{u 2 \%}}{H_{s}}=1.6 \gamma_{h} \gamma_{f} \gamma_{\beta} \gamma_{b} \xi_{o p}
$$

with a maximum value of: 


$$
\frac{R_{u 2 \%}}{H_{s}}=3.2 \gamma_{h} \gamma_{f} \gamma_{\beta} \gamma_{b} \xi_{o p}
$$

where $R_{u 2 \%}$ is the $2 \%$ runup level, or the runup value exceeded by only $2 \%$ of the incident waves, $\gamma_{h}$ is the reduction factor for a shallow foreshore, $\gamma_{f}$ is the reduction factor for slope roughness, $\gamma_{\beta}$ is the reduction factor for oblique wave attack, and $\gamma_{b}$ is the reduction factor for a berm. Equations 2.3 and 2.4 are only valid for $0.5<\gamma_{b} \xi_{o p}<4$ (van der Meer and Janssen, 1995). According to TAW (2002), the following equations for runup are recommended:

$$
R_{2 \%}=H_{m o}\left\{\begin{array}{cc}
1.75 \gamma_{f} \gamma_{\beta} \gamma_{b} \xi_{o p}, & 0.5 \leq \gamma_{b} \xi_{o p}<1.8 \\
\gamma_{f} \gamma_{\beta}\left(4.3-\frac{1.6}{\sqrt{\xi_{o p}}}\right), & 1.8 \leq \gamma_{b} \xi_{o p}
\end{array}\right\}
$$

where $H_{m o}$ is the spectral significant wave height at the toe of the structure.

Overtopping calculations are also empirically based and tend to estimate only the average overtopping magnitude (Dean et al., 2009). The recommended formulae by TAW (2002) are the following:

$$
\frac{q}{\sqrt{g H_{m o}^{3}}}=\frac{0.067}{\sqrt{\tan \alpha}} \gamma_{b} \xi_{o p} \exp \left(-4.3 \frac{R_{c}}{H_{m o}} \frac{1}{\xi_{o p} \gamma_{b} \gamma_{f} \gamma_{\beta} \gamma_{v}}\right)
$$

with a maximum of:

$$
\frac{q}{\sqrt{g H_{m o}^{3}}}=0.2 \exp \left(-2.3 \frac{R_{c}}{H_{m o}} \frac{1}{\gamma_{f} \gamma_{\beta}}\right)
$$


where $q$ is the average wave overtopping discharge $\left(\mathrm{m}^{3} / \mathrm{s}\right.$ per $\left.\mathrm{m}\right), g$ is in $\left(\mathrm{m} / \mathrm{s}^{2}\right), H_{m o}$ is the spectral significant wave height at the toe of the levee $(\mathrm{m}), \gamma_{v}$ is the reduction factor for a vertical wall on the slope, and $R_{c}$ is the free crest height above the SWL (m). The free crest, or freeboard, is the vertical distance between the SWL and the crest of the levee or dike.

According to the European Overtopping Manual (Pullen et al., 2007), Equations 2.6 and 2.7 are recommended as a deterministic approach to calculating the average overtopping discharge. This deterministic approach increases the average discharge by one standard deviation yielding a more conservative design approach. Regardless of the formula, it is evident thus far that the primary means of estimating the magnitude of runup and overtopping on levees is by traditional empirical equations. These traditional empirical equations are applied to specific cross-sections of levees or floodwalls under specific wave conditions, indirectly assuming that the cross-sections are uniform for a given levee or floodwall span; in other words, the equations do not provide any temporal or spatial variability (Kobayashi and Wurjanto, 1989). More complex geometries and spatial variability, such as a levee transition, require numerical or physical modeling to accurately and confidently predict overtopping and runup values (Hughes and Nadal, 2008; Kobayashi and Wurjanto, 1989).

\subsection{Previous and Current Experiments and Studies}

To comprehend the mechanisms of wave overtopping and wave runup, numerous experiments and studies have been conducted. Experiments have been conducted to create and validate equations used to estimate runup and overtopping values, and studies 
have served to assess the repercussions of underestimated design conditions as well as evaluate successful designs (Hughes and Nadal, 2008; Link, 2009; Sills et al., 2008). The first model tests on wave overtopping of sea dikes were performed in 1953, and since then have been refined to a sophisticated method of producing accurate estimations beneficial to final designs (Schüttrumpf and van Gent, 2003).

Though calculations of runup and overtopping as well as respected physical modeling have been refining previous methods for quite some time, especially in the last half century, numerous nonlinearities, physical processes, and unaccounted factors still remain unexpressed (Hughes and Nadal, 2008; Kobayashi and Wurjanto, 1989; Pullen et al., 2007). Recently realized, there is little design guidance that stipulates necessary amounts or types of cover on the protected-side of levees and floodwalls (Dean et al., 2009; Hughes, 2008). Usually the protected-side, or land-side, of a protective structure consists of grass or vegetation cover. This aspect is important since, as revealed by Hurricane Katrina, the protected-side of a levee or floodwall is arguably the most vulnerable to erosion due to overtopping (Dean et al., 2009; Hughes, 2008, Hughes and Nadal, 2008; IPET, 2007).

Dean et al. (2009) developed three "erosion criteria" to relate tolerable land-side erosion to velocities induced from overtopping as well as overall durations of the overtopping events. They developed methods to determine required levee crest heights for three basic grass cover varieties. These results were compared to present overtopping guidelines provided by TAW (2002). The results of Dean et al. provide variability in the levee design based upon different types of grass cover, unlike the present guidelines. 
Ultimately, Dean et al. (2009) has allowed grass cover to help govern the design levee crest height and, for the example presented in the paper, have determined that the range of required levee crest heights could vary up to $1.8 \mathrm{~m}$ between a levee with "poor grass cover" and a levee with a "good grass cover."

As a result of the devastation induced by Hurricane Katrina, Hughes and Nadal (2008) engaged in a physical model study to "develop design guidance in the aftermath of Hurricane Katrina." The physical modeling was conducted in a two-dimensional wave flume at the U.S. Army Engineering Research and Development Center (ERDC), Coastal Hydraulics Laboratory (CHL) in Vicksburg, Mississippi. The model was conducted using a model to prototype length scale of 1:25. The cross section was modeled after typical levee geometry located on the Mississippi River Gulf Outlet (MRGO), which suffered substantial overtopping during Hurricane Katrina. A total of 27 different overtopping conditions were tested by varying water elevations and characteristics of the irregular waves generated in the wave flume. Combinations and mechanisms of overtopping were based on the three overtopping scenarios depicted in Figure 2. Based upon experimental results, they developed new empirical equations to better describe the overtopping mechanisms for the specific levee tested for combination wave and surge overtopping. Hughes and Nadal also generated an empirical equation describing the mean flow thickness along the land-side of the levee. The results of the physical model are in fact dependent upon the specific modeled structure, as well as the uniform frictional effects of the structure; however, the experiment provides a basis of the importance of individual studies by highlighting the slight variability provided with 
traditional empirical equations developed by van der Meer and Janssen (1995) or recommended by TAW (2002) or Pullen et al. (2007).

In addition to physical model testing, van der Meer et al. $(2006,2009)$ have developed a method for testing full scale, in situ overtopping on the land-side of levees and dikes. "The Wave Overtopping Simulator" enables reproduction of overtopping for various overtopping rates at a constant rate without the generation of waves on the floodside. In situ testing negates the inherent model effects such as the inability to scale grass cover, soil types, etcetera. (van der Meer et al., 2009) A picture of the "Wave Overtopping Simulator" can be seen in Figure 9.
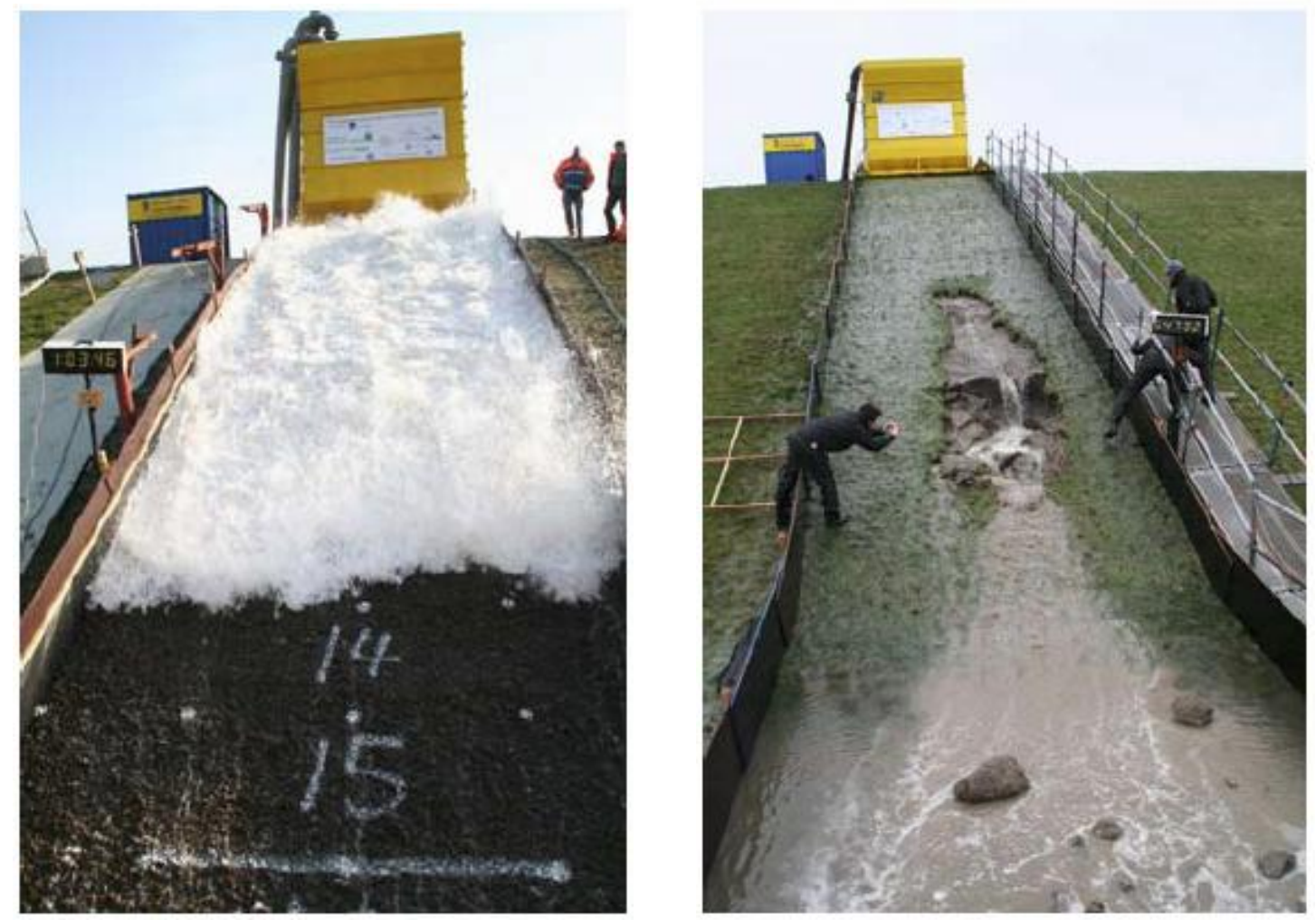

Figure 9. Example of Overtopping Simulator in Action and Erosion Effects (van der Meer et al., 2009). 
Based upon the tests, van der Meer et al. (2009) determined that greatest influence in erosion resistance is the presence of grass rather than the adequacy of the clay. It was also found that transitions from one slope to another, such as the transition between the initial land-side slope to the toe of the levee, create an area susceptible to significant erosion. Also, made evident by Figure 9, small holes or voids in the clay under the grass cover can generate considerable scour holes.

Besides physical modeling and in situ testing, another method of assessing overtopping and runup mechanisms for specific levee and floodwall geometry is by numerical modeling. Kobayashi and Wurjanto (1989) developed a two-dimensional numerical model to provide more detailed predictions of wave overtopping in lieu of standard empirical equations, which were limited to basic structural geometries with standard friction factors. These numerical models have advanced to include nonlinear shallow water wave equations to simulate wave interaction at the structure (van Gent, 2001). These numerical models can also include permeable structures that can be subject to various spectral densities. As more data is provided to describe overtopping and runup, calibration of numerical models has become more accessible. Newer models, as outlined by Lynett et al. (2009) incorporate Boussinesq wave models enabling "spatial resolution on the order of a meter and temporal resolution of a fraction of a second" to describe inundation and overtopping of levees for complex geometries, such as portions of the HPS. Tools such as STWAVE, WAM, and ADCIRC allow spatial resolution near $100 \mathrm{~m}$, and in some cases $30 \mathrm{~m}$, to predict the wave and water level conditions at specific study locations. These models can recreate evolutions of storm surges and 
floodwaters to estimate future and previous high water levels that may lead to a collapse of a protective structure (Ebersole et al., 2009). By highlighting these spatial variations, it is evident that evaluating the spatial variability in design is necessary for more complex geometries and deviations, such as a levee transition.

\subsection{Summary of Literature Review}

The literature presented in this section provides a background and an understanding of the importance of this research. It is essential to comprehend the necessity of coastal protective structures to ensure the welfare of communities, cities, and nations reliant on coastal commerce, tourism, and security. The HPS of New Orleans, Louisiana, is comprised of an intricate network of levees and floodwalls and exemplifies the importance of coastal protective structures. Hurricane Katrina provides countless examples of damages to floodwalls and levees and enables the reader to understand potential problematic areas within a levee and floodwall system. Highlighting tenuous regions, such as a levee transition, yields the opportunity for possible enhancement of design.

Basic empirical equations recommended by van der Meer and Janssen (1995), TAW (2002), and Pullen et al. (2007) are presented in Section 2.5, which describe the effects and factors of runup and overtopping. Observing the factors in the formulae enable visualization of the importance of each factor contributing to runup and overtopping. The specific empirical equations presented form the basis of traditional overtopping and runup calculations for design. Utilizing these equations during the results of this research enables comparison of the results and accents possible 
agreements and inconsistencies between the resulting data and traditional methods. Underscoring previous and current experimental studies such as Hughes and Nadal (2008) provided new ideas and experimental procedures utilized in the research contained in this thesis. The extent of the research shown in Section 2.6, such as van der Meer et al. (2006, 2009), not only emphasizes the need for experiments and numerical modeling to incorporate the nonlinearities and unaccounted effects inherently contained in unaltered, in situ situations, but it also accentuates the need for basic empirical equations as an expeditious method for calculating overtopping and runup. 


\section{SCOPE OF PROJECT}

\subsection{Introduction}

The purpose of this section is to provide insight of the actual scope of work completed in this evaluation of a levee transition. As highlighted in the previous sections, it is important to fully understand the most tenuous areas of protective systems in order to provide adequate estimates of structural integrity of the system under design conditions. Sufficient information is required to complete a successful physical model project; therefore, the specifics of the levee transition are addressed in this section, along with its detailed geometry. In addition to the specified dimensions of the levee transition, specific hydraulic conditions are introduced. These hydraulic conditions will form the basis of the design conditions used to evaluate the structure. The testing parameters and the dimensions of the levee and floodwall sections are based on recommendations provided by the USACE. The modeled structure is representative of a transition located within in the HPS; therefore, the modeled testing parameters are indicative of the region as well. Testing of the physical model was completed at the Haynes Coastal Engineering Laboratory at Texas A\&M University, College Station, Texas. A description of the laboratory facility is provided to allow perspective of the allotted space and to ensure validity of results.

\subsection{Levee Transition}

A levee transition can be defined in several different manners. For this particular scenario, a levee transition is simply defined as the transition between an earthen levee section to a vertical floodwall section. A generalized picture can be seen below. The 
picture is a Google ${ }^{\circledR}$ screenshot that depicts an actual levee transition in New Orleans. The right side of Figure 10 depicts the earthen levee section, which consists of a mildly sloped earthen levee section; the left side of the picture depicts the floodwall section, which consists of a vertical floodwall with an incorporated mildly sloped earthen levee at the base of the floodwall. The protected-side is pictured in Figure 10 as indicated by the presence of the road in the screenshot.

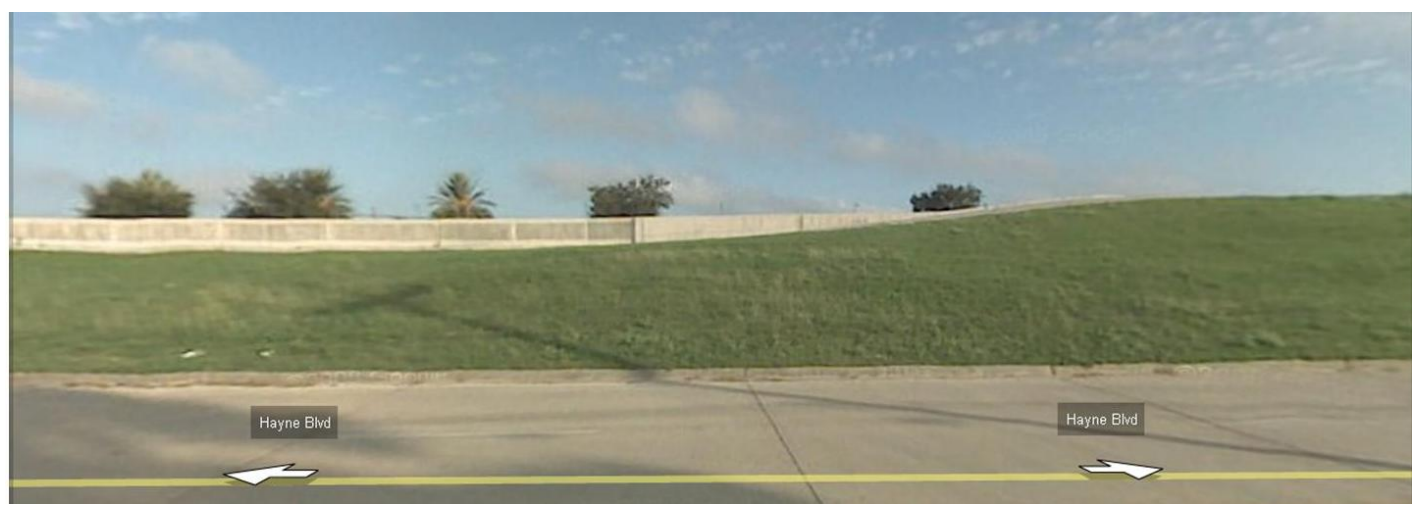

Figure 10. Example Levee Transition (Courtesy of Google Maps, (C) 2009).

The particular type of levee transition highlighted in this thesis does not serve as a representation of the majority of levee transitions, nor does it serve as an average representation. Each levee transition is unique in its own contours and geometry. The project and specific geometry herein, detailed in Section 3.3, is in reference to the specific recommendations provided by the USACE.

\subsection{Dimensions of Modeled Structure}

The modeled structure shall consist of two sections, the levee section and floodwall section. The two sections shall join together to form a transition between the 
two sections. The established dimensions of the two sections are addressed below.

The vertical datum of the levee section is at the toe of the levee, which is assumed to be $+0.0 \mathrm{~m}$. The levee crest has an elevation of $+8.23 \mathrm{~m}$, and the flood-side of the levee section is comprised of a composite slope. The slope is $1 \mathrm{~V}: 4 \mathrm{H}$ from the levee toe to an elevation of $+2.74 \mathrm{~m}, 1 \mathrm{~V}: 10 \mathrm{H}$ from $+2.74 \mathrm{~m}$ to $+5.49 \mathrm{~m}$, and $1 \mathrm{~V}: 4 \mathrm{H}$ from $+5.49 \mathrm{~m}$ to the levee crest at $+8.23 \mathrm{~m}$. Figure 11 illustrates the detailed prototype dimensions of the levee section.

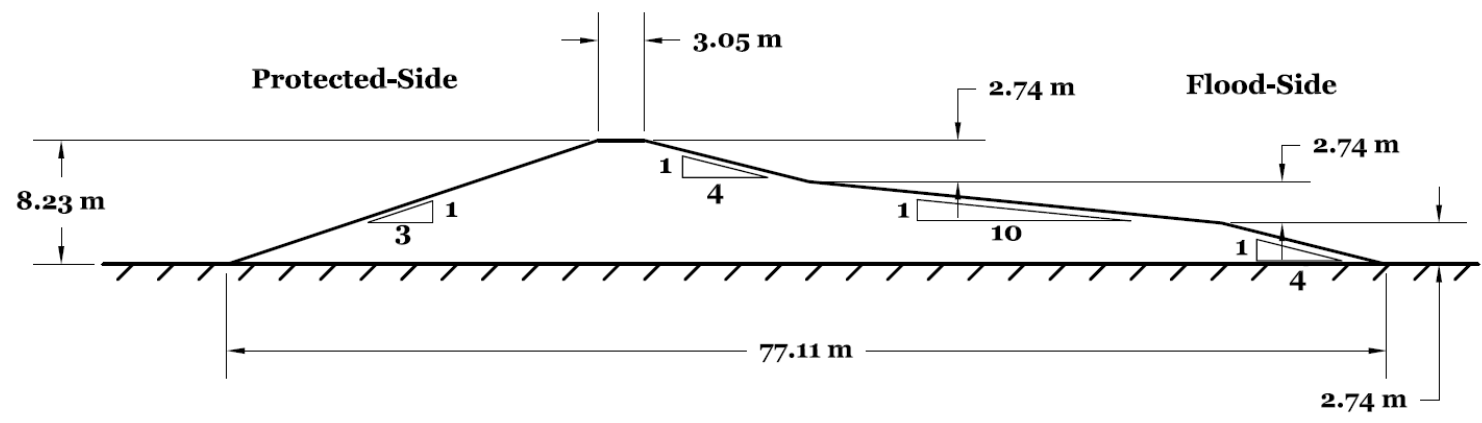

Figure 11. Levee Section Prototype Cross-sectional Dimensions.

The datum of the floodwall section dimensions is also at the toe of the levee, which is $+0.0 \mathrm{~m}$. The floodwall incorporates a levee with a crest at $+6.10 \mathrm{~m}$. The slope of the levee is a constant $1 \mathrm{~V}: 10 \mathrm{H}$ from $+0.0 \mathrm{~m}$ to the levee crest at $+6.10 \mathrm{~m}$. The floodwall crest is at an elevation of $+9.14 \mathrm{~m}$ and is located $0.61 \mathrm{~m}$ from the flood-side toe of the crest. The protected-side of the floodwall section was requested to incorporate a slope of $1 \mathrm{~V}: 3 \mathrm{H}$, which then transitions into a stability berm at $+3.66 \mathrm{~m}$. The stability berm would have a slope of $1 \mathrm{~V}: 30 \mathrm{H}$ to an elevation of $+0.0 \mathrm{~m}$. However, the protected- 
side of the floodwall section was modified from the requested dimensions for better utilization of the laboratory and instrumentation. This is discussed further in Section 4, which outlines the experimental setup. The flood-side of the floodwall section directly follows the specified dimensions. Figure 12 illustrates the prototype dimensions of the floodwall section and the modified dimensions of the protected-side.

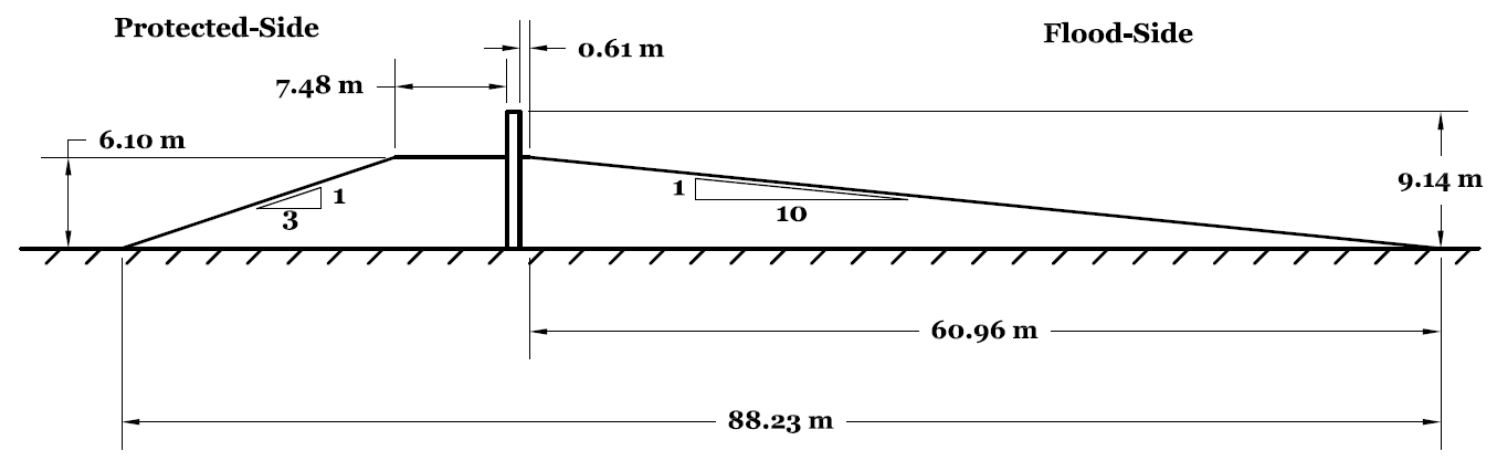

Figure 12. Floodwall Section Prototype Cross-sectional Dimensions.

\subsection{Hydraulic Conditions}

The testing parameters requested by the USACE are provided in Table 1. A total of 8 tests were requested, with variability in wave period at two characteristic water levels and wave heights. All waves propagate normal to the levee structure. Both Still Water Levels are referenced to the originally established datum of the levee toe. The significant wave heights are referenced to the SWL. The values presented in Table 1 are representative of an STWAVE and WAM analysis conducted by the USACE for the Lake Borgne area. 
Table 1. Requested Hydraulic Conditions

\begin{tabular}{cccc} 
TEST NO. & $\begin{array}{c}\text { SWL } \\
(\mathbf{m})\end{array}$ & $\begin{array}{c}\mathbf{H}_{\mathbf{s}} \\
(\mathbf{m})\end{array}$ & $\begin{array}{c}\mathbf{T}_{\mathbf{p}} \\
(\mathbf{s e c})\end{array}$ \\
\hline 1 & 5.79 & 2.29 & 6 \\
2 & 5.79 & 2.29 & 7 \\
3 & 5.79 & 2.29 & 8 \\
4 & 5.79 & 2.29 & 9 \\
5 & 6.89 & 2.74 & 6 \\
6 & 6.89 & 2.74 & 7 \\
7 & 6.89 & 2.74 & 8 \\
8 & 6.89 & 2.74 & 9
\end{tabular}

\subsection{Haynes Coastal Engineering Laboratory}

The Reta and Bill Haynes '46 Coastal Engineering Laboratory is comprised of two main basins. The first of which is a large tow and dredge tank. The second of which is a large three-dimensional shallow water wave basin, which is featured in Figure 13. The shallow water wave basin is $36.6 \mathrm{~m}$ long and $22.9 \mathrm{~m}$ wide. Water depth is variable up to $1.22 \mathrm{~m}$. The basin houses a directional wave basin that operates to a depth of $1 \mathrm{~m}$ creating waves of up to $61 \mathrm{~cm}$. The piston-type wave generator is comprised of 48 independent paddles, which enables directionality.

In addition to the directionality, the wave generator can create up to nine spectral shapes including JONSWAP, Pierson-Moskowitz, and TMA. Four axial flow pumps are housed below the basins to generate flow through either tank of up to 227 liters per hour. The waves are generated from the wave generator and propagate over a flat bottom until interaction with the tested structure. Waves that transmit beyond the structure encounter a rock beach, which dissipates approximately $85 \%$ of the wave energy, as shown in Figure 14. 


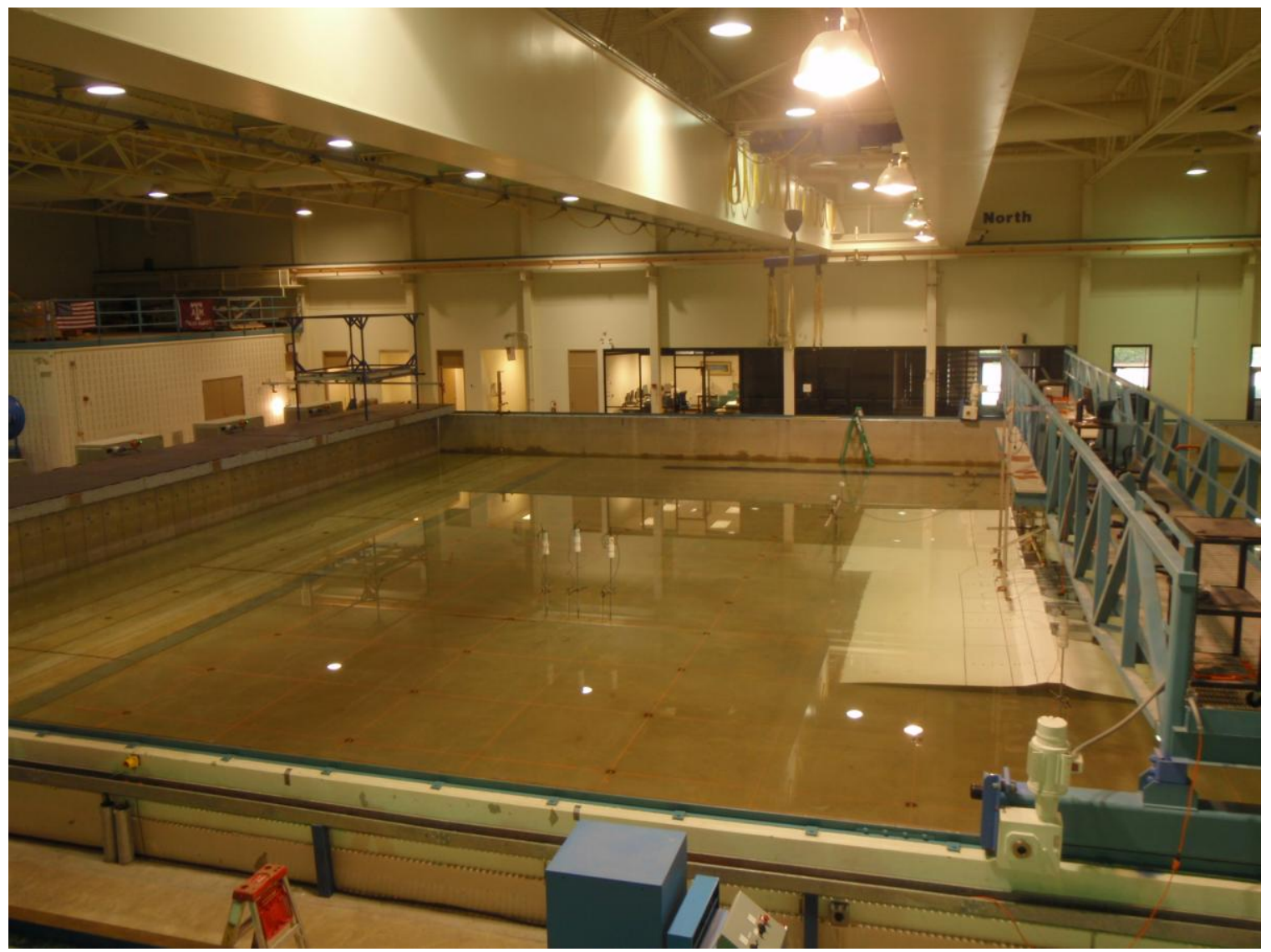

Figure 13. Haynes Coastal Engineering Laboratory.

A bridge spans the width of the basin and is mounted on tracks that enable movement along the length of the basin. The laboratory also has an incorporated threeton crane that spans the width of the building. The crane is also mounted on tracks, which enables movement along the length of the laboratory, allowing transport of rocks, material, sediment, and equipment to both basins.

The laboratory contains a wide array of laboratory equipment essential for physical modeling and wave basin testing. Relevant equipment include Acoustic 
Doppler Velocimeters, or ADV, wireless capacitance wave gauges, resistance wave gauges, tension and compression load cells, digital video cameras, online Internet cameras, and a laser bottom scanner.

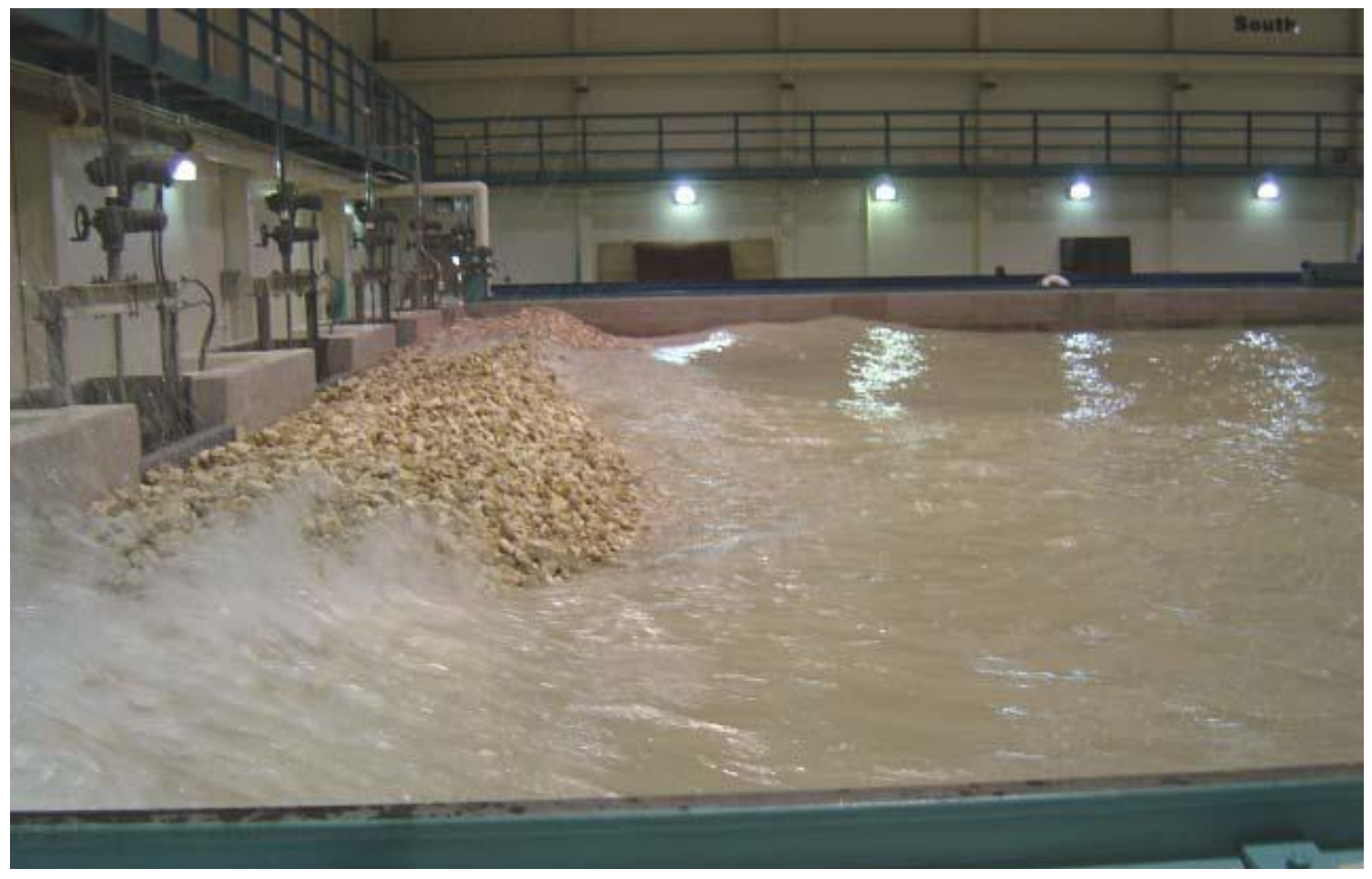

Figure 14. Rock Beach at Haynes Laboratory. 


\section{EXPERIMENTAL SETUP AND CALIBRATION}

\subsection{Introduction}

With the Haynes Coastal Engineering Laboratory and its shallow water wave basin and available equipment, the present section provides the detailed experimental setup for testing of the modeled levee transition. The setup is basically comprised of 4 major parts: construction of the physical model, setup of instrumentation, calibration and pretesting of the wave generator, and miscellaneous problems and solutions encountered during initial experimental setup.

\subsection{Construction}

As noted earlier, the levee transition consists mostly of two parts, the floodwall section and the levee section. Figure 15 illustrates the transition between these two sections. The levee section, highlighted in green, is rounded at the transition as it intersects with the floodwall section, which is presented in white. From the dimensions presented by the CORPS, the most efficient model scale is determined to be 1:20.

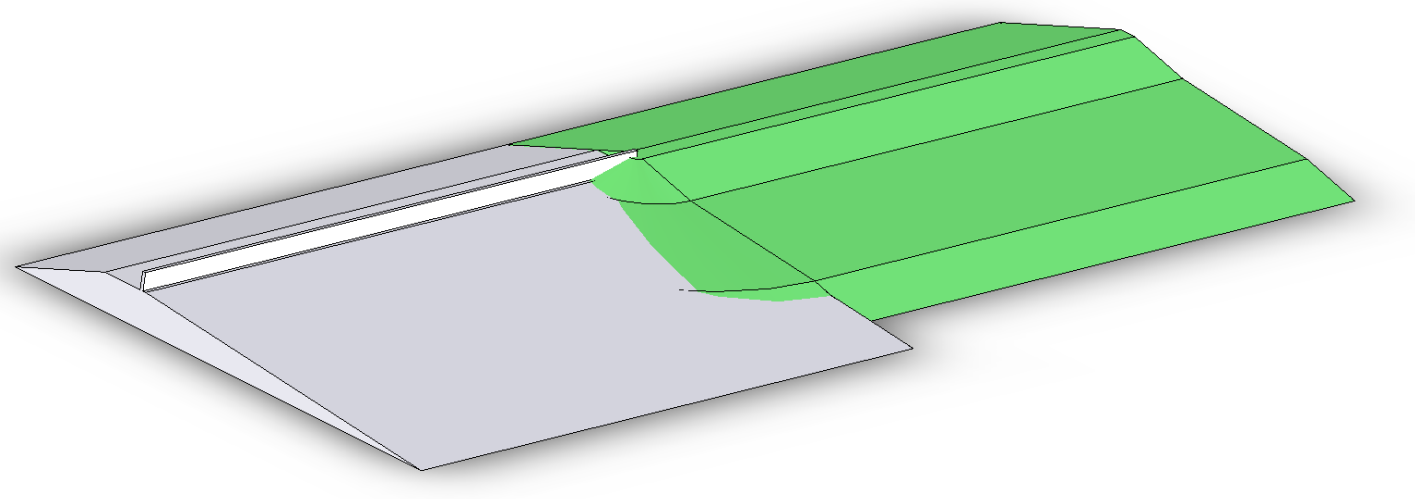

Figure 15. New Orleans Levee Transition. 
This scale allows the most adequate use of the wave basin, allowing the length of the model to be maximized to avoid major scale effects, reduce the stress required by the wave generator, and allow the most versatility with the available instrumentation. For all vertical dimensions, the referenced horizontal datum is the floor of the basin, or the toe of the levee.

A 1:20 scale allows a $213 \mathrm{~m}$ section to be modeled in the wave basin, with the levee section and the floodwall section to join at the center at $107 \mathrm{~m}$. In model dimensions the levee transition is a total length of $10.7 \mathrm{~m}$. A plan view of the model in the Haynes Coastal Engineering Laboratory wave basin is shown in Figure 16. The square grid spacing on the floor of the wave basin is $1.52 \mathrm{~m}(5 \mathrm{ft})$, which is $30.48 \mathrm{~m}(100$ $\mathrm{ft}$ ) in prototype dimensions. As shown, the chosen scale enables adequate placement of the model in reference to the wave generator and side walls in order to accurately measure the wave fields and avoid significant side wall reflections. The basin continues behind the model to a mildly sloped rock beach, which absorbs the incident wave that propagates beyond the model. Without a structure impeding the propagation of the majority of the waves, the rock beach absorbs approximately $85 \%$ of the wave energy. Additionally, there are wave absorbers along each side wall to minimize side wall reflections. These wave absorbers dissipate approximately $60 \%$ of the wave energy as a wave propagates through the absorber. In order to effectively measure the incident wave height coming from the wave generator, a three-gauge array must be utilized. Accordingly, for the three-gauge array to accurately decompose the incident and reflected wave spectrums from the wave field, the gauge array must be located at least 
one wavelength away from the structure and the wave generator (Hughes, 1993). Since the maximum peak wave length in the model is approximately $3.5 \mathrm{~m}$, the $13.4 \mathrm{~m}$ distance away from the wave generator generously satisfies this criterion.

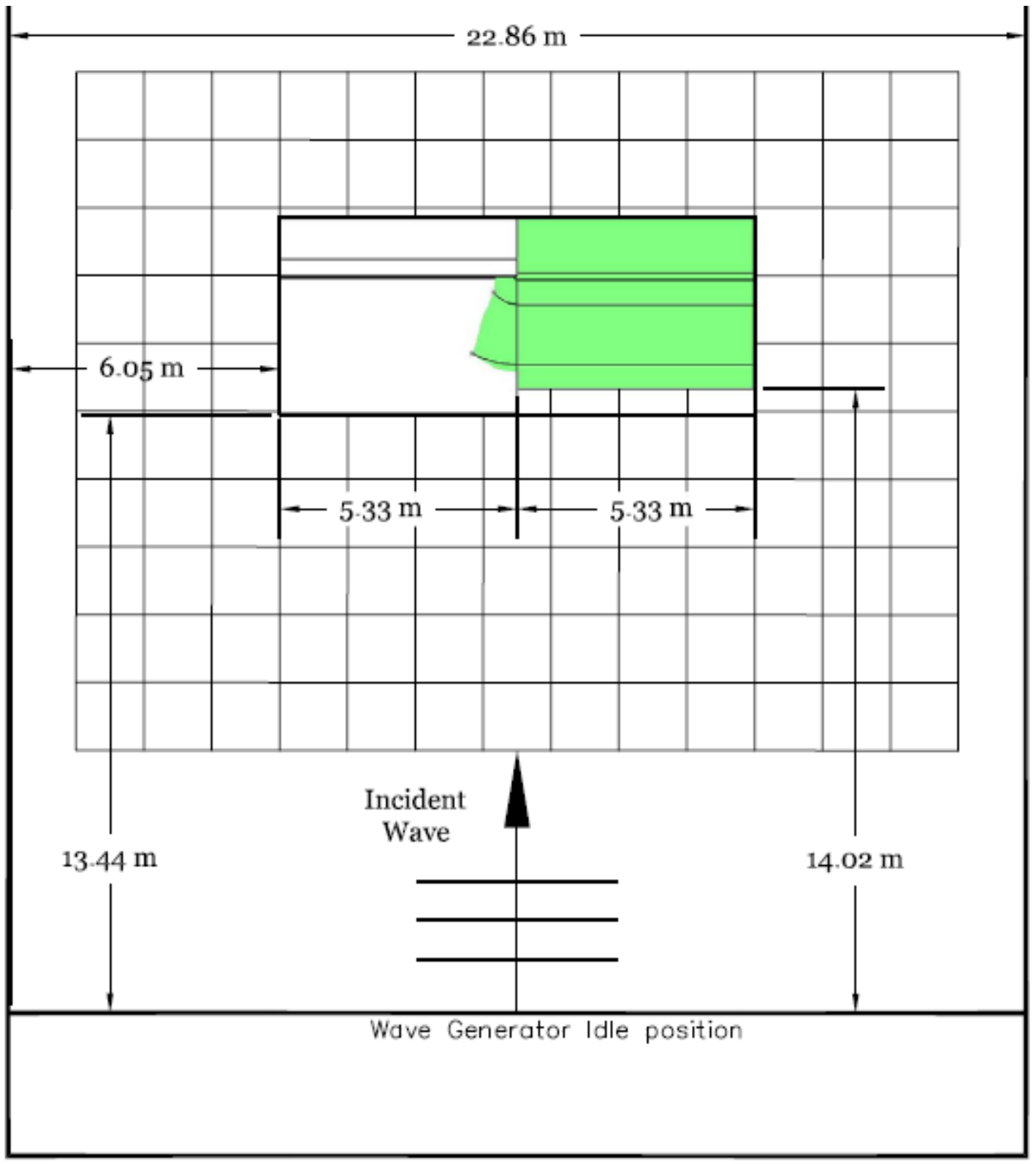

Figure 16. Plan View Levee Transition Model in Laboratory. 
Applying the 1:20 scale, the original dimensions based on the specifications set forth by the CORPS are scaled as shown in Figure 17. The width of the model is nearly $4.5 \mathrm{~m}$ at the floodwall section and $3.85 \mathrm{~m}$ at the levee section. As mentioned previously, the protected-sides of the levee transition have been modified to better integrate the instrumentation and to maximize the scale of the model. The modification seen in Figure 17 enables the backside of the levee section and floodwall section to match and end at the same distance from the center of the model. The width of the floodwall is dependent upon the material used for its construction. In this case, two sheets of metal, each $3 \mathrm{~mm}$ thick, will cover a framework of 2 in $x 6$ in lumber creating a nearly $5 \mathrm{~cm}$ thick model floodwall. The total height of the floodwall is $45.72 \mathrm{~cm}$, and the height of the levee crest is about $41.15 \mathrm{~cm}$.

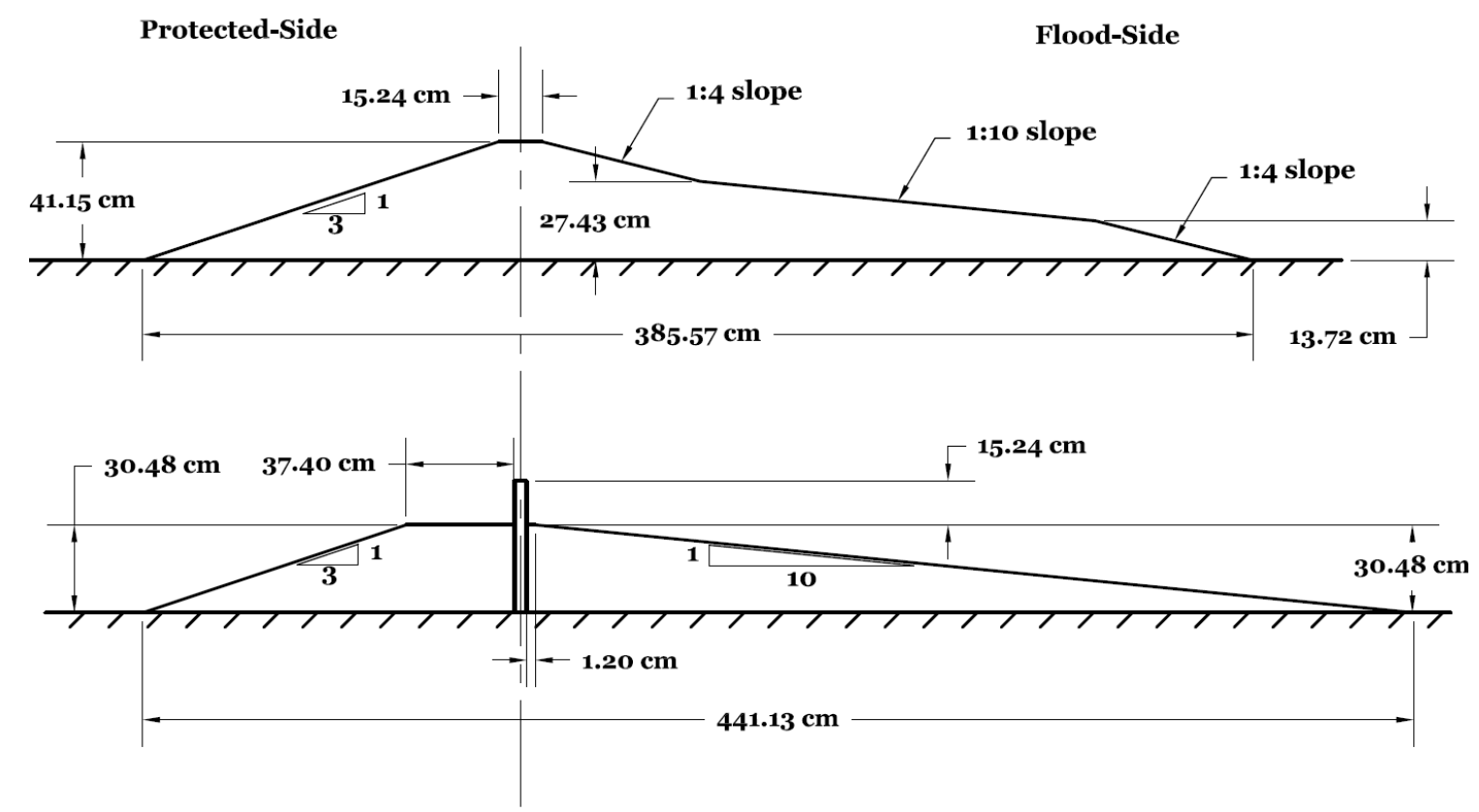

Figure 17. Levee Transition Model Cross-sectional Dimensions. 
In order to provide stability and overcome buoyancy forces, the levee transition model is composed of a rock core. The levee section of the model is constructed first to allow for a smoother transition between the floodwall section and levee section as shown in Figure 15. The floodwall is integrated into the rounded levee head, as shown in Figure 18.

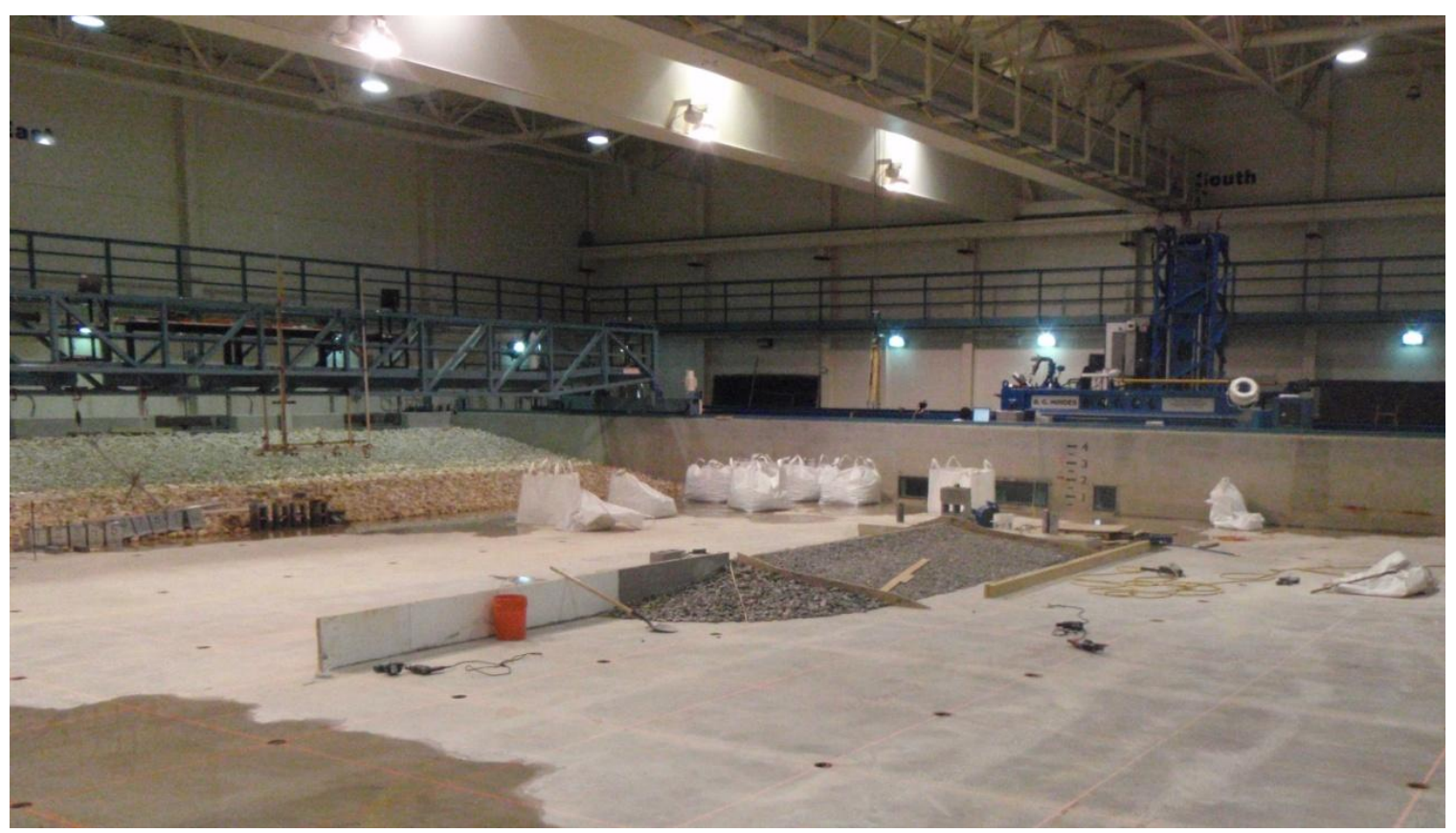

Figure 18. Initial Construction of Levee Transition Model.

A small rock diameter is used as the core to better form to the specified contours as well as to avoid any voids under the concrete shell which will serve as the outer layer of the levee section and the incorporated levee on the floodwall section. In addition to the small rock core, plastic is laid on top of the rock to form an even smoother and more stable foundation for the concrete shell. The concrete shell is designed to withstand the 
forces of people walking on the surface of the model as well as wave gauge stands or other mounting apparatus. Templates of these specified contours, cut from plywood, are integrated into the rock core to outline the desired shape as concrete is placed and smoothed. The average thickness of the concrete is $10 \mathrm{~cm}$, which allows enough strength to walk on the levee and floodwall surface. This process is depicted in Figure 19. The composite slopes of the levee section are continued to the midpoint of the model and curved to form a head to transition into the floodwall section.

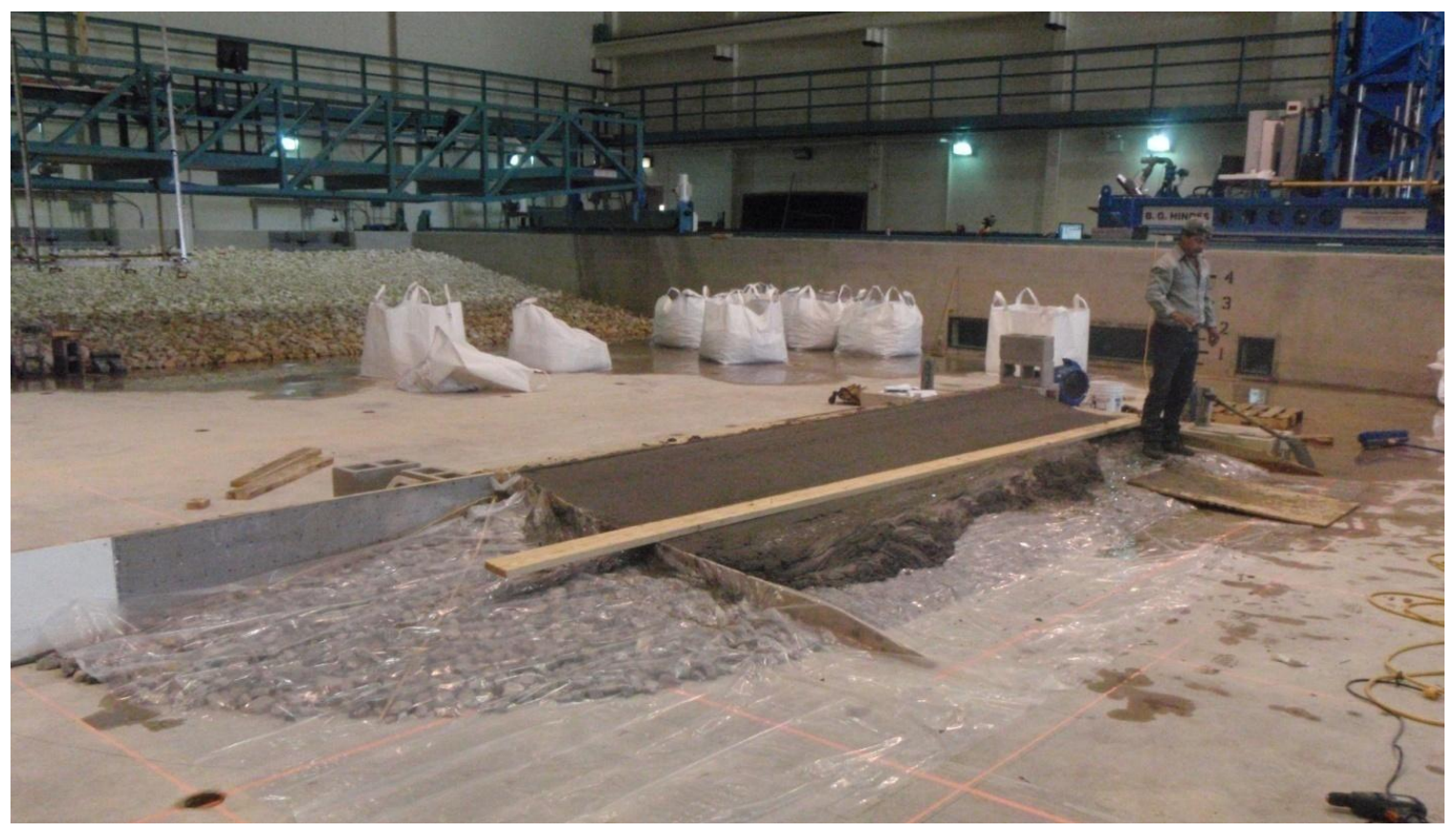

Figure 19. Placement of Concrete in Levee Transition Model.

The completed levee section is shown in Figure 20. The transitions between the slopes on the face of the levee section are gradual to provide a better representation of prototype, in situ conditions. Integrating the floodwall into the levee head stabilizes the 
floodwall to alleviate any significant vibrations induced from future wave forces during testing and serves as the connection between the floodwall section and levee section. The sheet metal and framing of the floodwall also reduces any flexure induced by wave loading. To prevent the rock core from exiting the ends of the levee transition, the ends are capped with concrete. Figure 21 demonstrates the placement of the concrete in the floodwall section. The concrete is placed from the end towards the transition to better match the contours at the transition illustrated in Figure 15. Supports are added to the back of the floodwall to keep it vertical and straight along the length of the floodwall section during construction. Rock and concrete is then added to the back of the floodwall section to provide more support for the floodwall. These supports are removed after the flood-side concrete is cured.

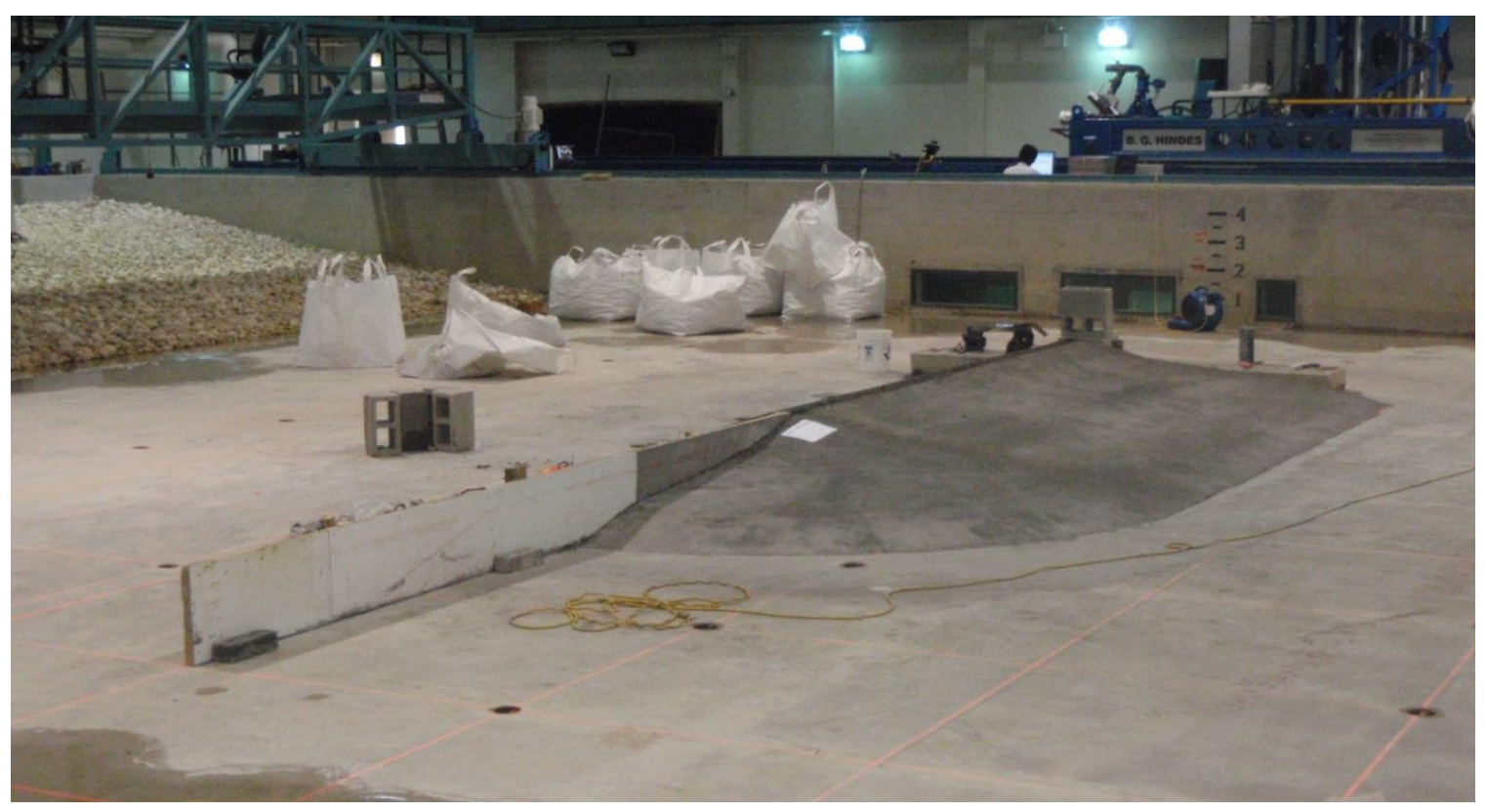

Figure 20. Completed Levee Section of Levee Transition Model. 


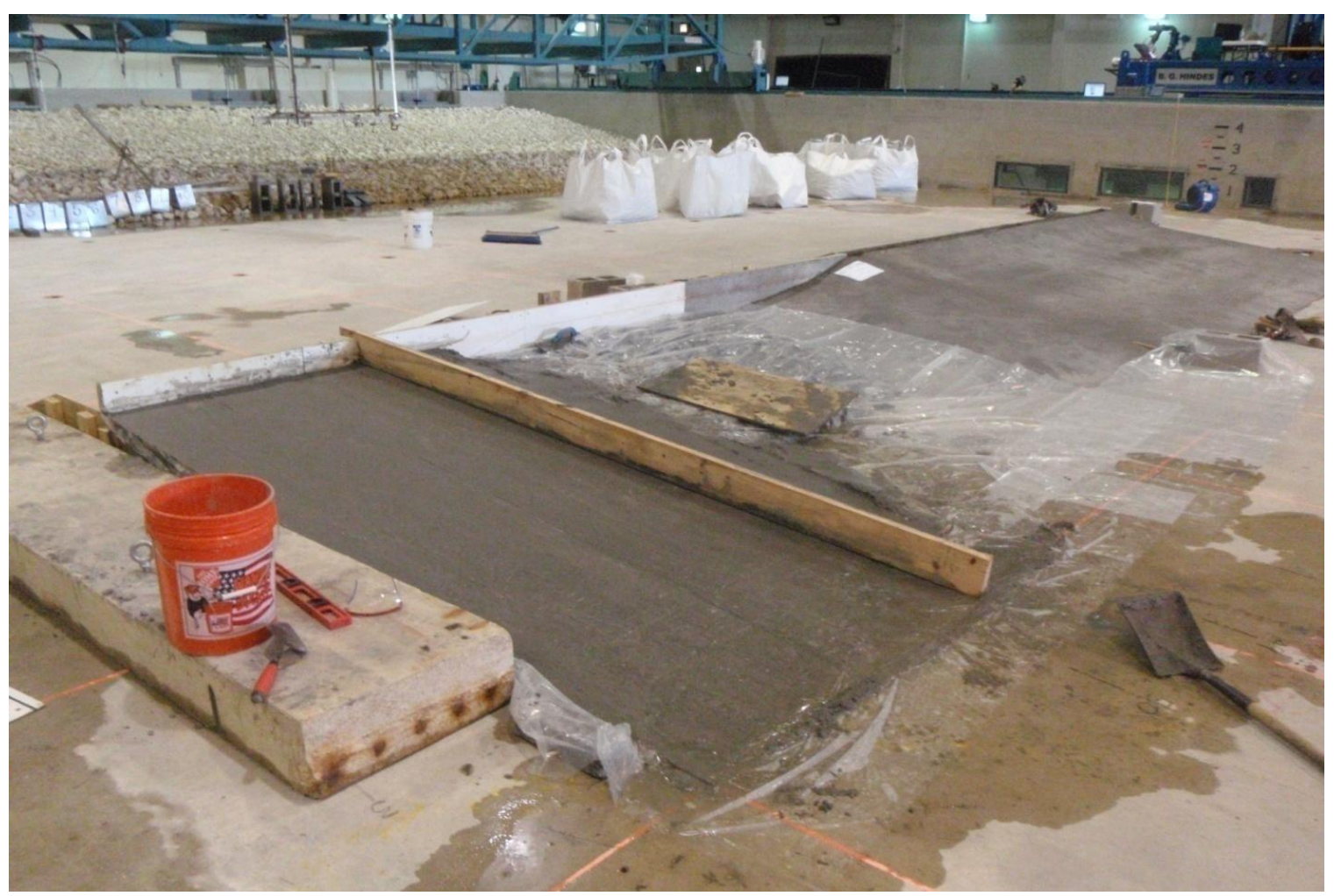

Figure 21. Placement of Concrete in Floodwall Section of Levee Transition Model.

The concrete is then smoothed towards the levee section, and the contours of the transition match exactly to the original three-dimensional rendering, as shown in Figure 22. The protected-side of the levee transition model is constructed similarly to the floodside utilizing a rock core and $10 \mathrm{~cm}$ of concrete for stability and strength to incorporate the instrumentation. Also, a lip is created on the protected-side of the levee crest to better capture the overtopping for the calculation of overtopping rates. A level is used along the entire levee crest to ensure it is uniformly horizontal along the section. Any divots or unlevel areas after the concrete cures are filled with mortar to provide a smooth, level surface. Seemingly small cracks or indentations can inherently model large holes or 
crevasses in prototype dimensions, which can possibly result in extreme isolated overtopping events at the specific locations.

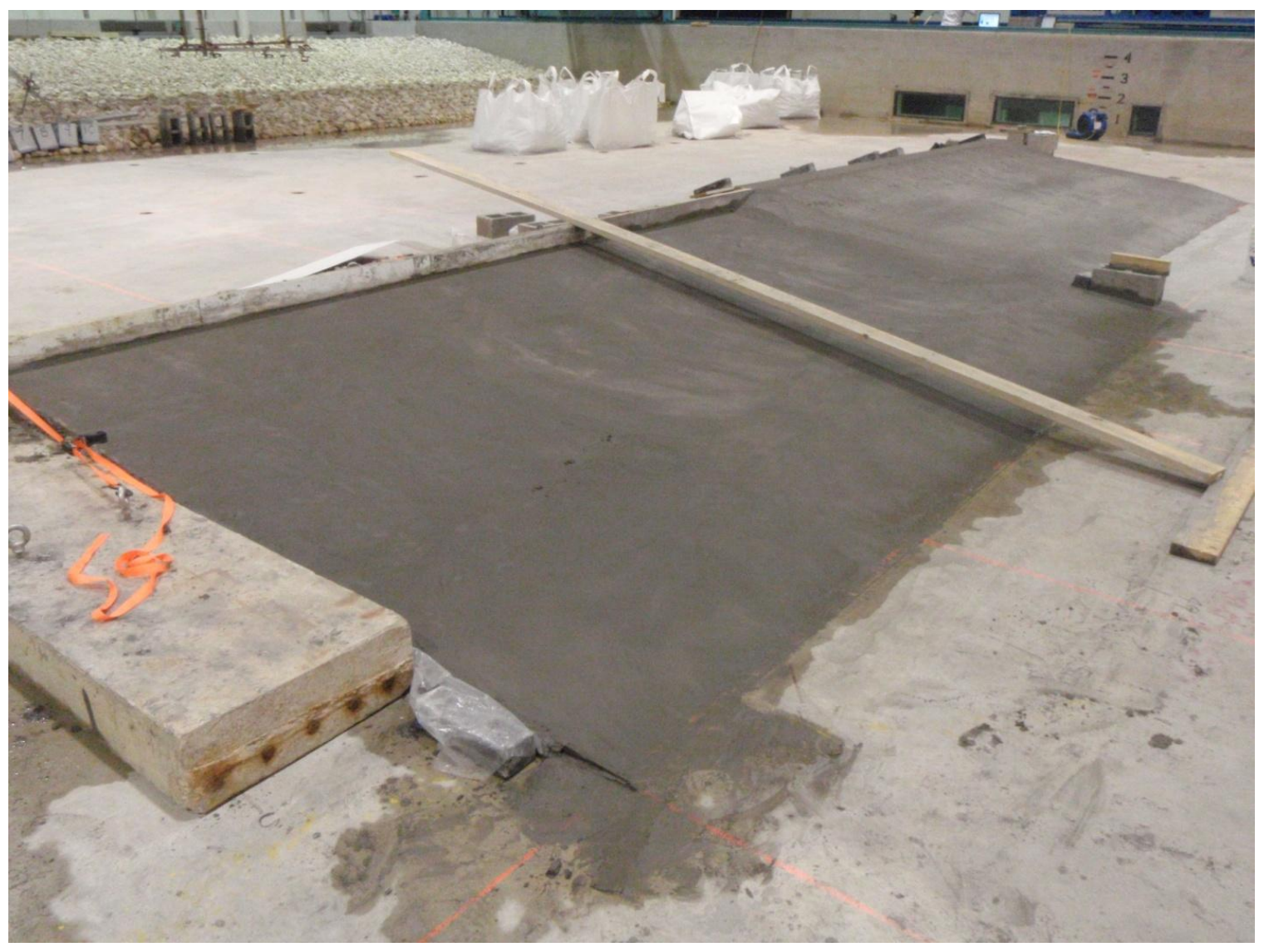

Figure 22. Finished Transition of Levee Transition Model.

The concrete is allowed time for curing before applying any paint. Two coats of latex paint are applied to ensure that the surface is smooth and to protect from minor scratches. Figure 23 depicts the painted levee transition model. Gridlines are then created on the levee surfaces in order to observe wave heights and runup along the levee surfaces and floodwall during testing and later scrutiny of video footage. The dimensions 
of the grid lines are shown in Figure 24. Solid black horizontal lines are drawn along the surface of the levees and floodwall denoting a prototype vertical spacing of $1.52 \mathrm{~m}(5 \mathrm{ft})$. The bottom line is $+4.57 \mathrm{~m}(+15 \mathrm{ft})$ in reference to the datum. The next line is at an elevation of $+6.1 \mathrm{~m}(+20 \mathrm{ft})$, which is the bottom of the floodwall. The floodwall then rises $3.05 \mathrm{~m}$ to its maximum crest elevation of $+9.14 \mathrm{~m}(+30 \mathrm{ft})$, as denoted by the top black line. The minor tick marks in between the continuous black lines are in reference to a $25.4 \mathrm{~cm}(1 \mathrm{ft})$ vertical spacing. The horizontal spacing of the grid lines is $15.24 \mathrm{~m}$ (50 ft). The lines are created with the aid of a laser level to ensure that the lines would remain at the same elevation as they are drawn across the levee transition. Figure 25 illustrates the grid lines on the levee section flood-side surface. Figure 26 shows the gridlines for the floodwall section as well as the contours at the transition; some gauges have already been placed on the levee section in the picture.

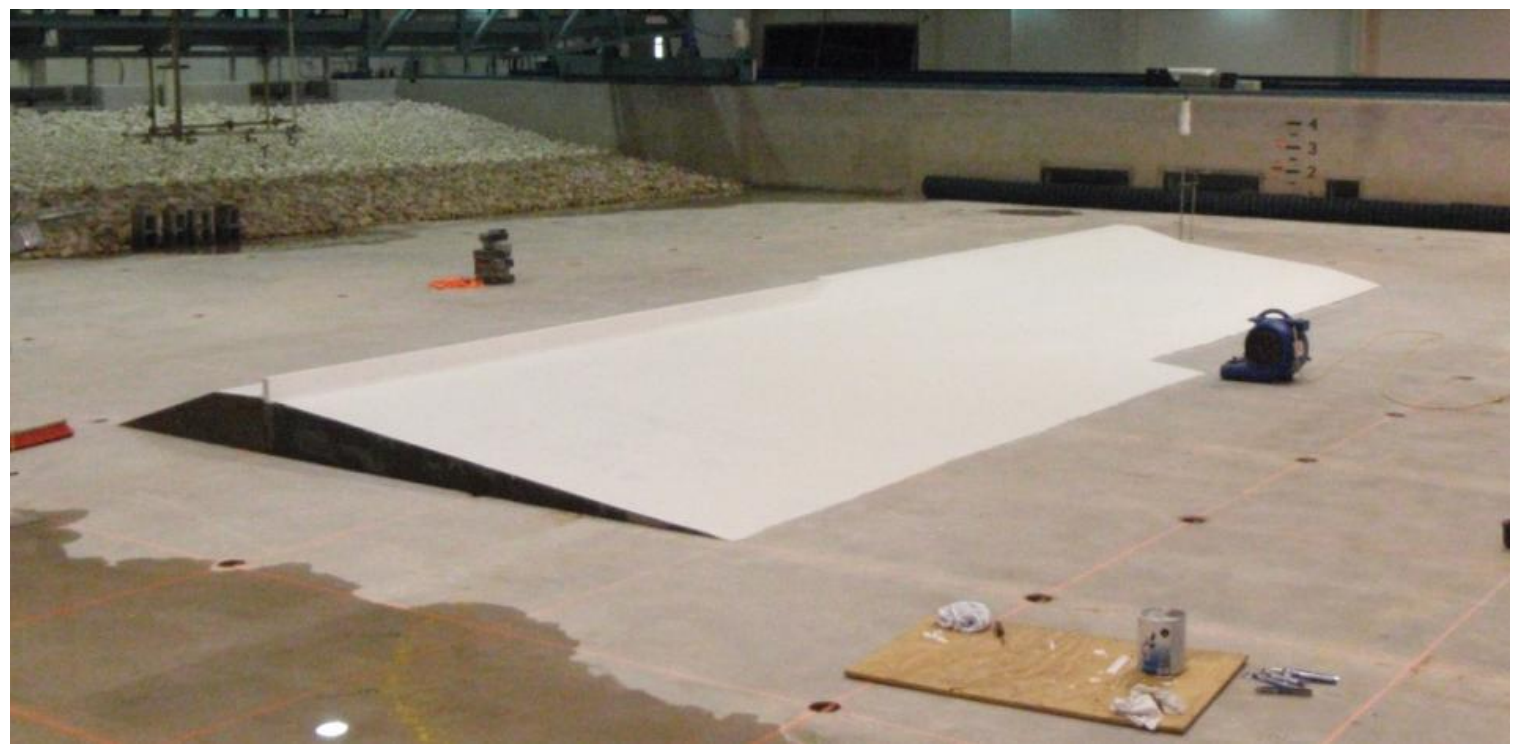

Figure 23. Painted Levee Transition Model. 


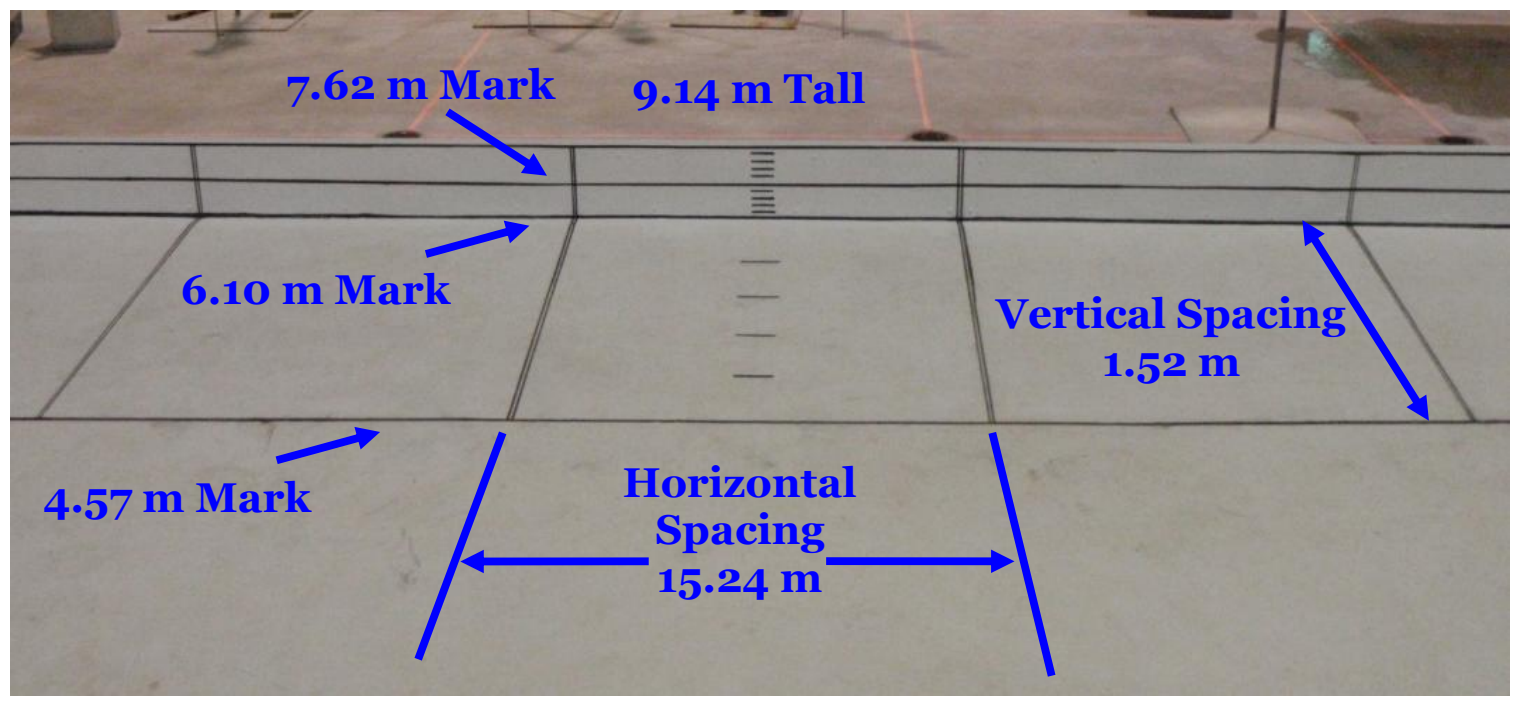

Figure 24. Grid Line Dimensions.

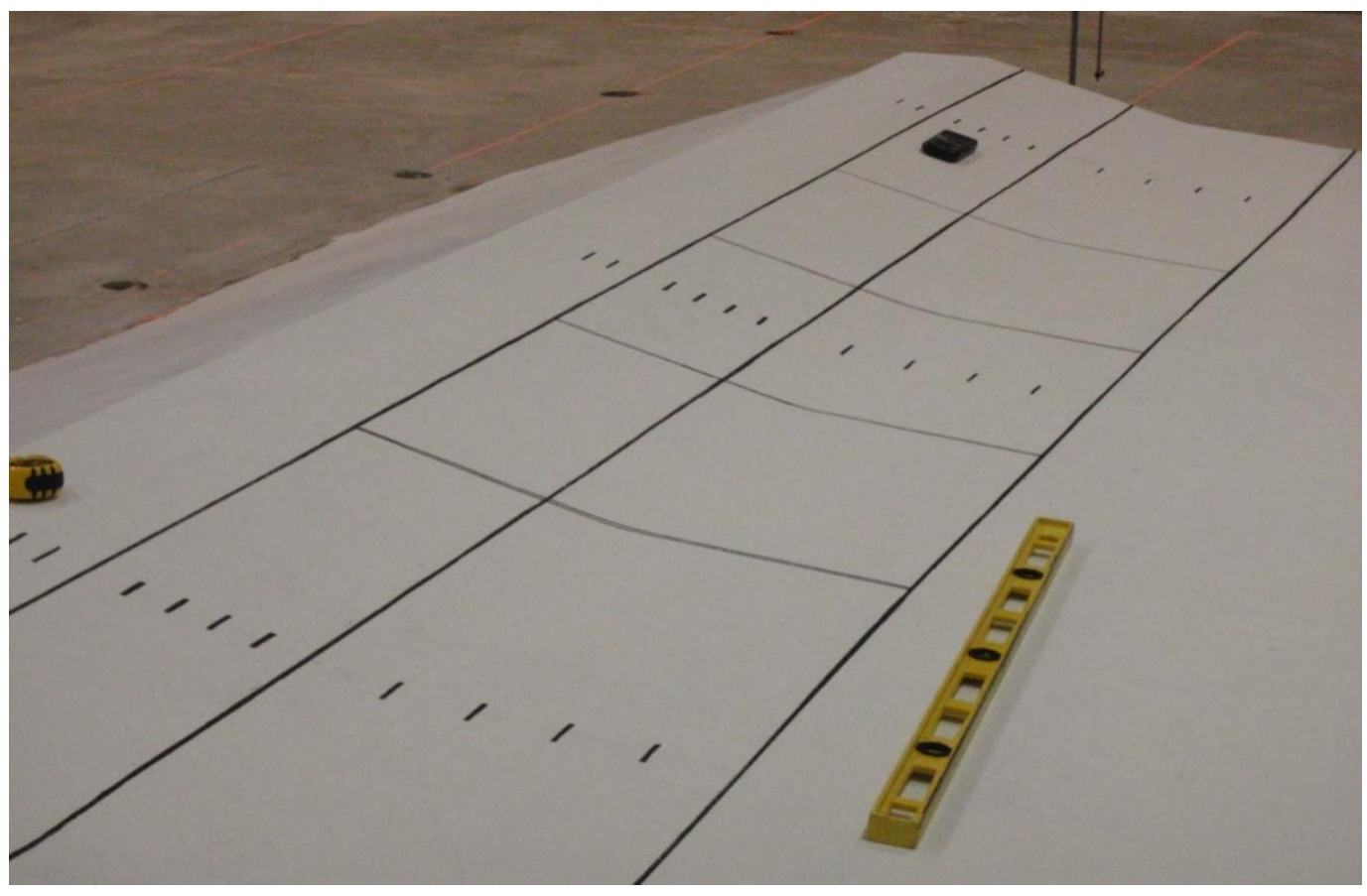

Figure 25. Levee Section Grid Lines. 


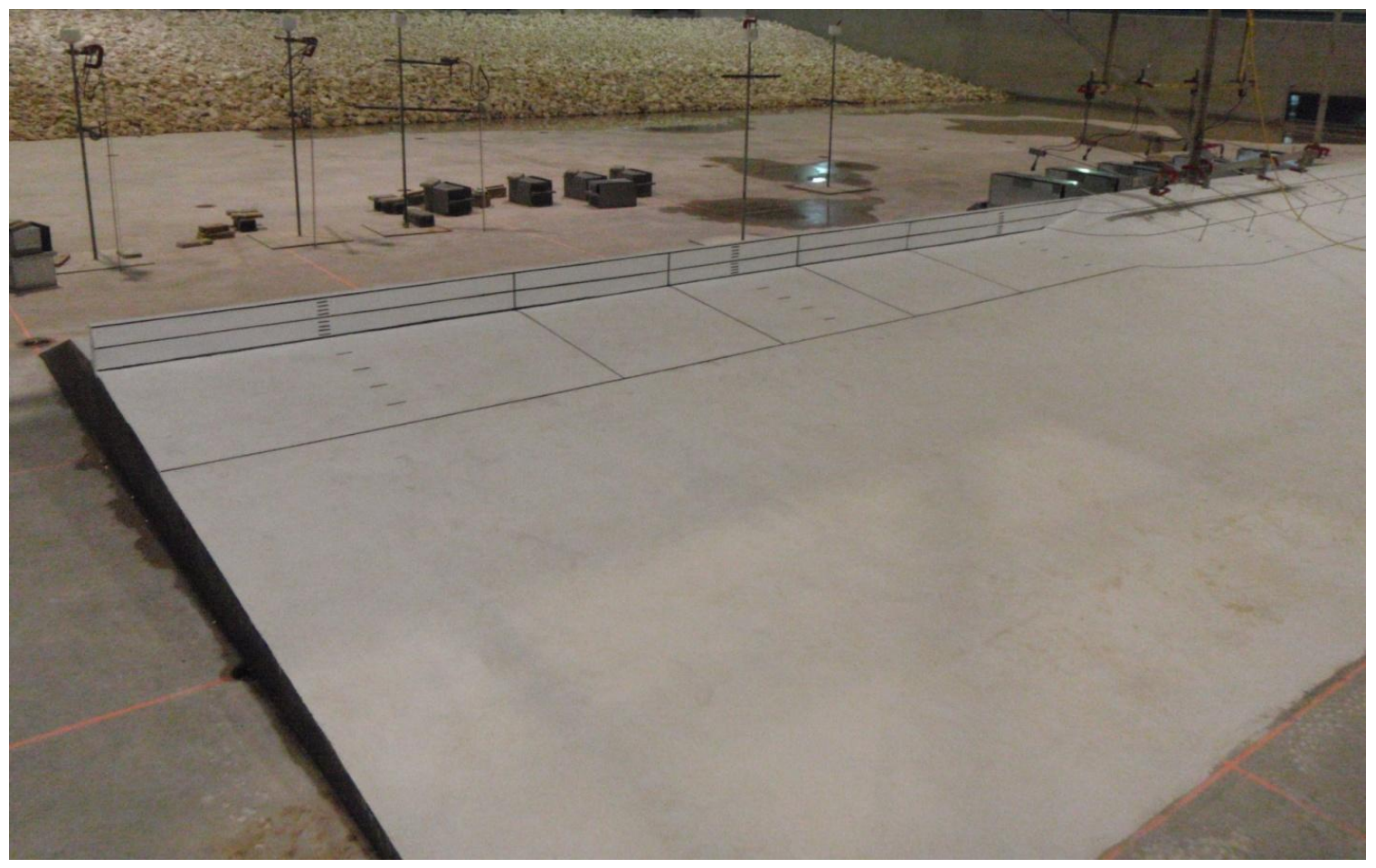

Figure 26. Post-Construction Levee Transition Model.

\subsection{Instrumentation}

The instruments referenced in this report and used in the data collection are of five major types: four floodwall wave gauges, four levee runup gauges, ten overtopping containers, five wireless wave gauges, and two video cameras. The overall placement of the instrumentation can be seen in Figure 27. The red staffs in Figure 27 represent the floodwall wave gauges (number 1), wireless gauges (number 4), and runup gauges (number 2). The number 3 in Figure 27 identifies the overtopping containers. As

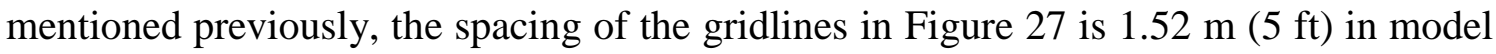
dimensions or $30.48 \mathrm{~m}(100 \mathrm{ft})$ in prototype dimensions. 


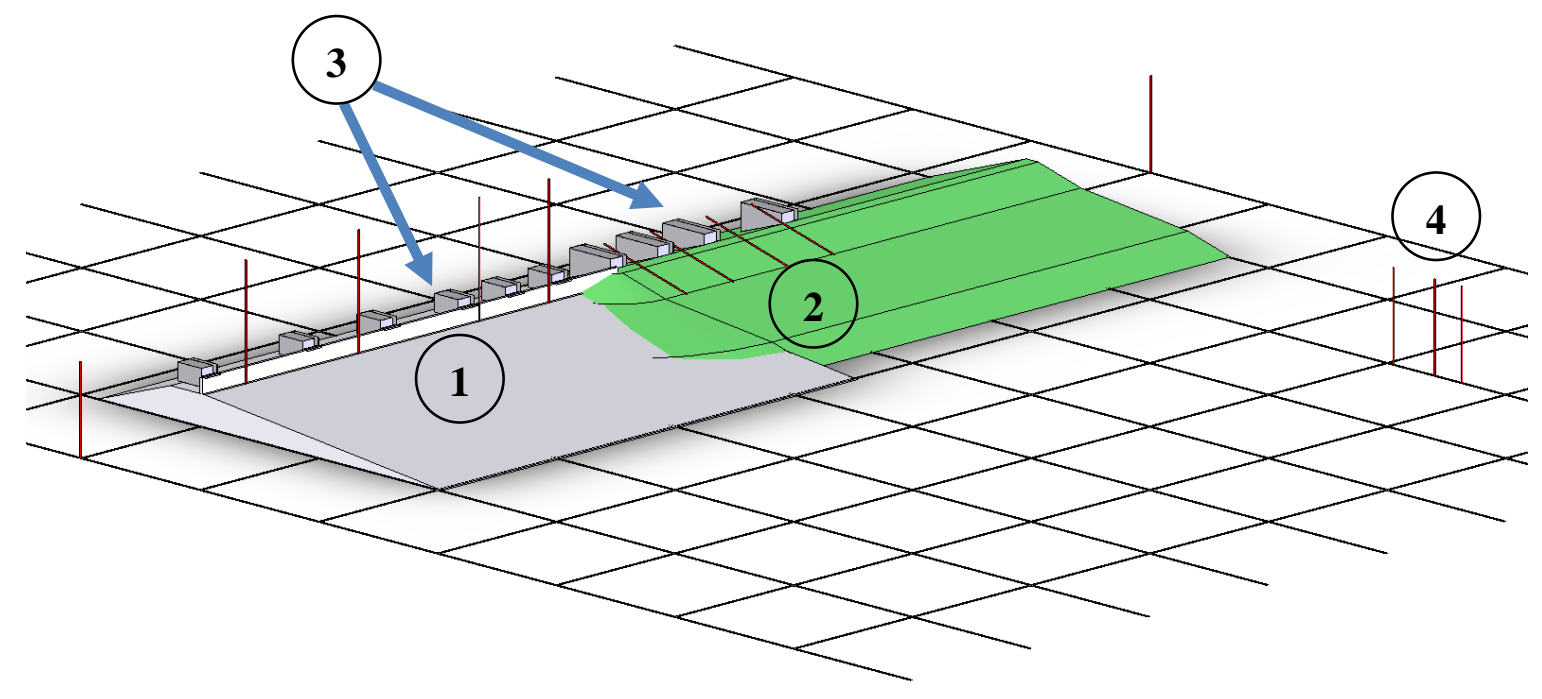

Figure 27. Instrument Placement.

The floodwall wave gauges refer to the wave gauges located directly in front of the floodwall. They are used to determine specific statistical pieces of information which are described in further detail in the Section 5 , which itemizes the methods of data analysis. The spacing of the floodwall gauges is shown in Figure 28. Each gauge is associated with a particular channel number in order to identify and distinguish among them. The floodwall gauges are ordered from $\mathrm{CH} 4$ to $\mathrm{CH} 7$, with $\mathrm{CH} 4$ closest to the transition. The distances in Figure 28 are in model dimensions and prototype dimensions in parentheses. For all horizontal dimensions, the vertical datum is the midpoint of the levee transition, or directly at the transition point, as referenced in Figure 28. 


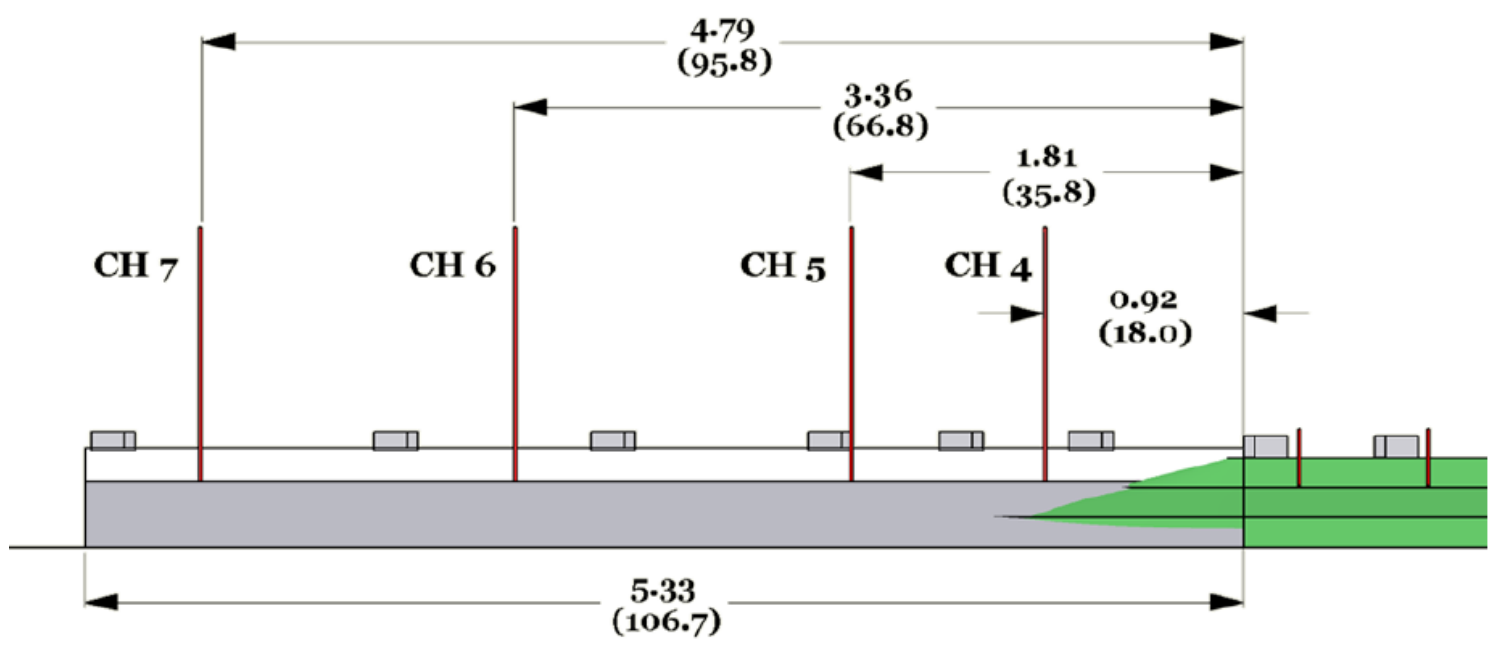

NOTE: All units are in meters. Prototype dimensions are in parentheses.

Figure 28. Floodwall Gauge Placement.

Figure 29 provides a picture of the actual placement of the four floodwall gauges. The gauges are supported by stands fixed to the back of the floodwall levee by large lead weights. The wires of the capacitance wave gauges are mounted on metal support rods which touch the surface of the floodwall levee to eliminate any vibrations or movement of the wave gauges during testing. The height of the floodwall wave gauges is approximately 1 meter. The distance between the support rods and the actual floodwall surface is on the order of $5-8 \mathrm{~mm}$.

Calibration of the floodwall gauges are completed individually. The voltages are recorded at vertical increments of $3 \mathrm{~cm}$. Increments of $3 \mathrm{~cm}$ with a total range of $30 \mathrm{~cm}$ enables 21 voltage data points for each gauge. From these data points, a linear fit was applied to the gauges, yielding calibration coefficients utilized for the conversion between recorded voltages and measured fluctuations in the free surface of the water. 
For all the calibration curves, a coefficient of determination $\left(\mathrm{R}^{2}-\right.$ value) greater than $99 \%$ is achieved for the linear conversion coefficients.

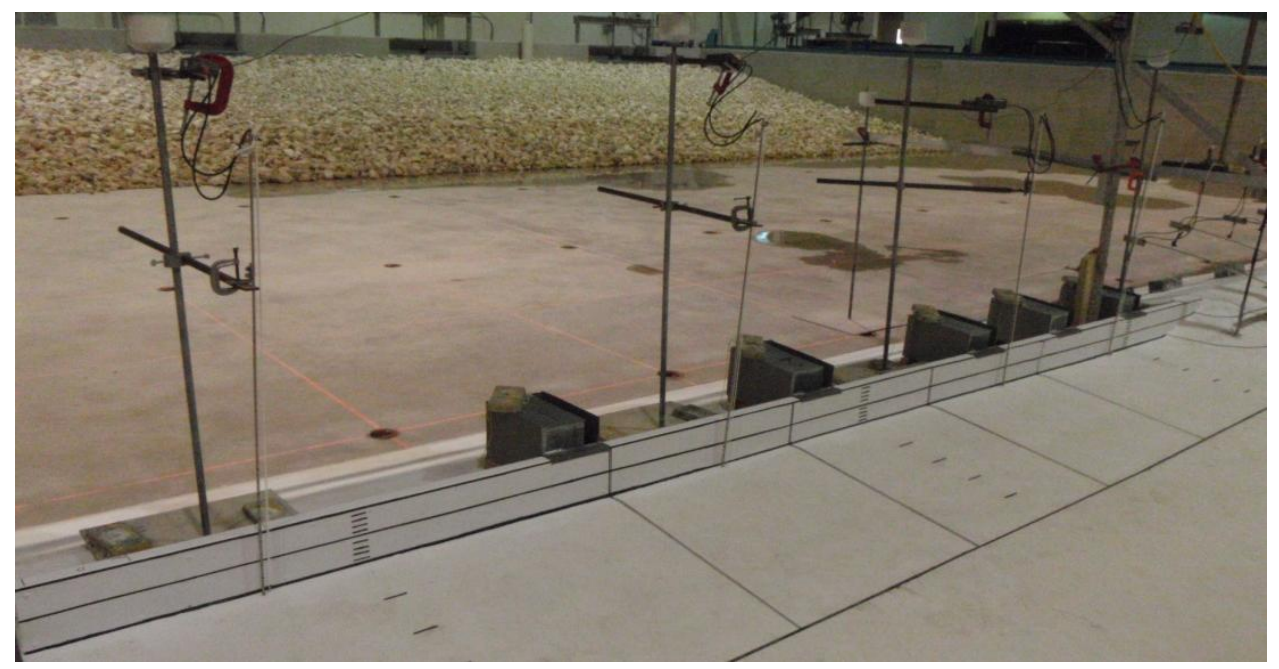

Figure 29. Floodwall Gauge and Overtopping Container Placement.

Similarly, the runup gauges are 1 meter capacitance gauges, but with a different supporting rod and are placed angularly on the levee surface. Since the surface of the levee is comprised of composite slopes, the four runup gauges are fixed only on the upper $1 \mathrm{~V}: 4 \mathrm{H}$ slope up to the levee crest. The placement of these gauges is shown in Figure 30; again, the distances are shown in both prototype and model dimensions. The channel number of the runup gauges is sequenced from the levee transition to the levee end. The runup gauges are mounted from the bridge that spans over the wave basin. 


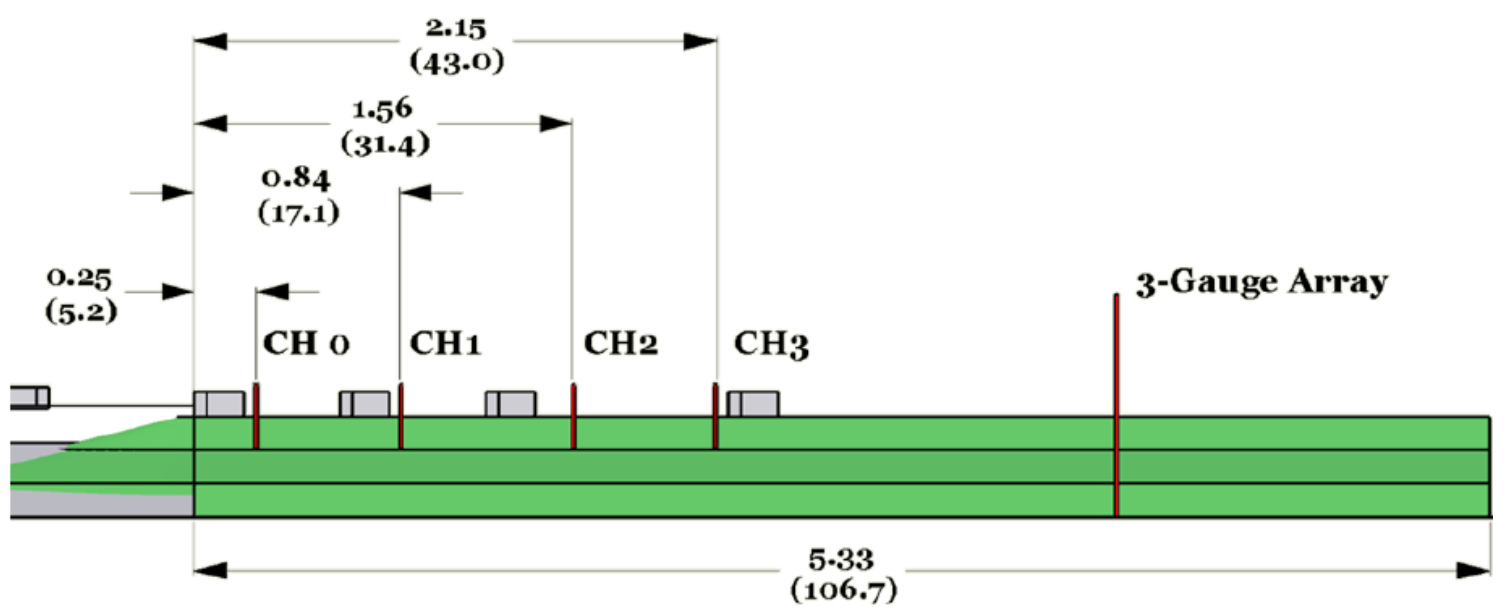

NOTE: All units are in meters. Prototype dimensions are in parentheses.

Figure 30. Runup Gauge Dimensions.

Figure 31 provides a picture depicting the runup gauges in their actual position on the levee transition model. The wires of the runup gauge are placed directly above the levee surface, and the supporting rods are mounted to a bracing attached to the bridge that crosses the wave basin. During calibration of the runup gauges, they remain fixed to their mounting apparatus; therefore, the gauges are kept at the same angle as during testing. The bridge is then driven forward away from the levee surface into open water. Here, the runup gauges' slope is held constant and the calibration can begin. Similarly, the runup gauges' voltages are recorded at $3 \mathrm{~cm}$ vertical increments. At total of 16 voltage data points are used to create the linear calibration coefficients. 


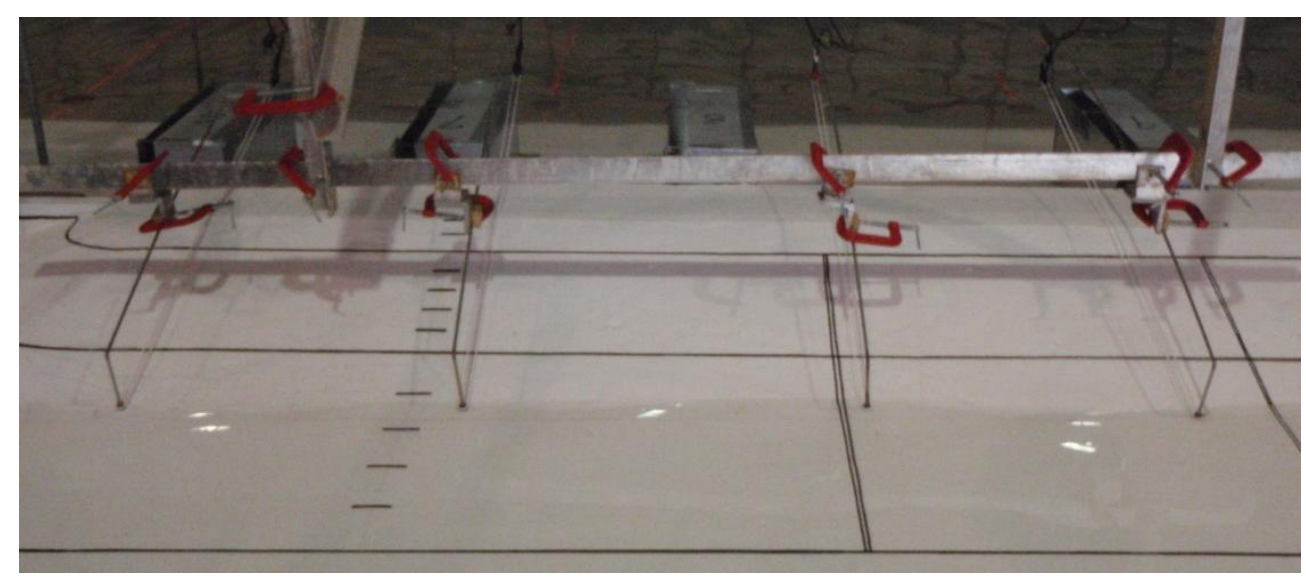

Figure 31. Runup Gauge Actual Placement.

A total of 10 overtopping containers collected any water overtopping the levee and floodwall during testing. The volume of water during the ten minutes of each test is measured yielding an overtopping rate. Knowing the width of the opening for the overtopping container enables an overtopping rate per unit width, or $1 / \mathrm{s} / \mathrm{m}$ measurement. If the overtopping container was completely filled before the testing was over, then the maximum volume of the container and the time required to fill the container determines the overtopping rate. The overtopping containers are placed on the levee section and floodwall section, each section having its own particular overtopping container. The floodwall overtopping containers are rectangular containers fabricated from sheet metal that can hold approximately 6.511 of water per container, or 52,103 1 of water in prototype dimensions. The front of the container has an opening $5.1 \mathrm{~cm}$ wide, or $1.02 \mathrm{~m}$ in prototype dimensions. The floodwall containers have a lip on the front of the container that allow them to hang over the edge of the floodwall to ensure no water can 
escape between the container and the back of the floodwall. An example of the floodwall overtopping container placement is shown in Figure 29.

The levee section overtopping containers are specifically constructed to rest on the back, sloped surface of the levee section. The containers can hold approximately 10.481 of water, or 83,8181 of water in prototype dimensions. The front of the container also has an opening $5.1 \mathrm{~cm}$ wide, or $1.02 \mathrm{~m}$ in prototype dimensions. The protected-side of the levee crest has a small lip in which the levee overtopping containers can slide under. This enables all overtopping at the containers to go directly into the containers; no water can flow under the containers. Examples of the levee section overtopping containers are shown in Figure 31 and the figure on page 58.

The dimensions and location of the overtopping containers are shown in Figure 32. The dimensions shown in Figure 32 are measured from the floodwall end to the center of the opening of the overtopping container. As before, the dimensions presented in Figure 32 are given in both model units and prototype units, with the prototype units in parentheses. Overtopping containers placed farther than container number 9 were not used due to the refraction occurring at the end of the levee section. This model effect also affected the results of overtopping container number 0 and floodwall gauge number 7; further explanation of the model effects are iterated in Section 4.6. This array of overtopping containers enables the calculation of an overtopping distribution along the levee transition and allows correspondence of overtopping values to the measured wave heights and runup values. Each of the overtopping containers is secured with a large lead weight to alleviate any movement or separation from the model during testing. 


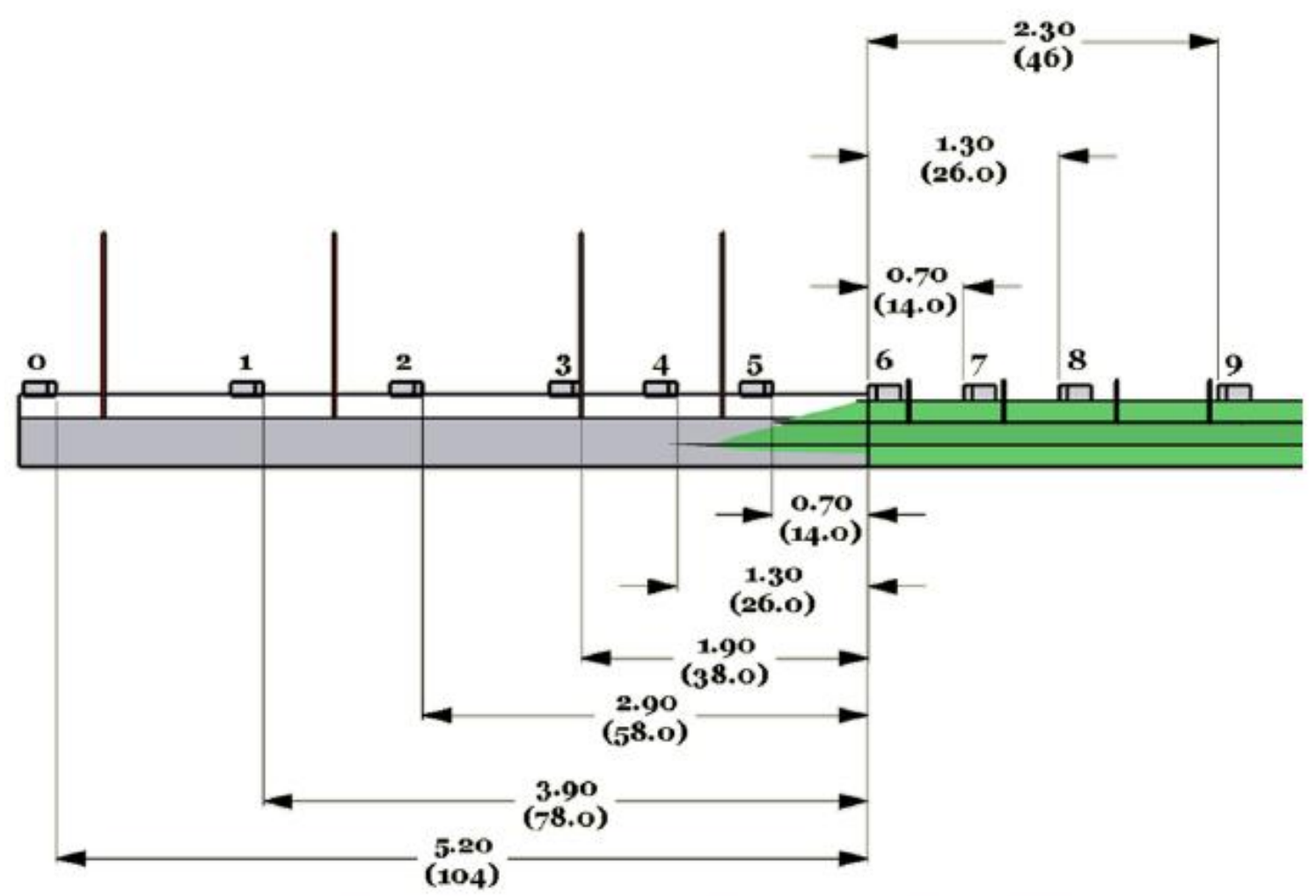

NOTE: All units are in meters. Prototype dimensions are in parentheses.

Figure 32. Overtopping Container Placement.

A total of 5 wireless wave gauges are used to record information of the wave fields propagating around and near the levee transition model. The wave gauges used are capacitance gauges that are attached to a transmitter with power supply. The signal from the transmitter is received and recorded by a computer where it then converts the voltages to displacements in accord to the linear conversion coefficients obtained during calibration. Three wave gauges are specifically positioned in front of the levee section to create a 3-gauge array for accurate measurement of the incident wave heights created by the wave generator. This 3-gauge array allows decomposition of the full wave spectrum 
into an incident and reflected wave spectrum by a least squares method (Mansard and Funke, 1980). The gauges on the side of the levee section and floodwall section allow measurement of the wave field without much interference of the reflected waves. Though the 3-gauge array enables measurement of the wave created by the wave generator, one should take into account that the in situ prototype wave field will also incorporate reflected wave energy which directly increases the wave energy near the levee transition; therefore, the full wave spectrum should also be taken into account. The wireless wave gauges are referenced by their transmitter number, and their location is shown in Figure 33. Transmitter number 3 (TR 3) is located off the end of the floodwall section, and TR 4 is located off the end of the levee section. TR 5, TR 6, and TR 7 comprise the 3-gauge array, with TR 7 closest to the levee section toe while ensuring each gauge's location satisfies the criteria set aside by Mansard and Funke (1980). The actual placement in the wave basin of the 3-gauge array in reference to the levee section toe and the wave generator can be seen in Figure 34. TR 4 is also visible at the end of the levee section under the bridge.

Calibration of each wireless gauge is conducted simultaneously using a calibration stand. All of the wireless capacitance gauges are fixed to the stand; the stand is then moved up and down incrementally by an electric motor on the stand. The voltages are recorded automatically, and the linear conversion coefficients are determined. 

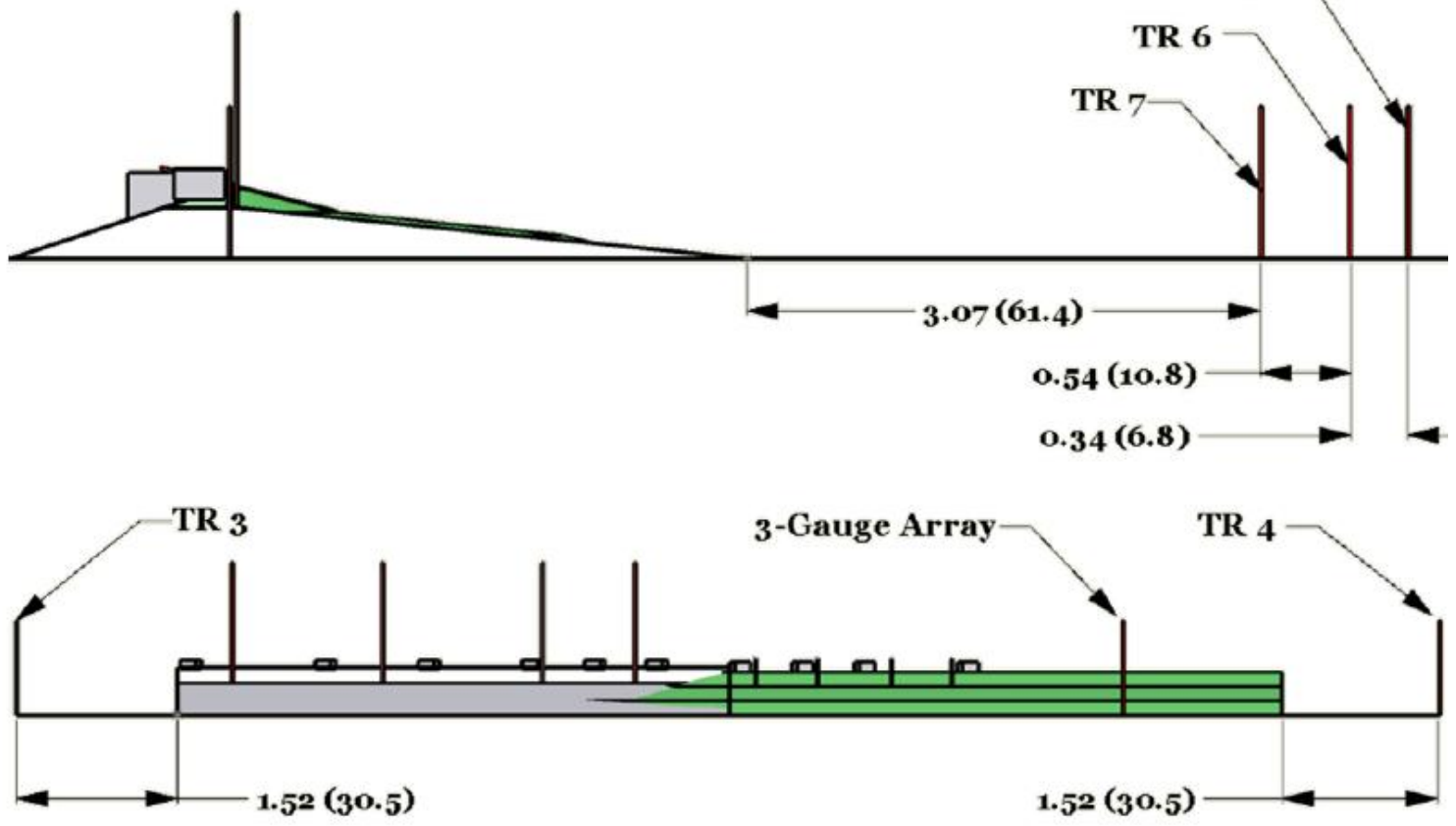

NOTE: All units are in meters. Prototype dimensions are in parentheses.

Figure 33. Wireless Wave Gauge Locations.

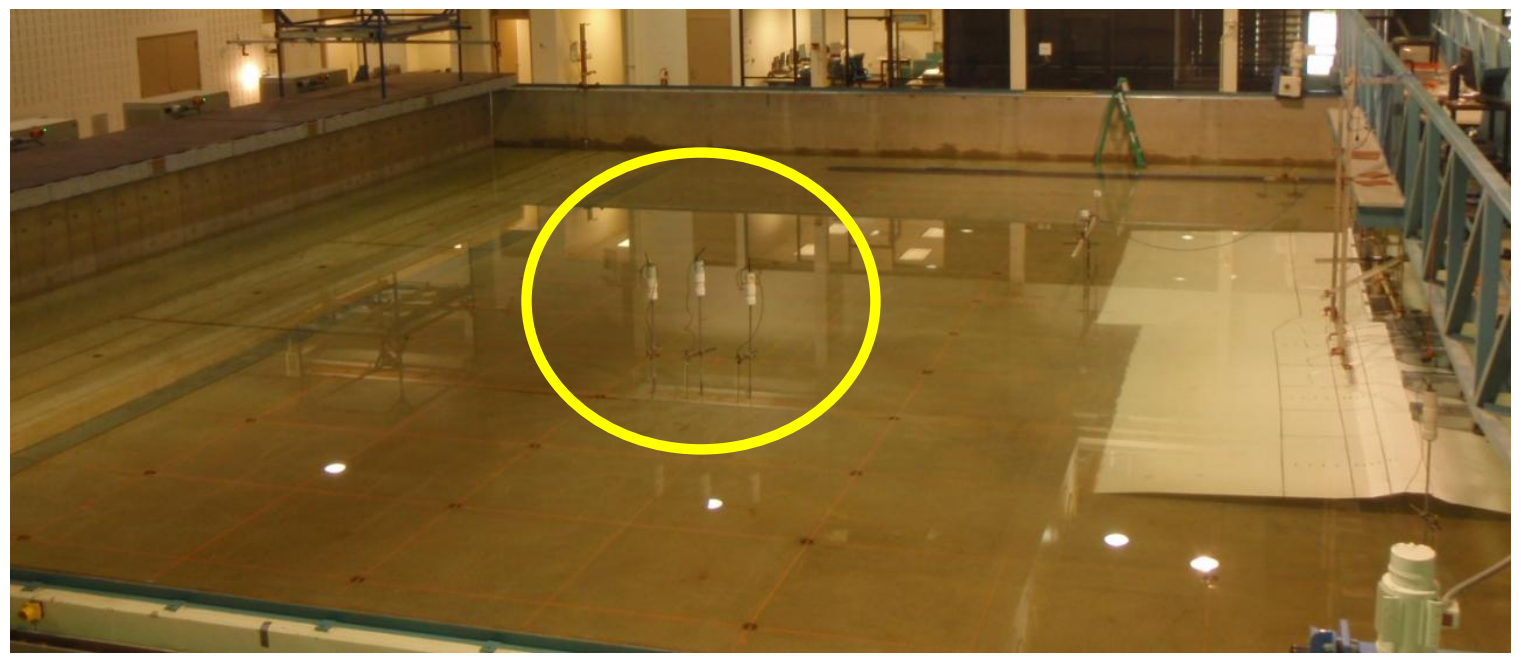

Figure 34. Three-gauge Array Placement. 
Two video cameras are utilized during testing to allow further observation after testing, enabling validation of extreme values or anomalies present in the resulting time series or measurements. One camera is placed outside of the wave basin and focused on the broader effects of the levee transition on the levee transition model. The second camera is placed in the basin to provide a closer view of the overtopping occurring at the floodwall. The footage begins with the test number and date as well as the incident spectral parameters obtained from the 3-gauge array. The placement of the floodwall overtopping video camera to the left of the floodwall section is shown in Figure 35.

Figure 35, Figure 36, and Figure 37 provide an overview of the instrumentation and model layout in the wave basin. Their intent is to provide the reader with a better visual of the experimental setup and to clarify the explanations set forth thus far.

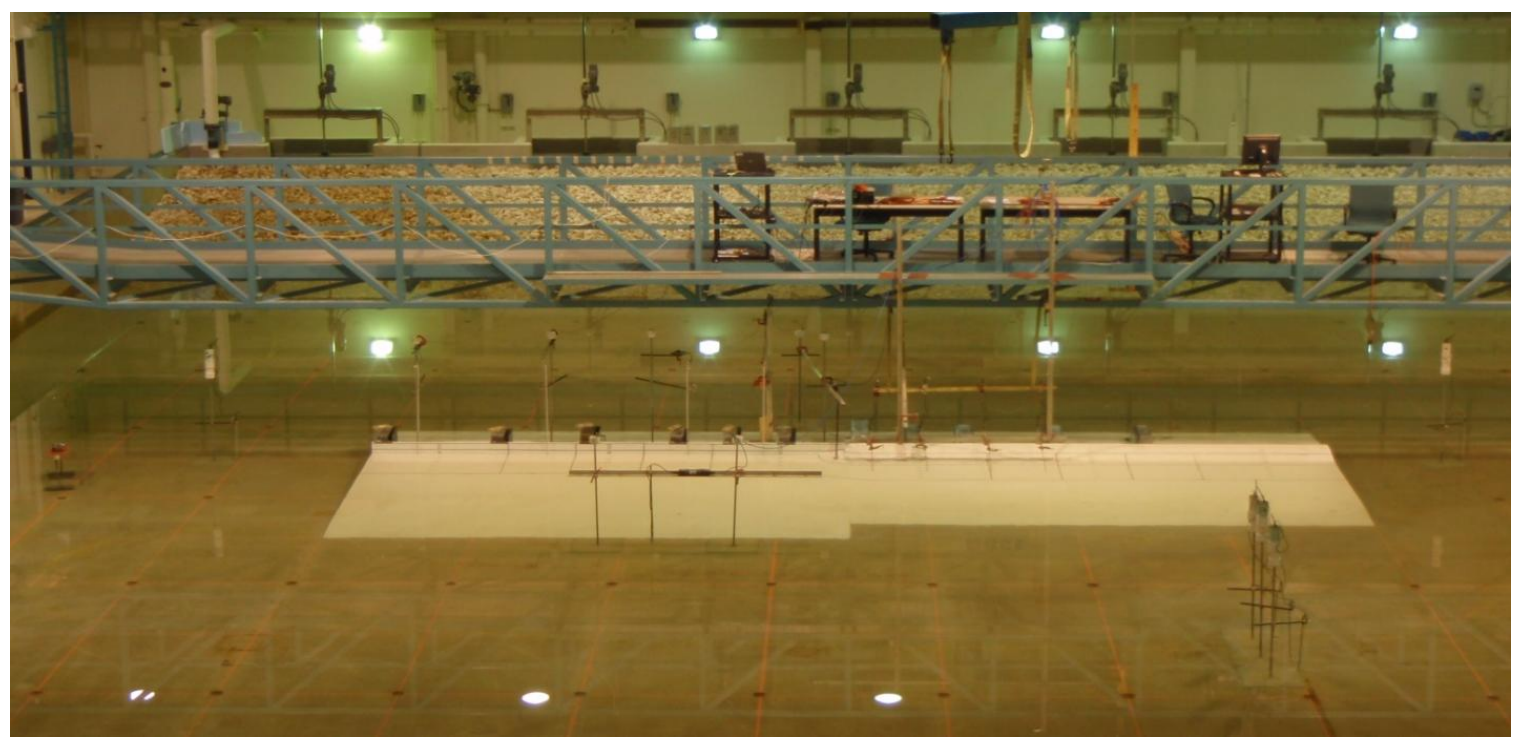

Figure 35. Front View of Levee Transition Model. 
The degree of accuracy for each of the instruments utilized is variable but minimal. In a comparison of the filtered data versus the raw data, it is shown that the degree of accuracy for the wave gauges is approximately $3 \mathrm{~mm}$ in model dimensions and $6 \mathrm{~cm}$ in prototype dimensions. Particular care is taken while measuring the overtopping volumes and times to ensure consistency among results. It is found that the variability in timing the overtopping rates is about 3 seconds for a 10 minute test; this results in an accuracy of $0.5 \%$. The accuracy in the volume of water collected is about 0.201 in a 10.5 1 container, which is less than $2 \%$. The accuracy of the overtopping containers is by far the most variable, which is the most influential factor for successive testing for each test. To ensure greater accuracy and validation of the floodwall gauge and runup gauge data, the gauges are changed and rotated, and the results are compared among the various runs per test. A high degree of accuracy and consistency is achieved with the gauges, as portrayed in Section 6.

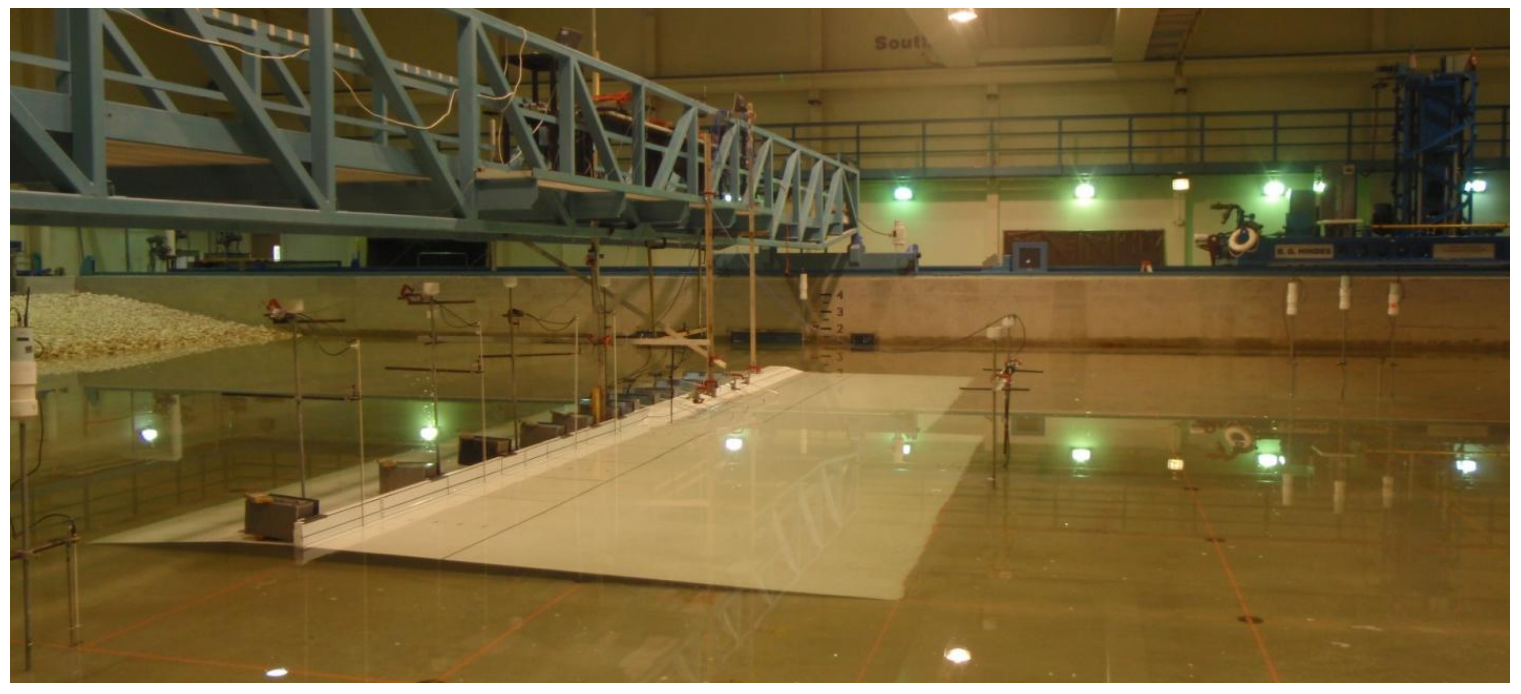

Figure 36. Floodwall Side Isometric View of Levee Transition Model. 


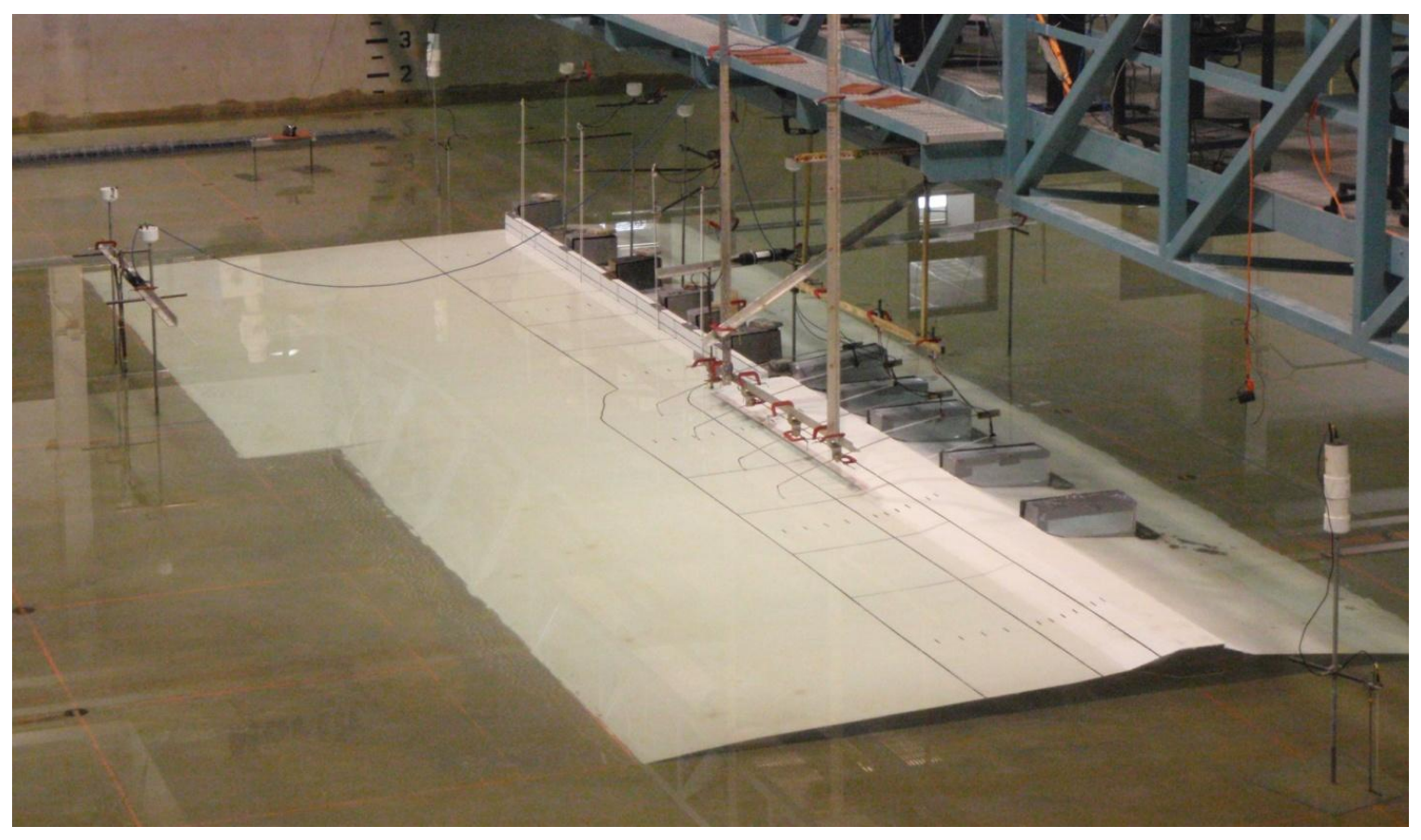

Figure 37. Levee Side Isometric View of Levee Transition Model.

\subsection{Wave Generator Calibration}

The physical model testing must first begin with a pretesting phase to establish the files necessary to run the wave generator and to produce wave fields most similar to the specified wave parameters. The testing parameters recommended by the USACE are provided again in Table 1 . Table 2 provides the tested hydraulic conditions in model units. A total of 8 tests are requested, with variability in wave period at two characteristic water levels and wave heights. To provide an averaged result and redundancy for possible errors in resulting data and instrumentation malfunction, 3 runs per test are completed yielding 24 tests total. All waves are propagated normal to the levee structure. All SWLs are referenced to the originally established datum of the levee toe. The significant wave heights are referenced to the SWL. 
Table 2. Requested Hydraulic Conditions in Model Units

\begin{tabular}{cccc} 
TEST NO. & $\begin{array}{c}\text { SWL } \\
(\mathbf{c m})\end{array}$ & $\begin{array}{c}\mathbf{H}_{\mathbf{s}} \\
(\mathbf{c m})\end{array}$ & $\begin{array}{c}\mathbf{T}_{\mathbf{p}} \\
(\mathbf{s e c})\end{array}$ \\
\hline 1 & 28.96 & 11.43 & 1.34 \\
2 & 28.96 & 11.43 & 1.57 \\
3 & 28.96 & 11.43 & 1.79 \\
4 & 28.96 & 11.43 & 2.01 \\
5 & 34.44 & 13.72 & 1.34 \\
6 & 34.44 & 13.72 & 1.57 \\
7 & 34.44 & 13.72 & 1.79 \\
8 & 34.44 & 13.72 & 2.01
\end{tabular}

The pretesting phase consists of creating wave generator files in an attempt to closely match the specified wave field parameters. The wireless gauges are utilized during pretesting to provide a measurement of the total wave field as well as the decomposed incident and reflected wave spectra, utilizing the methods set forth by Mansard and Funke (1980). During this period of pretesting a plateau is reached in which the wave generator cannot produce any greater wave heights at the structure due to the wave breaking energy loss over the flat bottom as the waves propagate towards the modeled structure, suggesting that the wave heights are in fact depth-limited. Another characteristic of a wave basin is the lack of wind energy in the wave field. In situ conditions encompass an added wind stress which serves to increase wave heights even after waves have broken. In addition, there was no active reflection absorption on the wave generator, so all reflected wave energy from the levee and floodwall will eventually be re-reflected by the wave paddles. This re-reflected wave energy will then become a component of the incident wave train, which is represented in Table 3, and has properties as close to the target wave as could be generated in the laboratory. Table 3 
provides the achieved hydraulic conditions, in prototype units, observed in the testing environment; for quick reference the requested prototype wave conditions are also provided. The provided results are an average of the three runs for each test. The range of results among the runs is minimal.

Table 3. Achieved Hydraulic Conditions, Prototype Units

\begin{tabular}{c|cc|cc|cc|cc|}
\multirow{2}{*}{ Test No. } & \multicolumn{2}{|c|}{ Incident Wave } & \multicolumn{2}{c|}{ TR 3 } & \multicolumn{2}{c|}{ TR 4 } & \multicolumn{2}{c|}{ Requested Wave } \\
\cline { 2 - 9 } & $\mathbf{H}_{\mathbf{m o}}(\mathbf{m})$ & $\mathbf{T}_{\mathbf{p}}(\mathbf{s})$ & $\mathbf{H}_{\mathbf{m o}}(\mathbf{m})$ & $\mathbf{T}_{\mathbf{p}}(\mathbf{s})$ & $\mathbf{H}_{\mathbf{m o}}(\mathbf{m})$ & $\mathbf{T}_{\mathbf{p}}(\mathbf{s})$ & $\mathbf{H}_{\mathbf{m o}}(\mathbf{m})$ & $\mathbf{T}_{\mathbf{p}}(\mathbf{s})$ \\
\hline 1 & 1.77 & 5.92 & 2.02 & 5.34 & 2.07 & 5.66 & 2.29 & 6 \\
2 & 1.82 & 7.35 & 1.91 & 6.31 & 2.07 & 7.65 & 2.29 & 7 \\
3 & 1.87 & 8.52 & 1.91 & 7.46 & 2.08 & 10.44 & 2.29 & 8 \\
4 & 1.86 & 9.10 & 1.76 & 7.46 & 2.08 & 9.79 & 2.29 & 9 \\
5 & 1.91 & 5.92 & 2.33 & 5.82 & 1.77 & 5.81 & 2.74 & 6 \\
6 & 2.03 & 6.73 & 2.26 & 5.95 & 1.81 & 5.95 & 2.74 & 7 \\
7 & 2.09 & 7.99 & 2.41 & 8.47 & 2.58 & 8.48 & 2.74 & 8 \\
8 & 2.10 & 8.87 & 2.31 & 9.29 & 2.95 & 9.69 & 2.74 & 9
\end{tabular}

\subsection{Physical Model Testing}

All gauges used are capacitance gauges, which are much more stable than resistance gauges. Capacitance gauges are less likely to fluctuate on a daily basis and are only calibrated after a complete water exchange in the wave basin or if a noticeable change in resulting voltage occurs, which is usually identified while zeroing out the gauges before a test begins. The results from each gauge are scrutinized separately between tests to recognize any anomalies.

Testing ensues for a period of three weeks in the Haynes Coastal Engineering Laboratory three-dimensional wave basin. Careful attention is taken to ensure consistency among the tests. As mentioned previously, three runs are completed for each 
test to provide an averaged result for potentially inconsistent data, such as overtopping rates, and ensure sufficient records to alleviate any voids in data due to instrument failure or other errors. The resulting wave field parameters are presented in Table 3. All gauges are synchronized to begin data collection simultaneously, and the test duration is 10 minutes for each test. The water level is checked between each test to make certain the water level is constant and accurate between tests. It is found that a small variation in the SWL, on the order of $1-2 \mathrm{~cm}$ can cause significant variations in the resulting time series and overtopping rates; therefore, the water level is monitored an accepted within the nearest millimeter. Figure 38 and Figure 39 provide an example of the levee transition model during testing.

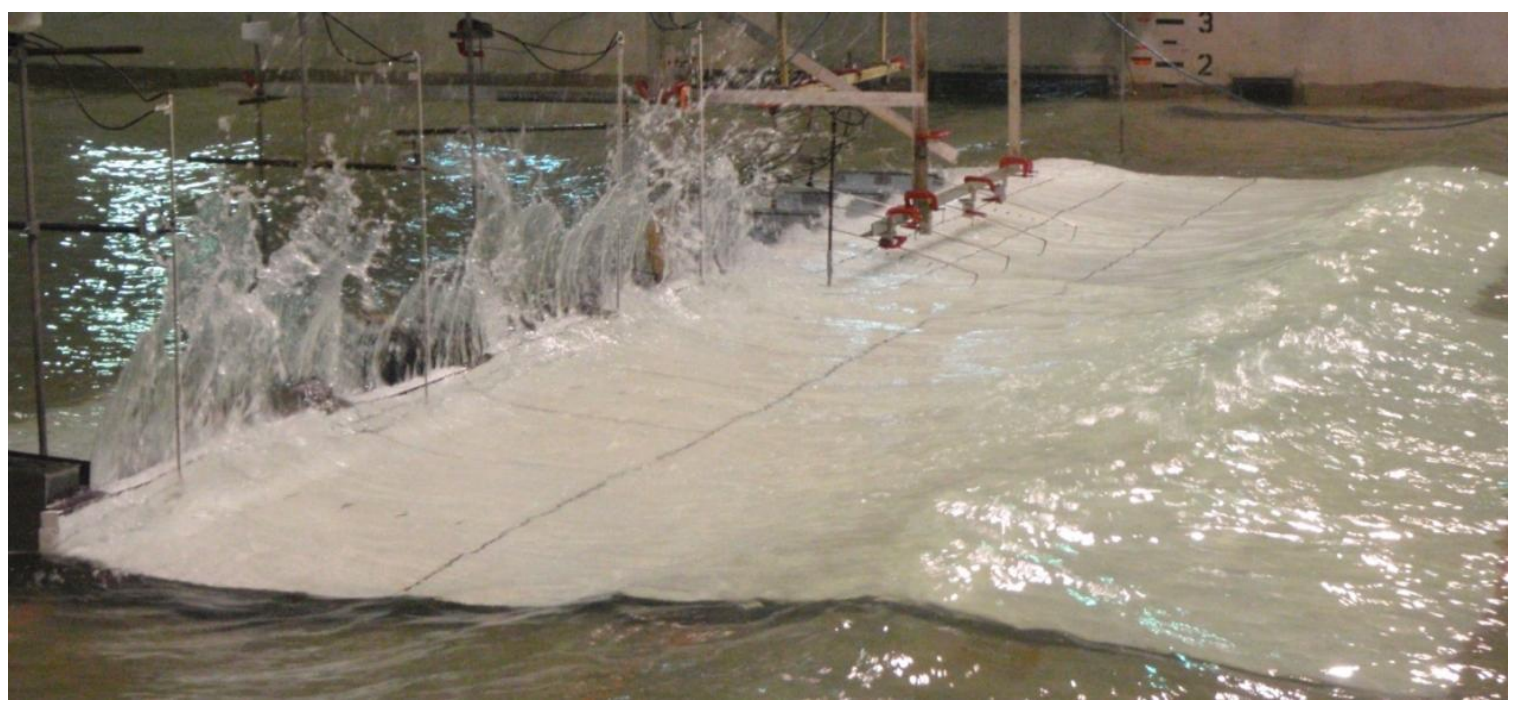

Figure 38. Floodwall Side of Levee Transition Model during Test No. 07. 


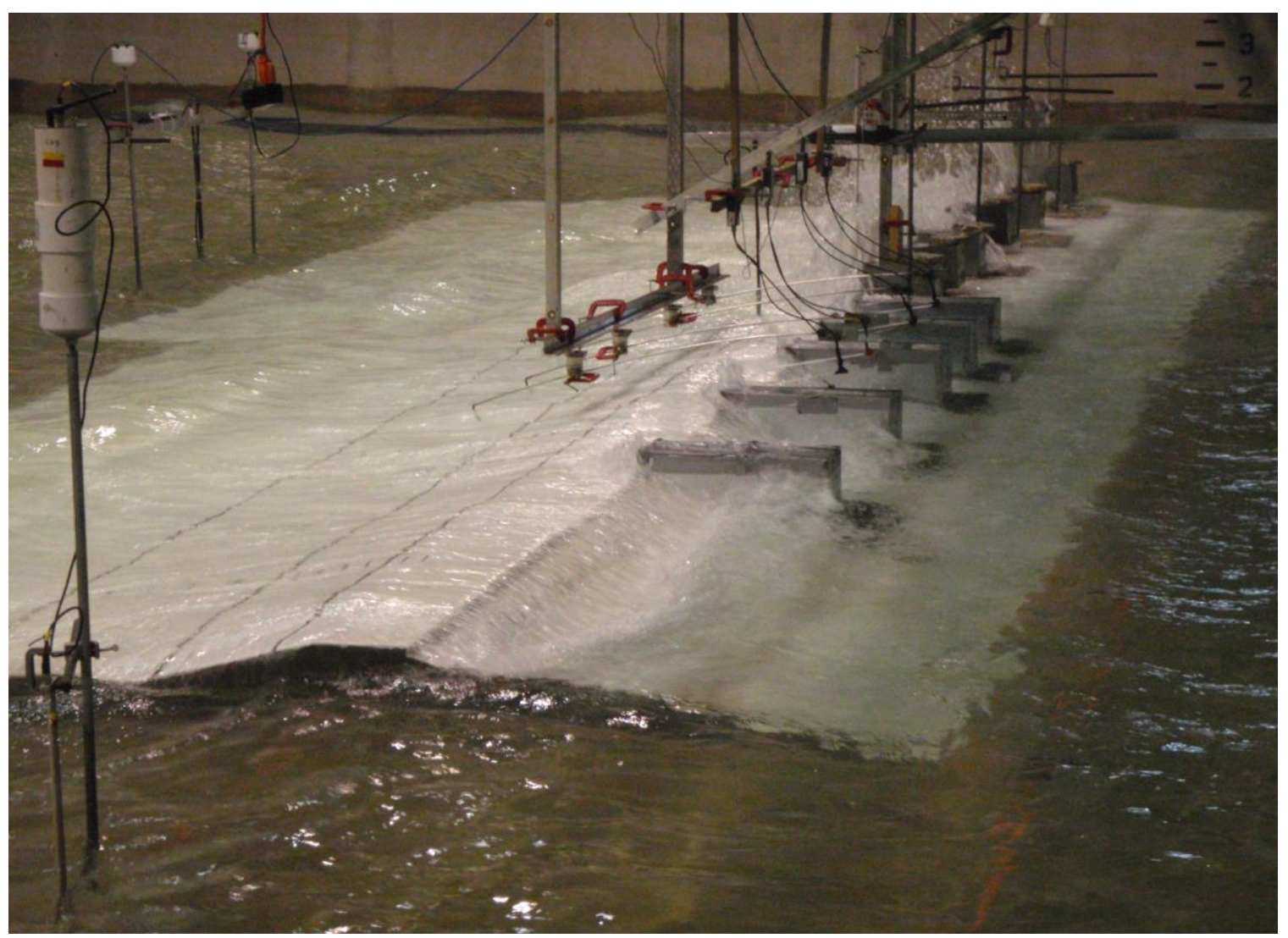

Figure 39. Levee Side of Levee Transition Model during Test No. 07.

Figure 38 and Figure 39 are examples of testing during Test No. 07. As seen, the overtopping is significant. As a reminder, the height of the floodwall in prototype units is $9.14 \mathrm{~m}$ from the levee toe; therefore, it is evident that the floodwall wave heights are significantly high, which is the major reason for the 1 meter capacitance wave gauges on the floodwall. To provide reference to the two figures above, Figure 40 and Figure 41 provide examples of the levee transition model during Test No. 03, which has the same $\mathrm{T}_{\mathrm{p}}$ as Test No. 07, but a lower SWL. Additional pictures of the testing are provided in Appendix B. 


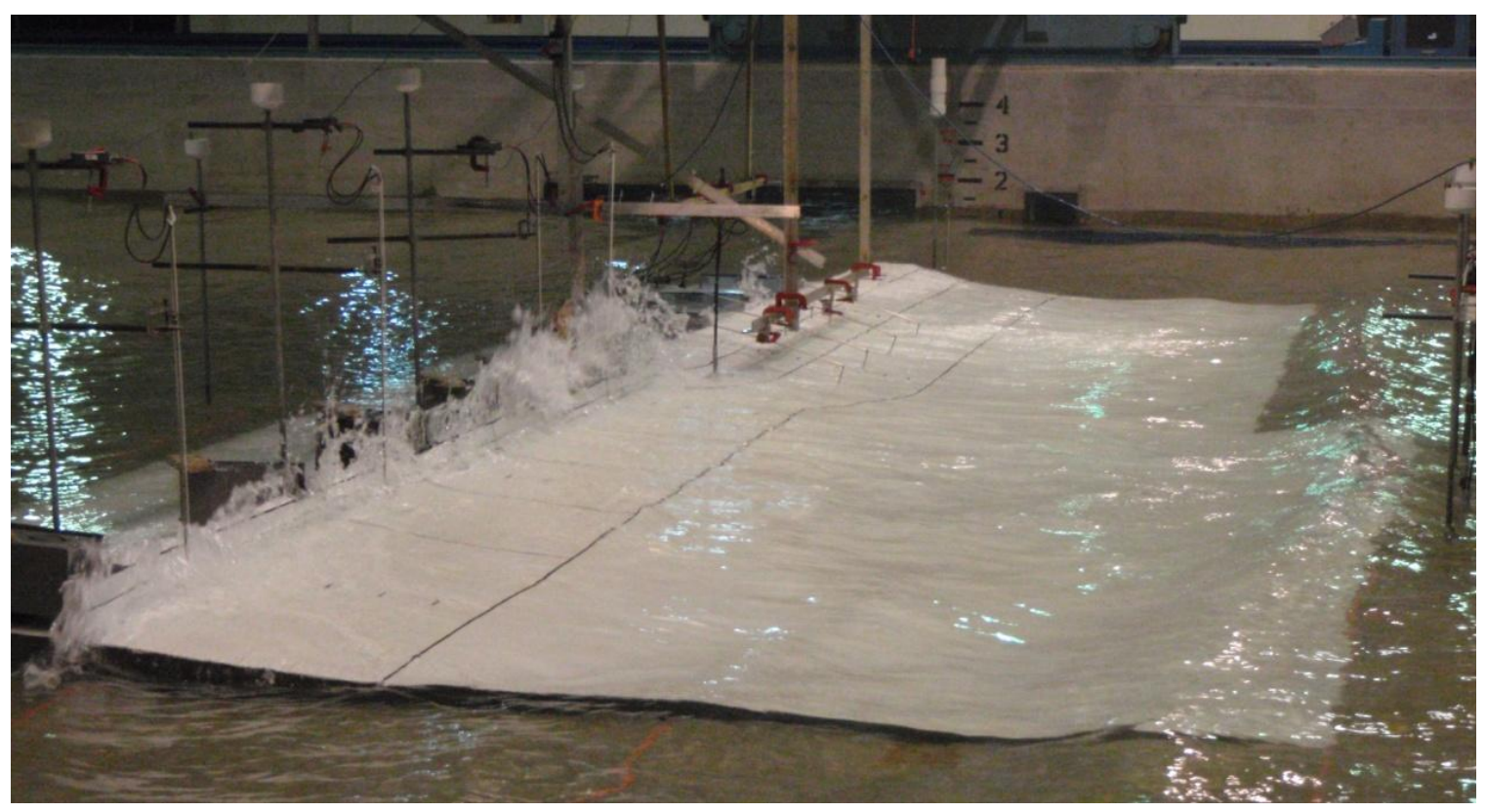

Figure 40. Floodwall Side of Levee Transition Model during Test No. 03.

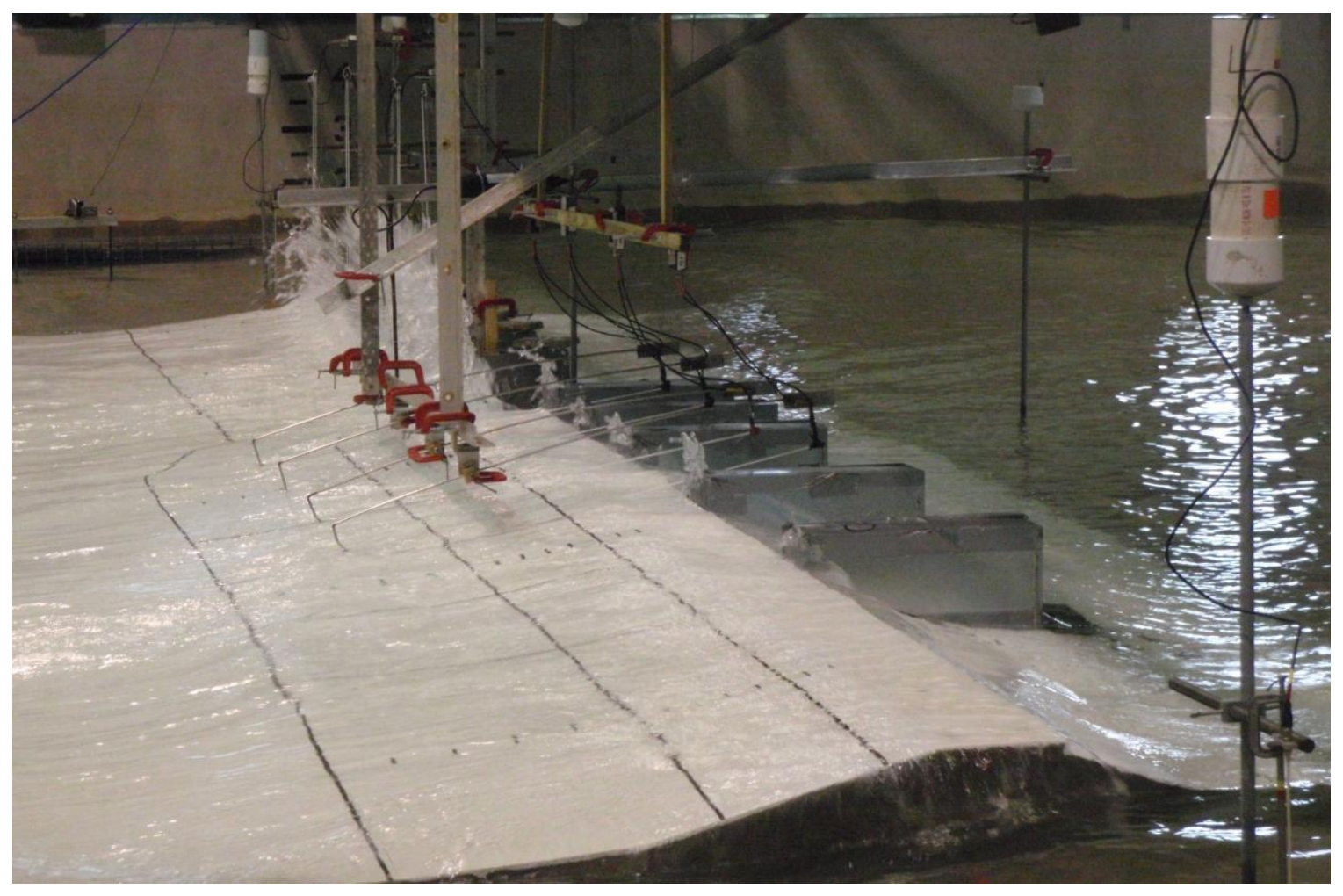

Figure 41. Levee-Side of Levee Transition Model during Test No. 03. 


\subsection{Physical Modeling Problems and Solutions}

The largest model effect was caused by the sudden drop-off at the model ends. This sudden drop-off caused the wave crests to refract towards the levee resulting in abnormally large overtopping rates near the end of the levee section and floodwall section. Consequently, overtopping measurements taken near the levee end and floodwall end are not represented; this includes overtopping container number 0 . The refraction at the end of the floodwall end also resulted in extreme wave heights at floodwall gauge $\mathrm{CH}$ 7. As a result, the gauge data obtained from $\mathrm{CH} 7$ is also not represented in the final data set.

Another intrinsic laboratory effect is the result of the wave basin's side walls. Due to the three-dimensionality of the levee transition testing, waves naturally refract around the structure and reflect directionally off the structure. These reflections eventually tend to reflect of the side walls, which results in a seiching in the basin. To eliminate this trapped energy and make the testing environment as realistic as possible, wave absorbers are placed along the side walls. From initial tests, it is calculated that the side wall wave absorbers tend to dissipate approximately $60 \%$ of the wave energy as waves propagate normally through the absorber. The wave absorber simply consisted of a "horse hair" fabric rolled inside a wire mesh, creating a rigid, yet porous structure. 


\section{DATA ANALYSIS}

\subsection{Introduction}

This section outlines the specific definitions of the resulting statistical pieces of information and the procedures for obtaining the final results. The three basic results of the testing are runup along the levee, wave heights along the floodwall, and overtopping rate distribution along the entire levee transition; all results presented are in prototype dimensions. All wave heights and runup values are referenced to either the toe of the levee or the SWL, and will be specified as needed.

\subsection{Runup along Levee Section}

As referenced in the Experimental Setup section, four runup gauges are positioned along the upper levee section surface at a slope of $1 \mathrm{~V}: 4 \mathrm{H}$. From the 10 minute time series obtained from the testing, a zero up-crossing analysis is performed and two resulting data are determined for each gauge for each test: $2 \%$ Runup and the Mean Shoreline Position (MSP). A maximum value threshold is applied to the runup gauges, and any elevation greater than the levee crest is set to the levee crest elevation. The assumption is based off the reasoning that once the runup reaches the levee crest, the water simply overtops without much separation from the levee crest. An example of a runup gauge time series is demonstrated in Figure 42 from Test No. 06. In Figure 42, the values are in model dimension. The data has already been cleaned, and the maximum threshold at the levee crest is clearly noticeable. The final runup value is measured vertically in reference to the datum of $+0 \mathrm{~m}$ at the levee toe for graphing purposes. To create the dimensionless runup parameter, the runup value must be reference to the 
SWL. With four gauges at specific locations, a 2\% Runup and MSP distribution is determined along the levee section.
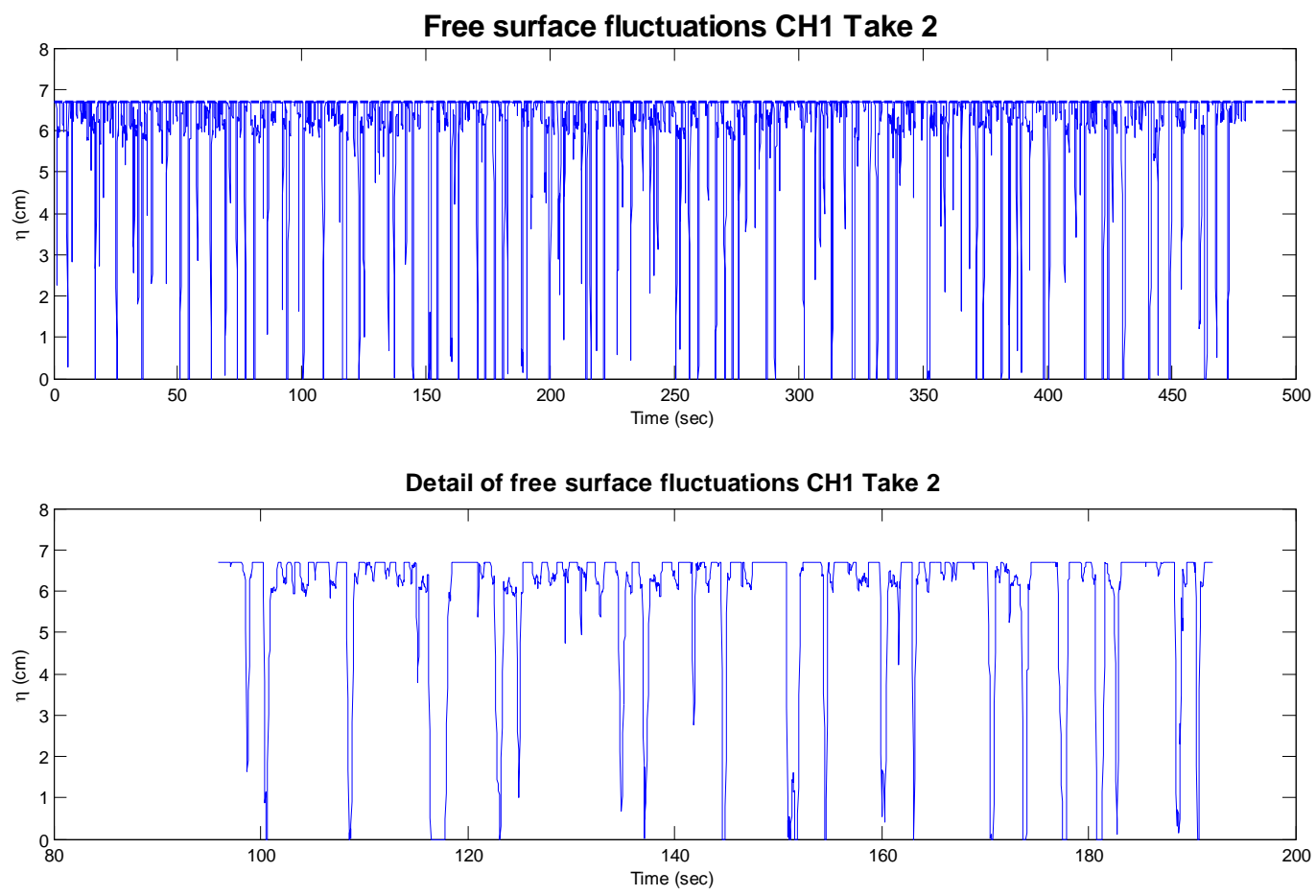

Figure 42. Example of Runup Gauge Time Series, Test No. 06, CH 1.

The $2 \%$ Runup, represented by $\mathrm{R}_{2 \%}$, value is defined as the wave runup level which is exceeded by $2 \%$ of the number of incident waves. For each run, the zero upcrossing analysis produces a record of the runup from each wave. The measured runup values are ranked by size, and from this record, the $2 \%$ Runup value is determined. From each run producing sufficient results, the $2 \%$ Runup values are averaged to produce a final result. Also presented is the total range of results among the repeatability runs for 
each test, showing how the plotted averaged value differs from the absolute maximum value and the minimum values obtained from the repeatability runs.

The Mean Shoreline Position is defined as the MWL along the surface of the levee, or the wave induced setup in addition to the SWL. From the 10 minute time series, the average value of the signal is taken to determine the setup in reference to the SWL. This value is simply added to the SWL depth for the particular test, and the MSP value for each gauge is determined. In addition, the absolute maximum and minimum values from the repeatability runs are presented.

\subsection{Wave Heights along Floodwall Section}

As referenced in the Experimental Setup section, four floodwall wave gauges are positioned vertically along the floodwall, three of which will be utilized for data analysis including: $\mathrm{CH} \mathrm{5,} \mathrm{CH} \mathrm{6}$, and $\mathrm{CH}$ 7. At this position, the gauges record the wave heights directly at the floodwall and well above the floodwall. From the 10 minute time series, three results are calculated from a zero up-crossing analysis: 2\% Crest Elevation, Floodwall Significant Wave Height, and Floodwall Mean Water Level. The final value for each of these statistics is measured vertically in reference to the datum of $+0 \mathrm{~m}$ at the levee toe for dimensional graphing purposes and is referenced to the SWL for calculating the associated dimensionless parameters. Unlike the runup gauges, no maximum threshold is implemented on the floodwall wave gauge data; the water which is splashed vertically above the floodwall is accounted for. With four gauges specifically positioned along the floodwall, a distribution of these statistics is presented. Figure 43 provides a representation of the time series of a floodwall gauge from Test No. 06. The 
floodwall crest is provided as reference to the wave heights in the time series. In Figure 43, the values are in model dimension.
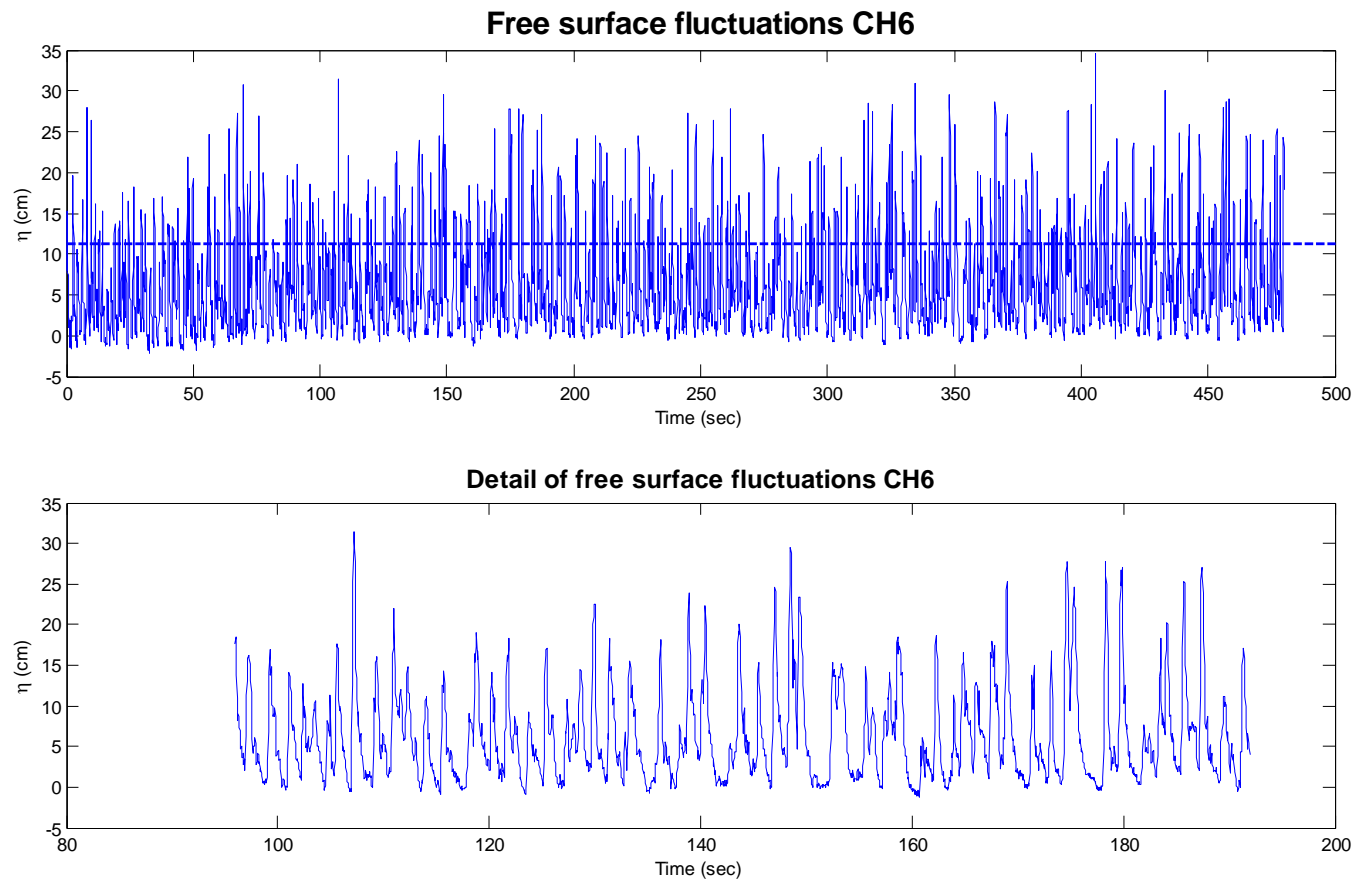

Figure 43. Example of Floodwall Gauge Time Series, Test No. 06, CH 6.

The $2 \%$ Crest Elevation is defined as the wave height at the floodwall which is exceeded by $2 \%$ of the number of recorded waves. For each run, the zero up-crossing analysis produces a record of the runup from each wave. The measured waves are ranked by size, and from this record the $2 \%$ Crest Elevation value is determined. From each run producing sufficient results, the $2 \%$ Crest Elevation values are averaged to produce a final result. Also presented is the total range of results among the repeatability runs for each test, showing how the plotted averaged value differs from the absolute maximum 
value and the minimum values obtained from the repeatability runs.

The Floodwall Significant Wave Height is defined as the average of the highest one-third measured waves occurring at the floodwall. This value is also determined from a zero up-crossing analysis of the 10 minute time series and ranking the measured waves. From the repeatability runs, an averaged value is determined for each gauge positioned along the floodwall. The total range of results for each gauge is presented as well.

The Floodwall Mean Water Level is defined as the MWL along the floodwall, or the wave induced setup in addition to the SWL. From the 10 minute time series, the average value of the signal is taken to determine the setup in reference to the SWL. This value is simply added to the SWL depth for the particular test and the Floodwall MWL value for each gauge is determined for dimensional graphing. Once again to determine the associated Floodwall MWL dimensionless parameter, the value is referenced to the SWL. In addition, the absolute maximum and minimum values from the repeatability runs are presented.

\subsection{Overtopping Rates along Levee Transition}

As mentioned in the Experimental Setup section, a total of 10 overtopping containers are used to produce an overtopping rate distribution along the entire levee transition model, but only 9 are utilized in the experimental results due to the refraction at the ends of the model. The results presented provide an averaged value of the overtopping rates per container per test from the repeatability runs. As before, the total range of results is presented from the runs for each test. 
The measured overtopping rates are compared with empirical overtopping rates determined using the Wave Overtopping Calculation Tool utilizing empirical calculations described in Chapters 5 to 7 of the European Overtopping Manual (2007), and represented herein as Equation 2.6 and 2.7. The two sections of the levee transition are calculated using separate empirical models. The overtopping value associated with the levee section requires a "composite slope model," which provides an estimate of the overtopping rate for variable sloped levee sections. The Overtopping Calculation Tool used for the levee section is presented in Figure 44. The example shown in Figure 32 is for Test No. 07. Since there is no option for a composite slope comprised of three slopes, the average of the first two slopes, between $+0.0 \mathrm{~m}$ and $+5.49 \mathrm{~m}$, is taken as the lower slope. The upper slope is taken as the additional $1 \mathrm{~V}: 4 \mathrm{H}$ slope between elevations of $+5.49 \mathrm{~m}$ and $+8.23 \mathrm{~m}$. Of the options available, this configuration is considered to most accurately represent the flood-side slopes of the levee section. The overtopping value associated with the floodwall section is achieved using a "composite slope with wall" model that is modified to a singular slope to better match the dimensions of the floodwall section. An example of this is shown in Figure 45. Both the upper slope and lower slope are $1 \mathrm{~V}: 10 \mathrm{H}$ creating a singular slope to replicate the incorporated levee on the floodwall section. All results from the calculation tool are deterministic, as discussed when Equations 2.6 and 2.7 are first presented. The deterministic value is given as the mean value plus one standard deviation for a more conservative approach since the uncertainty for the measured overtopping results is notable. 


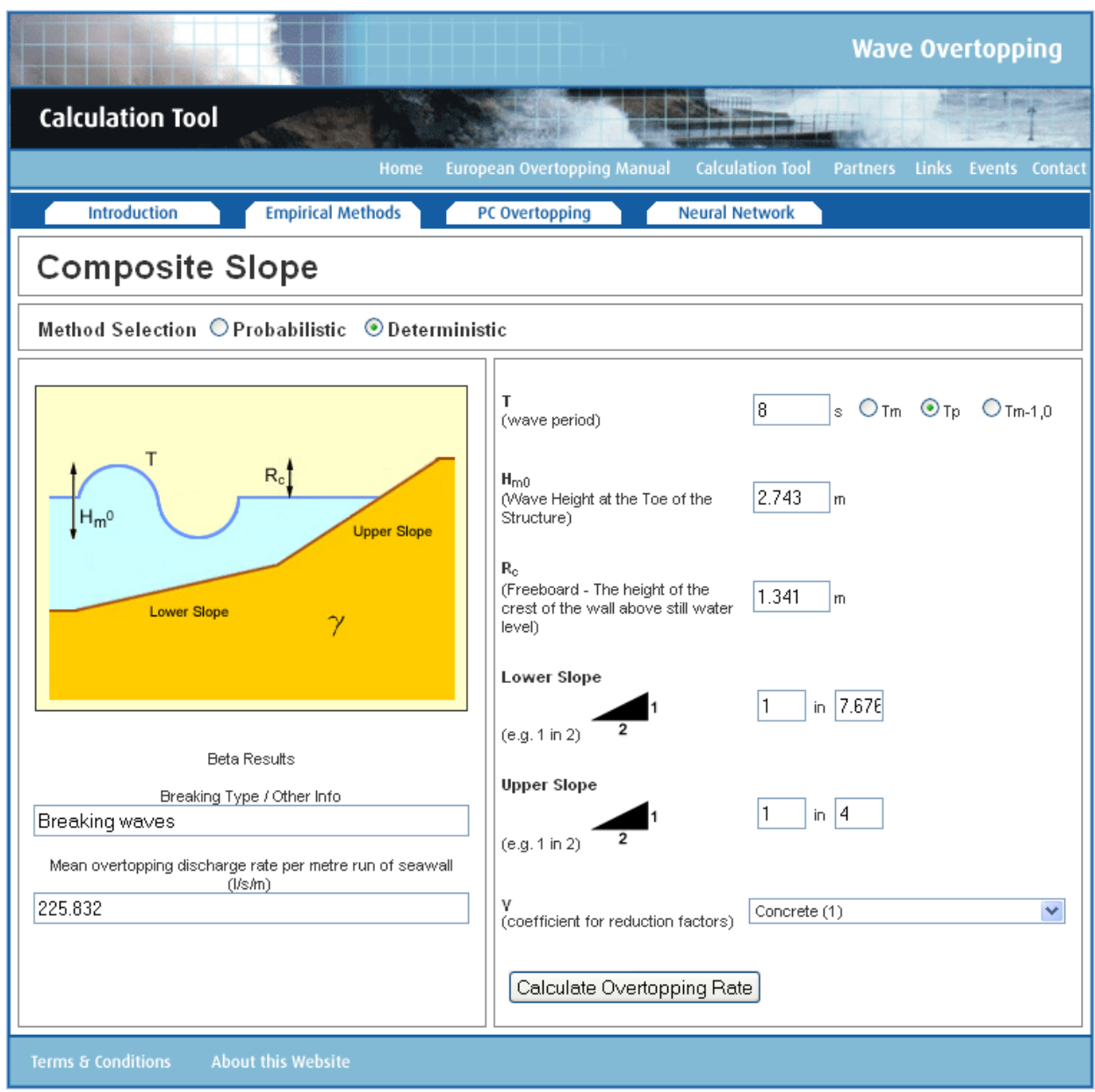

Figure 44. Wave Overtopping Calculation Tool for Levee Section (Wave Overtopping 2007).

Other empirical overtopping rates, based upon a Monte-Carlo approach, were provided by the USACE to provide a direct comparison of calculated values versus measured values. The values used for comparison are listed as q50 and q90, as provided by the USACE, and are defined as the overtopping values exceed by only $50 \%$ of the waves and $10 \%$ of the waves, respectively. The values of these empirical values are based upon hydraulic conditions provided in Table 1. Both q50 and q90 are presented in the plots in the next section and are units of $1 / \mathrm{s} / \mathrm{m}$. 


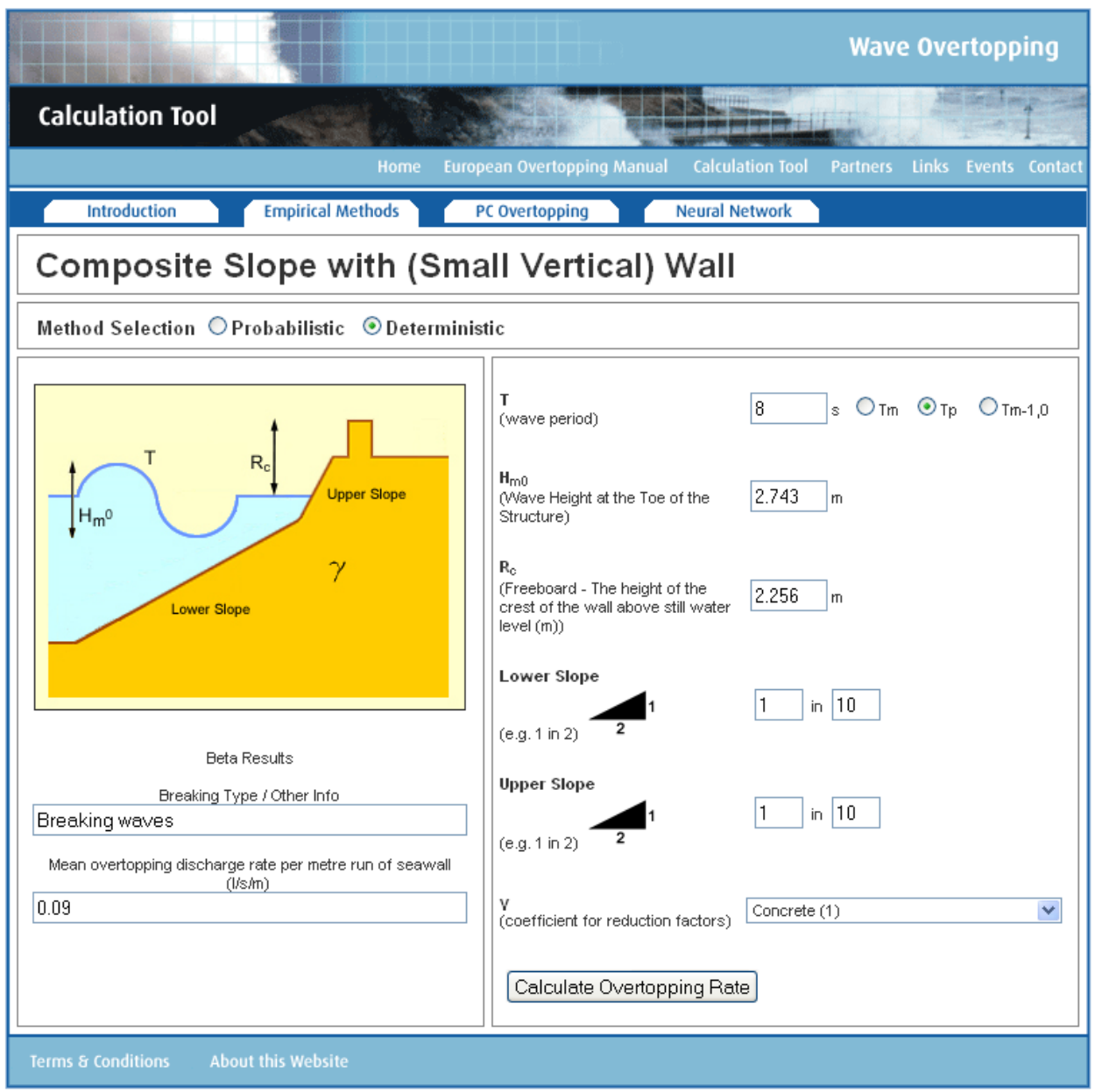

Figure 45. Wave Overtopping Calculation Tool for Floodwall Section (Wave Overtopping 2007).

\subsection{Three - Gauge Array}

As mentioned previously, the decomposition of the reflected wave energy and the incident wave energy is undergone by utilizing methods recommended by Mansard and Funke (1980). The placement of the three-gauge array is illustrated in Figure 33 and Figure 34. The placement of these gauges influences the placement of the modeled structure in the basin. According to the criterion proposed by Mansard and Funke, the three-gauge array must be located at least one wavelength away from the wave generator 
and the modeled structure. With the first gauge begin closest to the wave generator, or TR 5 in Figure 33, the distance between the first and second gauge can be no less than one-tenth of the peak wavelength. The distance between the first and third wave gauge, or TR 5 and TR 7, must be between one-sixth and one-third of the peak wavelength. For the analysis of the three-gauge array, a MatLab® script was modified from MACE free softwares website, maintained by Nobuhito Mori (2009). 


\section{EXPERIMENTAL RESULTS}

\subsection{Introduction}

From the data analysis expressed in the previous section, the results from each test are provided in this section and Appendix C. In Section 6.2, the figures present results of the runup along the levee and wave heights along the floodwall; Section 6.3 contains figures that present the overtopping rate distribution along the entire levee transition. All results in Section 6.2 and 6.3 are in prototype dimensions. All values in Section 6.2 are referenced to the toe of the levee, which is at $+0.0 \mathrm{~m}$. As mentioned before, the resulting data is obtained from 10 minute time series from four runup gauges and three floodwall gauges, $\mathrm{CH} 0$ through $\mathrm{CH} 6$, and measured discharges from nine overtopping containers. By utilizing these particular overtopping containers and gauges, the data set is void of any intrinsic scale effects. Again, the horizontal datum is at the midpoint of the model, which is at the transition.

Sections 6.4 and 6.5 present a non-dimensional analysis in an attempt to collapse the resulting data from all tests into one general trend to better explain the variation of the results along the levee transition. The dimensionless results enable direct comparison of each independent variable that directly affects the outcome of the results. Section 6.4 provides dimensionless plots of levee runup and floodwall wave height values, and Section 6.5 provides dimensionless plots of overtopping rates along the entire levee transition. The methodology of determining ratios that would best collapse the data as well as the methodology of establishing the best fit for the data is also discussed. The plots introduced in Section 6.4 and 6.5 can all be found in Appendix D. 


\subsection{Levee Runup and Floodwall Wave Height}

The plots contained in this section are dimensional and illustrate the variation of the levee runup and floodwall wave height values along the levee transition. Each of the plots is in reference to the toe of the levee at $+0.0 \mathrm{~m}$, and the elevations of the floodwall crest $(+9.14 \mathrm{~m})$ and levee crest $(+8.23 \mathrm{~m})$ are also plotted for perspective. Both the runup values and floodwall wave heights are plotted on a singular plot per test, displaying the variation of the generated water level statistics along the entire levee transition structure. The statistical values presented in the plots are described in detail in Section 5. Only four of the eight tests are represented in the following graphs; all resulting graphs can be viewed in Appendix C. In order to provide perspective on the variation of the data among the repeatability runs per test, the absolute or total variation is represented in the figures by an error bar that is plotted at each of the gauge locations. This enables the reader to confirm the results of the experiments and recognize the consistency exhibited during testing.

The floodwall wave heights and levee runup for Test No. 01 is shown in Figure 46. The left side of the plot, denoted by the negative distance from the transition, is designated as the floodwall side and presents the wave height characteristics measured in front of the floodwall. The red line indicates the 2\% Crest Elevation; the blue line represents the Significant Wave Height $\left(\mathrm{H}_{\mathrm{s}}\right)$ at the floodwall; and the green line symbolizes the measured Mean Water Level (MWL) at the floodwall. The location of each gauge, $\mathrm{CH} 6, \mathrm{CH} 5$, and $\mathrm{CH} 4$, is indicated by the markers along the line. The right side of the graph, beginning at $0 \mathrm{~m}$, characterizes the levee side of the modeled structure, 
as noted by the indication of the levee crest in the plots. The blue line denotes the $2 \%$ Runup level, and the black line indicates the Mean Shoreline Position (MSP). Again, the location of each gauge, $\mathrm{CH} 0$ through $\mathrm{CH} 3$, is characterized by the associated markers on the line. Similar to the floodwall side, the total range of results among the repeatability runs for the runup gauges is also plotted on the graph, as noted by the error bars. These characteristics are consistent among all the dimensional plots of the floodwall wave heights and levee runup levels.

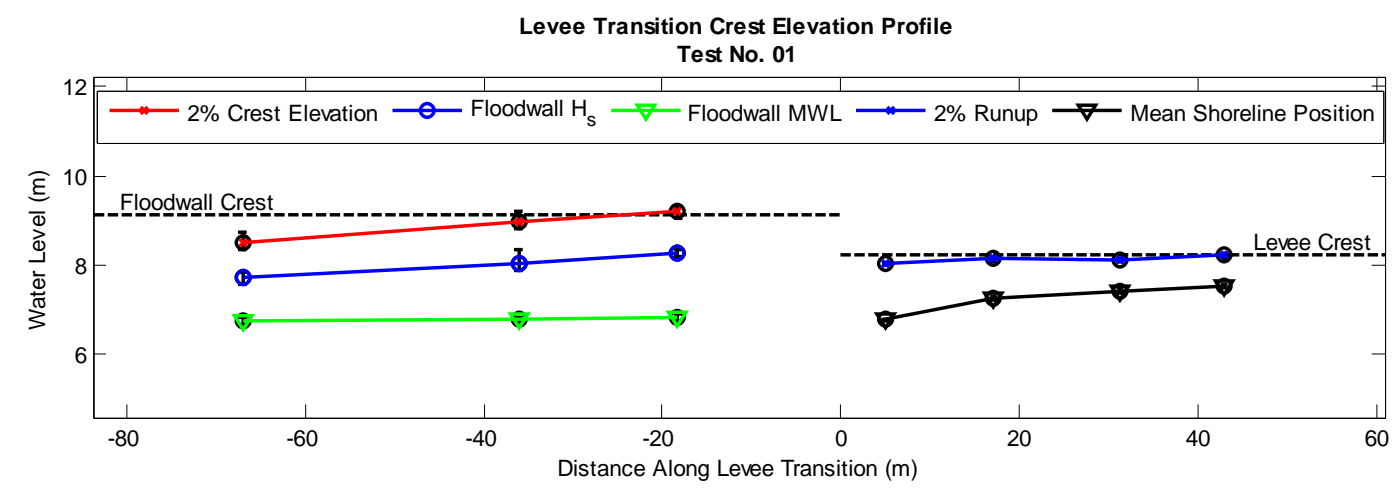

Figure 46. Floodwall Wave Heights and Levee Runup, Test No. 01.

From Figure 46, it is apparent that the floodwall wave height levels tend to increase towards the levee transition. The $2 \%$ Crest Elevation actually measures above the floodwall crest height at the gauge closest to the transition. For Test No. 01, the maximum height of the water level (SWL plus amplitude of wave) as the waves propagate towards the model, disregarding any wave reflection, is about $6.9 \mathrm{~m}$, which is nearly equivalent to the wave setup, or MWL, at the floodwall. On the levee side, the water level trend tends to be contrary to the floodwall side trends. In fact, the runup 
levels tend to decrease towards the transition. The $2 \%$ Runup level is nearly equal to the levee crest, even for Test No. 01. Plotting both the floodwall and levee sides on one plot enables comparison of the resulting water level values, especially the comparison of the MWL and MSP. Both are considered as the value of the vertical rise in water level due to the SWL and the wave-induced setup at the gauge location. Because of this definition, it is expected that the two statistical values should correspond near the transition or midpoint of the model. This is the case for basically all tests, as shown in the corresponding figures. The MSP and MWL do match up well at the transition, but the MSP then tends to increase away from the transition, increasing its value $10 \%$, in reference to the toe of the levee, which is an increase of over $75 \%$ in reference to the SWL. This is a result of the absence of the floodwall on the levee side. Consisting of a slope up to the crest of the levee enables the water to vertically run up the flood-side levee surface to a height greater than the floodwall side allows. For each of the measurements from the runup and floodwall gauges, the variation among the runs per each test is minimal.

The other representative test for the lower SWL is Test No. 03, portrayed in Figure 47. Similar to Test No. 01, the floodwall water level values tend to rise towards the transition. As a result of the increase in peak period, the induced wave heights and water levels at the floodwall are definitely greater. The $2 \%$ Crest Elevation is now greater than the floodwall crest height at the two gauges closest to the transition, and the Floodwall $\mathrm{H}_{\mathrm{s}}$ is approaching the crest. There is also a greater separation between the Floodwall $\mathrm{H}_{\mathrm{s}}$ and MWL, which is initially noticeable in Test No. 02 and continues 
through Test No. 04 for the lower SWL tests. The MSP and 2\% Runup also mimic the general precedent trends prevalent in Test No. 01, though all values are slightly increased due to the increase in peak period.

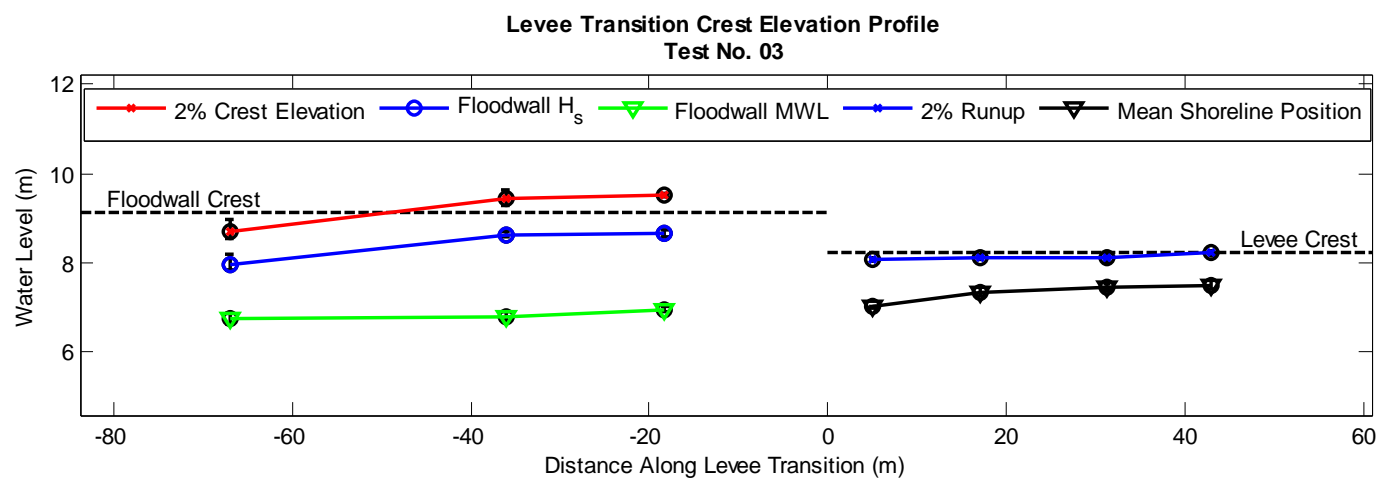

Figure 47. Floodwall Wave Heights and Levee Runup, Test No. 03.

All values are increased as the peak period increases, which is the case for Test No. 04, where all 2\% Crest Elevation values are at or above the floodwall crest height. For the lower SWL tests, the average percentage increase in floodwall wave heights, with respect to the levee toe, is nearly $2 \%$, about $12 \mathrm{~cm}$, for a one second increase in period. The levee runup values only increased an average of $0.5 \%$, only $3 \mathrm{~cm}$, for a one second increase in period. Test No. 05 is the first test for the higher SWL and slightly higher wave heights. As one can see in Figure 48, the results are dramatically different than the lower SWL tests. As indicated by the MWL and MSP values, it is expected that the overtopping rates for the higher SWL are also much greater. For the higher SWL tests, the 2\% Runup and MSP are essentially equal due to the enforcement of the threshold value on the runup levels, and the floodwall $2 \%$ Crest Elevation and $\mathrm{H}_{\mathrm{s}}$ are 
well above the floodwall. These trends are resonated in the overtopping rates shown in Section 6.3. Direct comparison of the water level value and the overtopping rates per test are more clearly seen in Appendix C.

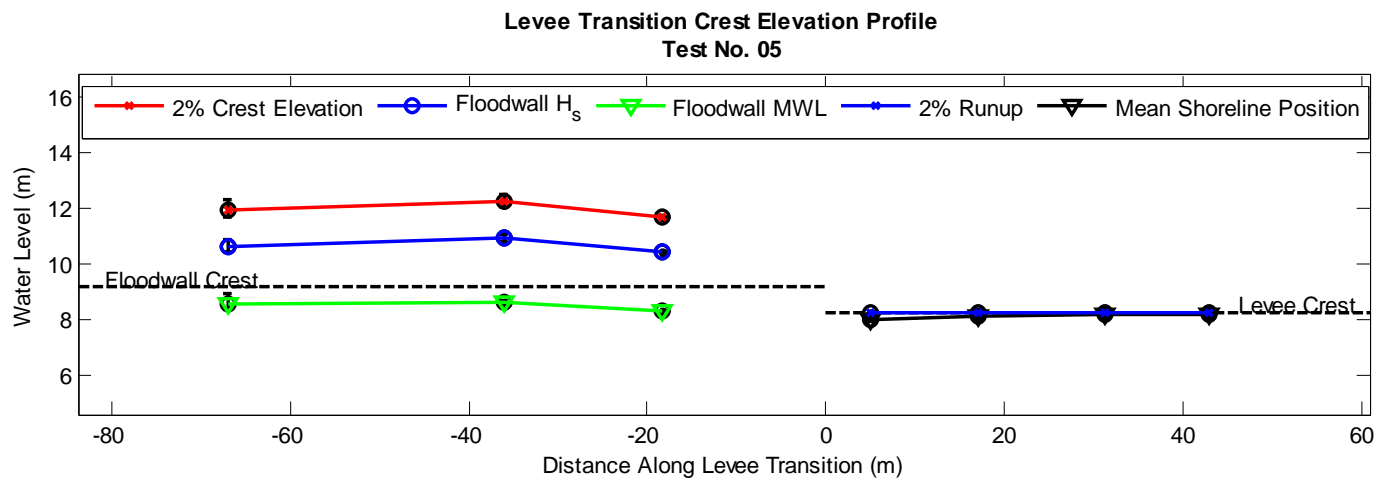

Figure 48. Floodwall Wave Heights and Levee Runup, Test No. 05.

The floodwall wave height trends are unlike those experienced with the lower SWL tests. The peak of the floodwall wave heights occurs in the middle gauge; from the middle towards the transition, there is actually a decrease in the wave height. In particular, these tests were run many times while changing out the wave gauges at the permanent locations along the floodwall to ensure accuracy and repeatability. This trend is evident in all high SWL tests, and as made apparent by the additional plot of the total range of results, the results are consistent. The reason for the decreasing trend is due to the fact that the floodwall MWL is essentially higher than the levee crest elevation. Near the transition, the wave induced setup simply flows around the floodwall and over the levee crest causing a divergence and lowering the MWL towards the transition. Consequentially, the corresponding floodwall wave heights also decrease towards the 
transition. The decreasing trend towards the transition for the floodwall wave heights is more noticeable as the wave period increases, as shown in Figure 49. The wave heights continually increase with the wave period, to a maximum 2\% Crest Elevation of 13.67 $\mathrm{m}, 35.8 \mathrm{~m}$ from the transition. For every second the peak period is increased for the higher SWL tests, the floodwall water levels increase about $2 \%$, similar to the lower SWL tests; furthermore, the runup values only increase about $0.1 \%$. This small increase is simply due to the fact that the runup values are subject to the threshold of the levee crest. By merely raising the SWL, the floodwall water level values increased over $30 \%$, and the runup values increased $10 \%$, both with respect to the lower SWL testing results. This increase in $10 \%$ is significant when considering the application of the threshold applied to the runup gauge data. Section 6.3 provides the immense overtopping measurements which correspond to the extreme water level values experienced during the high SWL tests.

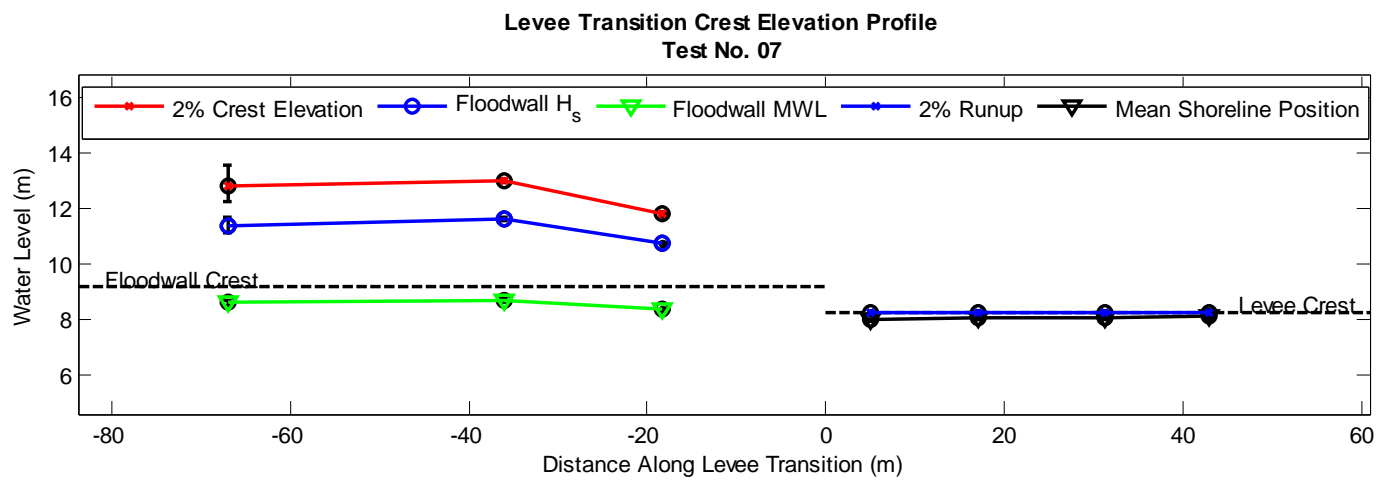

Figure 49. Floodwall Wave Heights and Levee Runup, Test No. 07. 


\subsection{Overtopping Rates along Levee Transition}

The following plots provide the results of the overtopping rates measured using the overtopping containers described in Section 4, and the overtopping statistics and analyses described in Section 5. The representative tests provided in the text are the same as those presented in Section 6.2 to provide direct comparison between the water level values and the overtopping distribution along the levee transition. As noted before, the measured values provided in the overtopping distribution plots are results of three runs per test. The marked values, which form the distribution along the levee transition, are the averaged values from the three repeatability runs. In addition to the averaged values, the total range of measured values is represented by the error bars. Of the data obtained, the overtopping measurements show the greatest deviation in values among the repeatability runs, but the discrepancies tend to be isolated along the levee section, where the overtopping is by far the greatest. To provide comparison of the measured results, two different forms of traditional overtopping methods are presented in each figure, as initially discussed in Section 5.

Figure 50 presents the results from Test No. 01. Immediately visible are the overtopping rates associated with the levee side of the protective structure. Clearly, the values of the levee side are much more significant than those of the floodwall side. This is expected, and is consistent among all tests. The deterministic overtopping rate, identified by the black dashed line, is determined using Equations 2.6 and 2.7 in Section 2 as well as the Wave Overtopping Calculation Tool provided by HR Wallingford (2007), as detailed in Section 5. From hydraulic conditions present in Test No. 01, these 
basic empirical equations predicted absolutely no overtopping along the floodwall for Test No. 01, Test No. 02, and Test No. 03, which evidently is not the case as noted by the measured values. Also clearly seen is the underestimated overtopping rate on the levee side of the structure; this is consistent for all tests. The green and red dashed lines signify the q50 and q90 values provided by the USACE. Further explanations of these values are also iterated in Section 5. The q50 and q90 values tend to provide estimates of overtopping that are above and below the empirically calculated deterministic overtopping rate. Among the three values of estimation of the overtopping rates on the levee side, the q90 value provides the most reasonable, yet unconservative, estimation for Test No. 01 through Test No. 03, shown in Figure 50 and Figure 51. Tests No. 02 and 03 provide the most agreement to the q90 value on the levee side of the structure. On the floodwall side, the only lower SWL test in which the q90 value provides the most agreement with the measured values is with Test No. 04. However, even during Test No. 04, the q90 value still underestimates the overtopping rate experienced $-25 \mathrm{~m}$ from the transition. This particular region of the floodwall tends to yield the greatest measured overtopping rates for all tests.

For the lower SWL tests, there is a gradual increase in the overtopping rates toward the transition along the floodwall, which is mimicked by the gradual increase in water level values along the floodwall, shown in Figure 46 and Figure 47. Though the values may be much smaller on the floodwall side, according to the European Overtopping Manual (2007), discharges greater than $1.0 \mathrm{l} / \mathrm{s} / \mathrm{m}$ can still induce erosion. Discharges greater than $10 \mathrm{l} / \mathrm{s} / \mathrm{m}$ yield significant overtopping rates, which will erode 
poorly protected levees and floodwalls; discharges greater than $50 \mathrm{l} / \mathrm{s} / \mathrm{m}$ will result in damages to the crest and rear slopes, unless these areas are well protected. These values are not considered conservative in regard to any floodwalls and vertical walls that may allow the overtopped water to fall to the protected-side. During this fall, higher fluid velocities can be reached that will inevitably yield higher erosion rates. An example of this failure mode is shown in Appendix A.

Another trend apparent in all tests, excluding Test No. 01, is the parabolic contour of the overtopping rate distribution along the levee side. For these tests, the overtopping rates have a tendency to reach their maximum value between $12 \mathrm{~m}$ and 25 $\mathrm{m}$ from the transition. From their peak, the overtopping rates decrease towards the end of the model and towards the transition.

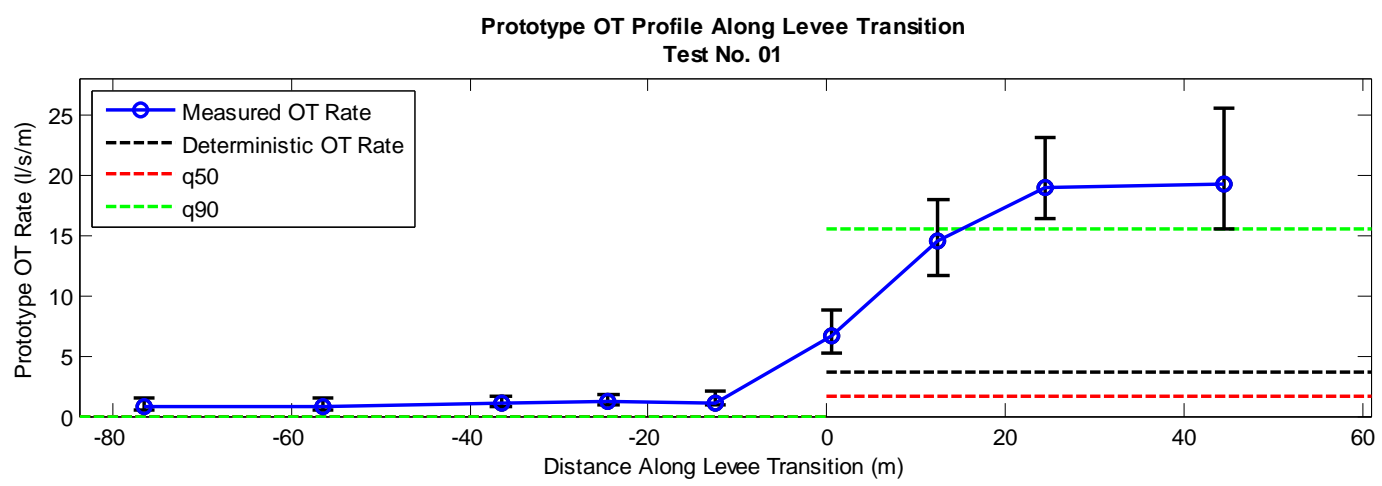

Figure 50. Overtopping Rate Profile, Test No. 01

Test No. 03 is the next representative case, shown in Figure 51. The values in Test No. 03 are indeed higher than those experienced in Test No. 01 and 02, providing evidence that the increase in wave period directly increases the overtopping endured at 
the structure. The values of Test No. 03 range from approximately $2 \mathrm{l} / \mathrm{s} / \mathrm{m}$ on the floodwall to a maximum value of nearly $40 \mathrm{l} / \mathrm{s} / \mathrm{m}$ on the levee side. Test No. 04 provides values of over $5 \mathrm{l} / \mathrm{s} / \mathrm{m}$ on the floodwall side and reaches overtopping rates exceeding 50 $1 / \mathrm{s} / \mathrm{m}$ on the levee side. These values are substantial and increase even more with the increase of the SWL for the remaining tests.

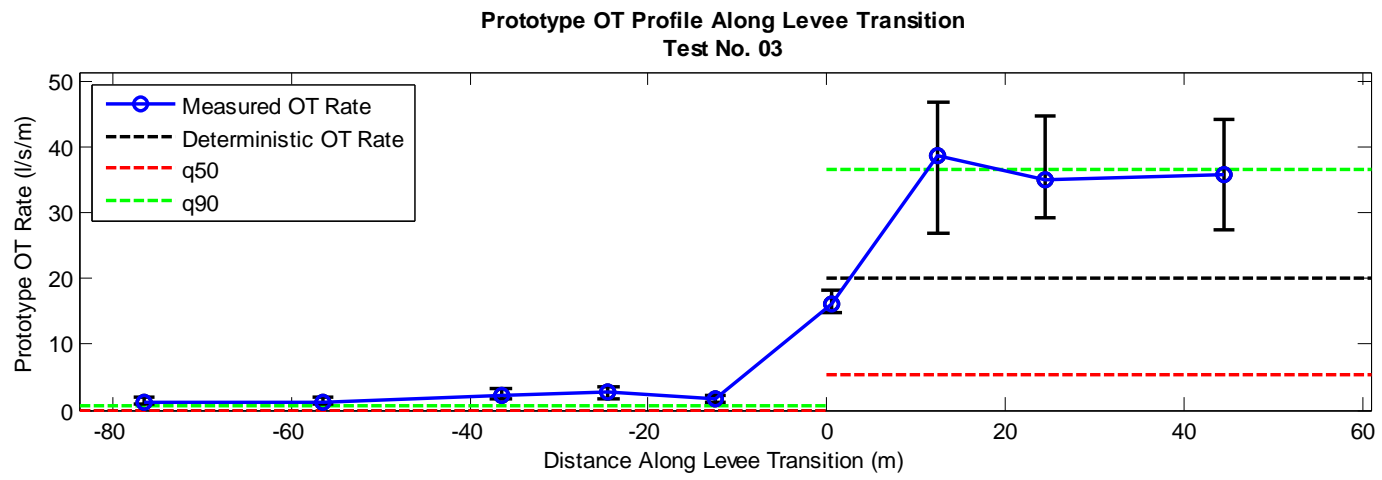

Figure 51. Overtopping Rate Profile, Test No. 03.

For the levee side of the structure, tests beyond Test No. 03 yield measured overtopping rates well below the provided q90 value, concluding that the q90 value offers a conservative design approach for Test No. 04 and for the higher SWL tests. For the floodwall side, tests beyond Test No. 06 also yield measured overtopping rates that are below the $\mathrm{q} 90$ value; therefore, the q90 value can also be considered conservative along the floodwall side for the extreme cases of Test No. 07 and Test No. 08. The values of Test No. 05 and Test No. 07 are demonstrated in Figure 52 and Figure 53. The values of the high SWL tests are extensive, and would most likely exceed the design conditions for a well protected structure. Again, the empirical overtopping rates 
calculated using Equations 2.6 and 2.7 tend to continually underestimate the experienced values, and the estimate begins to converge closer to the q50 value on the levee side, indicating that the empirical overtopping equation is not well suited for the calculation of the overtopping rates for this particular, spatially variable, protective structure.

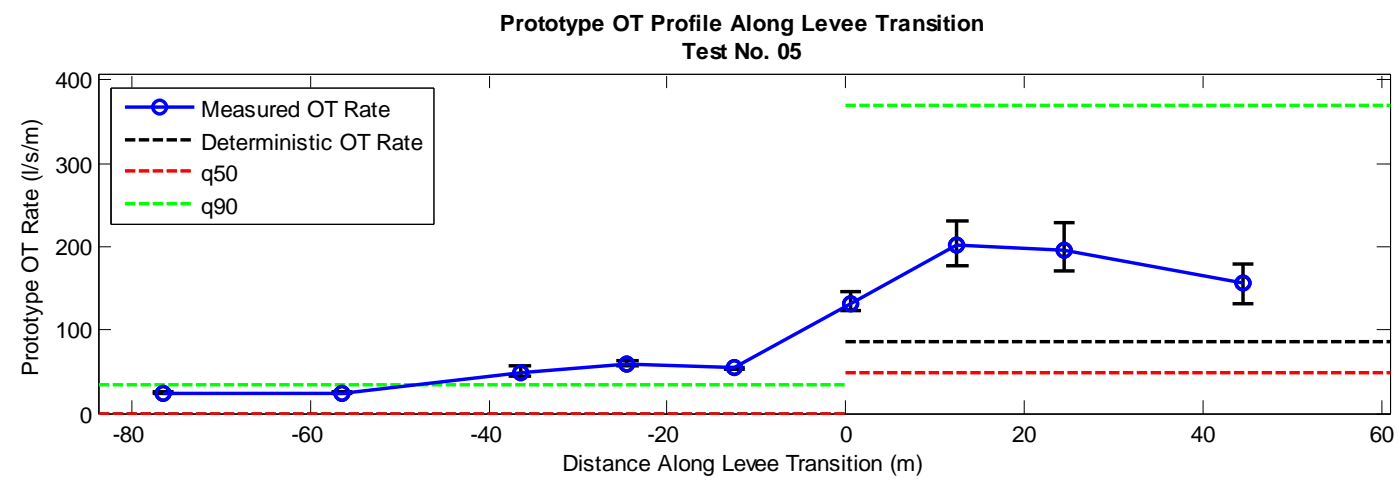

Figure 52. Overtopping Rate Profile, Test No. 05.

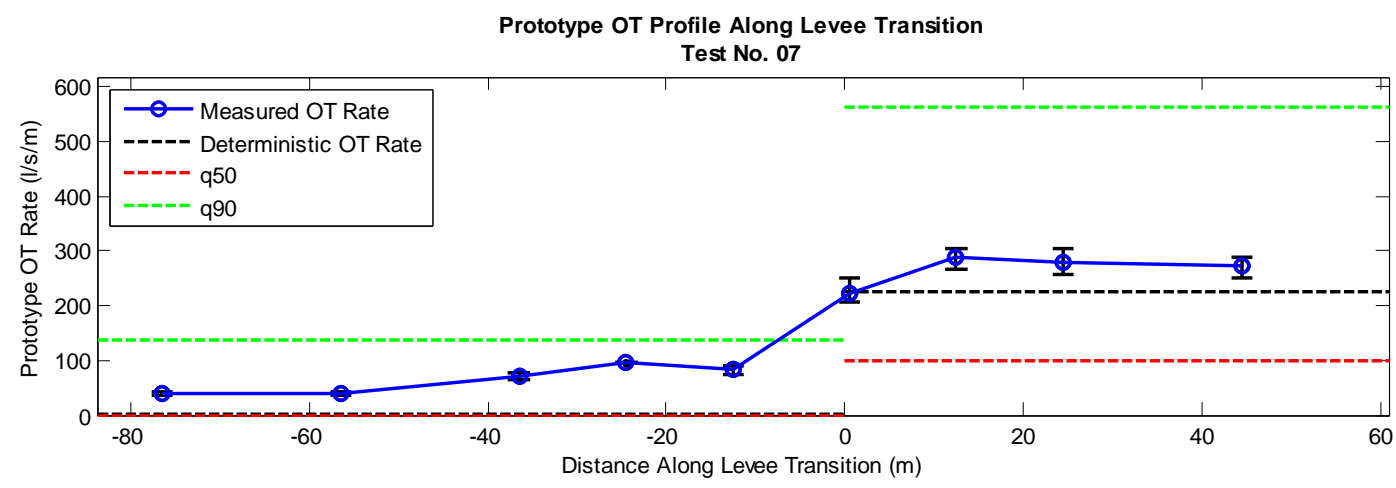

Figure 53. Overtopping Rate Profile, Test No. 07.

One noticeable and consistent trend in the distribution of the overtopping rates for all tests is the general maximum overtopping peaks that occur approximately $-25 \mathrm{~m}$ 
from the transition on the floodwall and +15 to $+30 \mathrm{~m}$ from the transition on the levee. This result is undoubtedly a phenomenon which cannot be explained using empirical methods, which assume a uniform cross-section along the length of a structure. In fact, these variations are generated from the three-dimensional contours at the transition, which in turn generate an undertow as seen in Figure 54, highlighted by the two arrows.

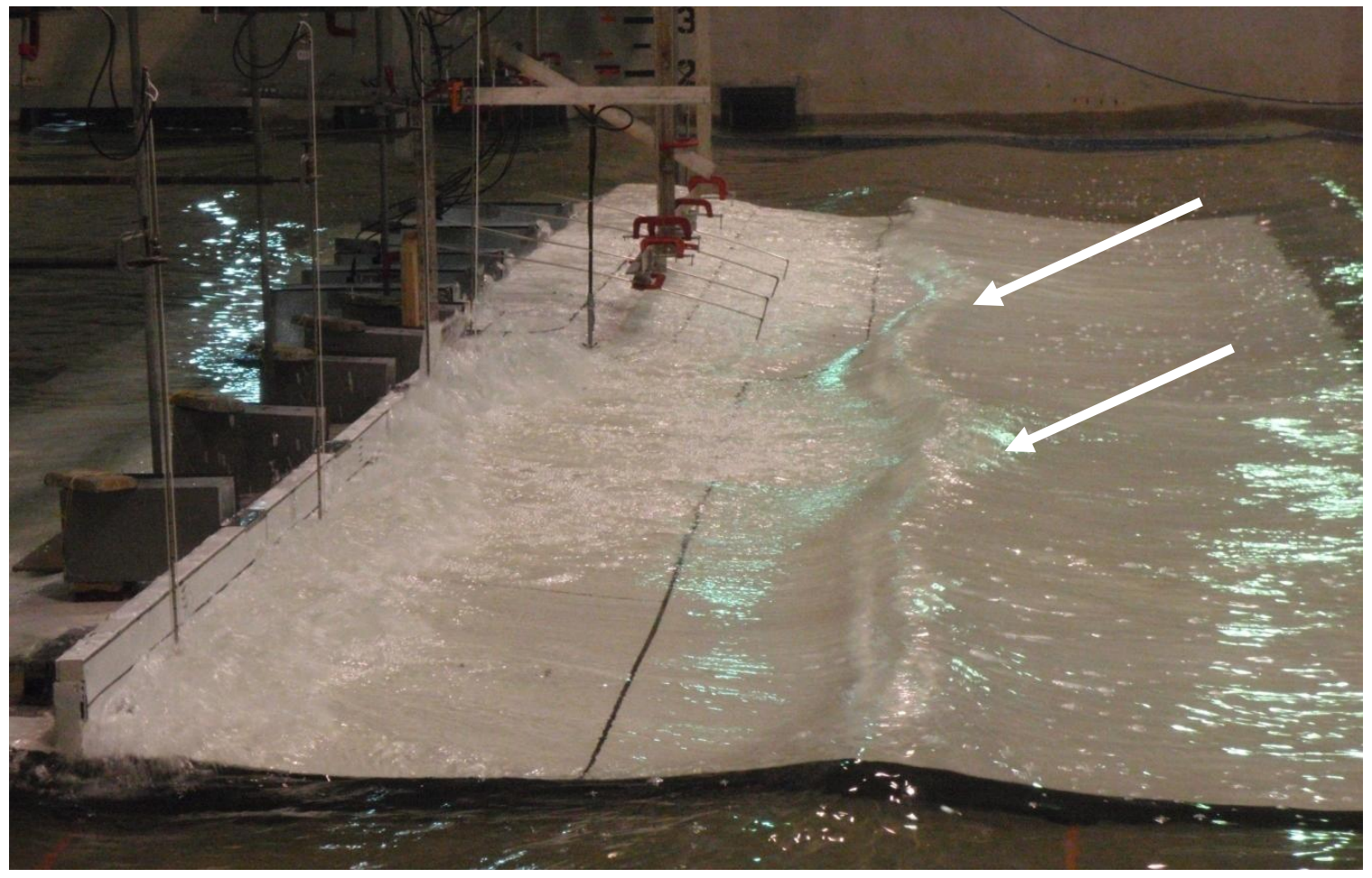

Figure 54. Experienced Undertow in Test No. 01.

At the transition, the contours cause the receding water to flow not only down the flood side of the structure, but also towards the floodwall side of the structure. As water flows down the contour in the longshore direction and down the structure in the cross-shore direction, a more prevalent undertow is generated near the $-25 \mathrm{~m}$ region of the floodwall 
side. This undertow then causes the incident waves to refract as seen in Figure 54. Also noticeable is the second wave refraction, which occurs at approximately $+20 \mathrm{~m}$ on the levee side. Since water is flowing down the contours away from the levee side, a divergence zone is created at the transition. As a result, water from the levee side will attempt to fill this divergence; this flow, coupled with the receding water, causes this undertow and incident wave refraction evident at $+20 \mathrm{~m}$. Due to the wave refraction, wave energy is focused at these locations, which ultimately yields higher overtopping values as shown in the dimensional overtopping rate profile plots for all tests in Figure 50 though Figure 53, as well as in Appendix C.

\subsection{Dimensionless Levee Runup and Floodwall Wave Height}

In order to quantitatively assess the influence and trends associated with the water level values measured by the floodwall and runup gauges as well as the overtopping rates calculated using the overtopping containers along the entire levee transition structure, a dimensionless analysis of these values is conducted. This section focuses on the procedures and methodologies developed to create the corresponding dimensionless parameters defined to collapse the water level data obtained by the gauges for all tests and the resulting plots. All resulting dimensionless plots can be viewed in Appendix D. For all values, two methods of scaling are completed. The first method, classified as simple scaling, consists of scaling parameters referenced within the literature review. The following dimensionless parameters are used for the simple scaling dimensionless plots, and are denoted by a prime.

The dimensionless $2 \%$ Crest Elevation, $H_{2}{ }_{2} \%$, is defined as follows: 


$$
H^{\prime}{ }_{2 \%}=\frac{H_{2 \%}}{H_{i}}
$$

where $H_{i}$ is the incident wave height determined from the three-gauge array, and $H_{2} \%$ is defined as the $2 \%$ Crest Elevation. All water level data is normalized by the incident wave height for simple scaling analysis. The dimensionless floodwall significant wave height, $H_{s}{ }_{s}$, is defined as the following parameter:

$$
H^{\prime}{ }_{s}=\frac{H_{s}}{H_{i}}
$$

where of course, $H_{s}$ is the significant floodwall wave height. The dimensionless floodwall Mean Water Level, $M W L$ ', is defined as:

$$
M W L^{\prime}=\frac{M W L}{H_{i}}
$$

The dimensionless levee 2\% Runup is calculated using the ratio described in Equation 6.4, and the normalized Mean Shoreline Position on the levee is shown in Equation 6.5.

$$
\begin{gathered}
R_{2 \%}^{\prime}=\frac{R_{2 \%}}{H_{i}} \\
M S P^{\prime}=\frac{M S P}{H_{i}}
\end{gathered}
$$

Serving as the abscissa axis on the dimensionless plots, utilized to maintain and observe the spatial variation of the data along the entire levee transition structure, a dimensionless longshore distance, $x^{\prime}$, is defined as follows:

$$
x^{\prime}=k x ; \quad k=\frac{2 \pi}{L_{i}}
$$

where $x$ is the distance along the levee transition; the transition, or midpoint of the 
model, serves as the datum for the longshore distance. The longshore distance is normalized by the characteristic incident wave number, $k$, calculated at the three-gauge array. The wave number is further defined as the ratio shown in Equation 6.6, where $L_{i}$ is the characteristic incident wave length, which is determined by iteratively solving the linear dispersion relation.

The first representative plot for the simple scaling dimensionless analysis is Figure 55. As initially evident in the dimensional plots in Section 6.2, the floodwall water level values followed different trends at the two different SWLs tested. This trend is mimicked in the dimensionless plots as well. The higher SWL tests resulted in larger dimensionless values since the floodwall water level values are more influenced by the rise in water level than the increase in incident wave height; therefore, a consistent separation between the two SWL tests is apparent in the plots. All curve fits are simply a linear least squares fit, which accent the general trends of the data.

Figure 56 provides the dimensionless results for the levee MSP. The MSP plot is chosen to provide correlation with the floodwall MWL plot. As noted prior, the MSP and MWL are essentially equivalent and ultimately are a combination of the SWL and the vertical rise in water level due to wave-induced setup. Therefore, the two measurements should converge to a common value at the midpoint of the model. Though the innermost runup and floodwall gauge are not coincident, the values are very similar for both SWL tests. Unlike the floodwall values, the levee side values tend to follow the same trend for both SWLs. This enables a better chance of further collapsing the data during the tuned scaling analysis. 


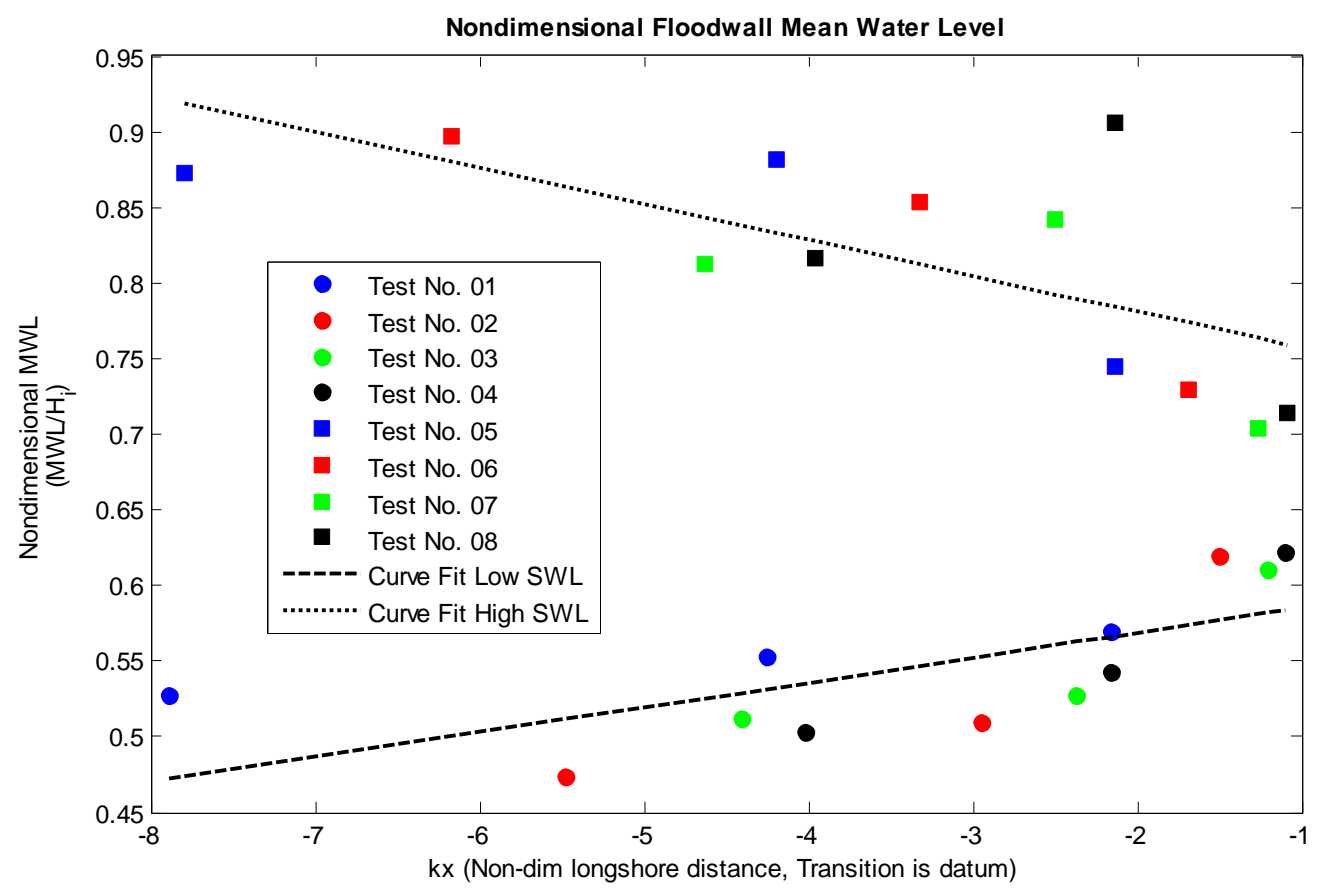

Figure 55. Dimensionless Floodwall MWL, Simple Scaling.

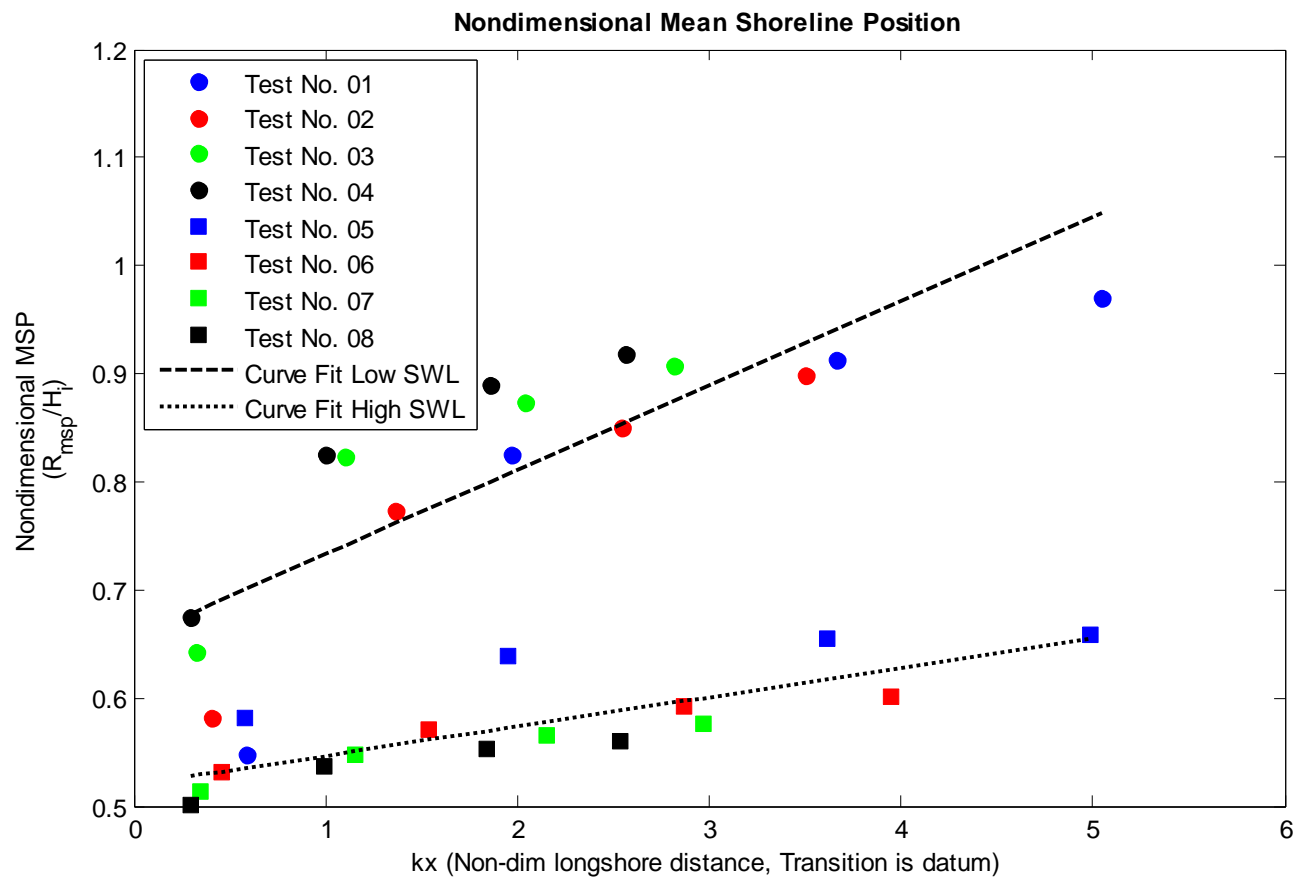

Figure 56. Dimensionless Levee MSP, Simple Scaling. 
There is still considerable separation between the SWL tests, which is more predominant in the $2 \%$ Runup dimensionless graph. Also noticeable is the fact that the results of the higher SWL tests have lower values than the lower SWL tests, contrary to the results of the floodwall side. Since extreme overtopping and runup is experienced on the levee side, the levee runup values are nearly equivalent to the levee crest elevation even for the lower SWL tests. As the SWL is increased, and the incident wave heights increase, more overtopping ensues, but the runup values cannot increase too much; consequently, the dimensionless 2\% Runup and MSP values decrease for the higher SWL tests. The cause of the greater separation for the $2 \%$ Runup dimensionless values is also a result of the application of the threshold value on the runup values. The MSP value does not drastically increase due to the rise in water level and wave heights, but it does increase more than the $2 \%$ Runup, which results in the greater separation between the different SWL tests in the 2\% Runup dimensionless plot.

To further collapse the data and negate the separation between the higher and lower SWL tests, another ratio is formed, which forms the basis for the tuned scaling analysis. This analysis is primarily beneficial to the dimensionless runup values and overtopping rates, described in Section 6.5, since the dimensionless floodwall parameters do provide consistent trends among all tests, primarily between the higher and lower SWL tests. The ratio required to collapse and resolve the differences between the two SWLs, is the ratio of the freeboard, $R_{c}$, and depth at the toe of the levee, $h$. This ratio can be found in each of the dimensionless parameters in Equations 6.7 through 6.11. 
The addition of this parameter newly defines the original dimensionless parameters defined in Equations 6.1 through 6.5. The new dimensionless parameters, referred to as tuned dimensionless parameters are noted by the superscript, $t$, and are displayed below.

$$
\begin{aligned}
H_{2 \%}^{t} & =\frac{H_{2 \%}}{H_{i}}\left(\frac{R_{c}}{h}\right) \\
H_{s}^{t} & =\frac{H_{s}}{H_{i}}\left(\frac{R_{c}}{h}\right) \\
M W L^{t} & =\frac{M W L}{H_{i}}\left(\frac{R_{c}}{h}\right) \\
R_{2 \%}^{t} & =\frac{R_{2 \%}}{H_{i}}\left(\frac{R_{c}}{h}\right)^{\zeta} \\
M S P^{t} & =\frac{M S P}{H_{i}}\left(\frac{R_{c}}{h}\right)^{\zeta}
\end{aligned}
$$

The exponent $\zeta$ is the most influential factor in 'tuning' the dimensionless parameters in order to obtain the most agreeable trend. This exponent is only incorporated in the dimensionless runup and overtopping rate parameters. It is not included in the floodwall water level parameters for the simple fact that regardless of the value of $\zeta$, there is no method for alleviating the differing slopes in the data's trends. Since the trend of the runup gauge data is relatively uniform throughout the data, it is necessary to include the exponent to optimize, or tune, the scaling parameter. In order to optimize the value of $\zeta$, a MatLab ${ }^{\circledR}$ script is created to test a multitude of possibilities for the exponent's value. Ultimately, the script enables the user to define an array of 
values for $\zeta$; it then applies this value to the dimensionless parameter and fits the resulting values with a least squares fit. The ensuing coefficient of determination, or $\mathrm{R}^{2}$ value, is then computed. The code stores all resulting $\mathrm{R}^{2}$ values and $\zeta$ values. The user can then input the optimized exponent into the script and graph the resulting dimensionless values as well as the least squares fit, with the corresponding $\mathrm{R}^{2}$ value displayed. The resulting graphs presented only demonstrate a linear or quadratic least squares fit. This method is also utilized for the dimensionless overtopping rates addressed in Section 6.5.

All dimensionless plots generated from the tuned scaling are provided in Appendix D. The floodwall MWL and levee MSP results are displayed in Figure 57 and Figure 58. These plots are chosen so the reader can readily observe the differences associated with the tuned scaling. Since the floodwall water values have varying trends associated with the SWLs, the data is kept separate; nevertheless, the tuned scaling analysis did in fact generate a quadratic trend in the higher SWL dimensionless floodwall water level values. This parabolic shape is most likely a result of the parabolic profile experienced in the dimensional graphs for the higher SWL. Also, the ratio of freeboard to water depth inverted the magnitude of the low SWL and high SWL tests since the ratio of freeboard to water depth is much less for the high SWL tests. 


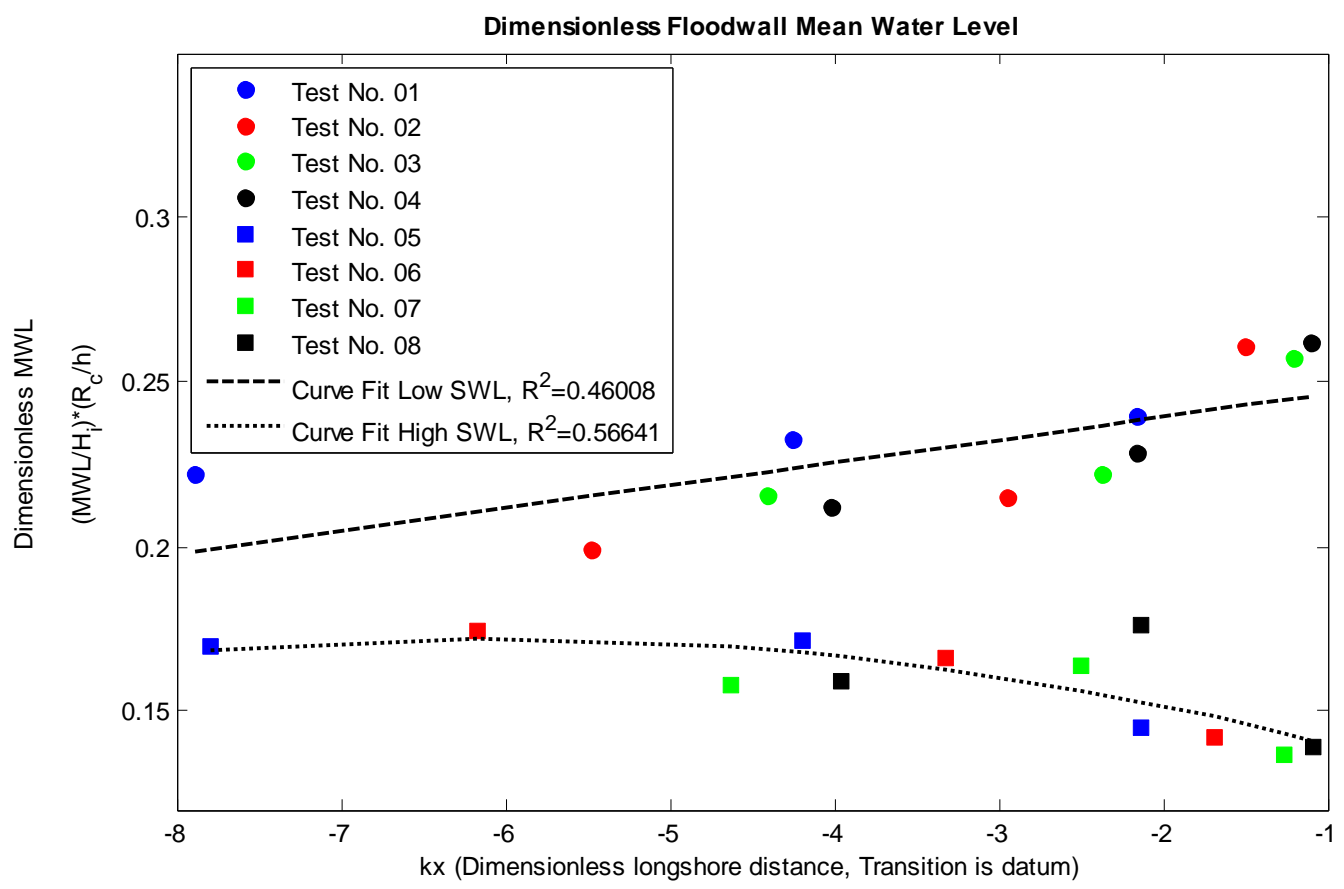

Figure 57. Dimensionless Floodwall MWL, Tuned Scaling.

Comparing the dimensionless runup results of the tuned scaling analysis to the simple scaling analysis in Figure 56, Figure 58 shows that the tuned scaling yielded a more efficient collapse of the data. Of the nearly 1,500 possible values of $\zeta$ tested, the optimized value of the exponent is -0.565 for the dimensionless $2 \%$ Runup and -0.46 for the dimensionless MSP, shown in Figure 58 and Appendix D. The dimensionless 2\% Runup plot showing the results of the tuned scaling analysis omits the values of the higher SWL test. The 2\% Runup values from the high SWL tests are identical and are equal to the elevation of the levee crest. This provides no variance among the tests and produces void data that illustrates no relationship with the variation of the SWL, peak wave period, or incident wave height. 


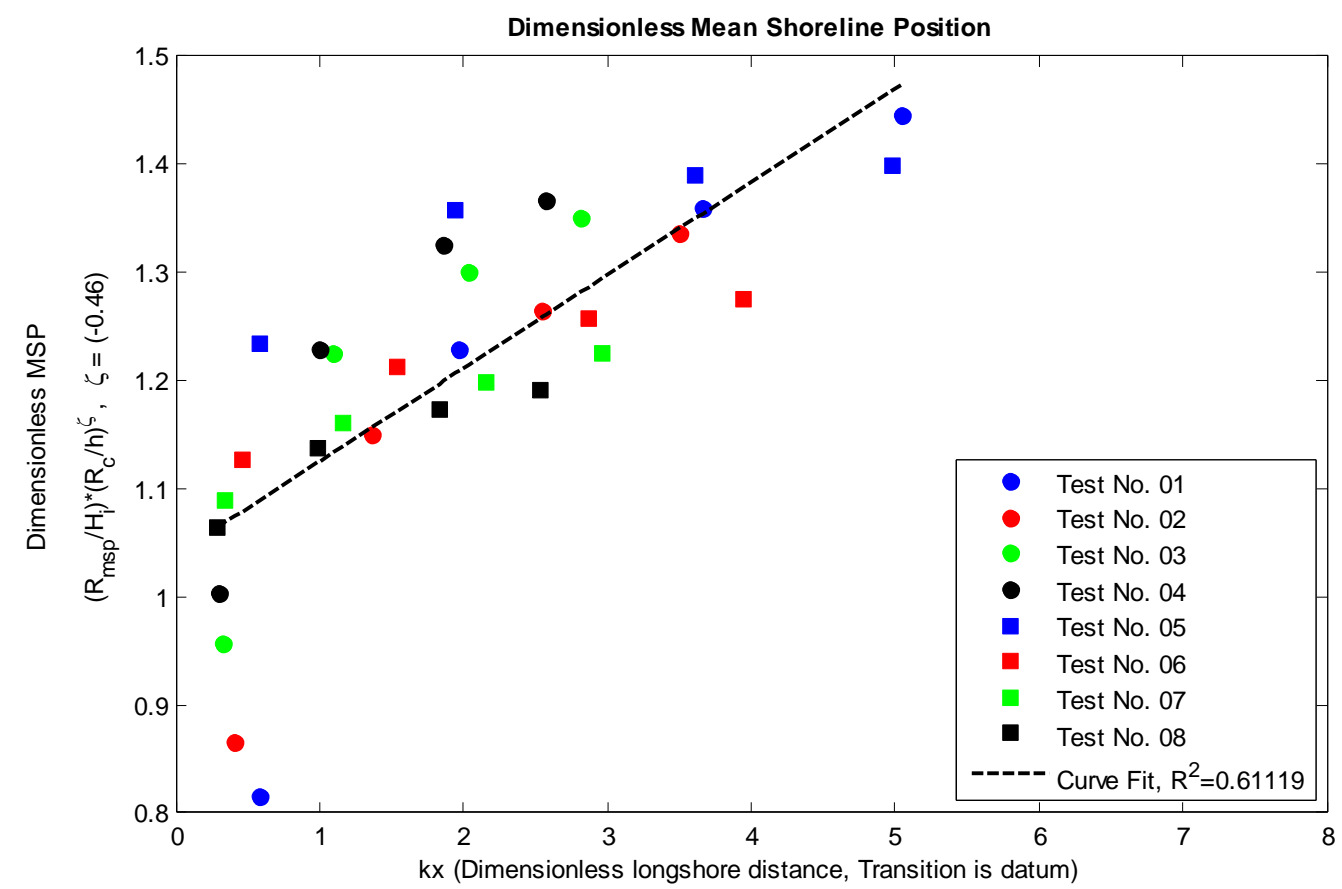

Figure 58. Dimensionless Levee MSP, Tuned Scaling.

Unfortunately, the dimensionless analysis for the resulting data never completely expressed an unmistakable or confident trend in the data; however, the steps taken are necessary to further evaluate the data and to hopefully determine a trend among the results. The literature review provided multiple examples of dimensionless parameters and methodologies, many of which formed the basis of this analysis, especially the simple scaling approach. The most prominent distinction between the analyses executed prior to this research, is the spatial invariability in the tested structure. Most tested structures are considered uniform in the longshore dimension. Omitting this spatial variation enables broader analysis of the effects generated by the hydraulic conditions of the tests and structural geometry of the modeled structure. For most cases, the abscissa axis is a normalized ratio of freeboard to incident spectral wave height $\left(R_{c} / H_{m o}\right)$ (Hughes 
and Nadal, 2008; Stockdon et al., 2006; van Gent, 2002). Placing this ratio on the abscissa axis enables direct comparison to Equations 2.6 and 2.7.

\subsection{Dimensionless Overtopping Rates}

As conducted for the water level values in Section 6.4, the overtopping rates are scaled using the same two scaling methods: simple scaling and tuned scaling. The dimensionless overtopping parameter for the simple scaling analysis is defined as the left-hand-side of Equation 2.6 and 2.7. This parameter is commonly seen throughout the literature review and is used to determine the innate relationship between the overtopping rates and the factors and variables which directly influence its outcome. Accordingly, the dimensionless overtopping parameter, $q$ ', is defined below:

$$
q^{\prime}=\frac{Q}{\sqrt{g H_{i}^{3}}}
$$

where $Q$ is synonymous with the variable $q$ in Equations 2.6 and 2.7, defined as the measured overtopping rate. The overtopping rate is normalized by the square root of the product of gravitational acceleration, $g$, and the cube of the incident wave height measured at the three-gauge array.

The graph presented illustrates the simple scaling analysis conducted on the overtopping rates. From Figure 59, it is immediately evident that the simple scaling does not provide an adequate means of collapsing the overtopping data. It is also apparent that the overtopping data will have to be divided among the floodwall section and levee section, as divided in the graph by the dashed red line. 


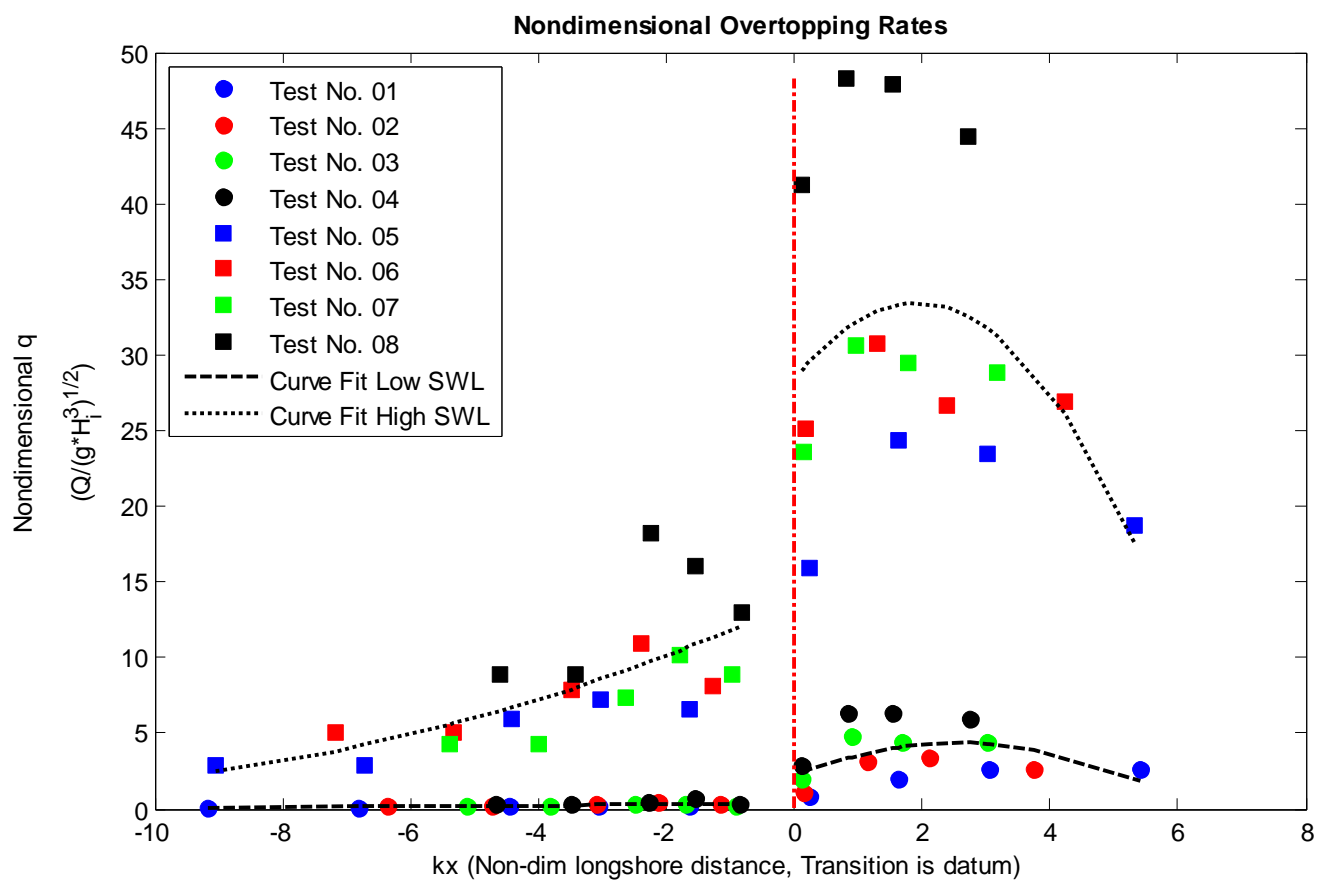

Figure 59. Dimensionless Overtopping Rates, Simple Scaling.

There are several outliers, most of which are created by the most extreme case,

Test No. 08. The overall trends expressed by the plotted values are not simply linear fits; in fact, only the dimensionless floodwall water levels for the lower SWL tests yield a linear least squares fit. The other exhibited fits are quadratic and tend to mimic the dimensional overtopping rates illustrated in Section 6.3. As before, the data is also separated by the different SWLs; in an attempt to negate this differentiation, the tuned scaling analysis is also conducted.

As demonstrated in Equations 6.7 through 6.11, the additional ratio of freeboard to water depth at the toe of the structure is utilized to alleviate the separation induced by the variation of the water depth among the tests. Employing the ratio into the already established dimensionless overtopping rate yields the following relationship: 


$$
q^{t}=\frac{Q}{\sqrt{g H_{i}^{3}}}\left(\frac{R_{c}}{h}\right)^{\zeta}
$$

where, again, the superscript $t$ denotes the tuned scaling analysis, and the exponent $\zeta$ provides the means of optimizing, or 'tuning,' the ratio, generating the most efficient collapse of the data, as detailed in Section 6.4.

Figure 60 depicts the results of the tuned scaling on the floodwall side overtopping rates. The value of $\zeta$ is iteratively calculated to be 4.415 , yielding an $\mathrm{R}^{2}$ value of nearly 0.40 . The quadratic least squares fit provides the general fit to the data, expressing an overall increase in the dimensionless parameter towards the transition, conveying that the overtopping generally increases towards the transition. Figure 61 provides the results of the dimensionless overtopping rates on the levee side. These values did not collapse as well as the floodwall overtopping rates, but they did maintain the overall parabolic trend. With $\zeta$ equaling 2.81 and an $\mathrm{R}^{2}$ value of only 0.18 , the plot can only confidently suggest a parabolic tendency along the levee section, denoting that the maximum overtopping generally occurs around $k x=2$. As before, the dimensionless analysis did not provide enough conclusive evidence to generate a confident expression relating the hydraulic and geometric parameters of the test to the experienced overtopping rates along the levee transition structure. There are many variables influencing the experienced overtopping rates, which make the task of dimensionless analysis all the more demanding. 


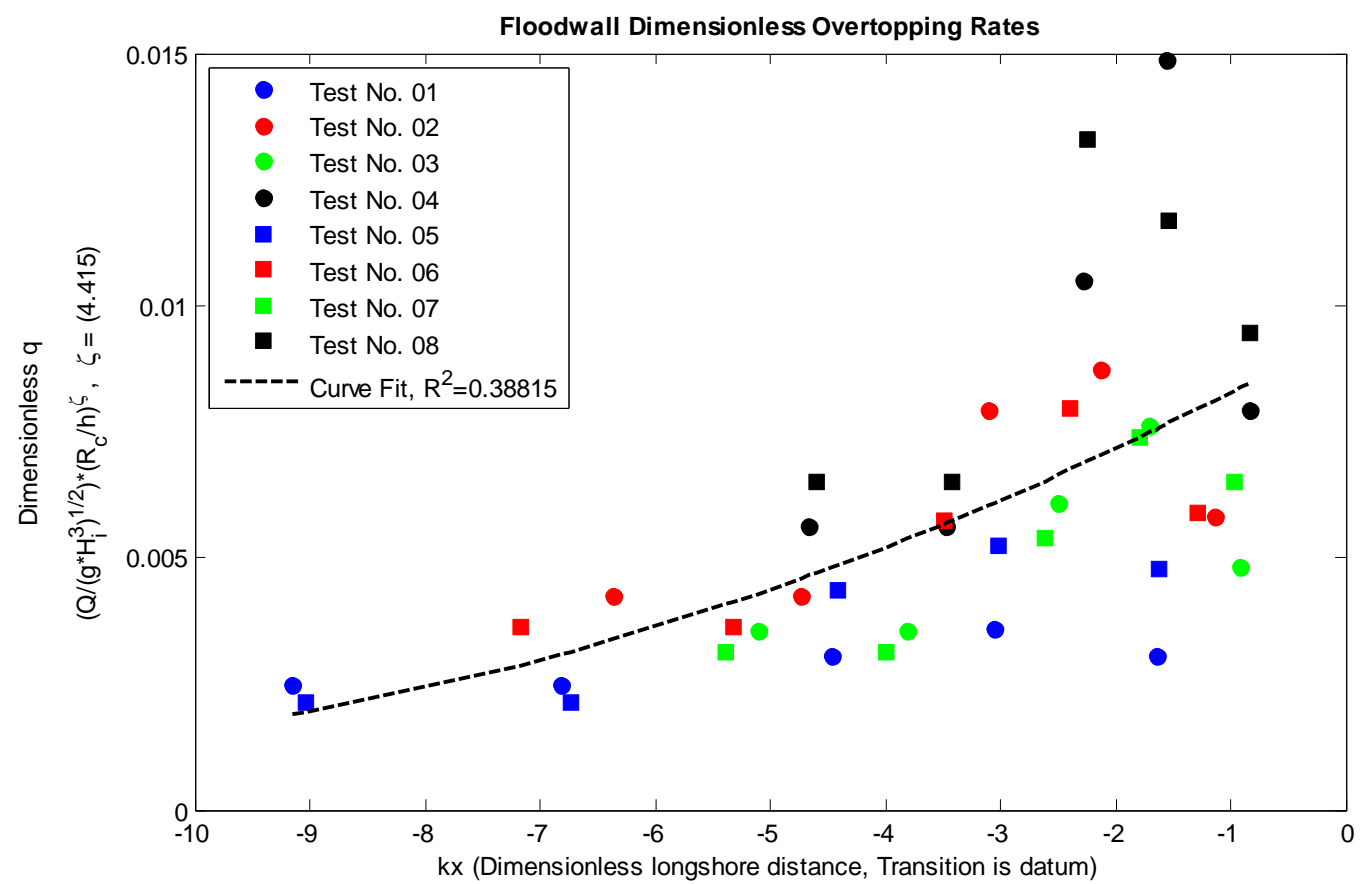

Figure 60. Dimensionless Floodwall Overtopping Rates, Tuned Scaling.

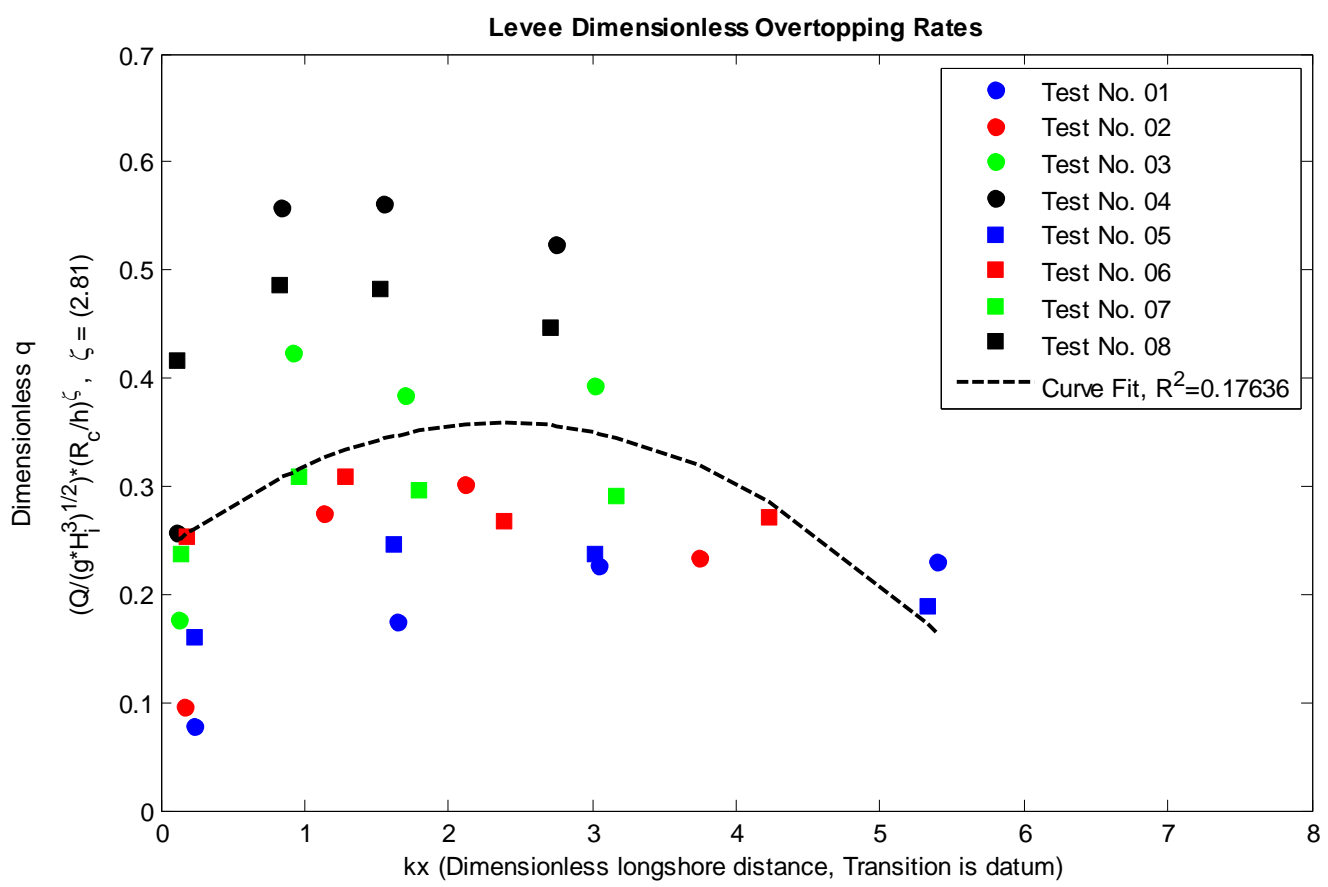

Figure 61. Dimensionless Levee Overtopping Rates, Tuned Scaling. 


\section{SUMMARY AND CONCLUSIONS}

The research presented herein outlines the evaluation and assessment of a specific levee transition structure tested under extreme design conditions. Tests varied hydraulic conditions such as incident wave period, incident wave height, and still water level. Response of the structure was investigated within a three-dimensional shallow water wave basin stationed within the Reta and Bill Haynes '46 Coastal Engineering Laboratory at Texas A\&M University, College Station, Texas. The testing facility enabled accurate and consistent testing in a controlled environment. The results of the testing were analyzed both dimensionally and non-dimensionally to fully understand and grasp the mechanisms contributing to the measured floodwall wave heights, levee runup, and overtopping rate distribution along the levee transition structure. From the results, there is overwhelming evidence that the methodologies employed to estimate the overtopping rates on the levee transition vastly underestimate the experienced and measured values. These values are mimicked by the results of the floodwall wave heights and levee runup values and definite trends are observed and addressed. The observed trends indicate spatial variability among the measured values along the levee transition caused by inherent three-dimensional effects, such as experienced undertows generated by the levee transition contours, which would otherwise be unnoticed without three-dimensional physical modeling. For the tests undergone at the laboratory, the most influential parameter for the overtopping rates and water levels measured at the structure was the variation in the SWL. Longer peak periods also resulted in higher overtopping rates and water level values at the structure. Measured overtopping rates exceeded 300 
$1 / \mathrm{s} / \mathrm{m}$ on the levee section of the structure and $100 \mathrm{l} / \mathrm{s} / \mathrm{m}$ on the floodwall section for the extreme hydraulic conditions, all of which were underestimated by existing empirical methods. Floodwall wave heights were measured up to 4-5 m above the floodwall crest elevation and wave induced setups allowed mean water levels to essentially equal the height of the structure. Overall, the measured values were substantial, and would ultimately require the structure to be well protected against the intrinsic erosion effects induced by the hydraulic conditions.

From this research, the necessity of further detailed investigations and evaluations, beyond traditional empirical formulae, on spatially variable coastal protective structures is apparent. It is also apparent through the extensive efforts exhibited during the course of this study that expeditious empirical equations are just as necessary. It is evident by the literature review that the consequential costs of not protecting developed coastal regions and infrastructures far exceeds the price of providing sufficient protection. Coastal protective structures are necessary to defend the forces of the ocean and high water levels and provide safeguard against otherwise inevitable devastation. Therefore, it is also necessary to continue with further analysis of these coastal protective structures; a few topics for future evaluation include:

- Testing of oblique waves, especially toward the levee side to observe runup directly on the contoured transition

- Increase number of wave gauges to increase the resolution of the variability along the levee transition

- Calculation of velocities along backside of the levee and floodwall 
- Creation of a more extensive data set by more testing, specifically tests which do not produce such extreme overtopping rates

- Testing both the floodwall section and levee section separately in a 2D wave flume to provide baseline overtopping rates and water level data to normalize measured values 


\section{REFERENCES}

Crossett, K.M., Culliton, T.J., Wiley, P.C., Goodspeed, T.R., 2005. Population trends along the coastal United States: 1980-2004. In: Coastal Trends Report Series. NOAA's National Ocean Service Management and Budget Office. Special Projects.

Dean, R.G., Rosati, J.D., Walton, T.L., Edge, B.L., 2009. Erosional equivalences of levees: Steady and intermittent wave overtopping. Ocean Engr., vol. 37. Elsevier, pp. 104-113.

Ebersole, B.A.,Westerwink, J.J.,Bunya, S., Dietrich, J.C., Cialone, M.A., 2009. Development of storm surge which led to flooding in St. Bernard Polder during Hurricane Katrina. Ocean Engr., vol. 37. Elsevier, pp. 91-103.

HR Wallingford Ltd., 2007. "Wave overtopping calculation tool." European Overtopping Manual. Web. 15 Aug. 2009.

<http://www.overtopping-manual.com/calculation_tool.html>.

Hughes, S. A., 1993 Physical models and laboratory techniques in coastal engineering. World Scientific. Singapore. Print.

Hughes, S.A., 2008. Levee overtopping design guidance: What we know and what we need. Solutions to Coastal Disasters, vol. 78. American Society of Civil Engineers, pp. 867-877.

Hughes, S.A., Nadal, N.C., 2008. Laboratory study of combined wave overtopping and storm surge overflow of a levee. J. Coastal Engr., vol. 56. Elsevier, pp. 244-259. 
Interagency Performance Evaluation Taskforce (IPET), 2007. Performance evaluation of the New Orleans and Southeast Louisiana Hurricane Protection System. In: Final Rep., Vol. 5. The performance - levees and floodwalls, U.S. Army Corps of Engineers.

Kobayashi, N., Wurjanto, A., 1989. Wave overtopping on coastal structures. Journal of Waterway, Port, Coastal, and Ocean Engineering, vol. 115. American Society of Civil Engineers, pp. 235-251.

Link, L. E., 2009. The anatomy of a disaster, an overview of Hurricane Katrina and New Orleans. Ocean Engr., vol. 37. Elsevier, pp.4-12.

Lynett, P.J., Melby, J.A., Kim, D., 2009. An application of Boussinesq modeling to hurricane wave overtopping and inundation. Ocean Engr., vol. 37. Elsevier, pp. 135153.

Mansard, E.P.D., Funke, E.R., 1980. The measurement of incident and reflected spectra using a least squares method. Proc. $17^{\text {th }}$ Coastal Engr. Conf.. ASCE, Sidney, pp. 154172.

Mori, N., 2009. "MACE Toolbox.” MatLab® Toolbox for Coastal Engineers. Web. 30 Jan. 2009. < http://www.oceanwave.jp/softwares/mace/>.

National Oceanic and Atmospheric Administration (NOAA), 2004. Economic statistics for NOAA. U.S. Department of Congress, Third Ed.

Nicholson, P.G., 2007. Preliminary reconnaissance and observations of the New Orleans levee and floodwall failures by independent assessment teams. Proc. of Geo-Denver 2007: New Peaks in Geotechnics Conf., Geotechnical Specialty Publications: 
Embankments, Dams, and Slopes, vol. 13. American Society of Civil Engineers, pp. 224-233.

Pullen, T., Allsop, N.W.H., Burce, T., Kortenhaus, A., Schüttrumpf, H., van der Meer, J.W., 2007. EurOtop: Wave overtopping of sea defences and related structures: Assessment Manual. <www.overtopping-manual.com>.

Schüttrumpf, H., van Gent, M.R.A., 2003. Wave overtopping at seadikes. Proc. of Coastal Structure Conf. ASCE, pp. 431-443.

Sorensen, R.M., 2006. Basic Coastal Engineering, Third Edition. Springer Science. New York, NY. Print.

Sills, G. L., Vroman, N. D., Wahl, R. E., Schwanz, N. T., 2008. Overview of New Orleans levee failures: lessons learned and their impact on national levee design and assessment. J. Geotech. Geoenv. Engr., vol. 134. American Society of Civil Engineers, pp. 556-565.

Stockdon, H.F., Holman, R.A., Howd, P.A., Sallenger Jr., A.H., 2006. Empirical parameterization of setup, swash, and runup. J. Coastal Engr., vol. 53. Elsevier, pp. 573-588.

TAW, 2002. Technical Report - Wave run-up and wave overtopping at dikes. Technical Advisory Committee for Flood Defence in the Netherlands (TAW), Delft, The Netherlands.

van der Meer, J.W., Janssen, W., 1995. Wave run-up and wave overtopping at dikes. In: Kobayashi, Demirbilek (Eds.), Wave Forces on Inclined and Vertical Wall Structures. American Society of Civil Engineers. New York, NY. pp. 1-27. 
van der Meer, J.W., Bernardini, P., Snijders, W., Regeling, E., 2006. The wave overtopping simulator. Proc. of $30^{\text {th }}$ Intern. Conf. on Coastal Engr., vol. 5. World Scientific, pp. 4654-4666.

van der Meer, J.W., Steendam, G.J., de Raat, G., Bernardini, P., 2009. Further developments on the wave overtopping simulator. Proc. of $31^{\text {st }}$ Intern. Conf. on Coastal Engr. World Scientific, pp. 2957-2969.

van Gent, M.R.A., 2001. Wave runup on dikes with shallow foreshores. Journal of Waterway, Port, Coastal, and Ocean Engineering, vol. 127. American Society of Civil Engineers, pp. 254-262.

van Gent, M.R.A., 2002. Coastal flooding initiated by wave overtopping at sea defences. Proc. of Coastal Disasters Conf. American Society of Civil Engineers, pp. 223-237. 
APPENDIX A

\section{LEVEE AND FLOODWALL CONFIGURATIONS AND FAILURES}




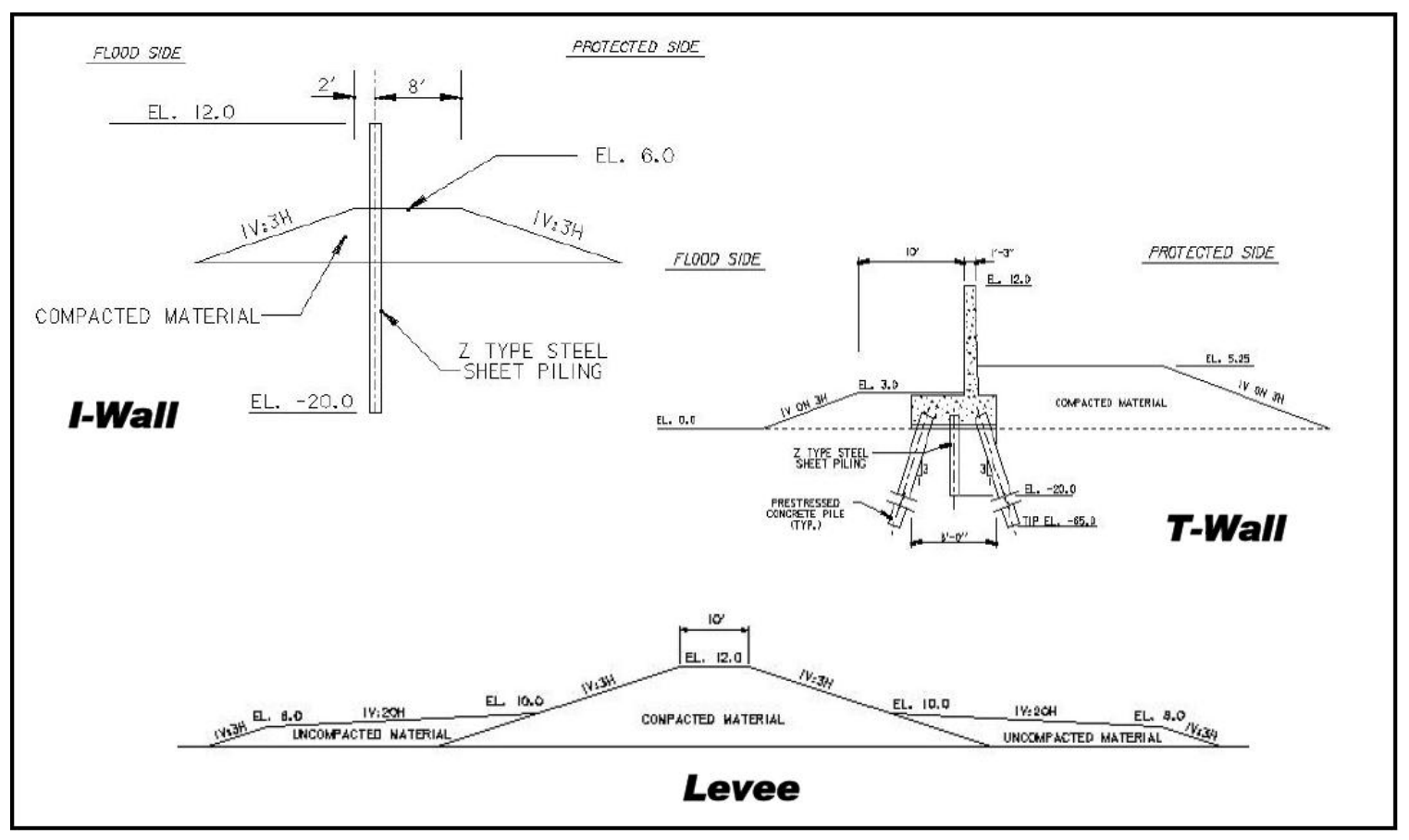

A-1. Example of HPS levee, I-Wall floodwall, and T-Wall floodwall (IPET, 2007).

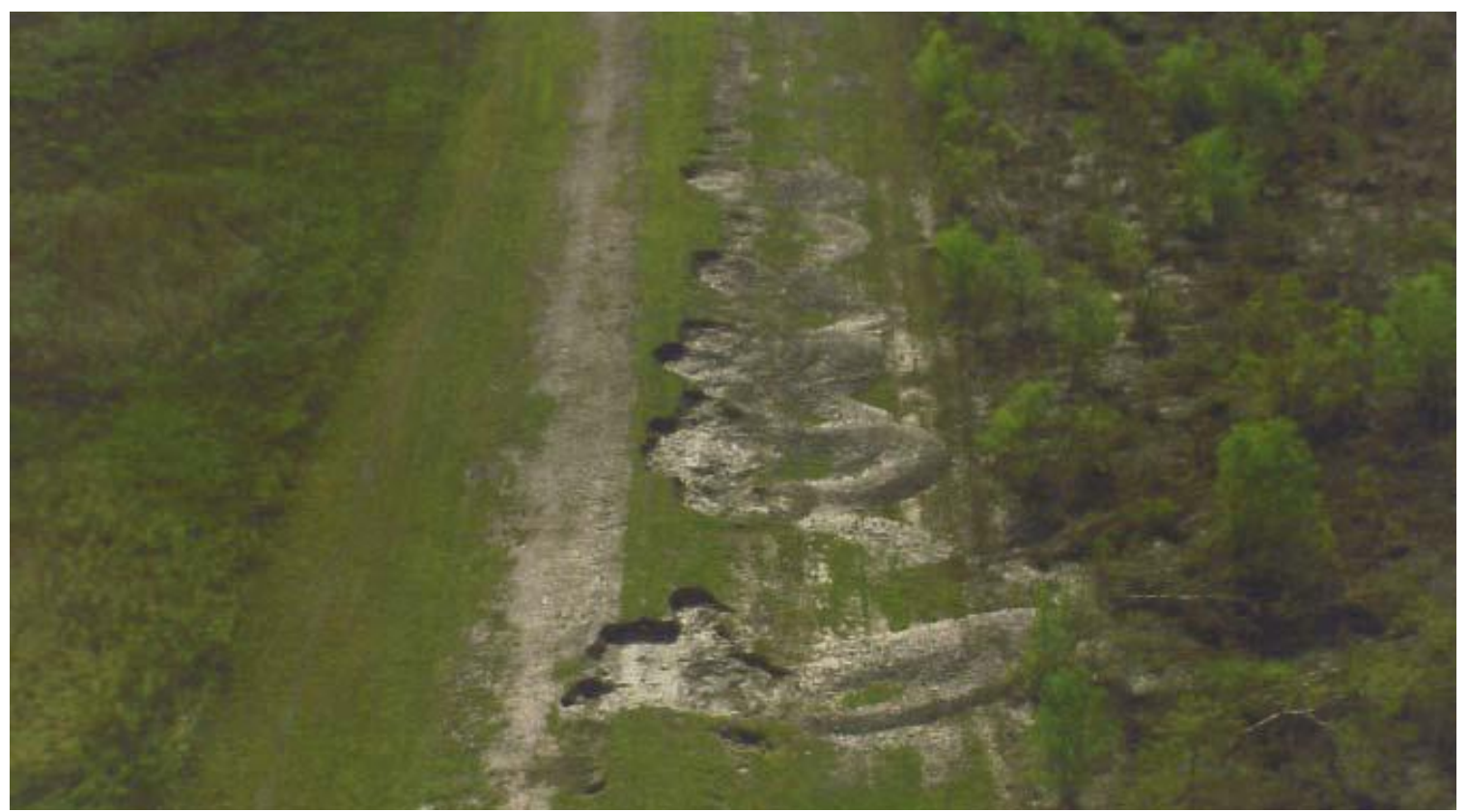

A-2. Example of overtopping-induced protected-side erosion on levee (IPET, 2007). 


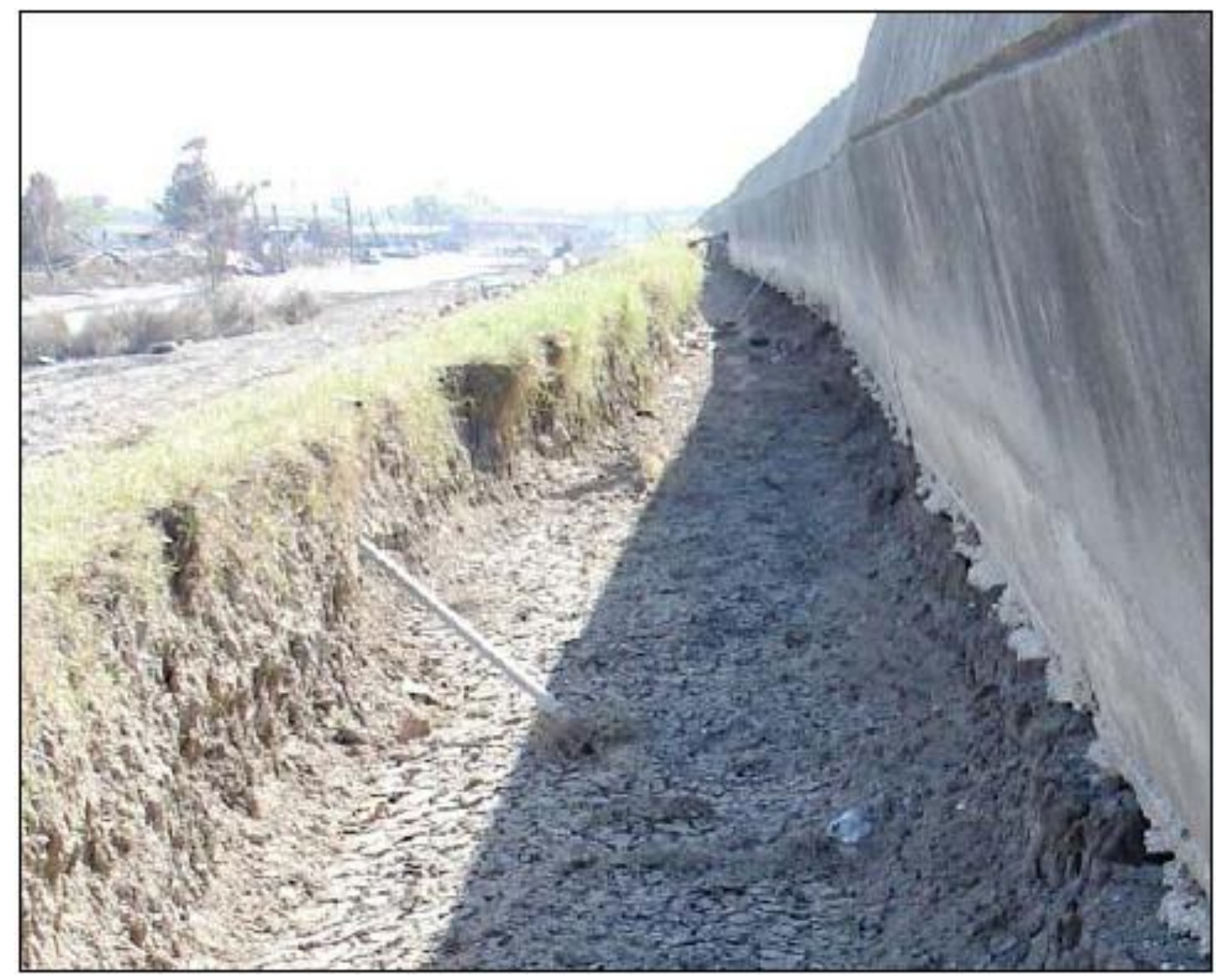

A-3. Backside floodwall erosion and tilting due to overtopping (IPET, 2007). 
APPENDIX B

PHYSICAL MODEL PICTURES 


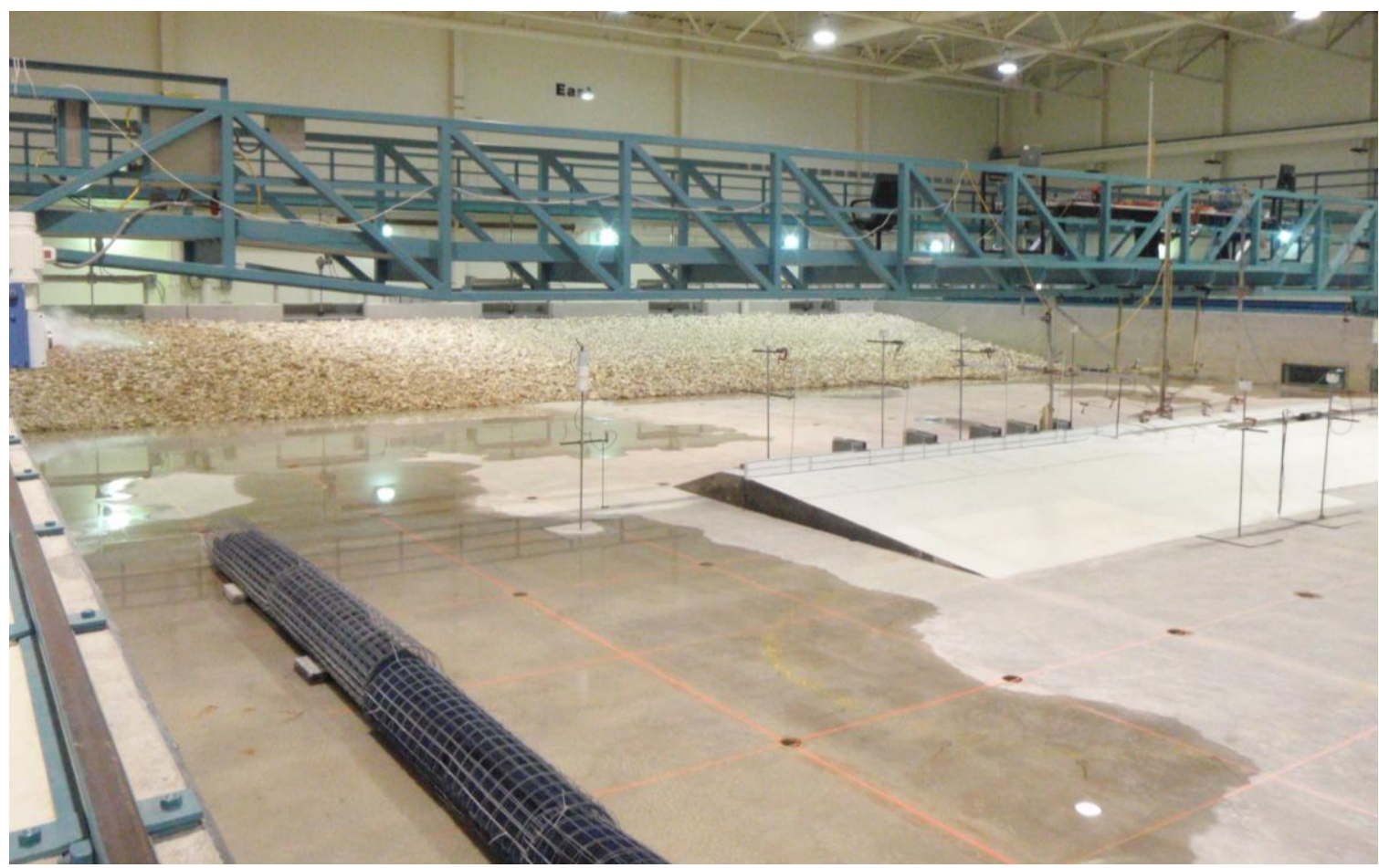

B-1. Floodwall side of modeled levee transition and sidewall absorbers during filling of basin.

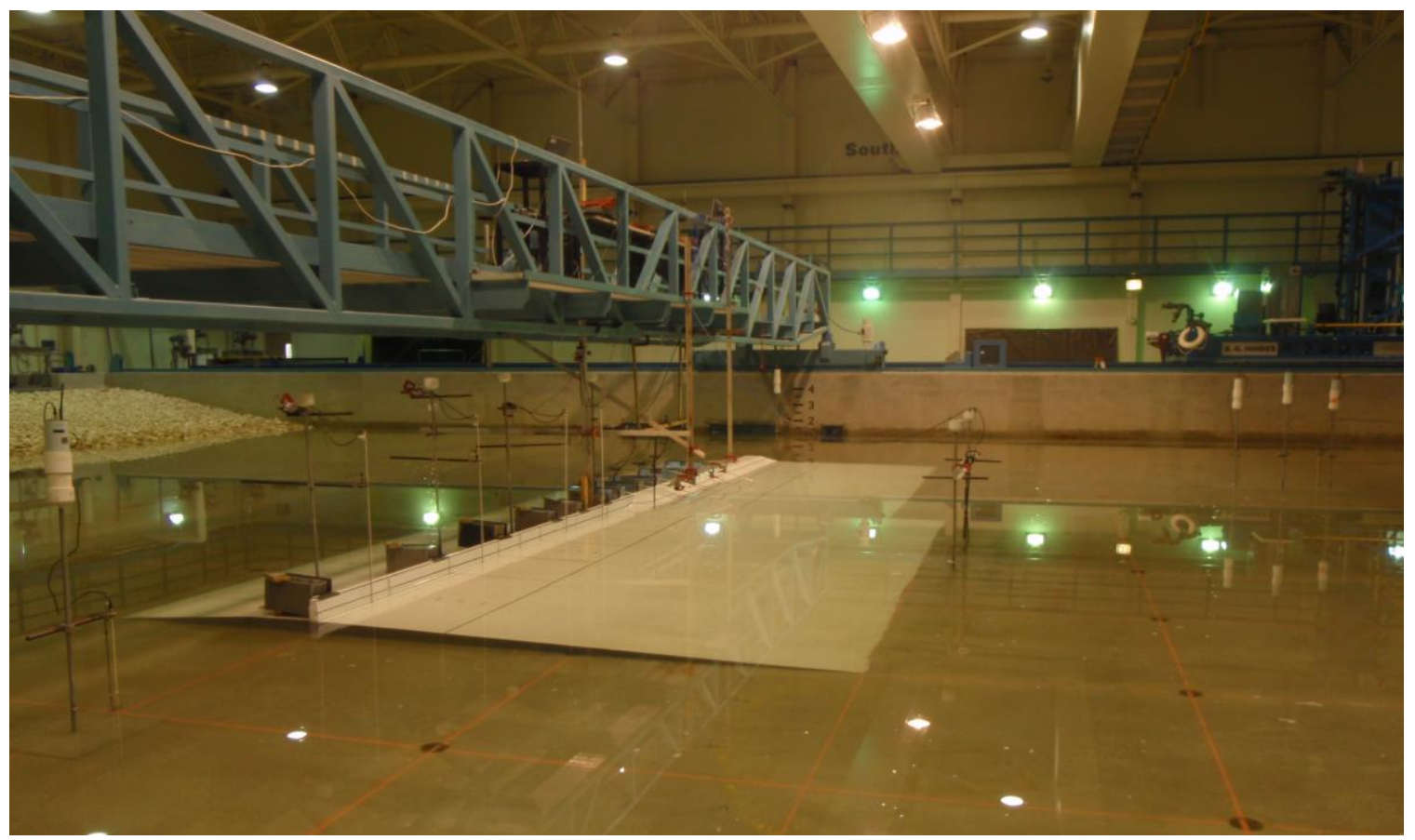

B-2. Floodwall side of modeled levee transition at high SWL. 


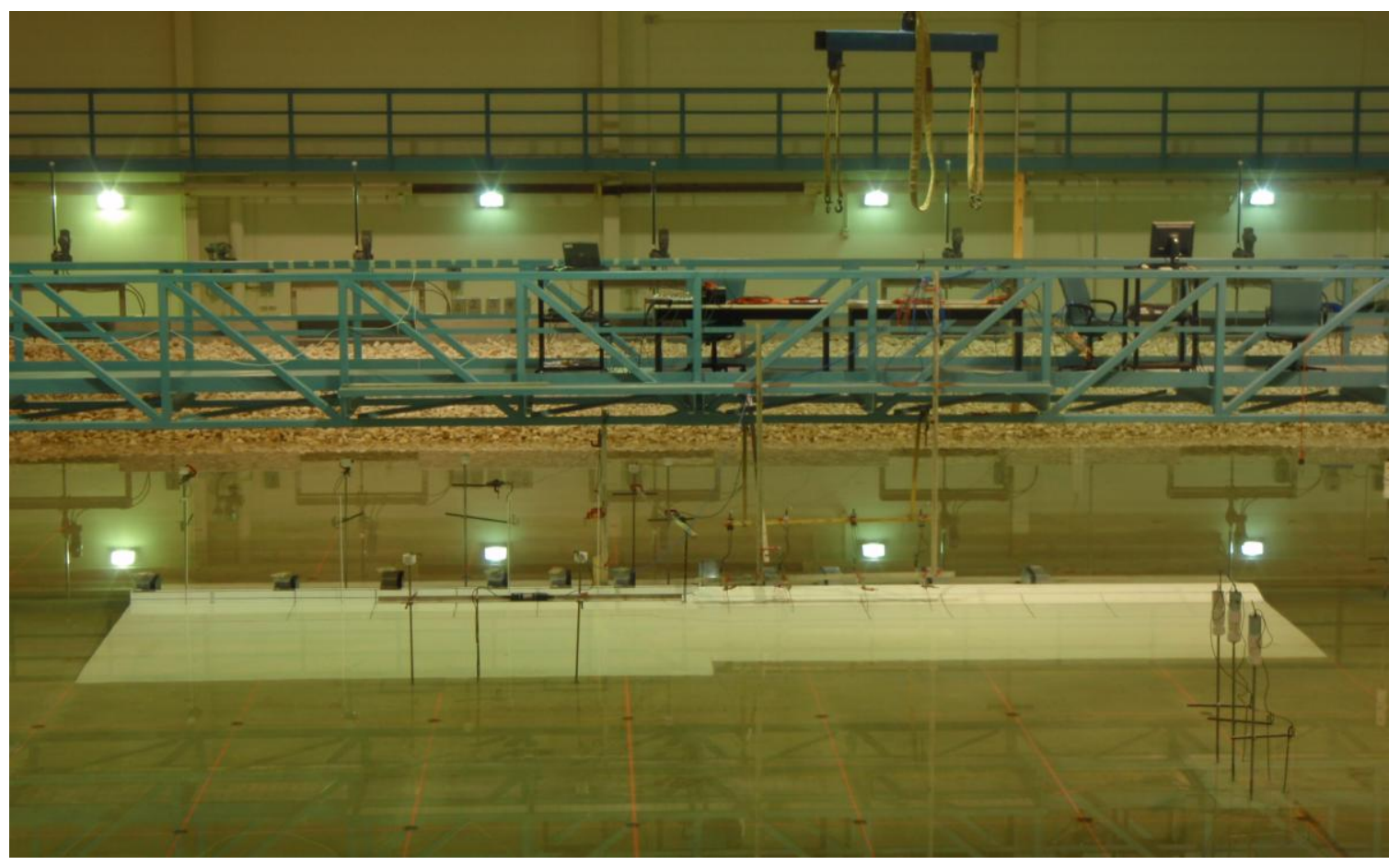

B-3. Front view of modeled levee transition at high SWL.

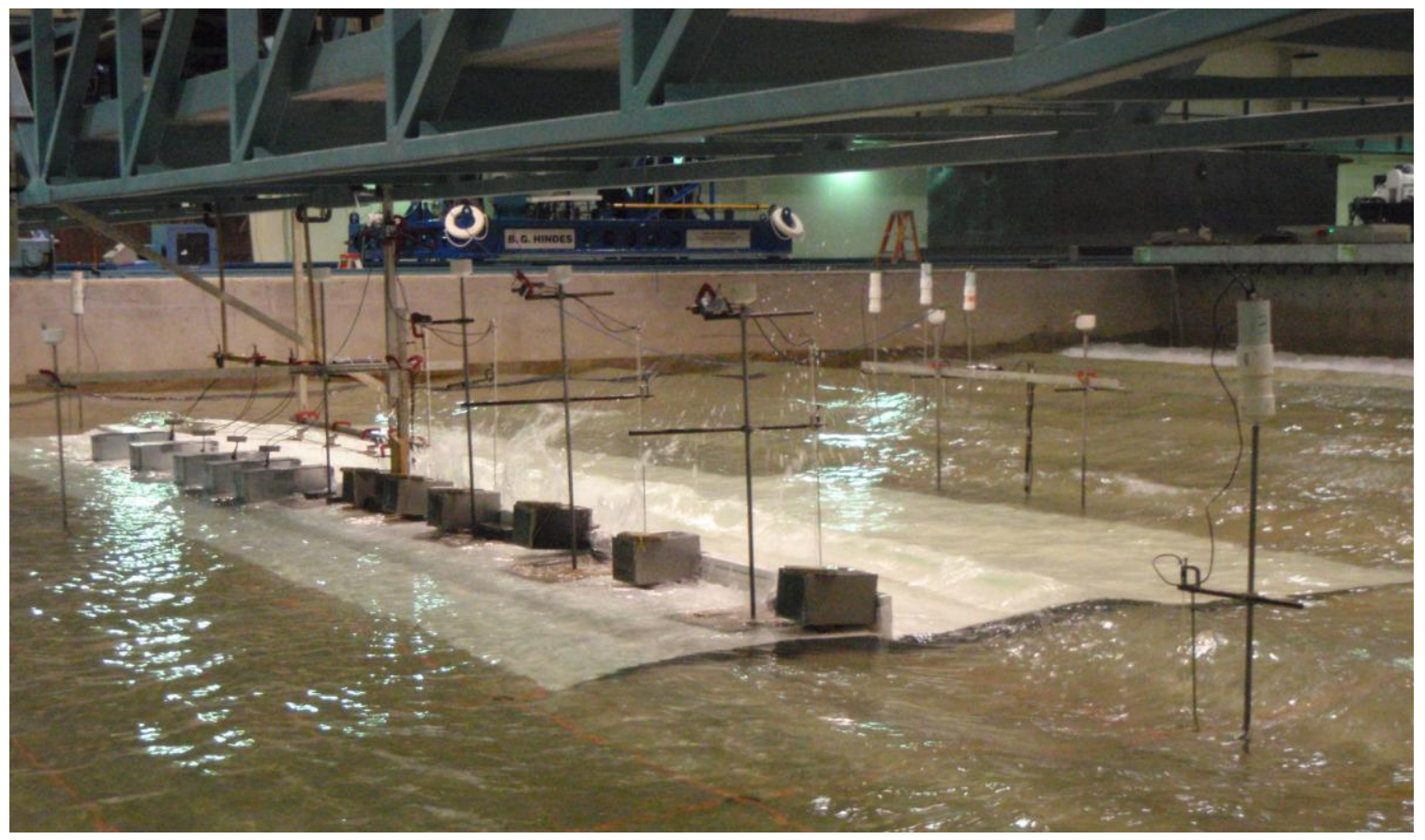

B-4. Backside of floodwall section during Test No. 05. 


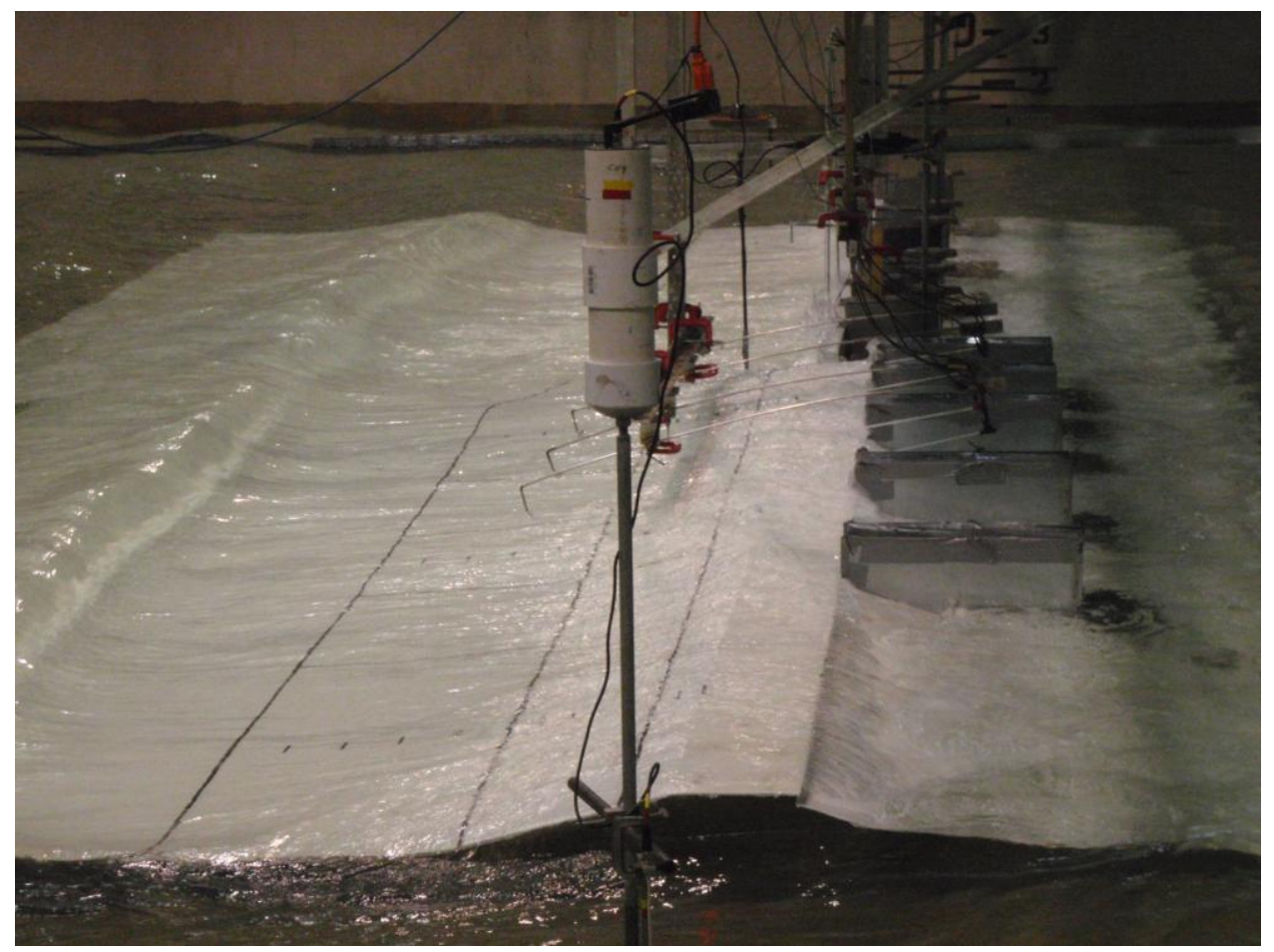

B-5. Levee side view of overtopping during Test No. 05.

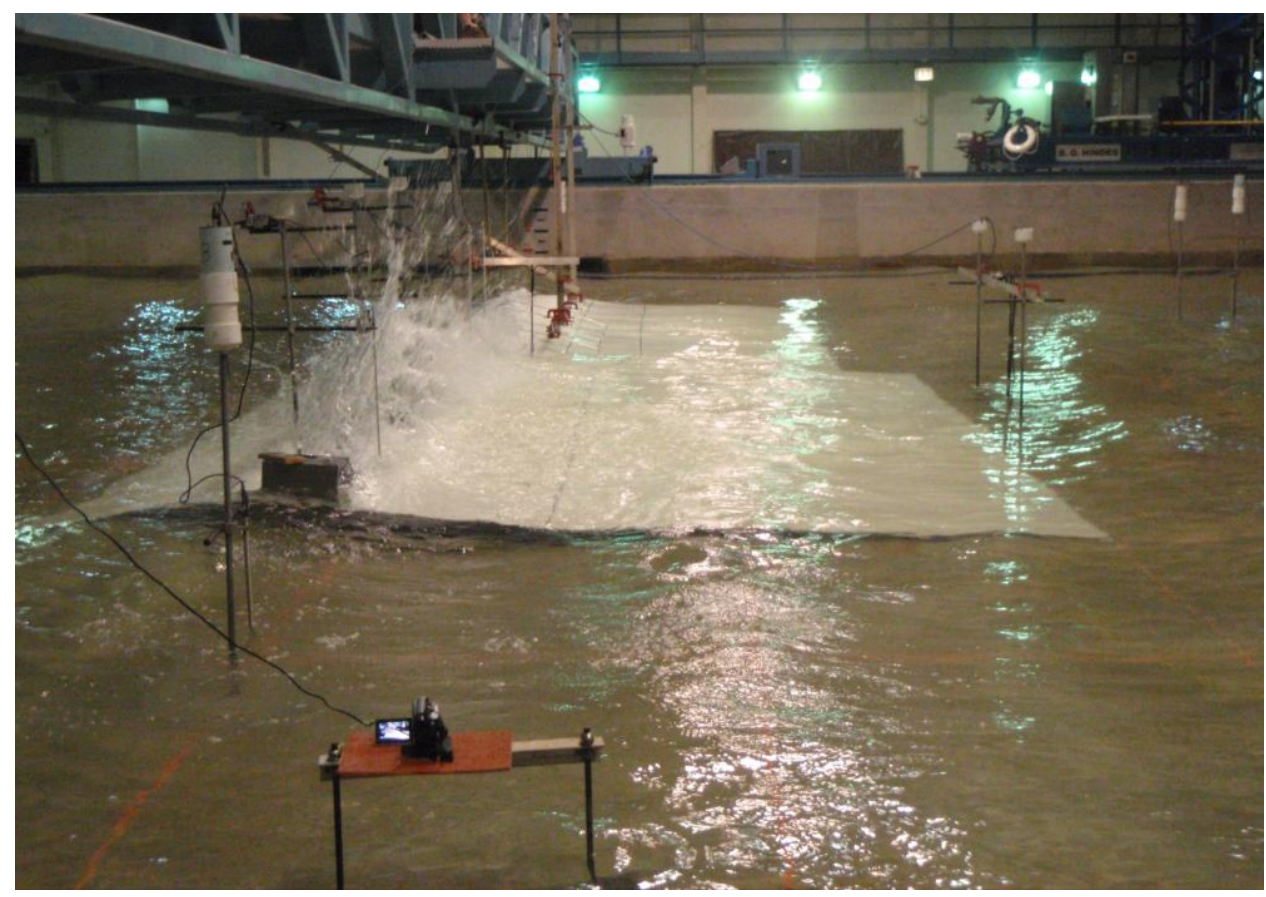

B-6. Floodwall side of modeled levee transition during Test No. 08. 


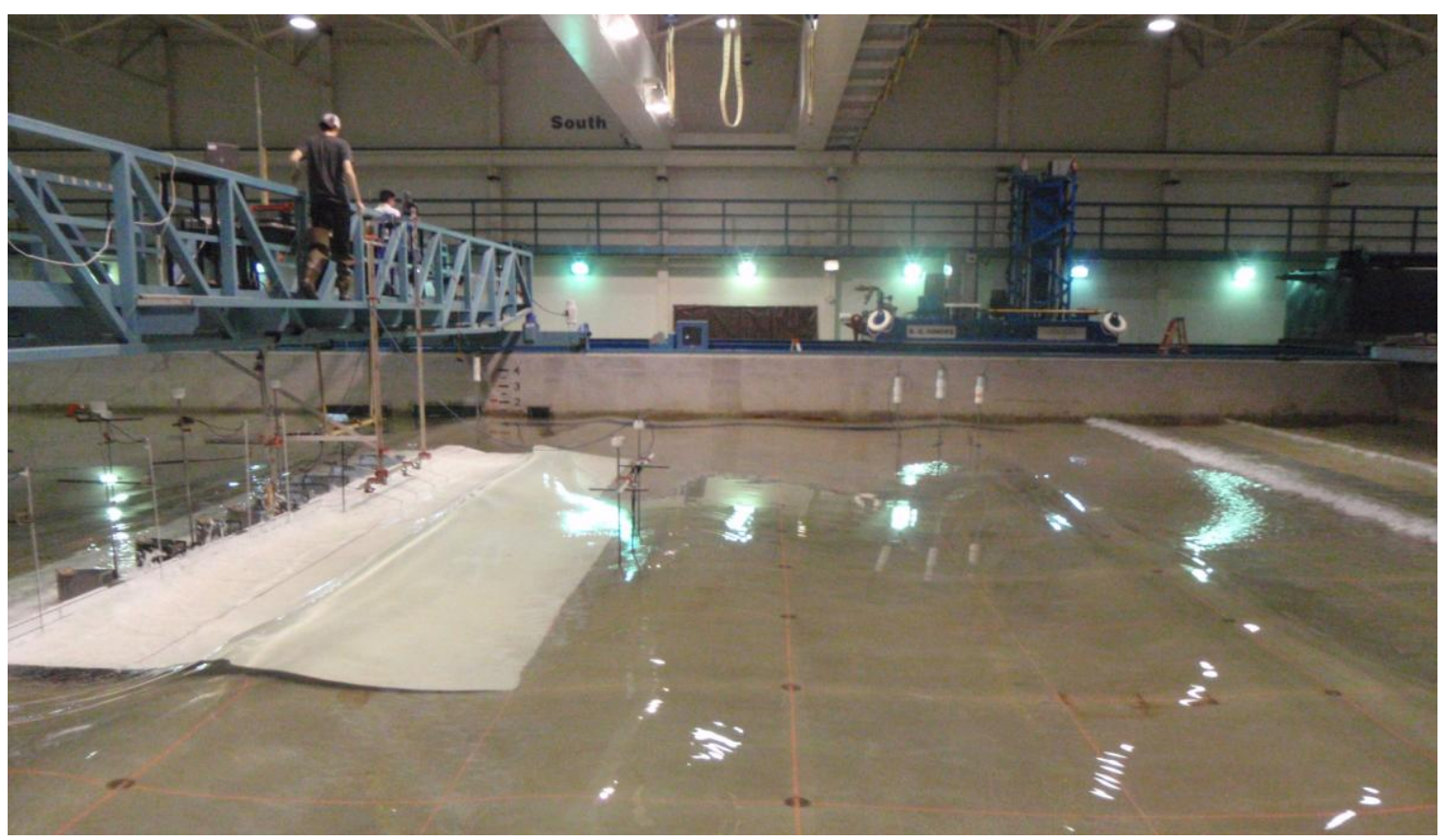

B-7. Wave train from wave generator, Test No. 07. Note the model effects (refraction) on model ends.

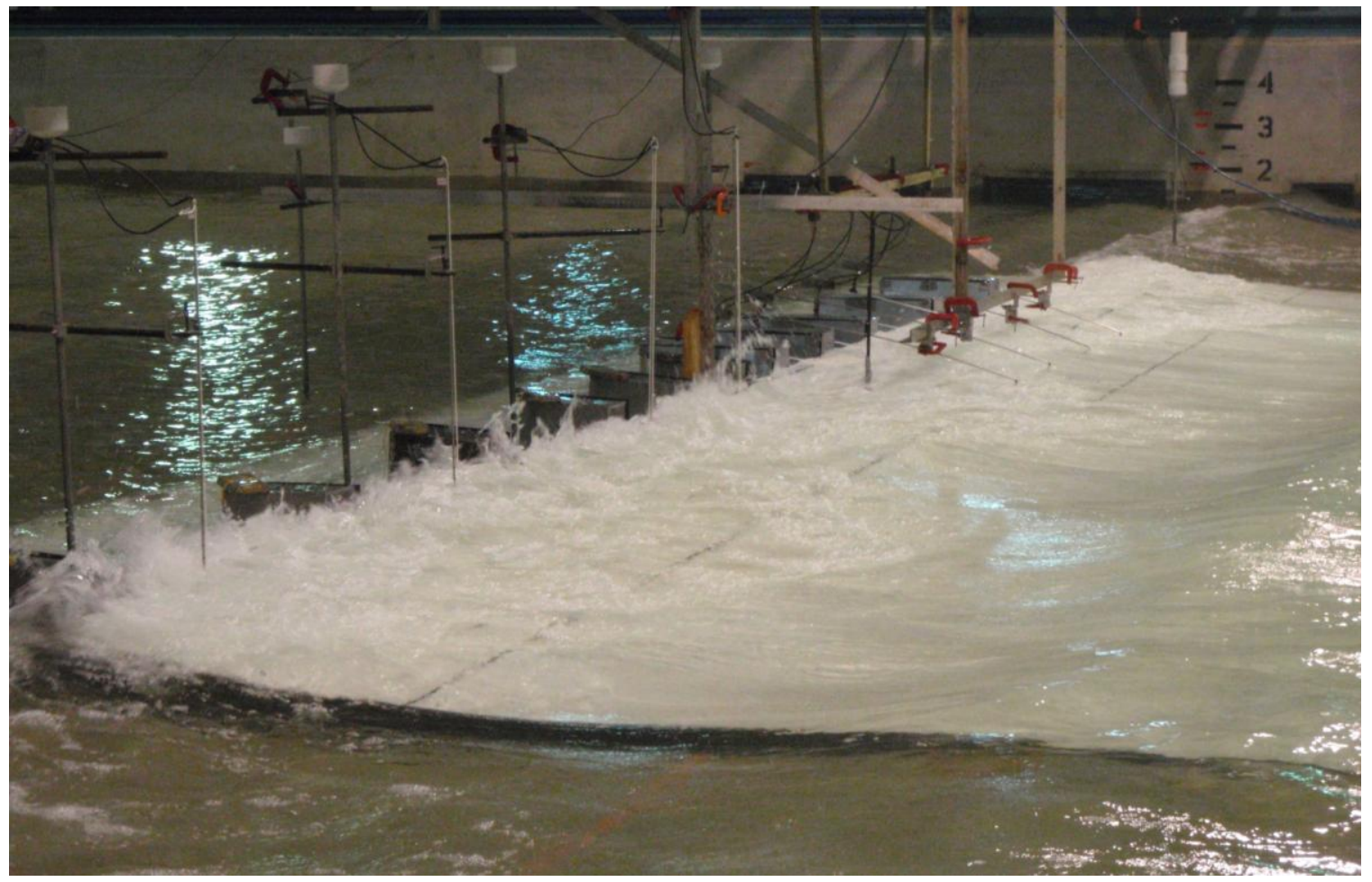

B-8. Floodwall overtopping, Test No. 05. 
APPENDIX C

RESULTING EXPERIMENTAL PLOTS 

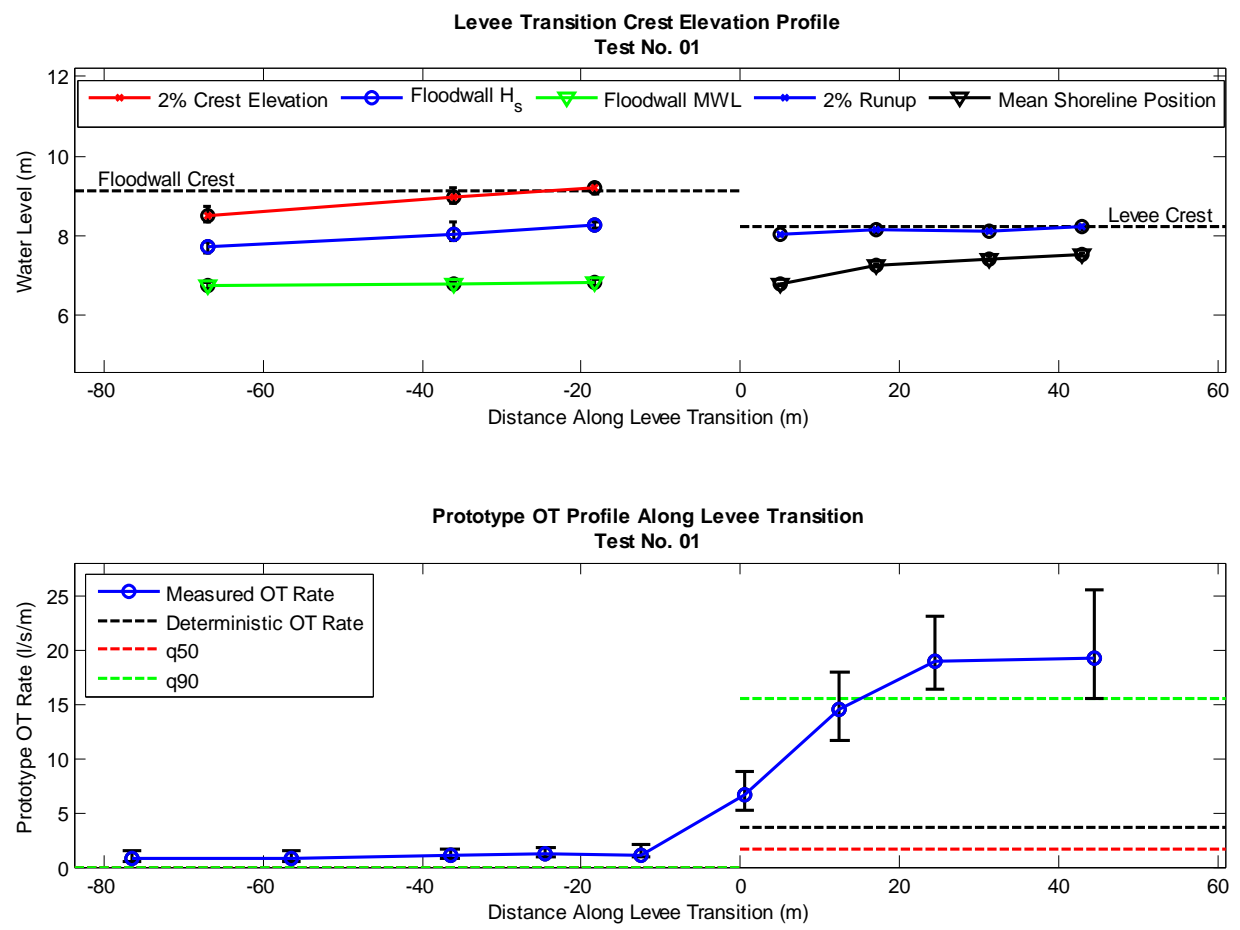

C-1. Prototype Results from Test No. 01
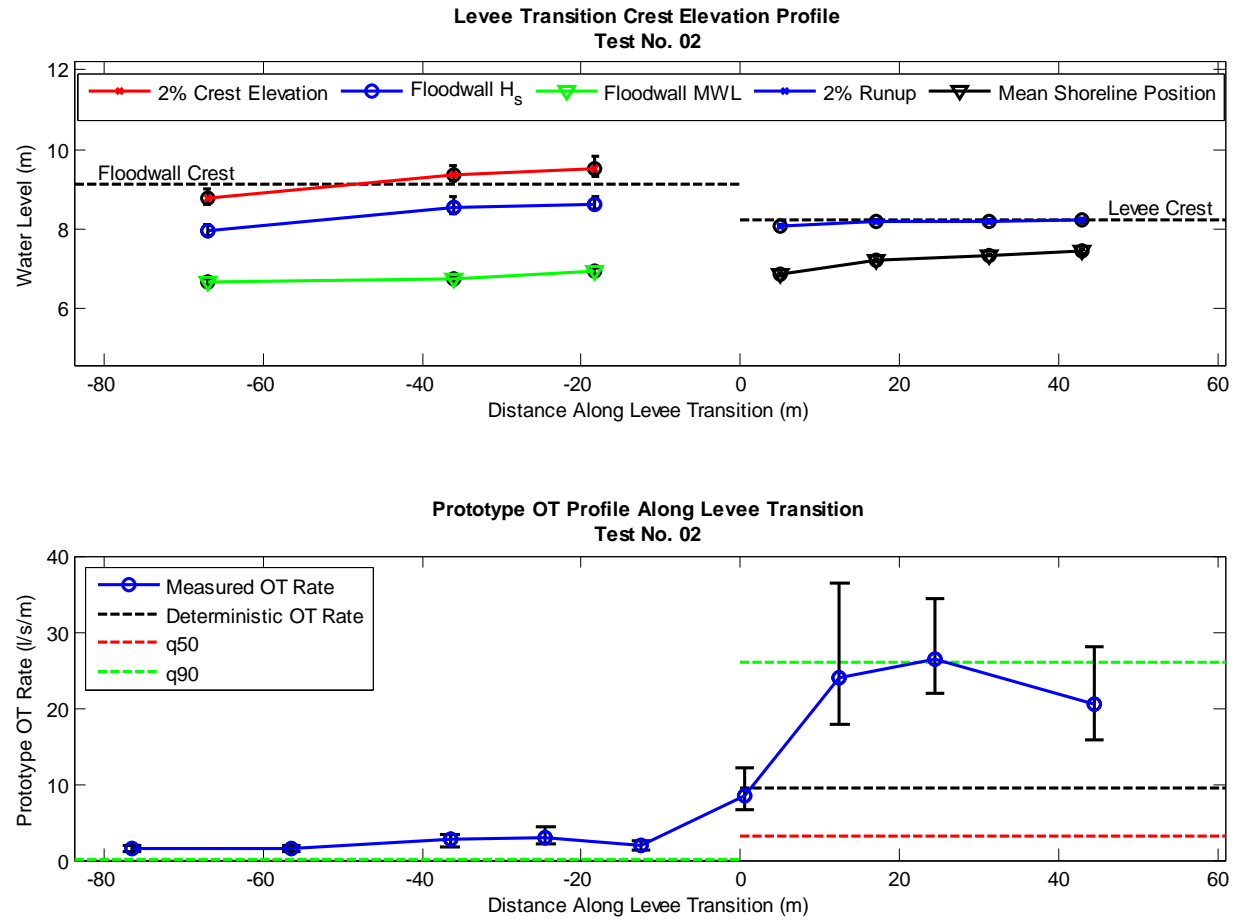

C-2. Prototype Results from Test No. 02 

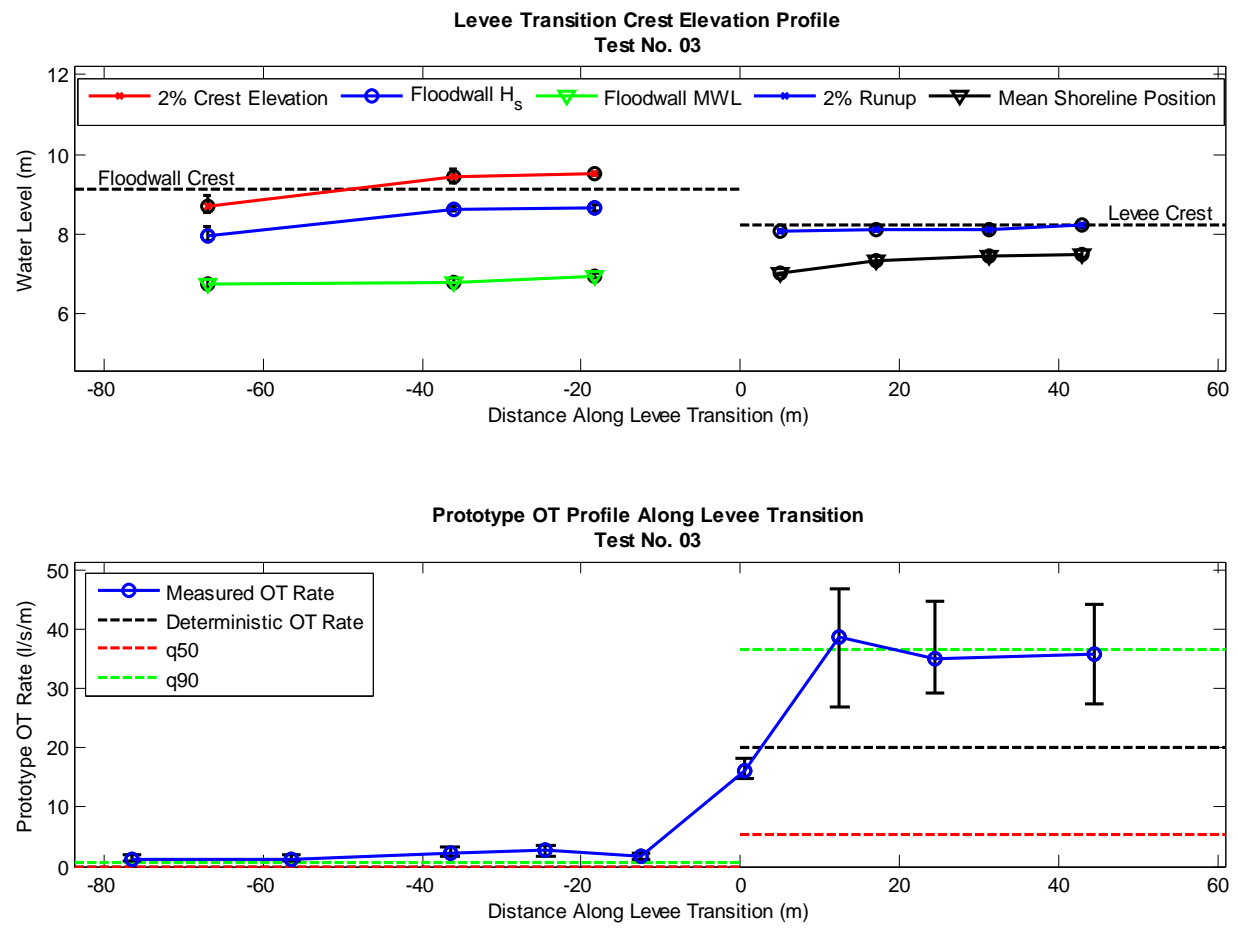

C-3. Prototype Results from Test No. 03
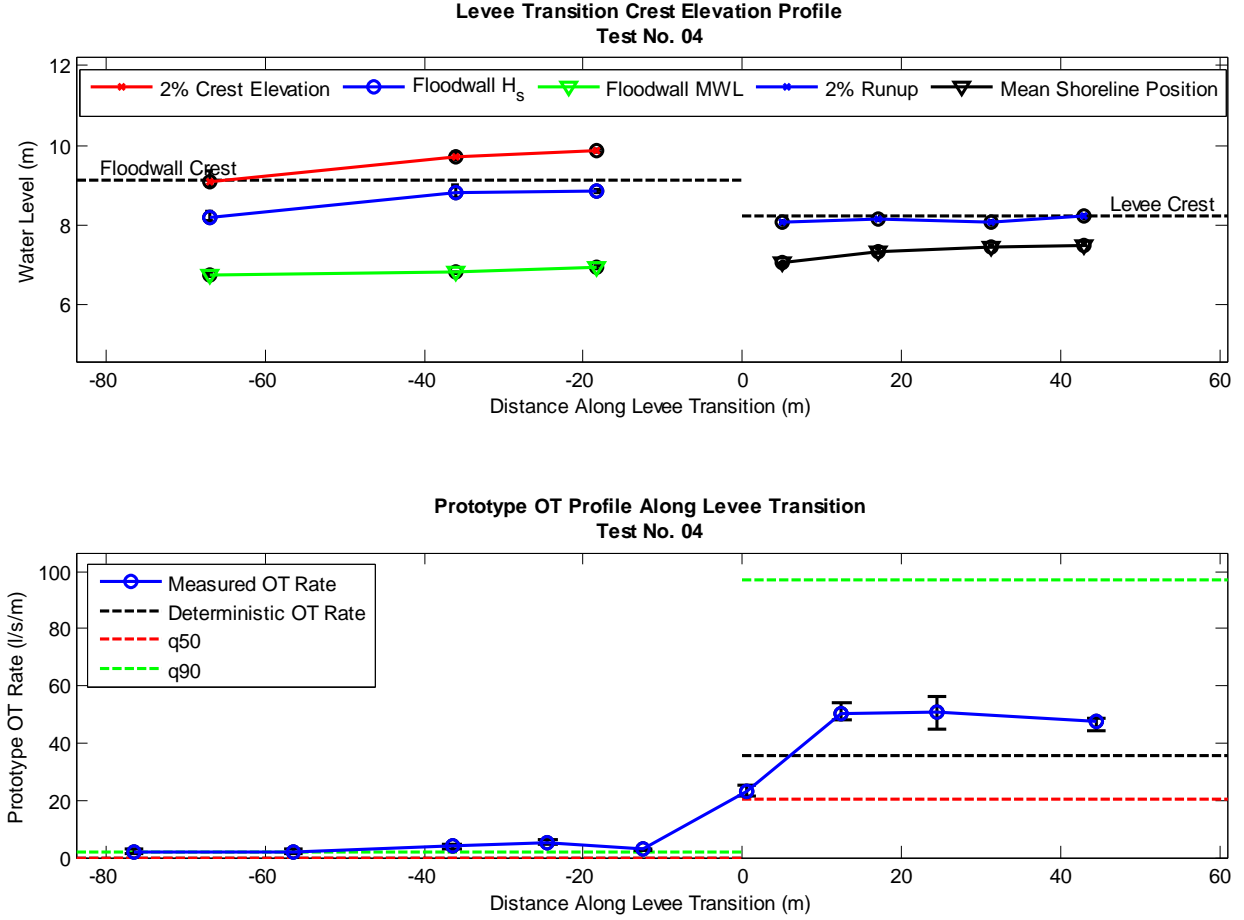

C-4. Prototype Results from Test No. 04 

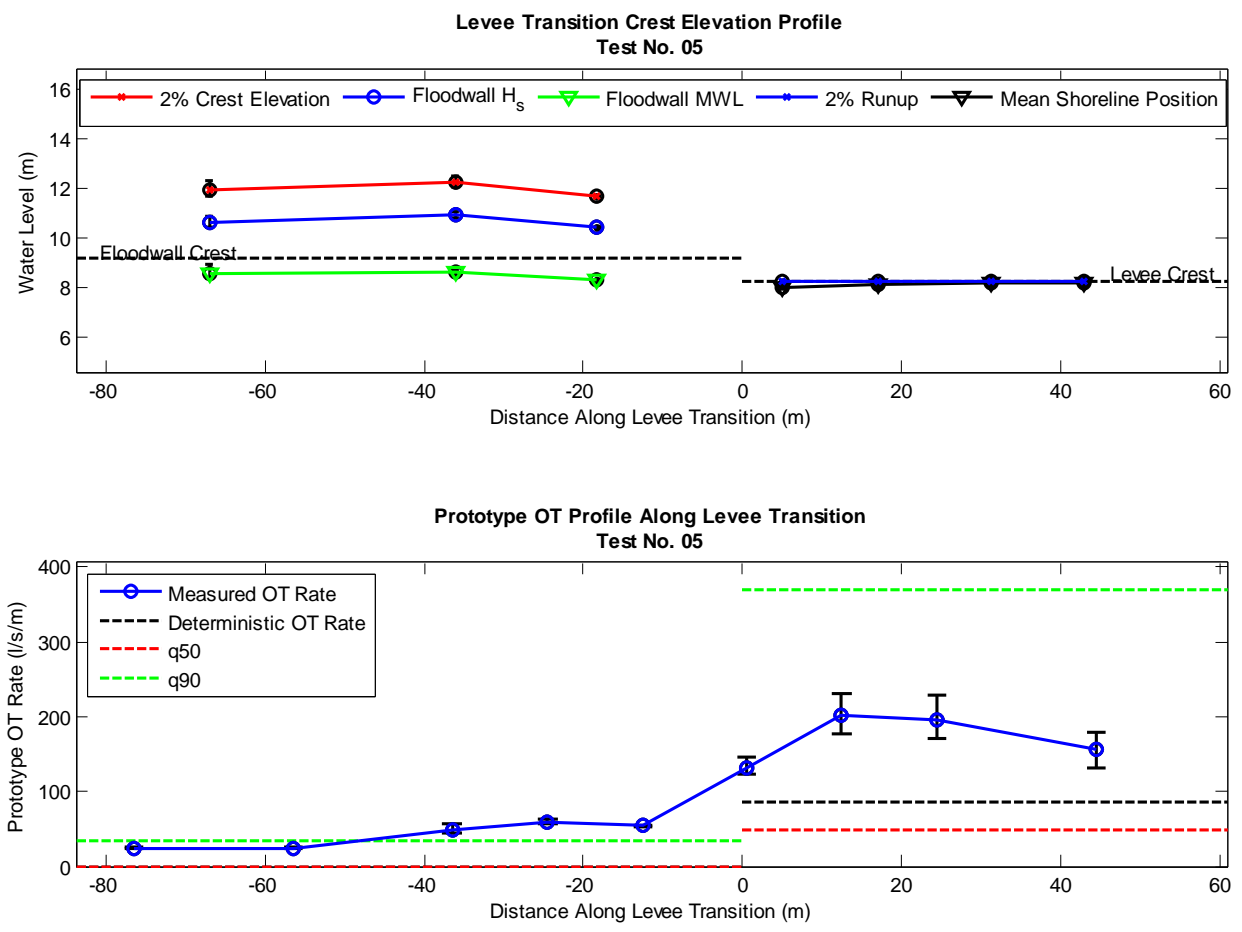

C-5. Prototype Results from Test No. 05
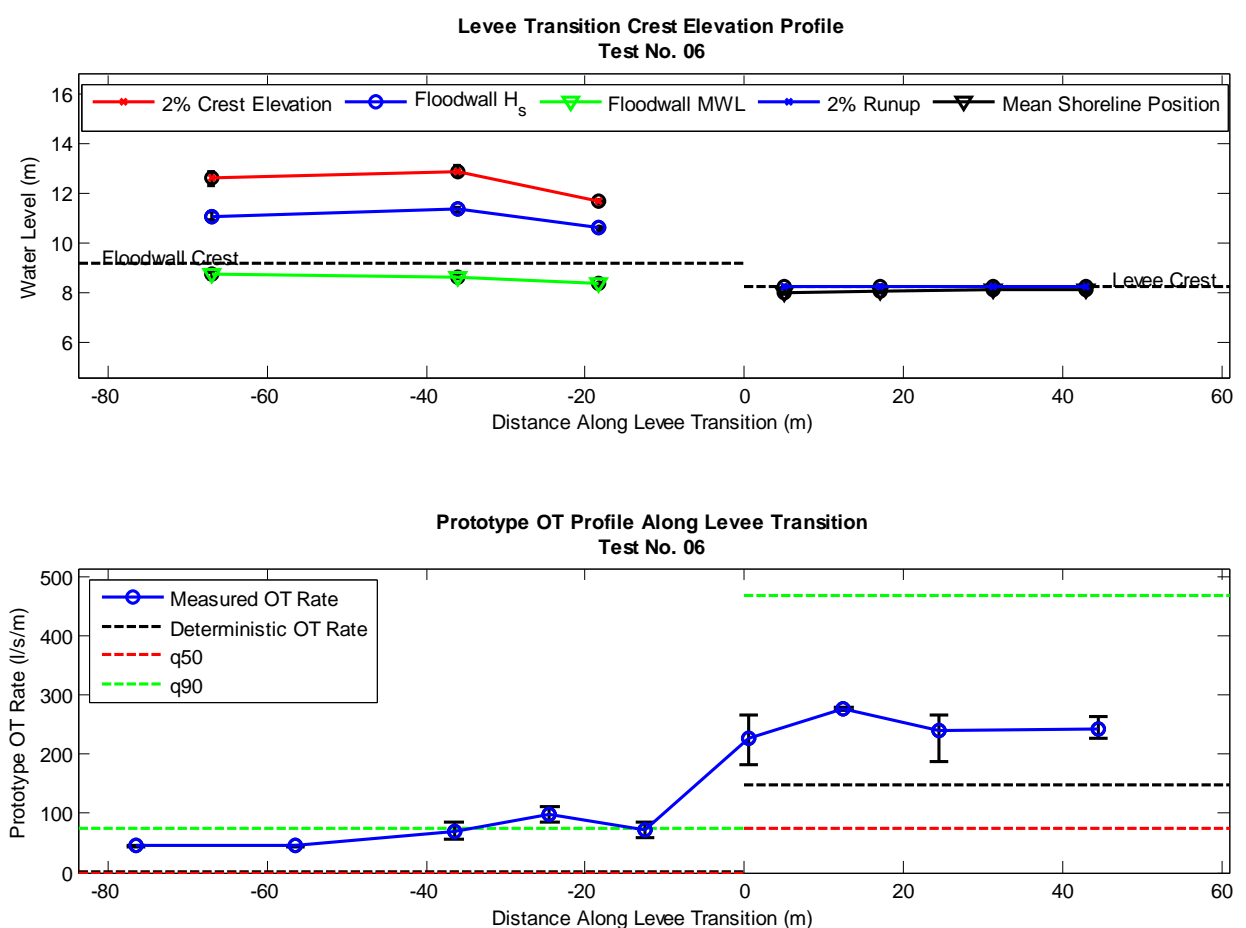

C-6. Prototype Results from Test No. 06 

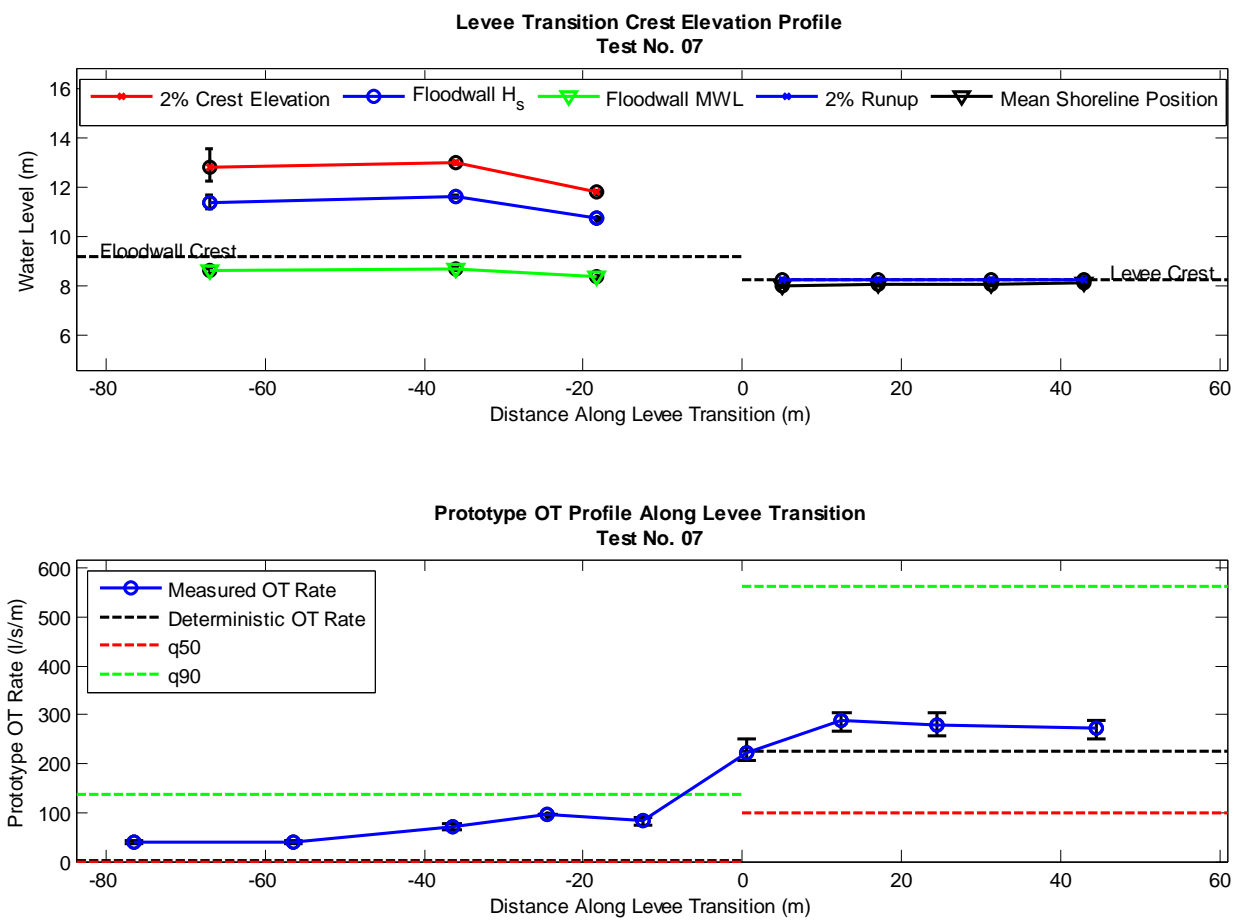

C-7. Prototype Results from Test No. 07
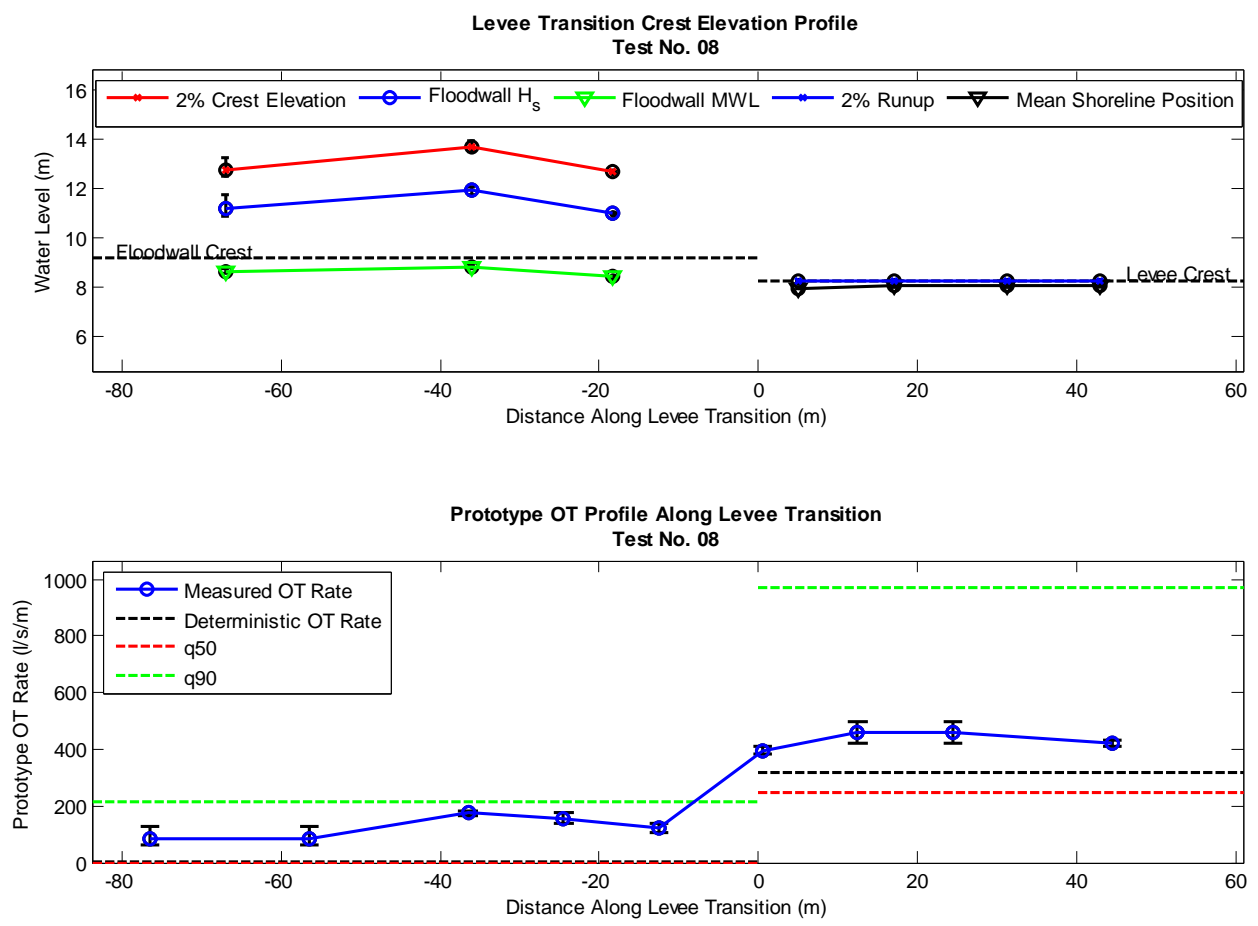

C-8. Prototype Results from Test No. 08 
APPENDIX D

RESULTING DIMENSIONLESS PLOTS 


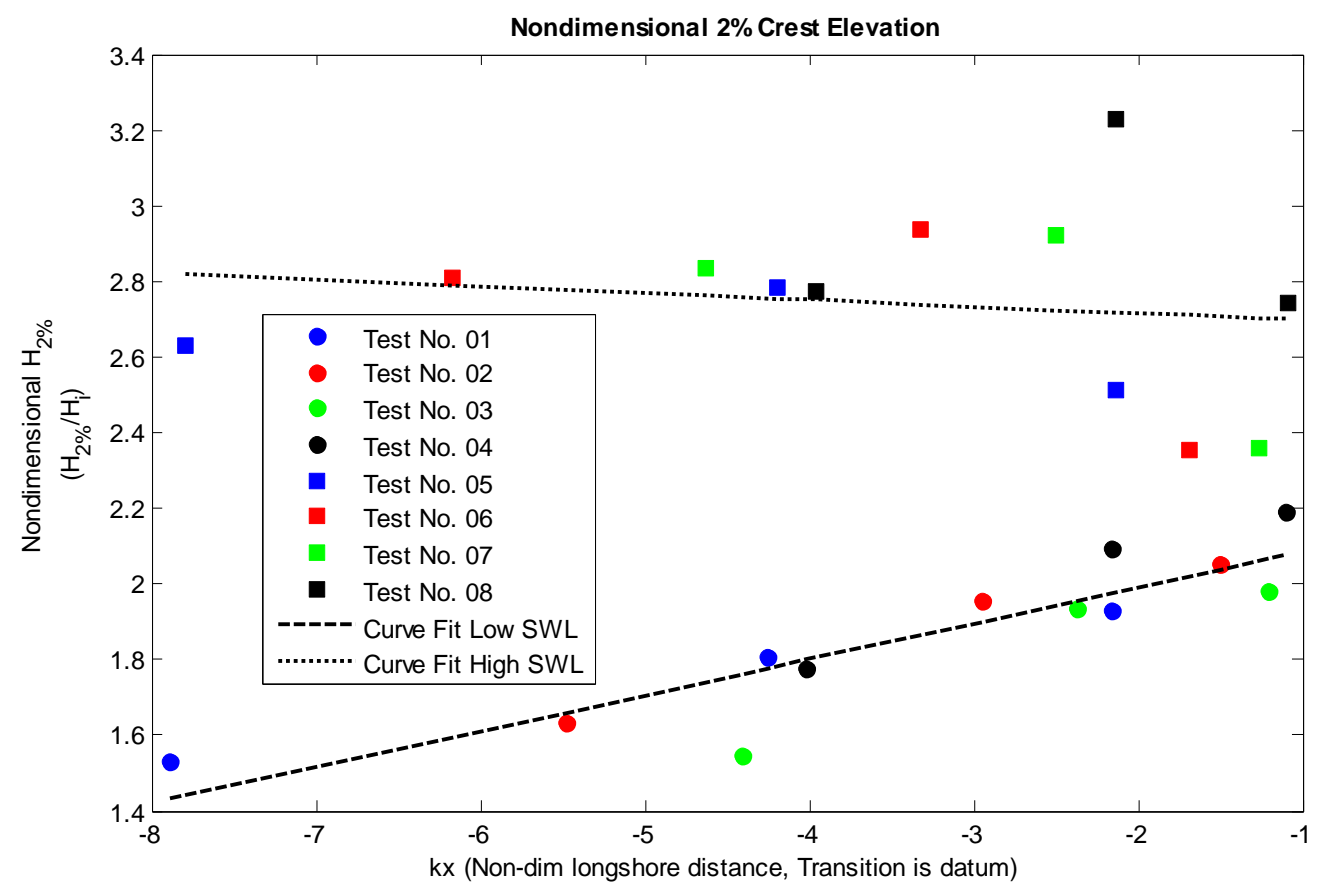

D-1. Dimensionless 2\% Crest Elevation, simple scaling.

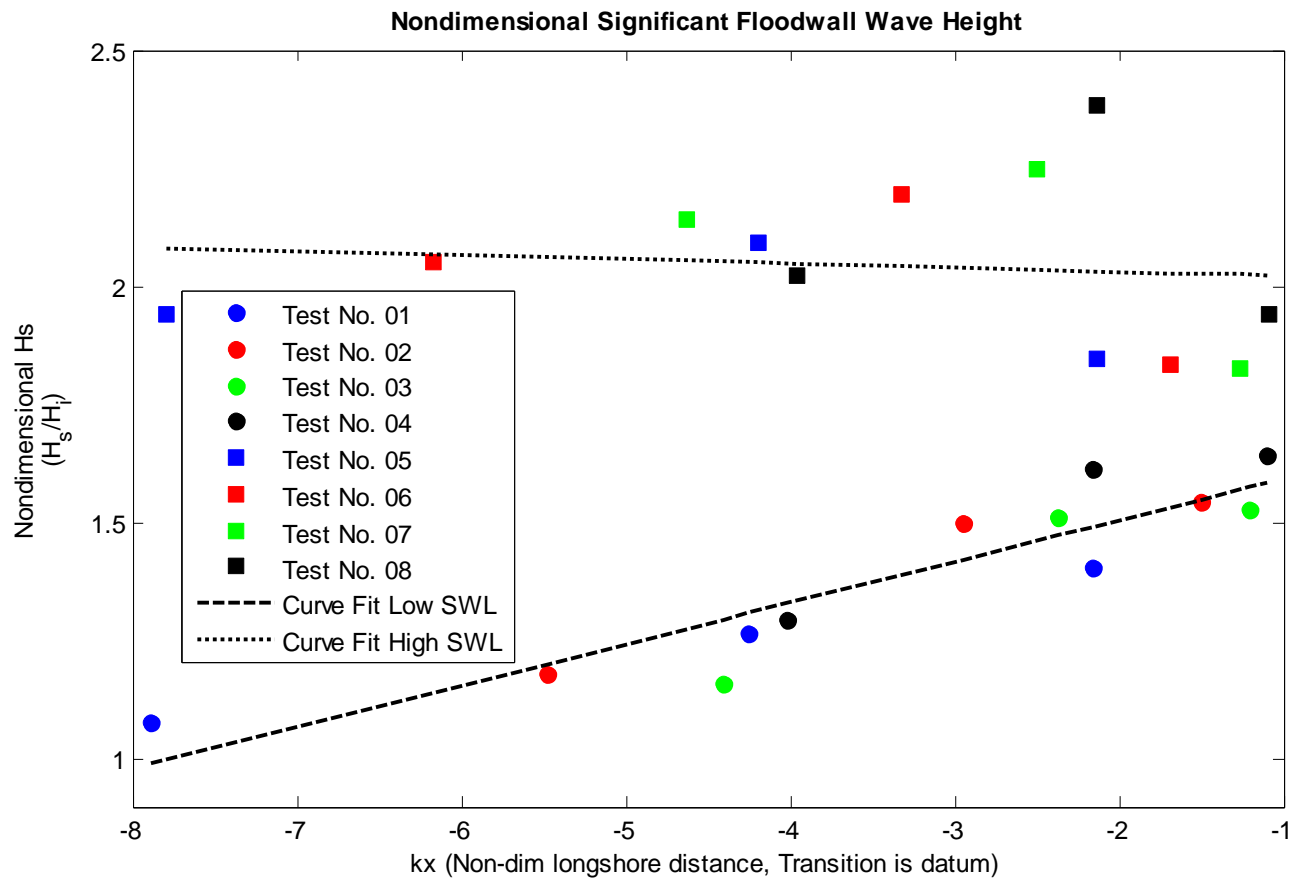

D-2. Dimensionless floodwall $\mathrm{H}_{\mathrm{s}}$, simple scaling. 


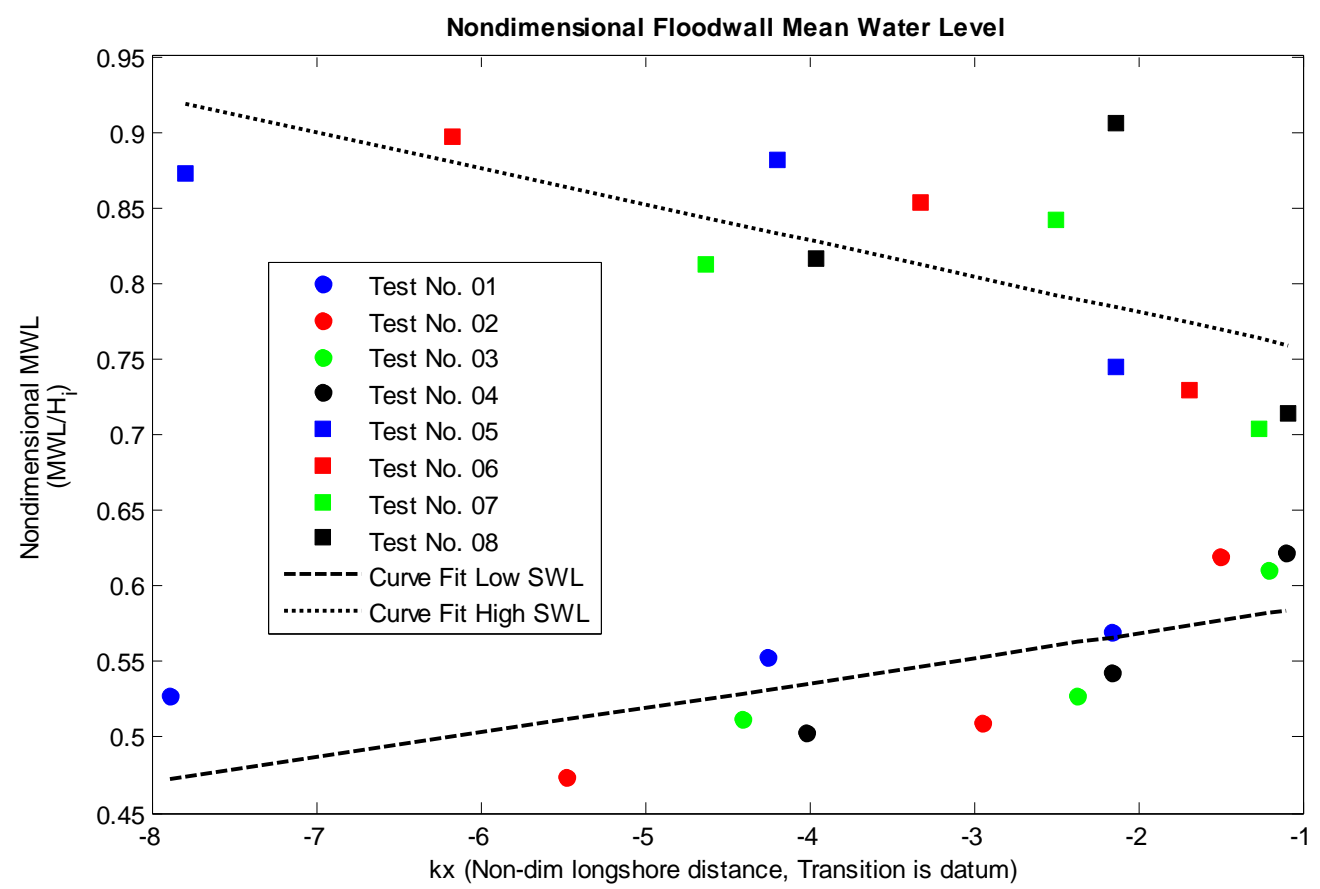

D-3. Dimensionless floodwall MWL, simple scaling.

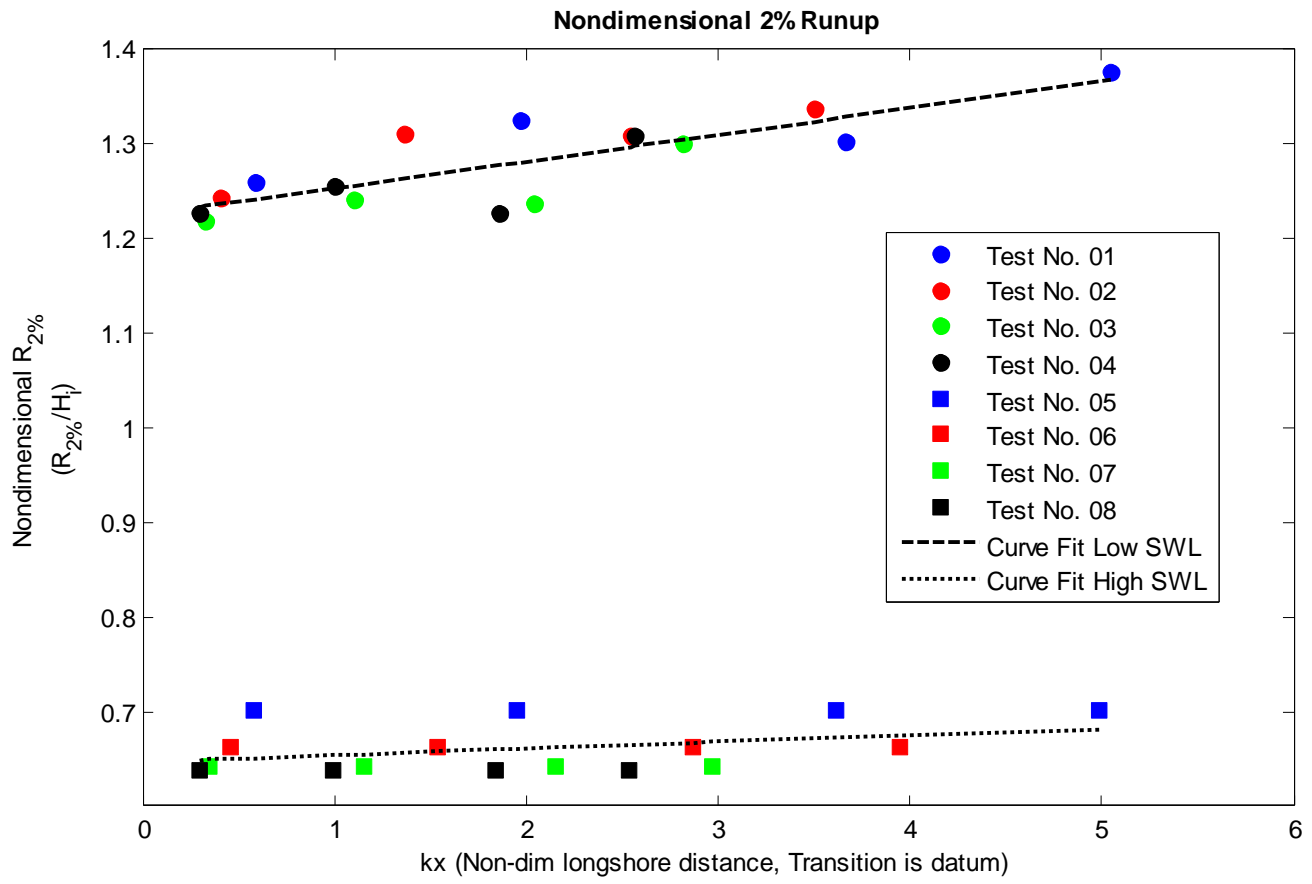

D-4. Dimensionless levee 2\% Runup, simple scaling. 


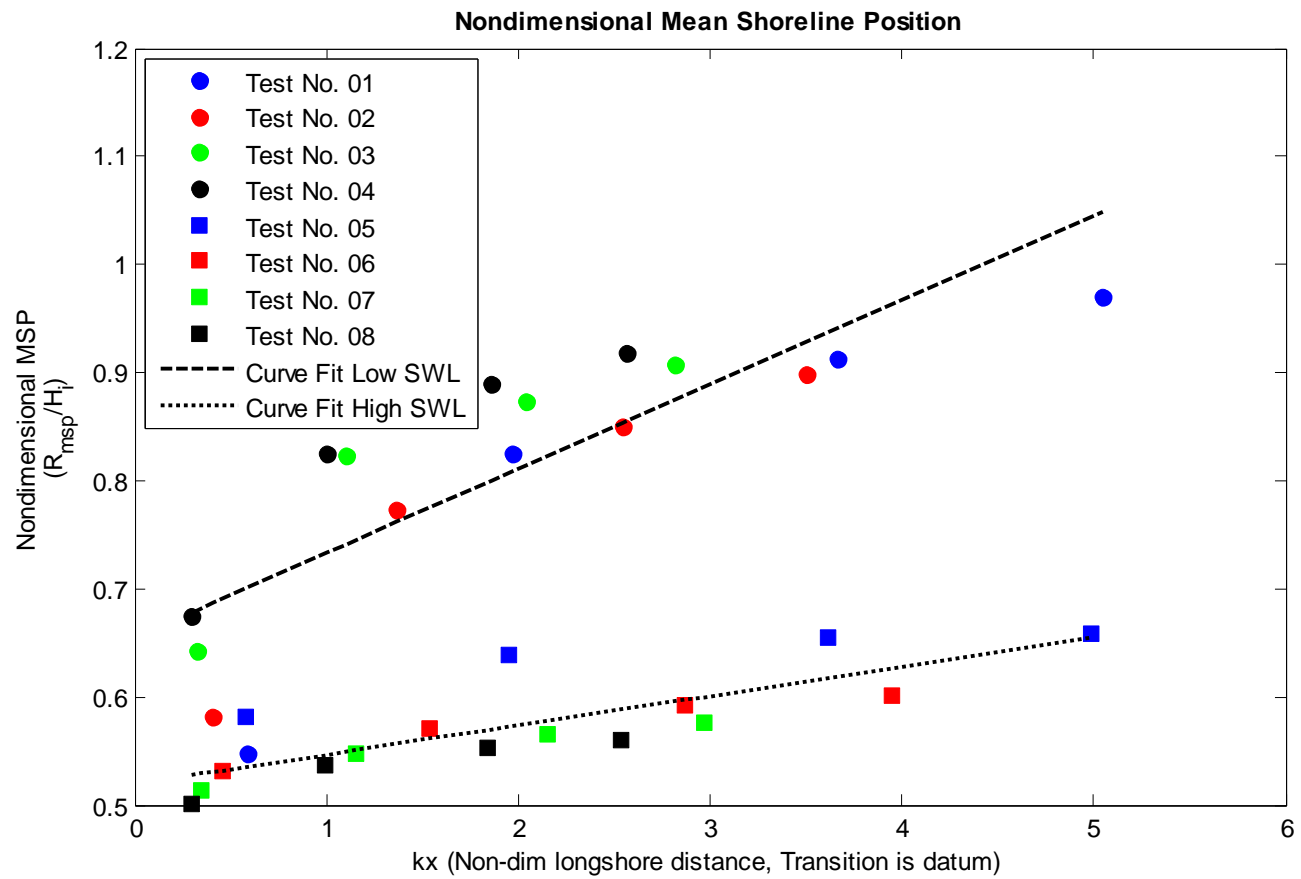

D-5. Dimensionless levee MSP, simple scaling.

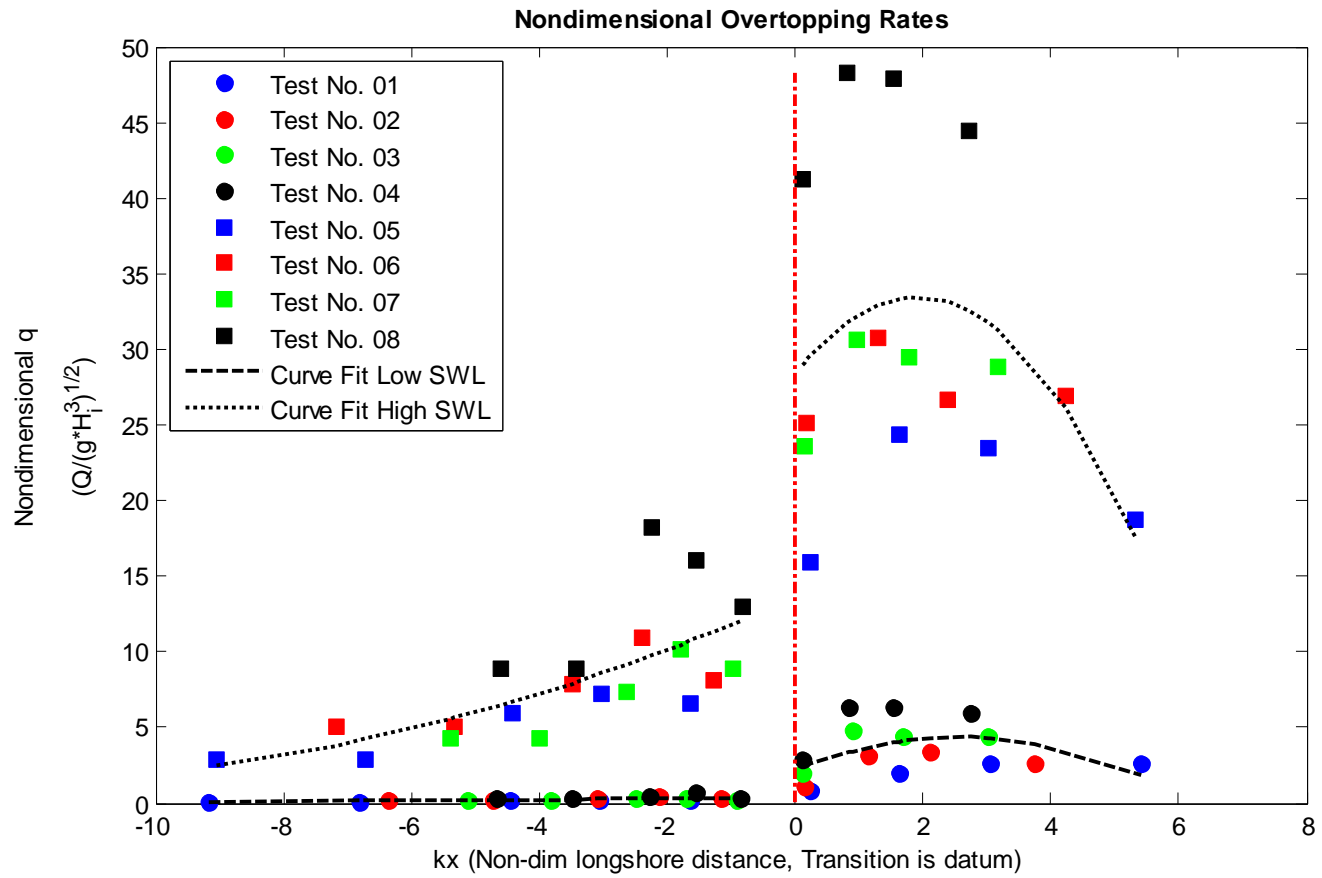

D-6. Dimensionless overtopping rates, simple scaling. 


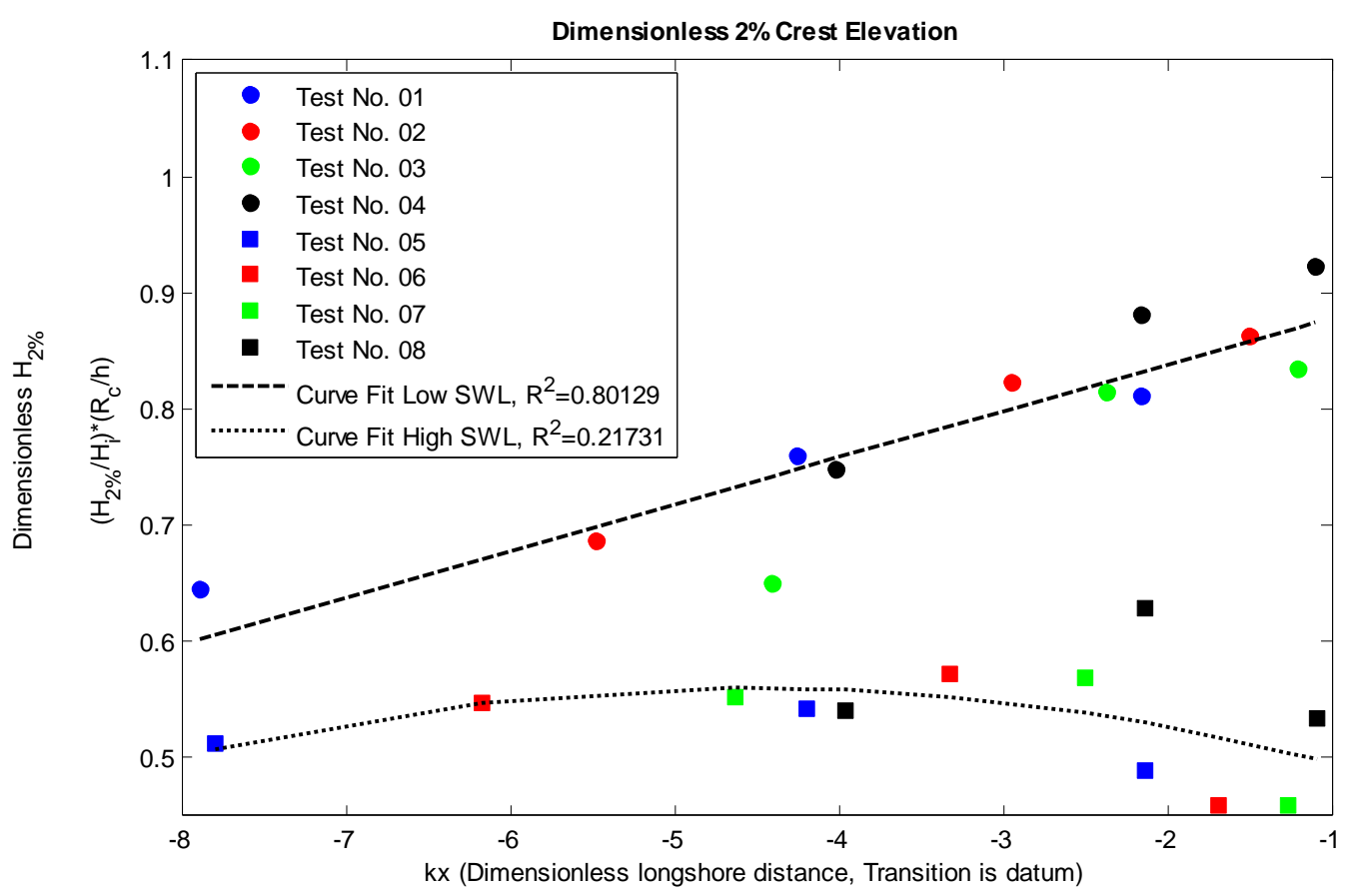

D-7. Dimensionless 2\% Crest Elevation, tuned scaling.

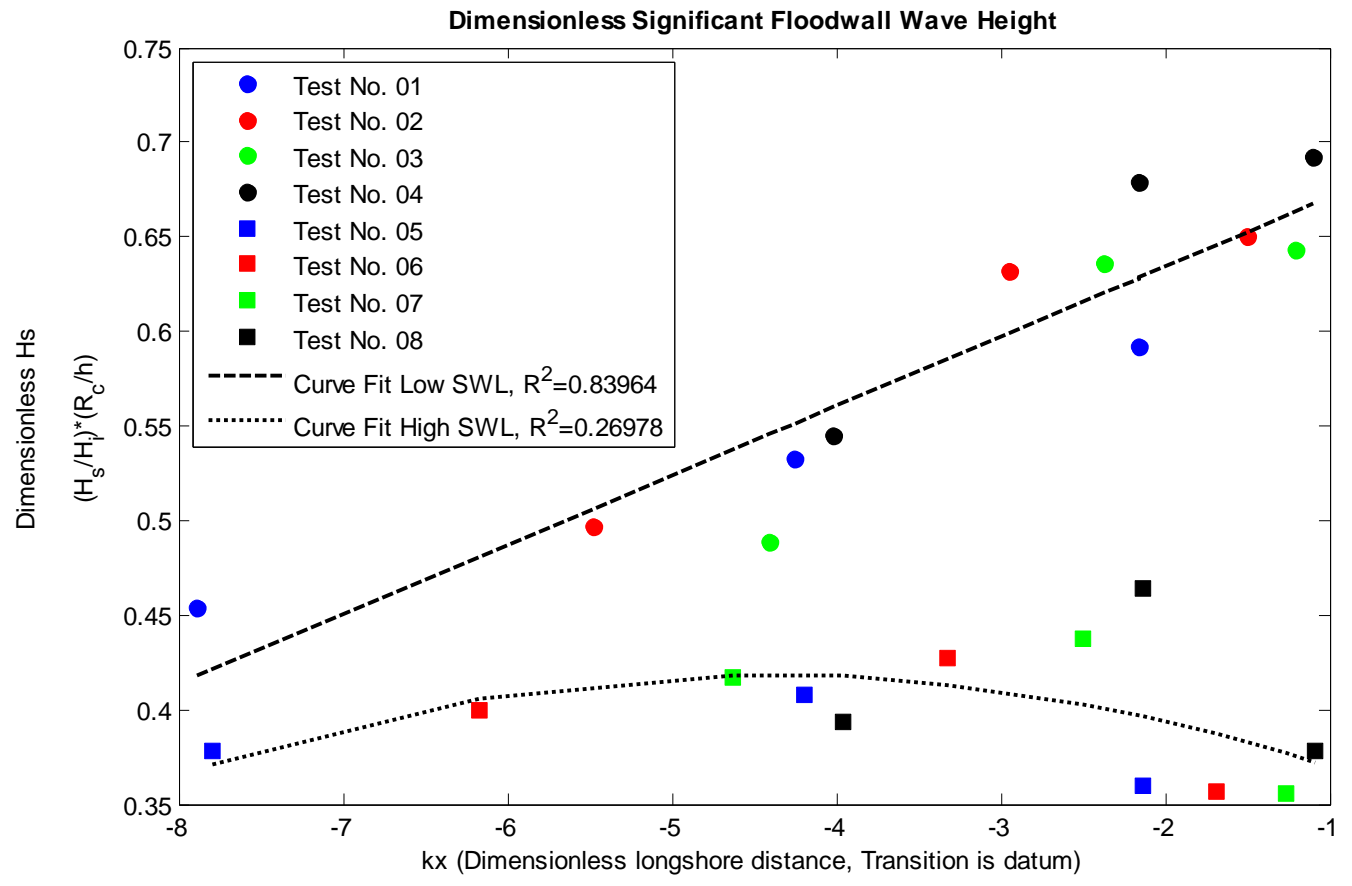

D-8. Dimensionless floodwall $\mathrm{H}_{\mathrm{s}}$, tuned scaling. 


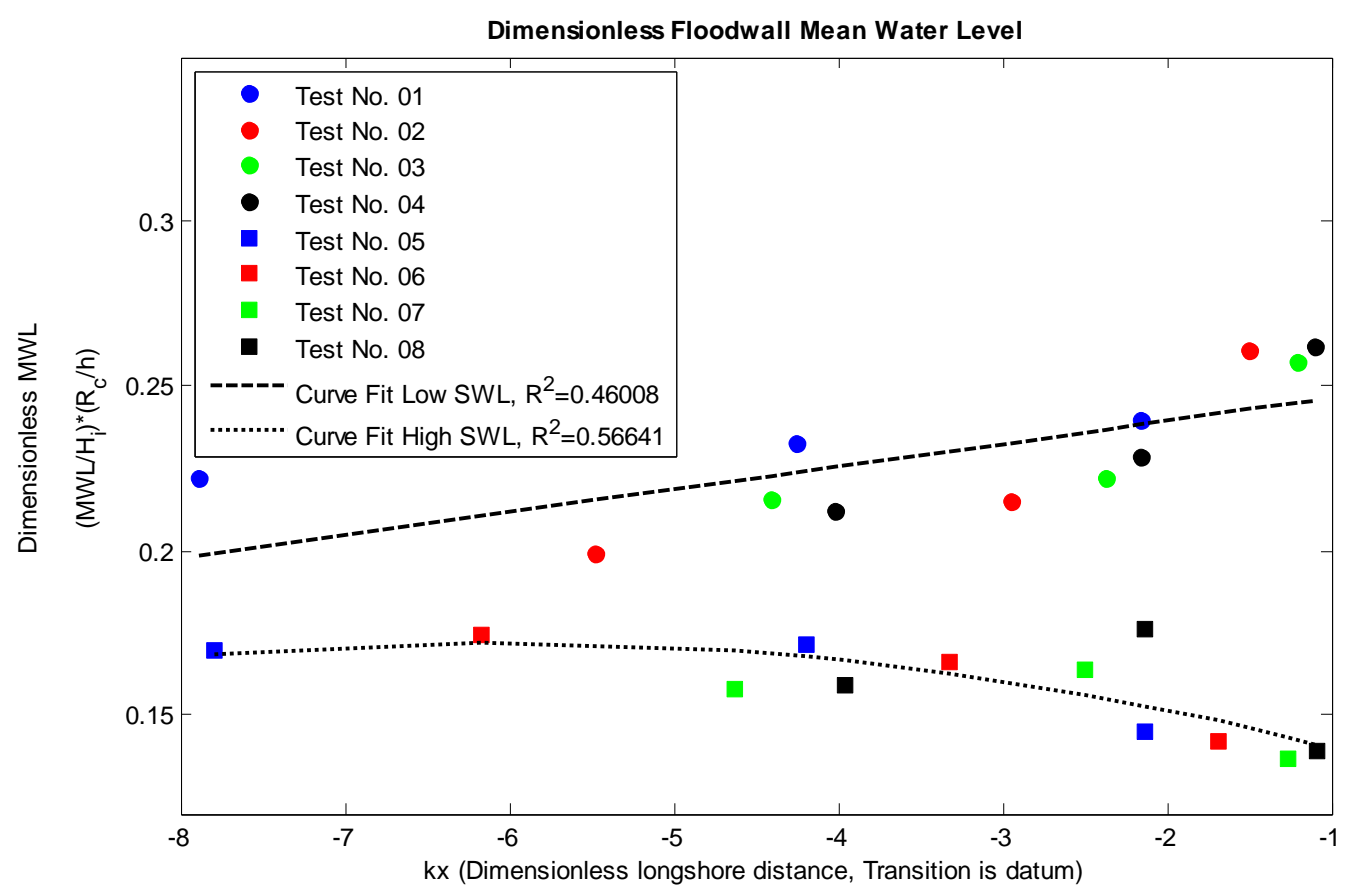

D-9. Dimensionless floodwall MWL, tuned scaling.

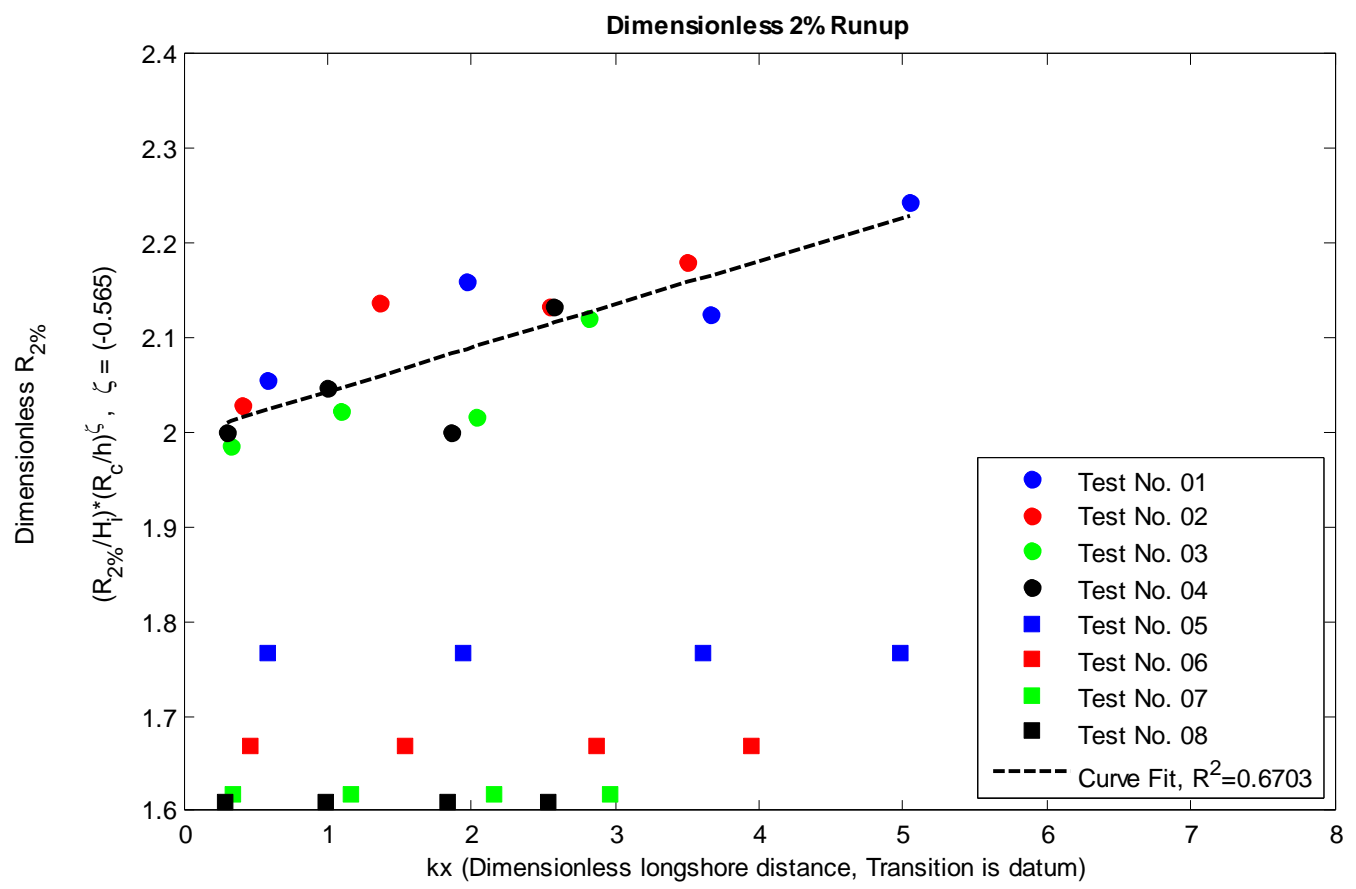

D-10. Dimensionless levee 2\% Runup, tuned scaling. 


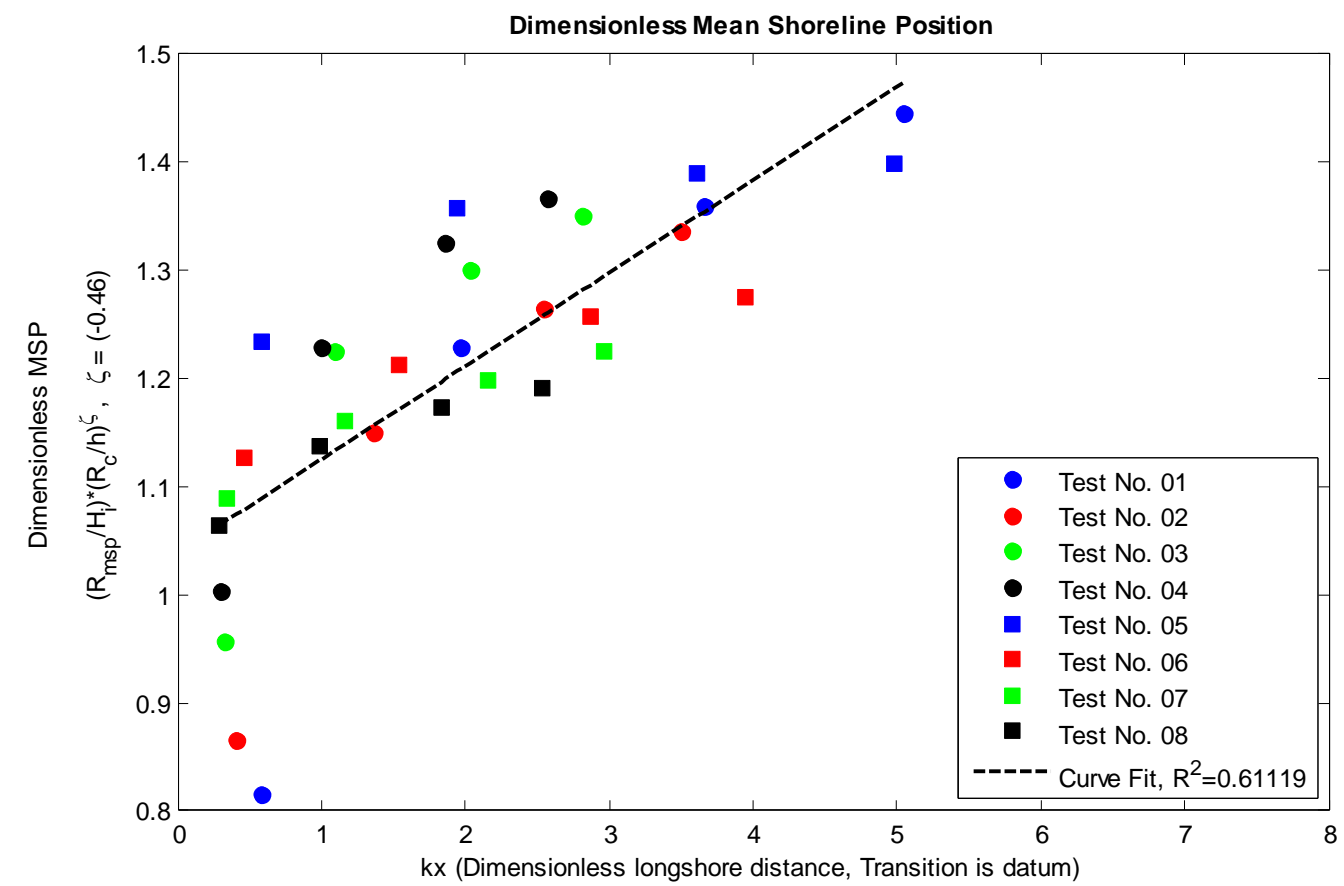

D-11. Dimensionless levee MSP, tuned scaling.

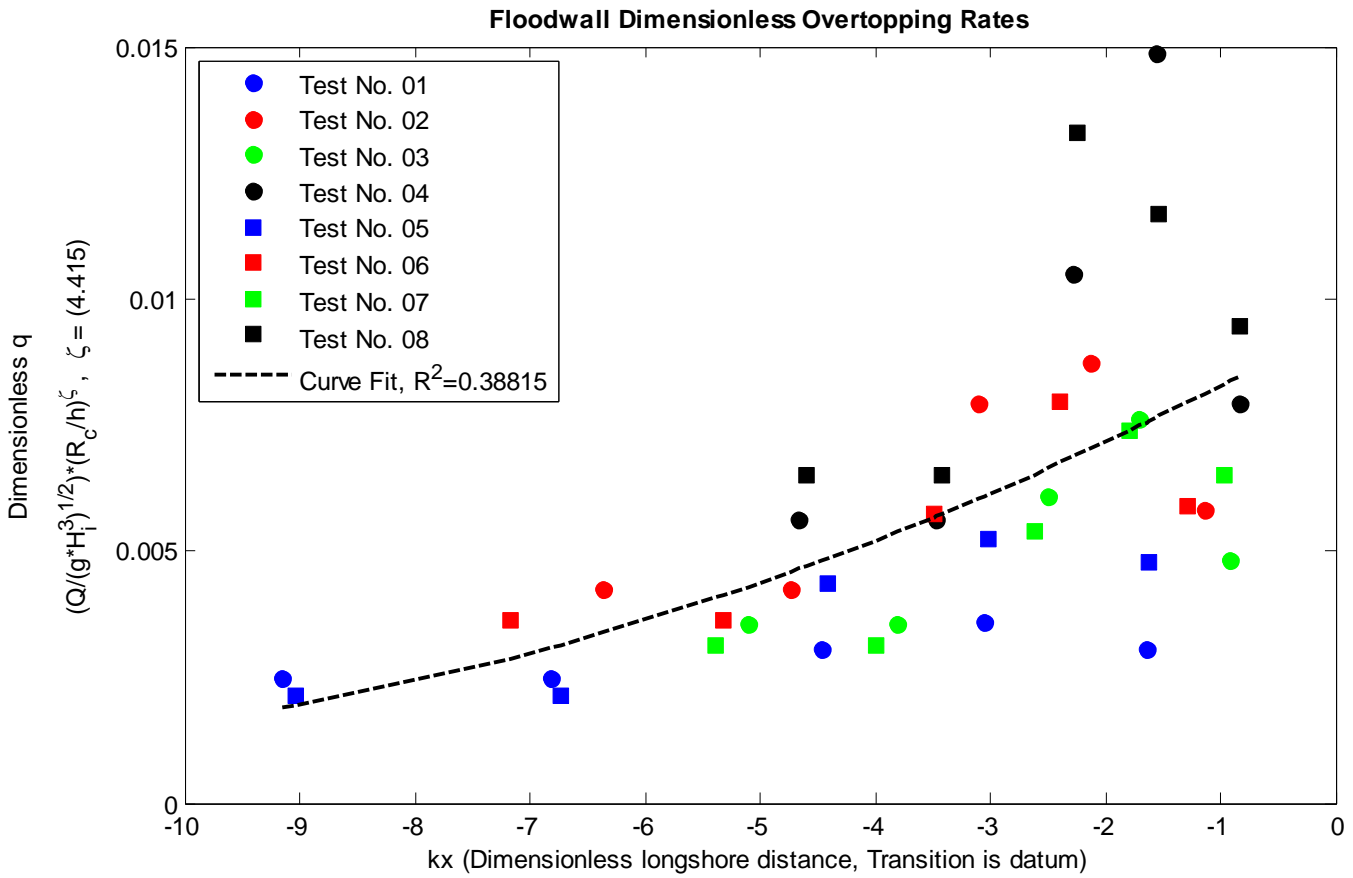

D-12. Dimensionless floodwall side overtopping rates, tuned scaling. 


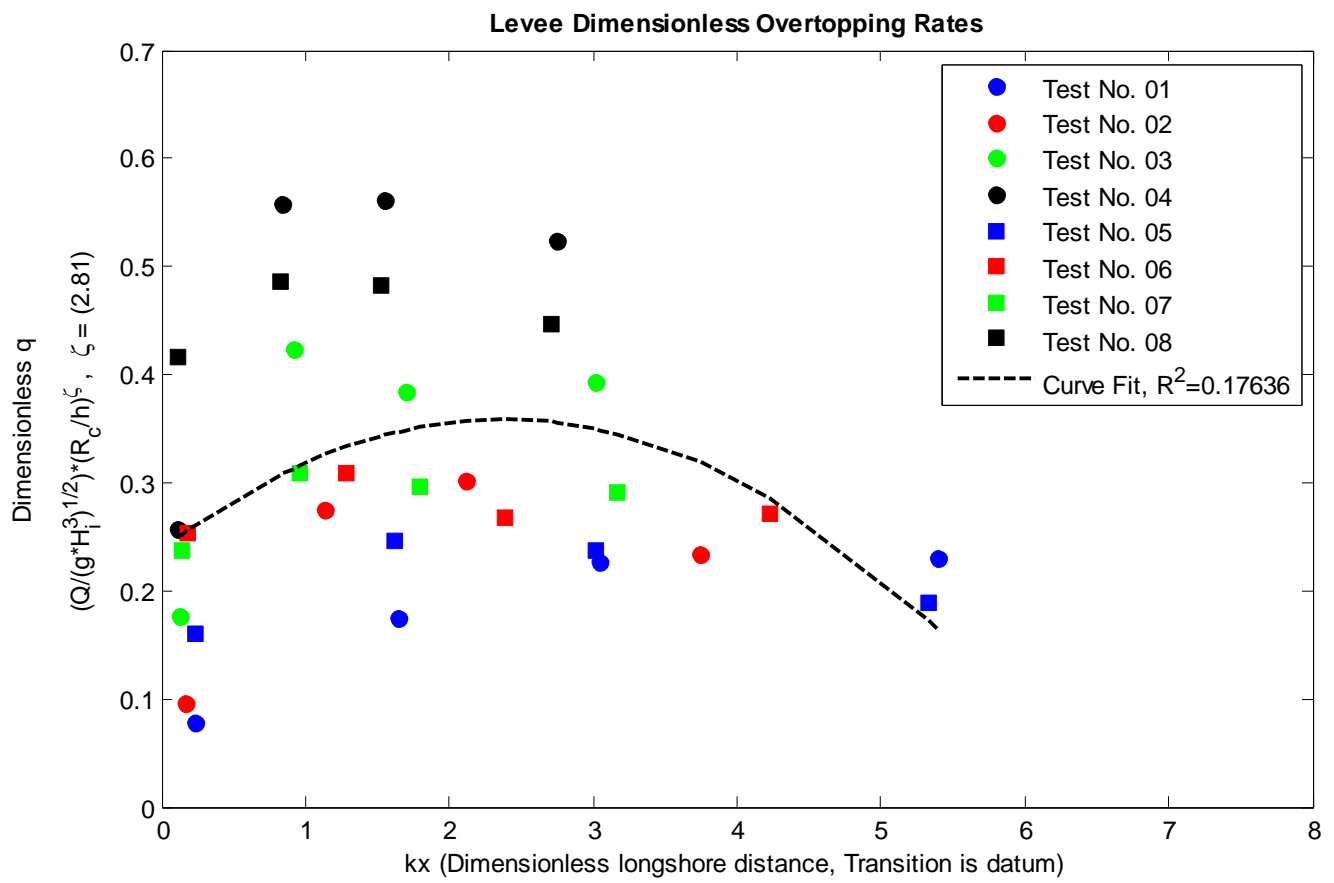

D-13. Dimensionless levee side overtopping rates, tuned scaling. 


\section{VITA}

Name: $\quad$ Drake Benjamin Oaks

Address: $\quad$ c/o Department of Ocean Engineering 3136 TAMU

College Station, TX 77843-3136

Email Address: drakeoaks@gmail.com

Education: $\quad$ B.S., Ocean Engineering, Texas A\&M University, 2008

M.S., Ocean Engineering, Texas A\&M University, 2010 